\title{
The Improvisation of Tubby Hayes in 'The New York Sessions'
}

\author{
Exegesis submitted in partial fulfilment of \\ a Masters in Musicology
}

Amity Rose Alton-Lee

20 February 2010

New Zealand School of Music 
"Imagine for a moment that it is 1959 and that you are a young jazz fan visiting the new Ronnie Scott's club in London; you descend the rickety staircase to the basement venue and are greeted by the overwhelming torrent of musical energy emanating from a small but rotund, sharply suited, incredibly confident looking young tenor saxophonist half crouched before a microphone." 1

\section{Introduction}

Tubby (Edward Brian) Hayes; prodigious self taught multi-instrumentalist and virtuoso tenor saxophone player has been proclaimed by some to be the best saxophonist that Britain has ever produced: "Indisputably the most accomplished and characterful British jazzman of his generation." 2 His career, although cut short (he died undergoing treatment for a heart condition in June 1973, aged 38) was perpetually intense, incredibly prolific, and non-stop from his debut at the age of fifteen until his premature death.

Hayes was proficient on many instruments; all saxophones, clarinet, flute, violin and vibraphone as well as being an accomplished bandleader and arranger. However it was his virtuoso tenor saxophone playing that found him acclaim.

Although well known in his time and widely renowned for his ability, Hayes until recently has been little studied. It is only in the last few years that many critics and students of jazz have attempted to gain an understanding of Hayes' improvisational concept, which has been both praised as genius and criticised as directionless:

Tubby Hayes has often been lionized as the greatest saxophonist Britain ever produced. He is a fascinating but problematical player. Having put together a big, rumbustious tone and a delivery that features sixteenth notes spilling impetuously out of the horn, Hayes often left a solo full of brilliant loose ends and ingenious runs that led nowhere in particular... ${ }^{3}$

However, Hayes, his legacy, and his inimitable style of tenor saxophone playing would truly leave their mark on the British Jazz community for generations to come.

Dave Gelly summed up Hayes by saying that Tubby "played Cockney tenor - garrulous, pugnacious, never at a loss for a word and completely unstoppable." ${ }^{4}$

\footnotetext{
${ }^{1}$ Simon Spillett 'The long shadow of the little Giant' November 2004 available from www.jazzscript.co.uk/extra/art.hayes.htm accessed 12 January 2009

${ }^{2}$ Simon Spillett, 2004

${ }^{3}$ Cook, Richard. Morton, Brian. The Penguin Guide to Jazz Recordings (8th ed.). New York: Penguin Group, 2006.

${ }^{4}$ Gelly, quoted in Spillett, 2004
} 


\section{Table of Contents}

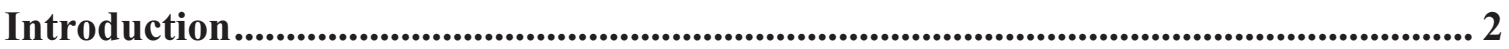

Section 1: Background............................................................................................ 4

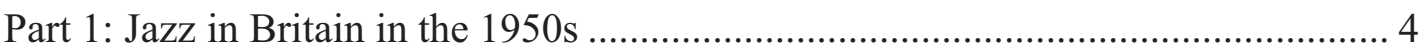

Part 2: Tubby Hayes' Biography and Career ............................................................. 6

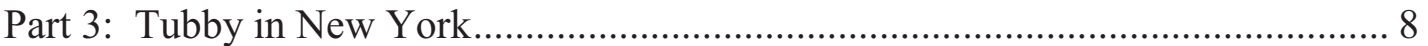

Part 4: The New York Sessions ........................................................................... 10

Section 2: Improvisation and Formula in Jazz ........................................................... 14

Formulaic Improvisation: Towards a Definition ................................................ 14

Formulaic Improvisation in Jazz and the Bebop Idiom ..................................... 14

Charlie Parker as a Pioneer of Formulaic Improvisation: ........................................ 16

The Roles of Creativity and Tradition in Jazz Improvisation .................................. 16

Licks and Patterns: A Personal Tradition Versus Spontaneous Creation ................ 19

Hayes and Formulaic Improvisation ............................................................... 20

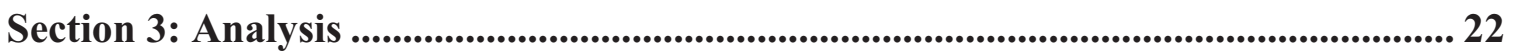

Analysis of Tubby Hayes' Solo on 'You for Me' .................................................. 22

Analysis of Tubby Hayes' Solo on 'Pint of Bitter' ..................................................... 28

Analysis of Tubby Hayes' Solo on 'Airegin' .......................................................... 31

Analysis of Tubby Hayes' Solo on 'Opus Ocean' by Clarke Terry .......................... 38

Analysis of Tubby Hayes' Solo on 'Soon' .............................................................. 41

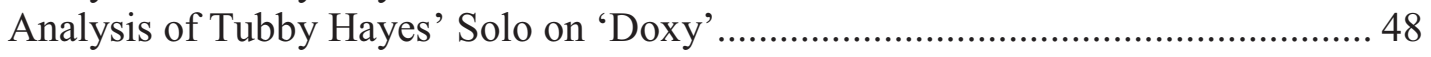

Analysis of Tubby Hayes' Solo on 'Soho Soul' .................................................. 50

Analysis of Tubby Hayes' Solo on 'The Simple Waltz' ......................................... 54

Analysis of Tubby Hayes' Solo on 'Half a Sawbuck' ........................................... 58

Analysis of Tubby Hayes' Solo on 'You Are My Everything' ................................ 62

Section 4: Hayes’ Improvisational Style: Summary and Overview ......................... 65

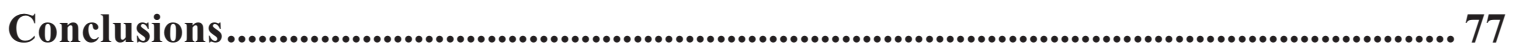

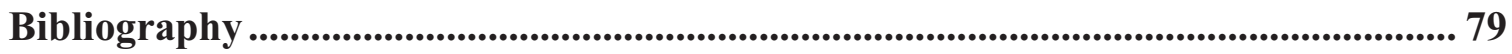




\section{Section 1: Background}

\section{Part 1: Jazz in Britain in the 1950s}

\section{Movements in British Jazz: The "trad" Jazz revival, Bebop, Hardbop, and Cool Jazz}

Throughout the 1930s and 40s jazz in Britain generally revolved around wartime and post-war dance bands, until the 'British Revival' of New Orleans jazz (commonly known as 'Trad'). This began as early as 1943 with the formation of pianist George Webb's band “The Dixielanders" in Barnehurst outside London. The Dixielanders' aim was to reproduce the jazz styles of 1920s New Orleans with King Oliver's Creole Jazz Band and Louis Armstrong as their main influences. British Jazz writer Jim Godbolt affectionately describes the beginning of this movement:

The exciting music of another race and another generation was profoundly affecting the musical activities of teenagers in the forties playing at home, to the distraction of parents and neighbours, in places as far removed from New Orleans as, say, Barnehurst, Kent...

This revival continued through the 1940s and early fifties and included bands led by such musicians as Chris Barber (trombone), Humprey Lyttleton (trumpet) and Ken Colyer (trumpeter/cornetist).

In 1948 a group of young musicians including John Dankworth and Ronnie Scott, focused around the Club Eleven in London, began a movement toward "modern jazz" or Bebop. Significant instrumentalists in this early movement were trumpeter-pianist Denis Rose, pianist Tommy Pollard, saxophonist Don Rendell, and drummers Tony Kinsey and Laurie Morgan. This style had begun in the London clubs as an imitation of the American bebop developed by Charlie Parker, Dizzy Gillespie, Thelonious Monk and others. It proved difficult for the public (and many musicians) to get to grips with this music and it would soon be replaced by a less frenetic 'post bop' phase

In America Cool Jazz came about at the end of the 1940s as a reaction against the relentless, driving, virtuostic nature of the Bebop movement. Among the originators of Cool were American musicians Miles Davis, Lennie Tristano and John Lewis. In Britain the 'Cool School' was led by alto saxophonist John Dankworth who, unlike many jazz musicians of his time had undergone formal classical musical training at the Royal Academy of Music. He formed the Dankworth Seven in 1950, which included vocalist Cleo Laine. In 1953 the Dankworth Seven expanded into what John Wickes refers to as Britain's “first successful modern big band". " Dankworth's big band arrangements were harmonically sophisticated and drew from classical and music hall traditions as well as

\footnotetext{
${ }^{5}$ Moore, Hillary. Inside British Jazz: Crossing Borders of Race, Nation and Class. Cornwall: NPG Books Ltd. 2007. pp 37-38

${ }^{6}$ John Wickes Innovations in British Jazz Chelmsford: Soundworld Publishers pp4
} 
his studies of the scores of Count Basie and Duke Ellington.

Kenny Graham, band leader, saxophonist and another close associate of Ronnie Scott was largely responsible for bringing Afro-cuban influences (as pioneered by Dizzy Gillespie) into British jazz with his group Kenny Graham's Afro-cubists (including influential british pianist Stan Tracey).

Joe Harriett, Jamaican born, British-based saxophonist, although schooled in Bebop was one of the first pioneers of Free Jazz, with his early experiments of free-form quite separate to the free jazz movements in America led by Ornette Coleman (of which Harriott had no knowledge at the time).

Hard bop, the style that originated with such musicians as Art Blakey, Horace Silver and Clifford Brown, was partly a reaction to the cool school. It was a style that incorporated elements of both bebop and the blues.

'The Jazz Couriers' the quintet co-led by tenor saxophonists Ronnie Scott and Tubby Hayes was often thought of as the high point in British Hard Bop as the group showcased the virtuostic talent of both players, who were well practised in the Bebop idiom. The Jazz Couriers were active from 1957, but Tubby Hayes first appeared on the British jazz scene in 1950.

March, I950, when I was running a jazz club in a little hut near Raynes Park, S.W. (Tubby's place of birth). One evening, a curly-haired, rather corpulent lad walked in, and asked if he could sit-in with the resident group, which included Lennie Hastings on drums. Somebody loaned him a baritone, as he didn't have his tenor with him, and-as you've guessed-he proceeded to astound everybody ${ }^{7}$

${ }^{7}$ Les Tomkins interviews Tubby Hayes. 1966. available from:

http://www.jazzprofessional.com/interviews/tubby_hayes.htm accessed 20th October 2008 


\section{Part 2: Tubby Hayes' Biography and Career}

Born into a musical family on the $30^{\text {th }}$ January 1935 Hayes' musical training began when he learnt the violin as a child. Influenced by listening to Charlie Parker and determined to be a jazz musician, at age 11 he picked up the saxophone that his father deemed "too big for him."

I always wanted to play jazz. As a little boy of five or six I can remember wanting to own a saxophone. I tried to talk my father into buying me one, but he told me: 'You'll never be able to blow that - it's much too big for you.' So I had a few years on violin and piano-which I don't regret, because it was a good grounding. ${ }^{8}$

His debut as a professional saxophone player was at the age of 15 and he was leading his own band, and regularly recording for the Tempo label by the age of 20 .

Hayes' earliest professional performances were with the bands of Kenny Baker, Vic Lewis, Ambrose and Jack Parnell. He spent a year with the Kenny Baker Sextet, of which he said:

That was a lot of good experience. The best thing that happened to me there was working with Jimmy Skidmore. He's a real natural player. I've never had any lessons on the saxophone, or anything like that-I'm self taught. I don't know whether Jimmy's ever had any lessons, but he taught me a lot in those days, travelling around. ${ }^{9}$

Tubby was also dependable as a section player. He played with big bands including Vic Lewis and Dave Ambrose. In an interview with Les Tomkins he mentions his stay with Dave Ambrose as being significant in his musical development.

Phil Seamen was in the band and he was playing up a storm. He showed me a lot about rhythms and things I hadn't thought about very much. Also I learned a great deal about arranging from Johnny Keating. ${ }^{10}$

Hayes achieved notable success with his quintet 'The Jazz Couriers' co-led with tenor saxophonist Ronnie Scott. The jazz couriers were formed in 1957 and were together until 1959. They recorded four albums during this time.

It was in 1951 on a provincial club gig that Scott first encountered Hayes as a cherubic sixteen year old who enthusiastically asked if he could sit in on a number. Scott later recalled that he greeted this request with patronizing amusement before Tubby began to play, when, in Ronnie's own words, he "scared me to death."11

In 1957, Tubby had taken up the vibes after Vic Feldman had given his instrument to him. In 1959 Hayes took up the flute, having gone to a music shop to purchase a new alto saxophone for a session date but emerging with a flute instead. He was playing the instrument on a gig within days. As a flautist, Hayes claimed to play "like a trumpet player." ${ }^{12}$ Flute features are scattered throughout Tubby's albums

\footnotetext{
${ }^{8}$ Les Tomkins interviews Tubby Hayes. 1966

${ }^{9}$ Les Tomkins interviews Tubby Hayes. 1966

${ }^{10}$ Les Tomkins interviews Tubby Hayes. 1966

${ }^{11}$ Les Tomkins interviews Tubby Hayes. 1966

${ }^{12}$ Simon Spillett 2004
} 
Hayes showcased his multi-instrumental skills on his album The Eighth Wonder (Tempo, 1958) on which he played (via fairly primitive overdubbing) alto, tenor and baritone saxophones, vibes and piano simultaneously.

Hayes' music kicked in violent reaction to the austere and 'mustn't-grumble' attitude which hung over the United Kingdom like a fog even during the late 1950s, and spoke of a very un-British confidence and lack of reserve that made virtually everything else on the local jazz scene wither into insignificance. ${ }^{13}$

In 1961 Hayes became the first visiting English jazz soloist to play a residency at New York club The Half Note, attracting audiences that included Miles Davis. In 1962 he returned to the United States for a further tour and to record with Rashaan Roland Kirk. During the next few years he would also record with tenor saxophonist Paul Gonsalves, appear in the movie All Night Long with Charles Mingus, and deputize in the Duke Ellington band at a London concert. Another legendary jazz figure, the bandleader Woody Herman, repeatedly offered Tubby a place in his big band, but Hayes declined. He was also accorded his own prime time TV show, Tubby Plays Hayes

Hayes success continued and he recorded throughout the 1960s including the rather unusual Tubbs from 1961; Tubby in a big band setting, and with a tuba added but no saxophone section. He also recorded Tubbs Tours in 1964, an album with a concept built around various locations and countries.

In the late 1960s Hayes health began to deteriorate. In 1965 he collapsed through sheer exhaustion brought on by overwork. There were further health problems the following year. These incidents were compounded by Tubby's increasing dependence on hard drugs. He had always drunk heavily with no apparent effect on his performance, but by the mid-1960s he was using serious narcotics with regularity. As a side effect of poor health and drug use, Hayes slimmed down drastically and his friends re-christened him "Tubey"

Hayes' health continued to decline and in 1970 doctors discovered Hayes had a faulty heart valve. He underwent an operation a year later and was out of action for the whole of 1971. It was confirmed that the replacement heart valve was failing and that a second operation was necessary. Hayes would not survive this second operation. He died undergoing surgery at 3pm on the afternoon of Friday June 8th 1973. He was thirty-eight.

The tragic and premature death of Tubby Hayes did not leave the loose end 'what if?' questions so typically asked of talented jazzmen who have died all too young. His career of a little over twenty years contained evidence enough of his being a truly mature talent and a forthright and honest musical voice. He had packed more than a lifetime's energetic enthusiasm into his art, and had become a well-loved larger than life figure on the British jazz scene. ${ }^{14}$

${ }^{13}$ Simon Spillett 2004
${ }^{14}$ Simon Spillett 2004 


\section{Part 3: Tubby in New York}

\section{Background}

\section{Ronnie Scott's Club}

After the 'Jazz Couriers' came to an end Ronnie Scott went on to open his own club, thought of by many as Britain's premier jazz venue. Ronnie Scott's club opened in a basement on Gerrard Street, Soho on October the $15^{\text {th }}$ 1959. Co-run with saxophonist Pete King, the initial policy of the club was to encourage and provide a venue for local talent. This policy soon changed and Ronnie Scott's club became a venue for hosting American musicians, particularly saxophonists. It was Ronnie Scott and Pete King who would be responsible for Hayes' first visit to New York.

\section{The Musicians Union Ban on Foreign Musicians Working in the United Kingdom}

The Musicians Union ban on Foreign Musicians working in the United Kingdom dated from 1932, and prevented overseas musicians from working in the UK - although classical music and vocalists were exempt.

In 1958, the union relaxed its embargo at concert level. American jazz musicians were allowed to perform in the UK - provided British musicians played reciprocal gigs in America. Ronnie Scott and business partner Pete King brokered a deal and in October 1961, the British saxophonist Tubby Hayes went to New York's Half Note for a onemonth residency and American saxophonist Zoot Sims played at Ronnie Scott's.

Although intended originally to protect the jobs of local British musicians, many found this ruling to be limiting, both from the point of view of the club owners, trying to attract interest to their clubs and among the top musicians in the UK such as Hayes who were looking to play with musicians on a similar level. Hayes describes his frustration with the jazz scene in the UK at this point:

I'm not putting England, or London, or any of the musicians down, but I do think that the environment tends to make you a little complacent at times. And that includes myself, when I'm here for too long. ${ }^{15}$

I know a lot of people would say: Oh, no, we've got to look after our own musicians, and that's why they made this barring thing in the first place years ago. But times have changed, and the world has become a much smaller place in the last 25 years. I think it's time they let everybody work on their merit, instead of keeping it a closed shop. I really do. Music is international. ${ }^{16}$

\footnotetext{
${ }^{15}$ Les Tomkins interviews Tubby Hayes. 1966

${ }^{16}$ Les Tomkins interviews Tubby Hayes. 1966
} 


\section{Tubby In New York}

The Half Note, where Hayes played in 1961, was a jazz club located at the corner of Hudson \& Spring Streets in Manhattan. The club was known for its showcasing of upand-coming jazz musicians in the 1950 s and 60 s.

Hayes described his main impressions of the New York scene:

For one thing - 75 to 8 o per cent of the musicians that I met over there are very much more conscientious than they are over here-because it's tough. Even if they've got a name - there's so much competition. And at the same time it's a terrible rat race. It's not easy - and, you know, people will soon turn round and row you out of something if they can... But there is a lot of enthusiasm - and a lot of hard work, which is probably why they come up with such good players. What surprised me was the fact that there were so few clubs, really, for the size of the place and the number of musicians who were there. There's Birdland which only employs musicians who have really big names, like Horace Silver, Dizzy Gillespie, Count Basie's orchestra. Nobody who's not known. They don't get a chance. The Village Vanguard might have the Miles Davis Quintet-and with him they'll have Irish folk singers, and all that kind of thing. The Half Note is a good club. They don't pay such good money, but they have some good musicians working there. ${ }^{17}$

Hayes appeared to be inspired by his time in New York. He describes working in the American jazz scene as a more challenging and competitive environment:

I know that whenever I've gone to the States-although I've often been there and thought: Oh, it'll be nice to get home- - but, at the same time, you come back with renewed enthusiasm, because of the competition that you've been faced with... Especially in New York. Like, I had to follow John Coltrane into the Half Note. Then there's Stan Getz and Zoot [Simms] and Al [Cohn] sitting there listening to you - it does certainly gee you up a bit. You can't afford to coast. You've got to try and be on top form as much of the time as possible. ${ }^{18}$

It was in This Visit to New York that Hayes went on to record the album The New York Sessions.

${ }^{17}$ Les Tomkins interviews Tubby Hayes. 1966

${ }^{18}$ Les Tomkins interviews Tubby Hayes. 1966 


\section{Part 4: The New York Sessions}

The New York Sessions is the album that has been selected for transcription and analysis. This is a landmark album for Hayes for a number of reasons: it was his first album recorded outside of Britain; it was recorded at a time when Hayes was playing particularly well; he had begun to reach maturity as a player; and it was recorded before Hayes began to suffer setbacks with his health.

\section{Background}

This album was recorded in Columbia Studios in New York City on October 3rd and 4th, 1961.

It was not released in this format as "The New York Sessions" until 1990, although 6 tracks recorded in this sessions (Tracks 1 to 6 ) had previously been released as the album "Tubbs In N.Y." by Fontana Records.

Tracks 7 to 10 are previously unreleased bonus tracks from the same session. The album was released in entirety by Columbia records as "The New York Sessions" in 1990.

The players on the album are discussed below. Other personnel include:

Producer [Digital] - Mike Berniker

Producer [Original Recordings] - Amy Herot, Gary Pacheco, Mike Berniker

Remix [Digital Engineer] - Larry Keyes

\section{Players on 'The New York Sessions':}

Clark Terry is featured on Trumpet on just four tracks on the album. Terry was born in St. Louis, Missouri on December 14th, 1920. He worked with Duke Ellington, with from 1951-1959 and later with the Doc Severinsen band, which played on the Johnny Carson Tonight Show. During this time, Clark worked and recorded with artists like J.J. Johnson, Oscar Peterson, and Ella Fitzgerald, then co-led a quintet with Bob Brookmeyer in the early 1960s.

Clark Terry has maintained a highly prolific career since, and is still alive today. Terry's place on the recording was to be taken by Donald Byrd, with whom Terry had appeared on Dizzy Reece's Blues In Trinity.

George Duvivier (Aug 17, 1920 - Jul 11, 1985) was an American jazz double-bass player. Duvivier was born in New York City and took up the cello and also the violin while in high school before settling on the bass. He also learned composition and scoring before going out on the road with Lucky Millinder and then with the Cab Calloway bands of the early 40 s after a stint in the army. He was an excellent composer and scored many tunes for those two big bands. Duvivier was a free lance bassist for most of his life, never belonging to any one particular group for any extended period of time, but rather playing 
with many famous names, including Coleman Hawkins, Paul Desmond and Ella Fitzgerald to name a few.

Horace Parlan (born January 19, 1931 in Pittsburgh, Pennsylvania) is an American hard bop and post-bop piano player.

Parlan has worked with Charles Mingus on the classic recordings Mingus Ah Um and Blues \& Roots, and tenor saxophonist Archie Shepp among others. Parlan's influences include African-American "roots", gospel music, as well as bebop. Parlan suffered from Polio as a child, partially crippling his right hand. The handicap, though, has contributed the development of his strong left-hand chord voicing style, while comping with highly rhythmic phrases with the right. Parlan is still alive today.

Samuel David "Dave" Bailey (born February 22, 1926) is an American jazz drummer. Born in Portsmouth, Virginia, Bailey studied drumming in New York City at the Music Center Conservatory following his stint in the Air Force in World War II. He played with Johnny Hodges, Charles Mingus, Gerry Mulligan, Ben Webster, Lee Konitz and Horace Silver among many others.

In 1969 he retired from music and became a flight instructor. Since 1973 he has worked in music education in New York.

Eddie Costa, (August 14, 1930 - July 28, 1962), was an American jazz pianist and self taught vibraphonist born in Atlas, Pennsylvania near Mount Carmel, PA in Northumberland County. Throughout his career he recorded with Phil Woods, Art Farmer, and Bill Evans.

Jazz commentator Stanley Dance covered the sessions for Jazz Journal, and had this to say:

When he (Tubby) came to record for Columbia, he was even more impressive. It was midnight on October 3rd and the trio assembled in the studio to accompany him consisted of Horace Parlan, Dave Bailey and George Duvivier. Between sets at Birdland with Gigi Gryce, Eddie Costa came over and joined in on vibes. The next night, the same personnel was augmented by Clark Terry. (Everything was) recorded in less than six hours with a minimum of fuss. There was enough material for two albums and supervisors Nat Shapiro and Mike Berniker were elated with both this fact and the performances. Tubby was, may we say, unflappable. He had the star role, but nothing dismayed him. There was a fairly consistent flow of visitors, including Gene Quill,Bill Potts, Doug Dobell and Timme Rosenkrantz. Manny Albam stayed for the whole of both sessions and obviously enjoyed himself. ${ }^{19}$

Hayes, when interviewed before the session, said simply: "It'll be a blowing date...the only things definite about the character of the sessions is that they'll be free and easy and they'll be well run." 20

\footnotetext{
${ }^{19}$ Simon Spillett February 1st, 2005 available from: http://forums.allaboutjazz.com/archive/index.php/t2099-p-2.html

${ }^{20}$ Simon Spillett February 1st, 2005 available from: http://forums.allaboutjazz.com/archive/index.php/t2099-p-2.html
} 


\section{'The New York Sessions' Summary Description}

1. 'You for Me' by B. Haines. This is a medium-up tempo version of the standard tune, beginning with an 8 bar solo saxophone introduction. Hayes plays four choruses of solo then returns to the melody, with no other solos taken. Hayes maintains a playful, "overwhelming exuberant" ${ }^{21}$ feel throughout the solo.

2. 'Pint of Bitter' by Clark Terry is an easy tempo swing tune, in which the trumpet and tenor play the melody in unison. It has a hard swinging, blues influenced-feel to it. It has an AABA form, modulating from $\mathrm{Bb}$ minor to $\mathrm{D}$ during the $\mathrm{B}$ sections. One-chorus solos are taken by Clark Terry, with trumpet and plunger mute, Hayes, Eddie Costa, and Horace Parlan.

3. 'Airegin' is a well known jazz standard written by Sonny Rollins. This is played uptempo, with four choruses from Hayes followed by solos from Eddie Costa, Horace Parlan and George Duvivier. Trades between vibraphone and tenor finish the solo section.

4.'Opus Ocean', another original by Clark Terry is played up-tempo, with the head in unison played by Hayes and Clarke Terry on fluegelhorn. Trills and flutter tonguing on the fluegelhorn give the head more interest. Four choruses of solo are played by Hayes followed by Clarke Terry and Horace Parlan. Trades occur between Hayes and Clarke Terry before the melody is reprised.

5. 'Soon' by George and Ira Gershwin is usually a ballad, but here is given a more uptempo feel, beginning with an eight bar pedal, piano introduction. After playing the melody, Hayes launches double time into a four chorus solo. Horace Parlan solos also before Hayes played the outhead, including an extended doubletime passage.

6. 'Doxy' is a strongly rhythmic interpretation of this jazz standard by Sonny Rollins. It is played at an easy tempo with a strong underlying triplet-driven blues feel. The head is played with Tenor and Vibraphone and solos are taken by Hayes and Eddie Costa.

7. 'Soho Soul' is an original by Tubby Hayes. It is a soulfully played G blues composition at an easy medium tempo. An unusual feature of this tune is the 8 bar drum break (after a twelve bar form) before returning to the head.

8. 'The Simple Waltz', another Clark Terry original, is a 3/4 waltz played over a 24 bar blues form. As the name suggests it has a very simple melody that is played by trumpet and tenor in unison. It was described by Stanley Dance in 1989 as having a "Good humoured kind of Gospel Happiness" ${ }^{22}$

\footnotetext{
${ }^{21}$ Stanley Dance, 1961, Liner Notes The New York Sessions, Tubby Hayes with Clark Terry.

${ }^{22}$ Stanley Dance, 1989, Liner Notes The New York Sessions, Tubby Hayes with Clark Terry.
} 
9. "Half a Sawbuck" is another original tune by Tubby Hayes. It is essentially a bebop tune, though hints at a Latin drum feel at times during the head. The tune centres around the key of A minor.

10. 'You are my Everything" is a beautifully played ballad by Harry Warren. Described by Stanley Dance as the biggest surprise of the album: "An envoi that reveals another facet of his musical character" ${ }^{23}$

${ }^{23}$ Stanley Dance, 1989 


\section{Section 2: Improvisation and Formula in Jazz}

\section{Formulaic Improvisation: Towards a Definition}

Hayes, as many players schooled in the bebop idiom, was in the habit of using what can be called 'formulaic improvisation'.

Formulaic improvisation can be defined as: The use of a wide variety of elements (including favorite licks or fragments, manipulations of intervals and range, interpolated phrases, etc.) in developing a solo. ${ }^{24}$

To begin to expand on the initial definition of formulaic improvisation, here are four types of improvisation, as itemised by Kernfield ${ }^{25}$ :

(1) Paraphrase improvisation. Here the solo is clearly an embellishment of the original melody. This is conceptually the least problematic.

(2) Chorus Phrase improvisation. The solo in this instance follows the form and harmony of the original melody, but is not based on its motives.

(3) Motivic improvisation. The solo is fashioned from motivic references heard in the original melody.

(4) Formulaic improvisation. The solo repeats melodic ideas heard in other improvisations. Persistently recurring ideas are called "formulas".

It is possible that a type four improvisation could be a subset of type 2 in this taxonomy. The transcribed solos found on this recording, while including elements of each type of improvisation as itemised here, principally tend to fall under the rubric of "Formulaic improvisation". This is particularly apparent in the fast tempo tunes and the double time passages analysed.

\section{Formulaic Improvisation in Jazz and the Bebop Idiom}

Formulaic improvisation in jazz has come about from imitation. That is, the practice of listening to another player's ideas, and imitating and practising them until they become internalised. Jazz players, particularly in the bebop idiom, would often hear an idea, imitate it, and apply this idea to other tunes. Many players would take a given idea and learn it in all keys in order to be able to apply it in different contexts. These ideas become internalised into a player's subconscious and integrated into their "vocabulary" in such a way that it becomes a "natural" part of their improvisations. These pre-learnt formulas

\footnotetext{
${ }^{24}$ Columbia University Centre for Jazz Studies, 'The jazz glossary' available from http://ccnmtl.columbia.edu/projects/jazzglossary/f/formulaic_improvisation.html accessed 10th August 2009

${ }^{25}$ Barry Kernfield Two Coltranes Annual Review of Jazz Studies, Vol 2, 1983, pp7-66 Itemised from Pervious work: Andre Hodeir. Jazz, It's Evolution and Essence. New York, Grove Press 1956
} 
might not always be played the same way but may be used as a basis for an improvised line.

In creating a jazz line Thomas Owens (1974) suggest that any given phrase is not generally used in the same way over and over again, but instead used as a base to build on, and can be varied "by augmenting or diminishing it, by displacing it metrically, or by adding or subtracting notes." ${ }^{26}$ The pre-learnt phrases are varied and combined in different ways from solo to solo. "No two choruses are exactly alike... The mix of familiar motives is always different." 27

As Barry Kernfield (1983) points out, difficulties can arise for the analyst in identifying any one formula, given the way a skilled improviser will vary each formula, asking questions such as: "How long can and must a formula be?"; "What exactly is the relationship to other fragments?" 28 Kernfield begins to address these questions by examining the way certain formulas are connected to each other in a study analysing John Coltrane's solos and creating a tabular system to investigate formulaic relationships.

Many improvising musicians (if not most) throughout jazz history, used formulaic improvisation as a means to be able to improvise "in real time". It is a method that is typical of, but certainly not limited to the bebop period, where a move towards faster tempos and quickly moving chord changes made it necessary for many musicians to have access to pre-learnt material, in order to play these tunes and create coherent, appealing phrases in real time. "Many of the components of those phrases must be at the finger-tips of the player before he begins if he is to play coherent music."29

The inclusion of such formulas (or material that has been pre-learnt) in these improvised solos brings up questions as to the actual definition of "improvisation" and just how much of these 'improvised' solos are actually improvised. Inspection and analysis of improvised solos will begin to show us that much of what a player will include in his or her improvised solo has been pre-learnt. Gregory Smith (1983) discusses the lack of a universally accepted definition of improvisation: "It is a term loosely used, a term allied with various, often contradictory notions". 30 Smith goes on to explain that "Students of the art usually reject any literal notion of improvisation as a spontaneous act, since the spontaneity in most cases is more apparent than real." He describes formulaic improvisation as "a process of making the appropriate choice of compatible formulas". 31

\footnotetext{
26 Thomas Owens Charlie Parker Techniques of Improvisation 1974 pp35

27 Thomas Owens 1974 pp35

${ }^{28}$ Kernfield 1983 pp 17

${ }^{29}$ Thomas Owens 1974 pp35

${ }^{30}$ Gregory Smith Homer, Gregory, and Bill Evans? The Theory of Formulaic Composition in the Context of Jazz Piano Improvisation. 1983 pp 16

${ }^{31}$ Gregory Smith 1983 pp99
} 


\section{Charlie Parker as a Pioneer of Formulaic Improvisation:}

Charlie Parker can be given much of the credit for the acceptance of the use of formula in jazz. As Henry Martin points out "It seems possible that Parker's brilliance and pursuance of jazz as an art form have created an atmosphere in which formula based music could not only be accepted but also thrive. Parker is not directly responsible for this development of course: but he is perhaps the prime exemplar of the fine-art tradition in jazz, as first manifested by bebop." ${ }^{32}$

Charlie Parker's improvisations were heavily based on formula. Thomas Owens (1974) stated that "In spontaneously composing, he drew primarily on a repertory of about 100 motives of varying lengths, modifying them and combining them in a great variety of ways. ${ }^{33}$ Owens further suggests that Parker's improvisational style - especially at faster tempos - is very heavily dependant on these melodic formulas.

Charlie Parker however was by no means the only musician to use this method of creating an improvised solo or the first. Mark Gridley ${ }^{34}$ cites Louis Armstrong as the original improvising musician to create a vocabulary of licks and patterns that were copied by others. Jazz performers of the 40s and 50s who were "called upon to produce three or four hours of improvised music five to seven days a week" ${ }^{\$ 5}$ developed collections of "instrumental finger patterns" which were related to keys and chords. ${ }^{36}$ "The motifs are the performer's own independent musical ideas, among which, naturally, stereotyped phrases are always to be found, as every mature musical language has its idioms ${ }^{37}$

\section{The Roles of Creativity and Tradition in Jazz Improvisation}

"Before an improviser opens his mouth or sounds the first notes on his instrument, one knows, provided one knows his tradition, within what bounds the piece will lie"38 Knepler (1969)

In studying improvisation as a series of varied pre-learnt formulas, we can begin to question the role of creativity in jazz improvisation. To what extent is creativity in jazz improvisation? And is it possible to still incorporate creativity while still playing in a formulaic, essentially traditional style?

\footnotetext{
${ }^{32}$ Henry Martin Charlie Parker and Thematic Improvisation. 1996. pp 126

${ }^{33}$ Thomas Owens 1974 pp35

${ }^{34}$ Mark Gridley. Jazz Styles. 2006 pp

${ }^{35}$ Frank Tirro.Jazz: A History. $2^{\text {nd }}$ ed.1993. pp273-274

${ }^{36}$ Frank Tirro 1993. pp275

${ }^{37}$ Janos Gonda, "Problems of Tonality and Function in Modern Jazz Improvisation," Jazzforschung/Jazz Research, $3 / 4$ (1971/9172) pp198.

${ }^{38}$ Georg Knepler (1969) Quoted in Smith 1983 pp37
} 
Paul Rinzler (2008) closely examines the roles of creativity versus playing in such a manner that follows a tradition ${ }^{39}$. After closely examining both creativity and tradition Rinzler explains the necessity of both of these elements in improvised jazz. He states that "any creative improvisation is an improvisation on something", suggesting that traditional and pre-learnt elements need to be in place in order for creativity to follow. Rinzler also points out that, "A choice is always a choice selected in relation to something" which in the context of transcription analysis is the choice the improviser has made in relation to the chord changes and/or melody of the tune being played. "Creativity in Jazz generally takes the core tradition and modifies it drawing on diverse sources". ${ }^{40}$ In the case of Hayes improvisational style it is very easy to see the core of tradition in the form of a strongly recognizable vocabulary of licks and patterns, and 'standard jazz language' that has been learnt from different sources.

With the table shown below, Rinzler defines jazz improvisers by their level of creativity versus adherence to long-standing tradition: ${ }^{41}$

\begin{tabular}{|c|c|c|c|}
\hline \multicolumn{2}{|c|}{$\begin{array}{c}\text { Tradition } \\
\text { (Stimulus-Bound) }\end{array}$} & \multicolumn{2}{|c|}{$\begin{array}{c}\text { Creativity } \\
\text { (Stimulus-Free) }\end{array}$} \\
\hline Type 1 & Type 2 & Type 3 & Type 4 \\
\hline $\begin{array}{l}\text { Completely within } \\
\text { the tradition }\end{array}$ & $\begin{array}{l}\text { Within the tradition, } \\
\text { but creative }\end{array}$ & $\begin{array}{l}\text { Changing the } \\
\text { tradition, but } \\
\text { comprchensible }\end{array}$ & $\begin{array}{l}\text { Radically changing } \\
\text { the tradition }\end{array}$ \\
\hline $\begin{array}{l}\text { Standard (tried } \\
\text { and (rue) ideas }\end{array}$ & $\begin{array}{l}\text { New ideas, but } \\
\text { similar to } \\
\text { standard ones }\end{array}$ & $\begin{array}{l}\text { Some new, } \\
\text { nonstandard ideas }\end{array}$ & $\begin{array}{l}\text { Nearly all } \\
\text { nonstandard } \\
\text { ideas }\end{array}$ \\
\hline $\begin{array}{c}\text { Comfortable } \\
\text { (boring?) }\end{array}$ & Interesting & Fascinating & $\begin{array}{l}\text { Challenging } \\
\text { (bewildering?) }\end{array}$ \\
\hline $\begin{array}{l}\text { Jazz musician } \\
\text { students }\end{array}$ & Young lions & $\begin{array}{l}\text { Miles Davis's } \\
\text { mid-1960s quintet }\end{array}$ & Free jazz \\
\hline $\begin{array}{l}\text { Creativity is } \\
\text { minimized }\end{array}$ & Juxtaposition & Dynamic tension & $\begin{array}{l}\text { Tradition is } \\
\text { minimized }\end{array}$ \\
\hline
\end{tabular}

Types 1 and 2 are defined under the umbrella of adherence to tradition while types 3 and 4 value creativity to various extents above adherence to a tradition. The 'New York Sessions' clearly fits into Rinzler's "Type 2" as it "Follows the tradition of jazz but still incorporates much creativity". It is apparent that much of Hayes vocabulary does not appear to have been spontaneously conceived on the spot (i.e. is not creative improvisation) but has rather been learnt from the tradition, most likely by imitating other players in the bebop idiom, particularly Charlie Parker.

It is not at all unusual for a musician to have a "vocabulary" or an internalised set of pre-

\footnotetext{
${ }^{39}$ Paul Rinzler. The Contradictions of Jazz. 2008 pp129

${ }^{40}$ Paul Rinzler. 2008 pp129

${ }^{41}$ Paul Rinzler. 2008 pp127
} 
learnt formulas to draw from. "Every mature jazz musician develops a repertory of motives and phrases which he uses in the course of his improvisations. His "spontaneous" performances are actually pre-composed to some extent." ${ }^{, 42}$ What is creative in these solos is the manner in which these formulas are combined, put together, and then varied. Hayes "continually find[s] new ways to reshape, combine and phrase his well-practised ideas" $" 43$

Rinzler suggests that "Many people find such jazz interesting but still grounded in the familiar". "Often the inclusion of such formulas that have been heard before can give the audience a point to relate to. The improviser engages the audience by using a language that is already familiar to them. In the context of Hayes' improvisational style "the familiar" consists of jazz language that has been used before by other artists such as Charlie Parker, and commonly used blues vocabulary.

There can be a case for both playing "creatively" (without pre-conceived ideas) and for following a tradition more closely. Rinzler states that "Making an individual, creative, and unique statement in a jazz improvisation is one of the highest musical goals in jazz" ${ }^{45}$

This is a view shared by many jazz performers and enthusiasts to different extents. On the other side of the coin is the importance that some commentators place on playing from a more traditional sense. Eric Nisenson (1997) has summarized the theory of a jazz tradition as seen by Stanley Crouch and Albert Murray: "Playing within this tradition gives a musician a kind of legitimacy, placing him within a community that supports and understands his music, while playing outside this tradition is simply amorphous music making. Music played outside the tradition was music in a vacuum, unconnected to people's lives". "Stanley Crouch also makes a strong statement that the jazz tradition is essentially not innovative but is based on four elements:

The irrefutable fundamentals that have maintained themselves from generation to generation: $4 / 4$ swing, blues, the meditative ballad, and the Spanish tinge [...] There is little measured thinking about what is going on and little respect for those who are not bent on "innovation"... the vast majority of musicians at any time in history and in any idiom are not innovators themselves-even if they are among the first to embrace new vocabularies." ${ }^{, 47}$

Consonant with this, Rinzler points out the value in playing jazz that incorporates more familiar rather than 'creative' material.

Familiarity with a known idiom is a requirement for successful communication. Tradition has the better chance of successfully communicating with a larger audience through a larger common denominator because, by definition, tradition has not just been created, it's been around for a while, so the audience will be more familiar with it." ${ }^{, 48}$

\footnotetext{
${ }^{42}$ Thomas Owens 1974 pp17

${ }^{43}$ Thomas Owens 1974 pp17

${ }^{44}$ Paul Rinzler. 2008 pp127-128

${ }^{45}$ Paul Rinzler. 2008 pp81

${ }^{46}$ Eric Nissenson Blue: The Murder of Jazz pp15

${ }^{47}$ Stanley Crouch Considering genius pp 209

${ }^{48}$ Paul Rinzler. 2008 pp134
} 


\title{
Licks and Patterns: A Personal Tradition Versus Spontaneous Creation
}

\author{
"Recurrent melodic patterns are accepted as an inevitable and necessary feature of the \\ improvisational process in jazz." 49
}

Following the considerations between playing 'within the tradition' or playing 'creatively' is the question of whether formulaic playing is a valid course in creative improvisation. How valid is this improvised music if it is pre-learnt to such an extent? By the very nature, formulaic playing falls strongly into the category of playing within a tradition, as the formulas are preconceived and more often than not learnt from sources such as other players.

On the use of formulas, (more commonly referred to by musicians as "licks" or "patterns") Rinzler points out:

On a practical level, no one can be creative all the time. But the improviser must create continually because he or she creates in real time which flows continuously. So the only hope the improviser has is to be as creative as possible most of the time, and otherwise try to be as tasteful and interesting as possible with tried-and-true noncreative material. ${ }^{50}$

On one hand, a vocabulary of licks or patterns or formulas does enable a musician to create an improvised solo proficiently in real time and also to be "tasteful and interesting" $"$ at times where one is not creating new ideas. Rinzler also observes that the flipside is eventual reliance on this personal vocabulary at the expense of creativity: "The more technically proficient one becomes, the more likely one will fall into a rut that has been constructed out of that technical facility. We tend to do what we do best, and what we do best is what we have practiced." Dieter Glawischnig sums up:

The basic dilemma concerning all practicing, all studying, all preparing for the real moment of spontaneous playing, for "the act of creation" is, on the one side, you must get your material together by the process of hard work in order to simply play anything. On the other side, creativity could be blocked by repeatedly falling into the trap of reproducing learned habits, something similar to a conditioned reflex. ${ }^{52}$

Hayes echoed this same frustration in the context of his own playing to Sal Nistico:

"I find that everything I've been practising over the years is no help to me. In fact, it's a restriction." 53

Ronald Byrnside (1975) also notes that an improviser "cannot escape his own musical habits, his previous musical experiences, his personal performance facility and compositional procedures. ${ }^{, 54}$ Hayes echoed this sentiment too:

But, you know, I feel, in a lot of ways, that I've exhausted that kind of thing, and I've got

\footnotetext{
${ }^{49}$ Gregory Smith 1983 pp144

${ }^{50}$ Paul Rinzler. 2008 pp133

${ }^{51}$ Paul Rinzler. 2008 pp133

${ }^{52}$ Dieter Glawischnig quoted in Rinzler 2008 pp133

${ }^{53}$ Les Tomkins 2000 Tubby Hayes meets Sal Nistico available from: http://www.jazzprofessional.com/Exchange/HayesNistico.htm accessed January 13th 2009

${ }^{54}$ Ronald Byrnside, The Performer as Creator: Jazz Improvisation in Contemporary Music and Music Cultures 1975 pp223.
} 
to try and get into something else. And it's very difficult to do that, isn't it? You can't just stop overnight doing what you've been doing for nearly twenty [years] ... If you get complacent, that's the end of everything. In the last year or so I've felt, not that I'm playing badly, but that, having played a certain way for fifteen years in the business, I've come to this wall now. I don't want to carry on coasting along the way I've been playing. I'm only thirty-one-I see no reason to give in now. I'm young enough to keep on into something else. But, at the same time, I don t want to just go and play completely another way just for the sake of it. ${ }^{55}$

What is contradictory, however, is that while not always seen as creative, it is largely these very formulas that a player will use that make their sound so unique and personal. No two musicians will ever use the exact same combination of formulas in their solos. For many players it is the ideas they choose and the way they combine them, coupled with how these ideas are executed during an improvised solo that make their playing unique and recognisable. By imitating another player's ideas, a soloist is playing in a manner that follows a tradition. By continually playing a selection of formulas and reshaping them in a personal way, he/she is creating their own personal tradition. A musician playing their known vocabulary is playing from their own past and personal experiences. As Ronald Byrnside (1975) comments, improvisation is "considerably more reflective than purely spontaneous in nature" ${ }^{, 56}$. A number of the ideas commonly used by Hayes have been identified in section four.

\section{Hayes and Formulaic Improvisation}

An extremely high percentage of Hayes' improvisations are based on pre-learnt material including: licks, patterns, scales and arpeggios. He relies heavily on this vocabulary throughout the course of his solos, particularly in fast double time passages, at fast tempos and during fast moving changes. Hayes uses these pre-learnt phrases (or "formulas"), which are frequently linked together with scalar ideas, digital patterns and enclosures. Hayes tends to use digital patterns to get through fast moving chord changes, particularly where the root motion of the chords is descending. (This is seen most clearly over 'Doxy' in bars in bars 37-38 where Hayes builds a phrase using similar digital patterns repeated with minor variation in descending motion.):

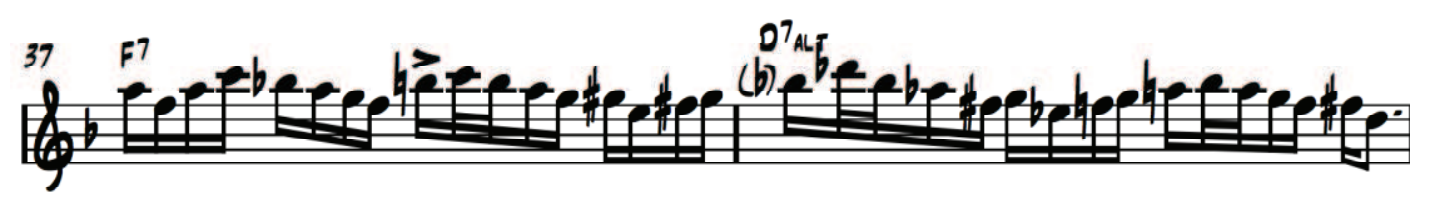

Hayes most formulaic playing is seen in eighth-note passages in his solos on 'Airegin' and 'Opus Ocean' (two faster tunes) and in the double-time passages in 'Soon', 'You for

\footnotetext{
${ }^{55}$ Les Tomkins 2000 Tubby Hayes meets Sal Nistico available from: http://www.jazzprofessional.com/Exchange/HayesNistico.htm

${ }^{56}$ Ronald Byrnside, the Performer as Creator: Jazz Improvisation in Contemporary Music and Music Cultures 1975 pp223.
} 
Me', 'Half a Sawbuck', 'The Simple Waltz', and 'Doxy'.

Formulaic playing is appropriate for many types of music, as Henry Martin (1996) points out: "Pervasive application of formula is particularly appropriate in certain jazz and popular styles" ".77. Formulaic playing is well suited to the bebop tunes, fast moving chord changes and fast tempos. It certainly does have its limitations. It lacks an element of basic in-the-moment creativity, and has stylistic limitations, particularly in playing more modern styles of jazz. While formulaic improvisation was an area where Hayes gained a great deal of skill, he did come to find it limiting as he discussed in an interview with fellow saxophonist, Sal Nistico: "When you've got used to playing a certain tune in B flat on the tenor for years and years - well, you can't always be fresh." ${ }^{, 58} \mathrm{He}$ also goes on to describe his frustrations with his limitations:

The way it's going towards playing 'free' these days-like, listening to Lee Konitz in Ronnie's - I find that everything I've been practising over the years is no help to me. In fact, it's a restriction. ${ }^{59}$

\footnotetext{
${ }^{57}$ Henry Martin Charlie Parker and Thematic Improvisation. 1996. pp 126

${ }^{58}$ Les Tomkins 2000 Tubby Hayes meets Sal Nistico available from: http://www.jazzprofessional.com/Exchange/HayesNistico

${ }^{59}$ Les Tomkins 2000 Tubby Hayes meets Sal Nistico available from: http://www.jazzprofessional.com/Exchange/HayesNistico.htm
} 


\section{Section 3: Analysis}

\section{Analysis of Tubby Hayes' Solo on 'You for Me'}

\section{Composer: B Haines}

Style: Medium- up tempo bebop

Form: AB 32 bar form.

Solo Section: 6 choruses

Tempo: 200 beats per minute

Key: C major

Phrasing and Articulation: Hayes maintains a very playful feel throughout the solo.

Melodic Development:

1. Many examples of sequence are found in this solo. Six have been located in total.

79-80:

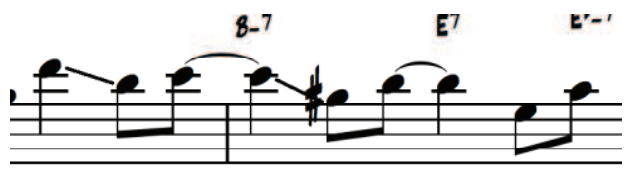

85-86:

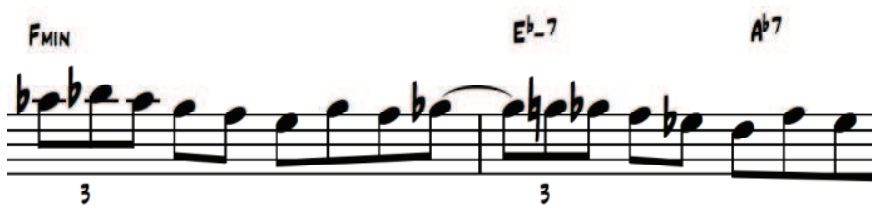

113-114:

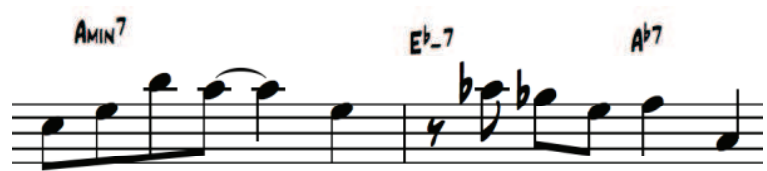

117-118: 


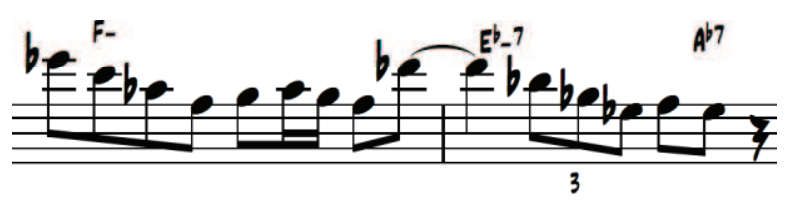

149-150:

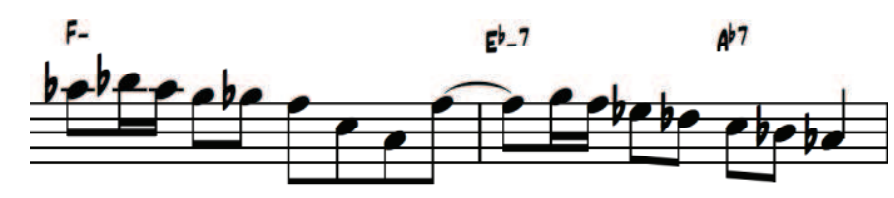

and 193-194:

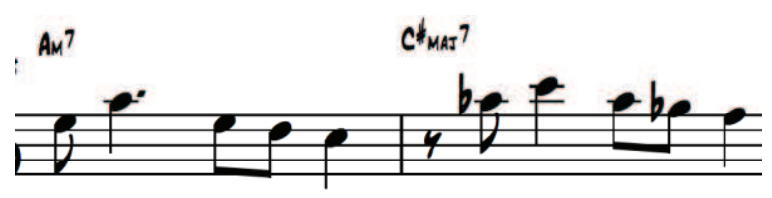

In nearly all of these cases (excepting bars 79-80) these sequences appear to be a way to get through specific chord changes in 'less comfortable' keys. They occur in two specific places in the form in each chorus: bars 9-10 of each form where one bar of A minor 7 chord is followed by a short 2-5 progression resolving to Db major; and in bars 13-14 of each form where on bar of $\mathrm{F}$ minor 7 chord is followed by a short 2-5 progression resolving to $\mathrm{Db}$ major.

2. A repeated phrase bases on the A Blues scale is used from bars 159 to the first beat of bar 163:

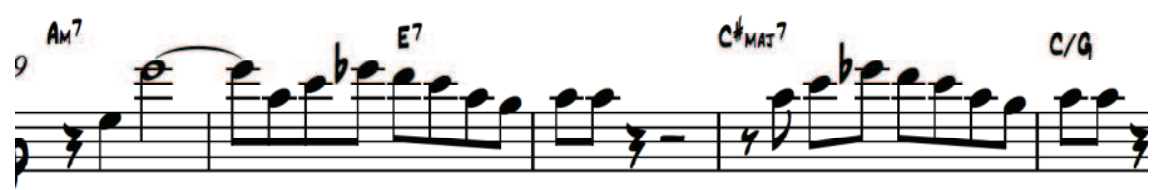

This is nearly identical to the C Blues Scale lick used in the first bar of the solo (bar 41):

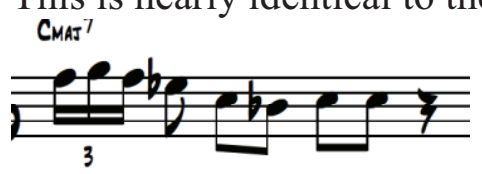

and also leading into the first bar of the second chorus (bars 72 and beat one of bar 73):

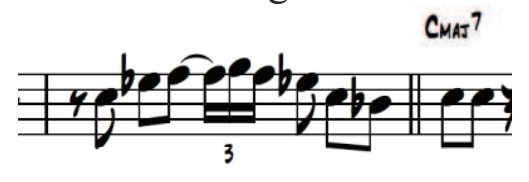

This return to a simple blues phrase helps to give a sense of overall melodic structure to the solo. 


\section{Content: Vocabulary, Formula, Repeated Material:}

Double time passages: Due to the fast tempo of this tune, there is not a huge amount of double time playing, compared to Hayes' other tunes, with just four extended double time passages found in this solo. Repeated formulas found in these double time passages are as follows:

1. A chromatic movement from the minor 3rd of a given chord to the fifth. This is found frequently in many of Hayes' solos and is shown here on the third beat of bar 59 used over a $\mathrm{C}$ major chord.

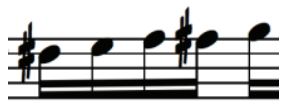

2. The following $\mathrm{C}$ major Scale pattern, which has been used through bars 59-60 with the chromatic passage (mentioned in example 1) is inserted on beat 3 of bar 59 .

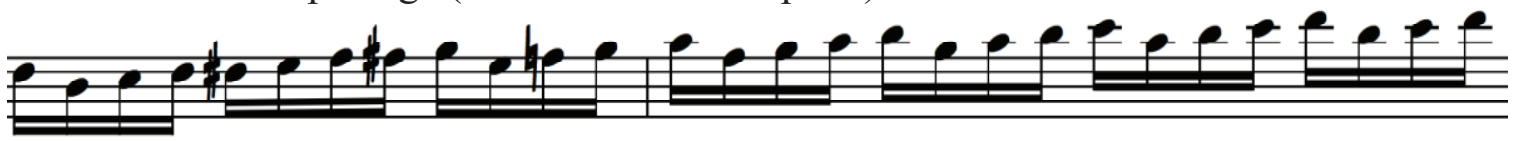

3. C major bebop scale descending over an octave. This occurs twice: in bar 58 it is started from the 5 th of the chord:

$a^{7}$

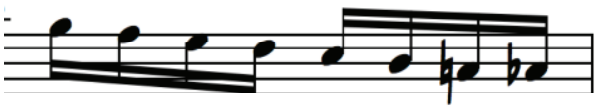

and in bar $15 \hat{4}$ from the root of the chord:

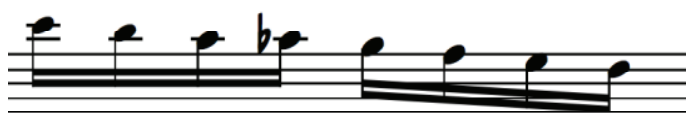

4. The following passage used over an A minor chord is a simple change running scalar pattern, which is quite standard apart from its use of the major 7 th over a minor 7 chord. This occurs twice, in bars 127

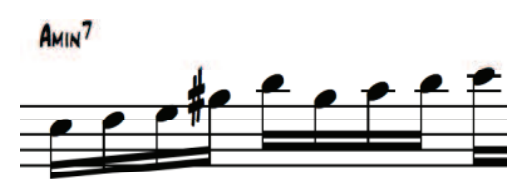

and 129: 


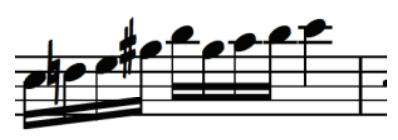

and both times is preceded with a descending chromatic scale passage from the fifth to the third of the A minor chord (here in bar 129).

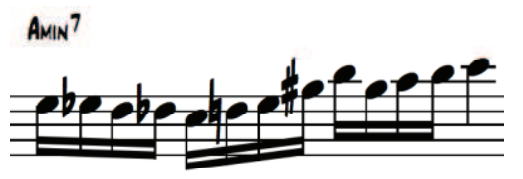

5. A variation of the bebop lick, which is used twice over a G7-C resolution. Both times starting on $\mathrm{Bb}$ (the sharp 9 of the $\mathrm{G} 7$ chord) which is a slightly less conventional use for the bebop lick, although it does work well in this context because it outlines the flat 9 and sharp 9 of the dominant chord and resolves to the fifth of the major chord. This variation is shown here in bar 44:

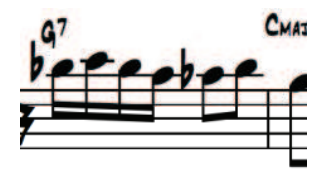

and bar 139:

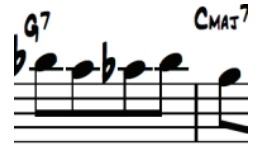

This variation of the bebop lick occurs also in bars 58 and 93 respectively, as part of an extended double-time passage in both cases
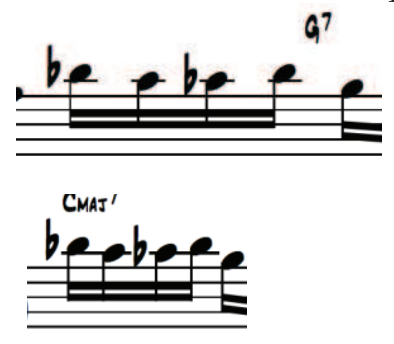

6. This passage is used three times over the course of this solo, in bars 89 : $\mathrm{CMaT}^{7}$

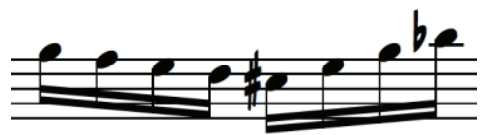

124: 


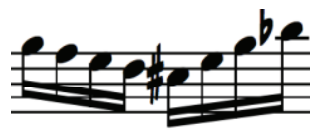

And 155 (where is it varied by 1 note):

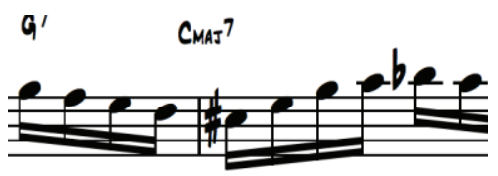

It alternates a partial $\mathrm{C}$ major scale with a $\mathrm{C} \#$ diminished chord. It may be that Hayes was implying an A7b9 chord following the $\mathrm{C}$ major chord in each case.

Other devices found in the double time passages include change running, enclosures, and many scale fragments and digital patterns. Including the unusual addition of an E major digital pattern used over a G7 chord in bar 90:

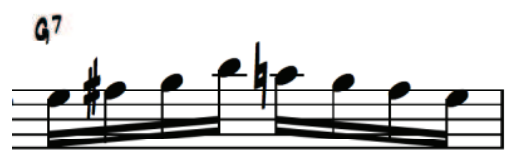

It appears that this has been added as part of an ascending sequence rather than having any association with the chord changes being played at this point:

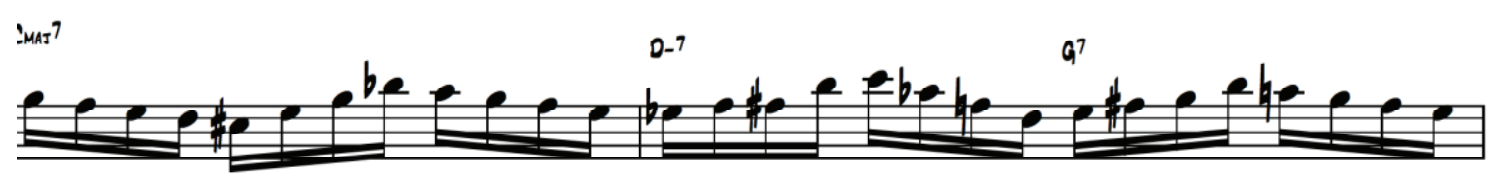

Other Repeated Material/Formula:

The following phrase is often played over a Db major chord (shown here at bar 83):

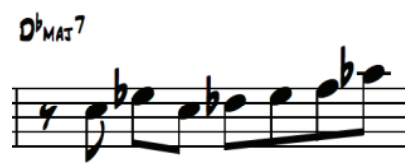

It occurs twice in its (almost) exact original form at bars 83 and 87 and partially in bars 54, 147, 179 and 183. Similar digital patterns are used over the Db major chords in bars 115, 117 and 151. This suggests that Hayes was less comfortable playing in this key and relied heavily on pre-learnt material in order to play over these chord changes at speed.

\section{Other Devices Used:}

This chromatic diminished passing chord substitution (that Hayes will also use in his solos on "Opus Ocean', and 'Soon') appears in this solo twice: bars 75-76 (punctuated by a turn on beat 1 of bar 76): 

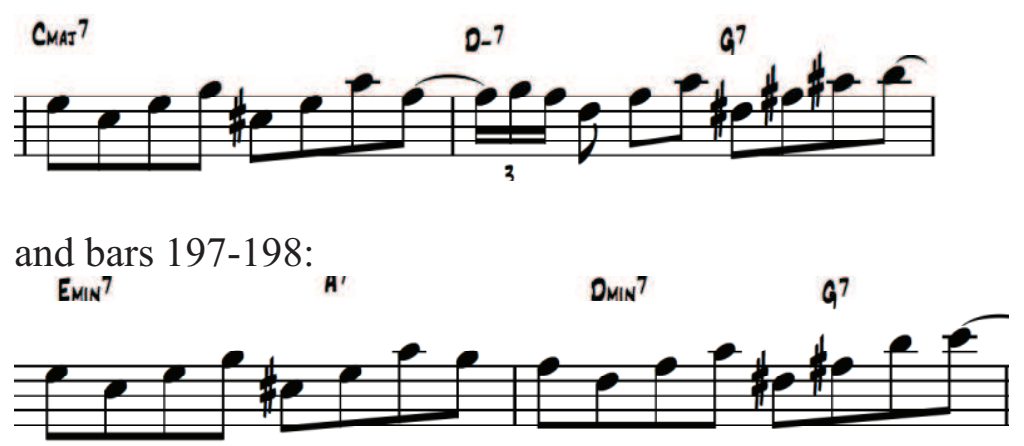

The "Cry Me a River" lick appears 3 times in full or part (and often with a turn added) at bars 68:

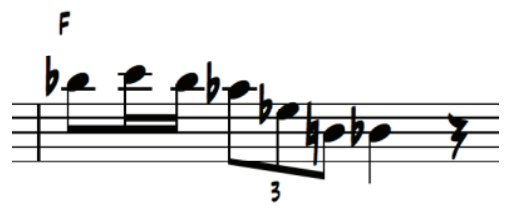

100:

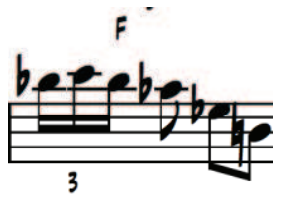

and 132:

F

beb-a

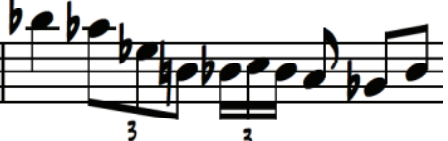

In each case the lick is started on the $\mathrm{Bb}$ over an $\mathrm{F}$ major chord, a less conventional use for this lick.

Shown here is another lick that recurs a number of times in this solo.

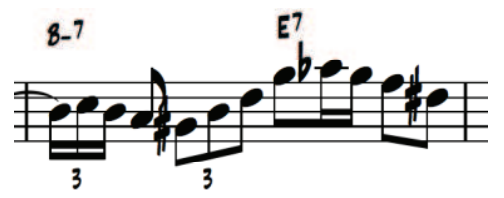

It is a phrase that is used in full or part over a B minor to E7 6 times throughout the solo in bars: 46, 64, 110, 129, 142 and 190. 


\section{Analysis of Tubby Hayes' Solo on 'Pint of Bitter'}

Composer: Clark Terry

Style: Easy swing, Relaxed and blues influenced.

Form: AABA,

Solo section: 1 chorus

Tempo: 112 beats per minute

Key: $\mathrm{Bb}$ modulating into $\mathrm{D}$ during the $\mathrm{B}$ sections of the form

Phrasing and Articulation: There is an uncharacteristic use of space in this tune. Many of the slower rhythms are triplet driven with an underlying 12/8 feel. Dynamics (crescendos and decrescendos) are used to shape phrases. The articulation is varied throughout the piece. Accents, pitch bends, fall offs, and ghosted notes add to the blues feel of the solo.

Melodic Development: Hayes' opening phrase is a loose reference to the melody with the descending blues scale line landing on the root of the $\mathrm{Bb}$ chord on beat one at the start of the chorus, in the same way that the melody does.

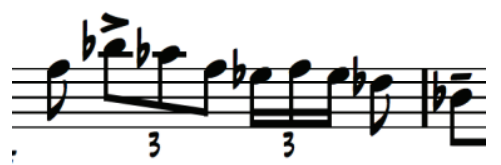

This reference to the melody is continued into the next phrase. Similarly the melody is implied at the end of the second A section with the descending blues scale line landing on the root of the chord $(\mathrm{Bb})$ in the $15^{\text {th }}$ bar of solo. Hayes lands on the root of the chord again at the beginning of the last $\mathrm{A}$ section which serves to both imply the melody and mark the return to the key of $\mathrm{Bb}$ after the bridge section is played in $\mathrm{D}$ major. Once again, Hayes lands on the root of the $\mathrm{Bb}$ chord:

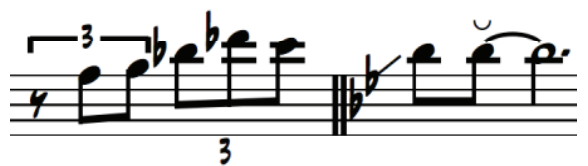

(approached this time with an enclosure rather than a blues scale passage) as an end to his solo on the first beat of the next chorus.

Content: Vocabulary, Formula, Repeated Material:

Scale Choices In the A sections Melodic Phrases are generally based either on the Bb blues Scale: (example bar 35) 


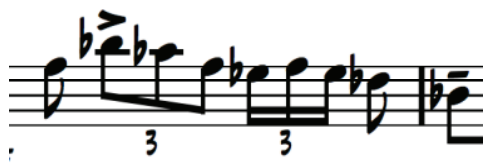

or G (relative minor) blues scale: (example bars 38-39)

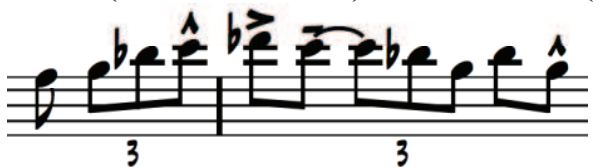

or a combination of both.

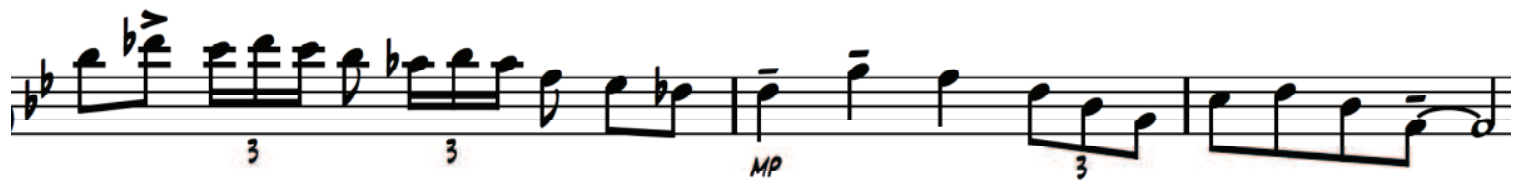

This serves to give Hayes' solo a similar feel to the melody of the tune, which is based solely on Bb Blues Scale (in the A sections) and D Blues Scale (in the bridge). Bb major is also used as a blanket scale. Other scales used include the chromatic scale, half-whole diminished, and the Superlocrian scale (often used with a chromatic passing tone).

The double time passages are created from typical jazz language linked with enclosures, arpeggios and scale passages.

\section{Repeated Material}

This is a repeated rhythmic figure involving double-time triplet based turns. This is a key feature in Hayes' improvising style, and appears in most of his solos on this album: bars 43:

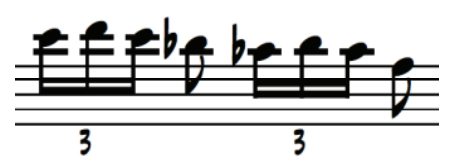

and 52:

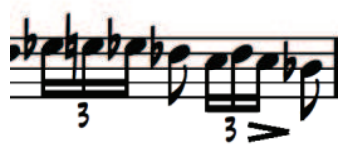

This repeated phrase is seen both in bars 60

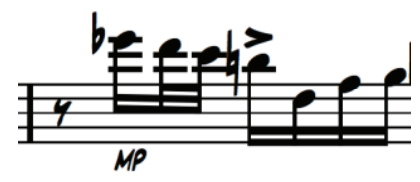

and 61-62 where it is rhythmically displaced by three beats:

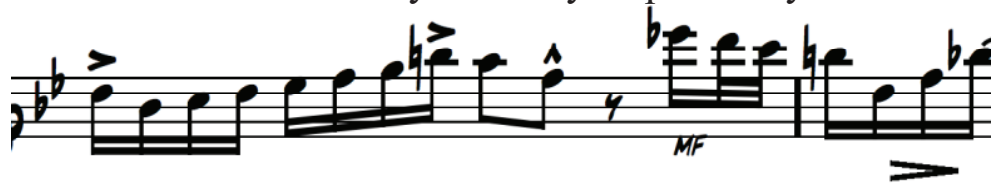


While it is used over a Bb6 chord and a $\mathrm{C} 7$ chord respectively it seems to be hinting at a passing $\mathrm{G} 7$ chord in both cases.

\section{Hayes' Vocabulary:}

This is a very typical bebop lick, often used by Hayes in various keys, at the beginning of bar 41:

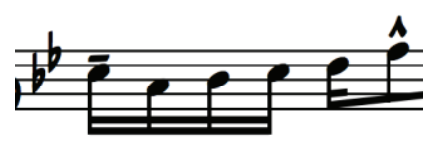

This G minor digital pattern (shown here in bar 47) is also seen in 'Airegin' in bar 93.

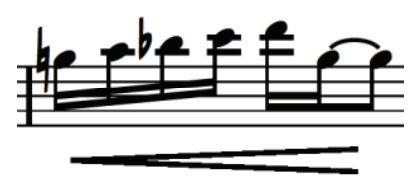

This same lick is seen in 'Soon' (bar 57-58).

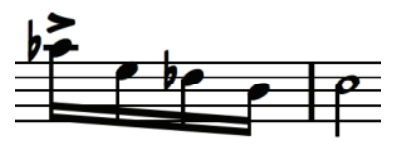

This lick shown here briefly from the last beat of bar 63 through to the first beat of bar 64 is essentially a series of 'bebop' licks.

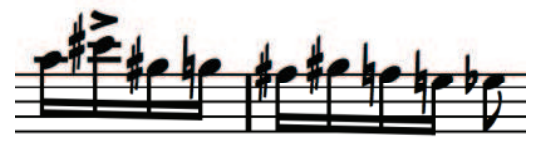

This same idea can be seen in Hayes' other solos; 'Opus Ocean' and 'Airegin', and in a longer extended form throughout the solo cadenza in 'You are my Everything'. 


\section{Analysis of Tubby Hayes' Solo on 'Airegin'}

\section{Composer: Sonny Rollins}

Style: fast driving bebop

Form: AB 36 bar form

Solo Section: 4 choruses

Tempo: 270 beats per minute

Key: G minor

Phrasing and Articulation: Hayes uses standard bebop articulation. He frequently accents the highest note of each phrase, giving another element of rhythmic interest to the solo.

\section{Content: Vocabulary, Formula, Repeated Material:}

The overall feel of this tune is that of fast, driving bebop.

Due to the (moderately- compared to some of Hayes' other recordings) fast tempo of this tune, the solo consists of a very large proportion of pre-learnt material, in the form of scale passages (including harmonic minor, blues, whole-tone and various major scale modes) licks, digital patterns and clichés.

Scale passages:

$\mathrm{G}$ harmonic minor (and at times $\mathrm{C}$ harmonic minor) are used as blanket scales for extended passages throughout the solo.

Here is an example where $\mathrm{G}$ harmonic minor is used exclusively through bars 36 (from beat 3) to the end of bar 39 .

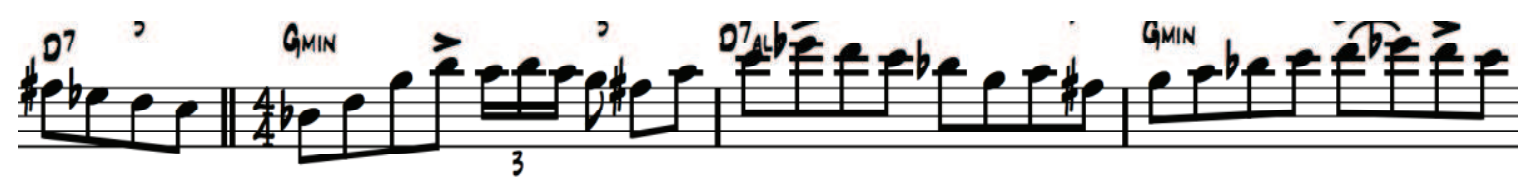

This next example from bar 57 through to the third beat of bar 59 also uses the $\mathrm{G}$ harmonic minor scale exclusively, using the technique of combining the G minor triad with a diminished arpeggio from the sharpened $7^{\text {th }}$, a technique that Hayes also uses on other solos including 'Soon' (also in the key of G minor) 


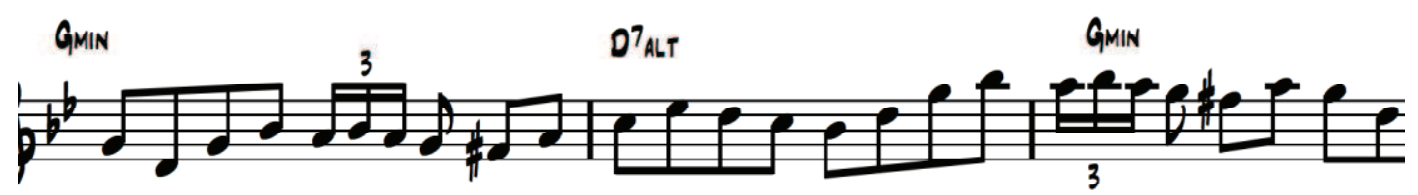

$\mathrm{G}$ harmonic minor is also used through bars 92-93:

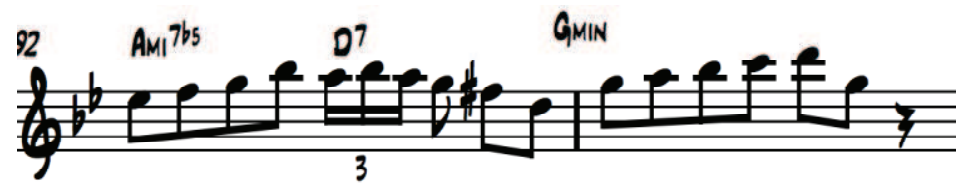

The Whole-tone scale is used exclusively from bars 73-75:

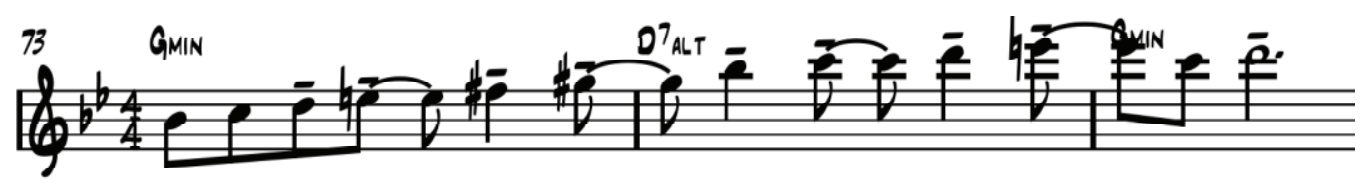

Repeated Material:

1. This $\mathrm{C}$ major lick shown in bar 51

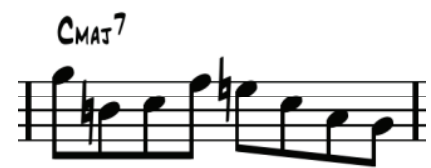

also occurs in the key of D major at bar 47 (and 194 in the 4 bar trades also )

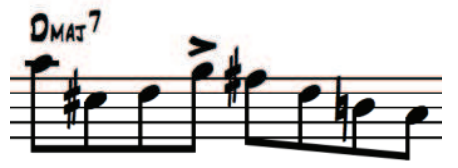

and (shortened) in bar 87.

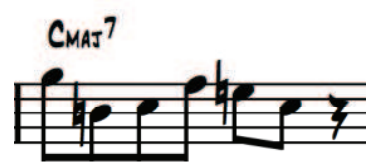

2. This major scale lick (consisting of a diatonic enclosure preceding a digital pattern) occurs in various keys in many of Hayes' solos, though just twice throughout this solo: 
In $\mathrm{Bb}$ major at bar 55:

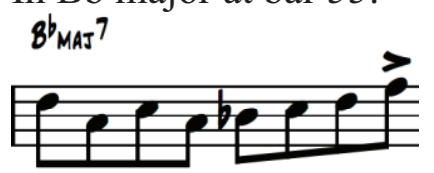

And again at bar 218 during the 4 bar trades.

In D major at bar 119: 47 (and 194 in the 4 bar trades also )

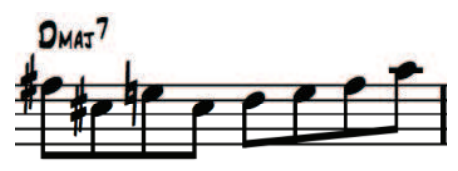

3. This commonly played jazz lick (217135) occurs in various keys in many of Hayes' solos. Shown here in C major at bar 52:

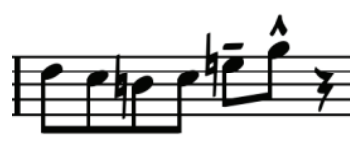

4. This phrase shown here at bar 54

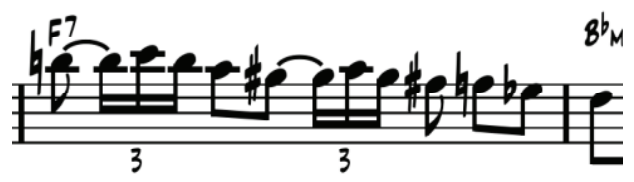

Is played again at bar 70 displaced by two beats:

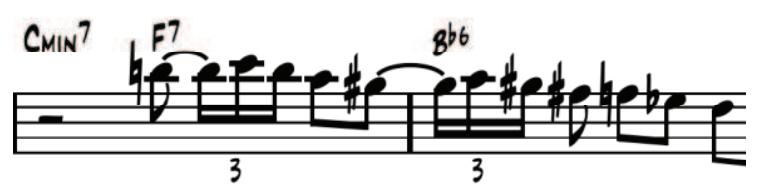

Hayes plays rhythmically similar ideas many times through the solo, example bar 64 (here the rhythm of this phrase is virtually identical except there is no turn in the second half of the bar):

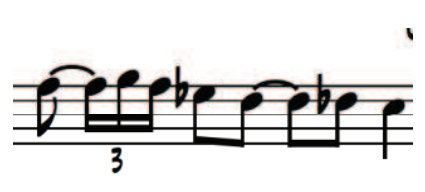

and at bars 48, 156 and 195. All nearly identical phrases played over a short two-five progression - Eb minor to $\mathrm{Ab} 7$ :

Bar 48: 


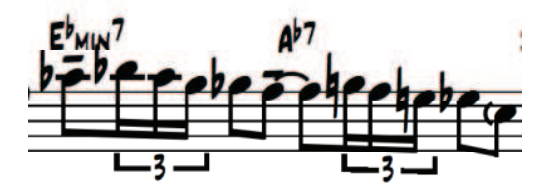

Bar 156:

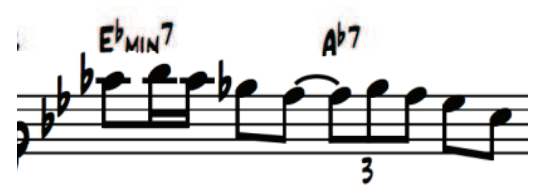

Bar 195:

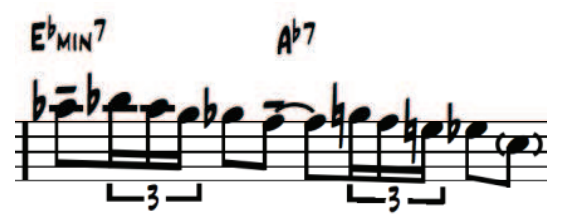

5. This G Harmonic minor scale phrase is first seen in bars 37-38 (the beginning of the first chorus of solo)

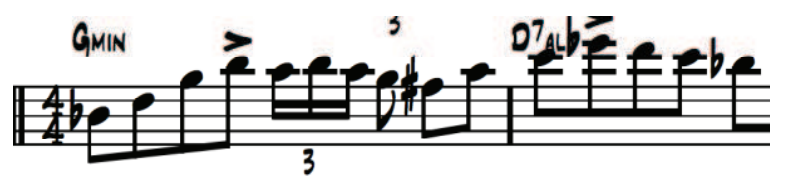

and again in bars 57-58 (with the slight variation of a different first note)

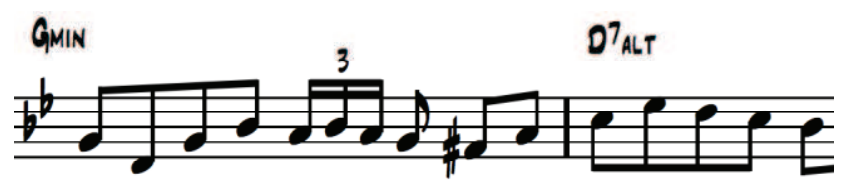

And partially in bar 72

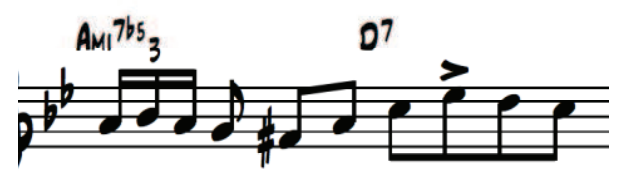

and bar 167:

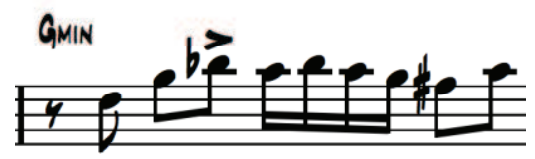

and bar 185 (minus the turn):

34 


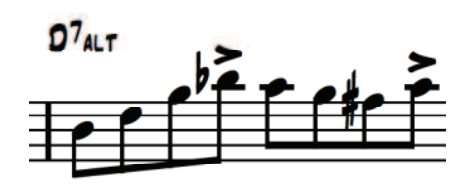

This phrase is also seen. In part in the key of C minor in bar 149:

AMIN

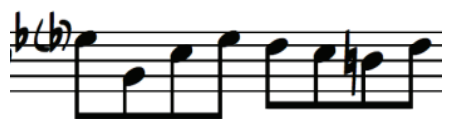

5. This G minor lick (seen in Hayes' other solos including 'Soon' where it is played in the same key of G minor) shown here at bar 109:

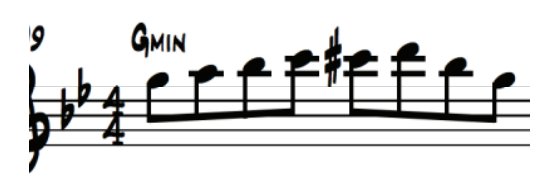

Is played at bars 94-95 displaced by two beats:

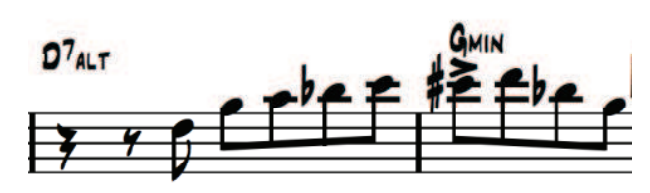

6. This Db major lick (consisting of the digital pattern 9789 followed by a chromatic enclosure to a $\mathrm{G}$ natural, which serves to anticipate the next chord change), shown here at bar 49:

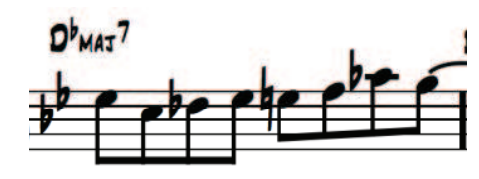

also occurs at bars,

and with variation (a more diatonic version of this idea) at bar 157:

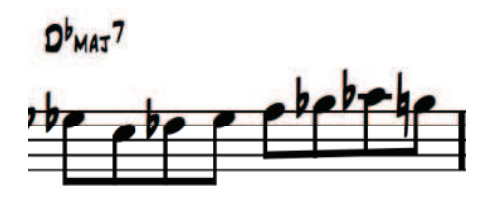

7. The following blues scale lick shown here at bar 146: 


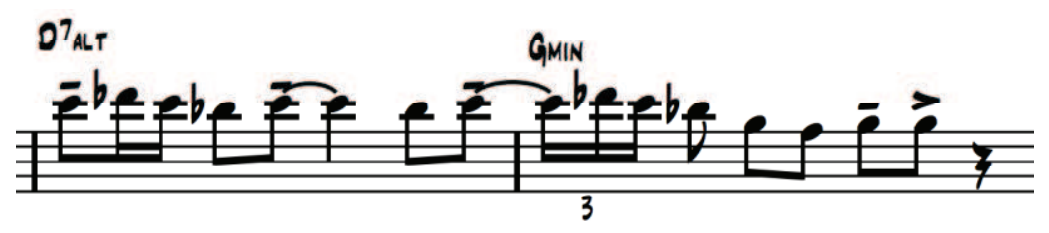

Is also seen through bars 95-96 displaced by two beats:

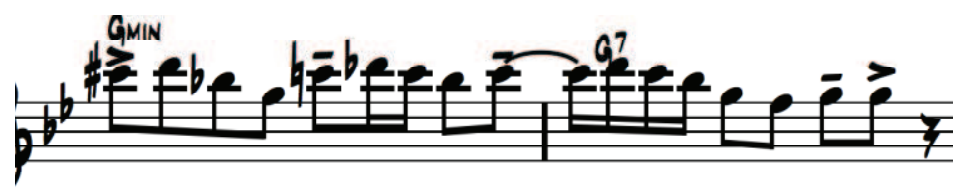

And partially in bars $240-241$ in D (blues scale):

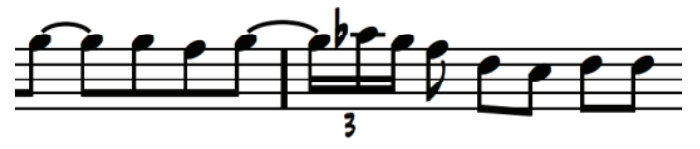

8. The following $\mathrm{C}$ Harmonic Minor scale lick is shown at bar 151:

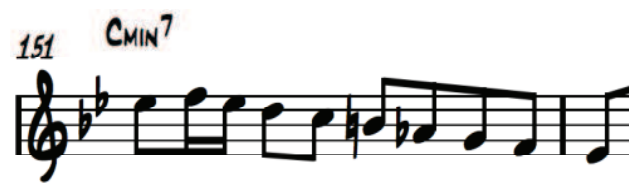

Is seen during the four bar trades at bar 242:

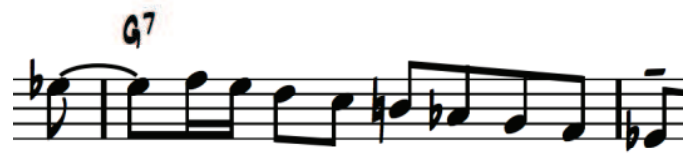

At bar 183 this idea is seen in G minor (here it is followed by the same idea played in the lower octave with the last three notes back up the octave)

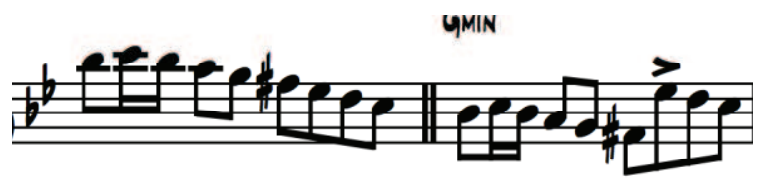

9. This two-five lick (comprising of an enclosure followed by an ascending flat nine arpeggio from the third of the A7 chord is usually played on an E minor -A7 progression, as shown here in bar 45:

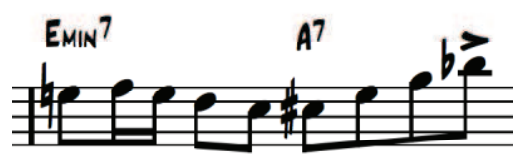

and (partially) at bar 154: 


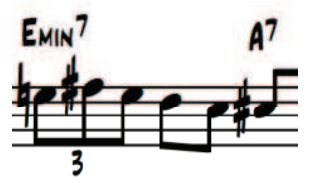

although here at bar 138 it is used over a $\mathrm{C}$ minor 7 chord:

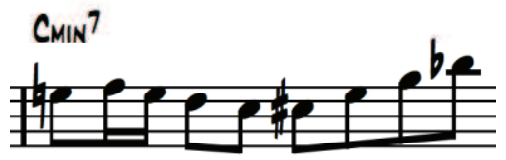

also at bar 66 where it is displaced by one beat:

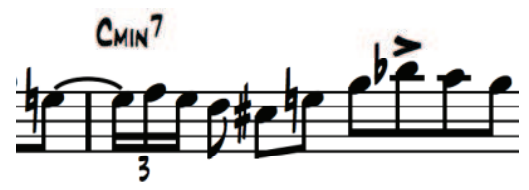

Several variations are seen on this $\mathrm{Bb}$ major idea (a major 9 arpeggio from the third followed by a 1235 pattern in $\mathrm{Bb}$ major. Shown here at bar 91:

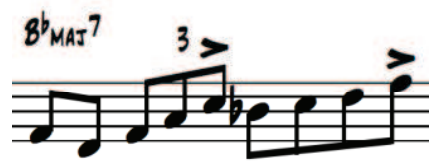

with rhythmic variation at bar 127 :

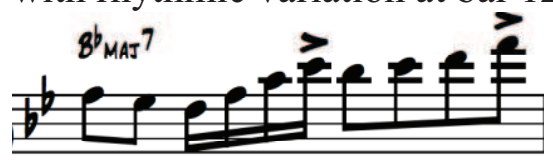

Partially played at bars 142-143:

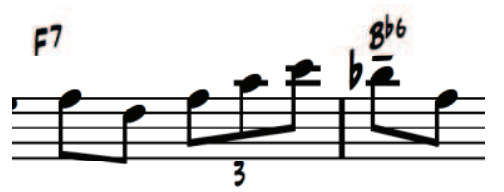

and with the variation of a C\# (serving as a chromatic approach note) at bar 163:

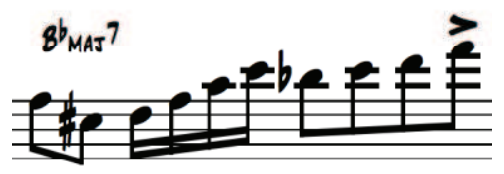




\title{
Analysis of Tubby Hayes' Solo on 'Opus Ocean' by Clark Terry
}

\author{
Composer: Clark Terry
}

Style: very fast driving bebop

Form: The form of this tune is AABA with the A sections being a 12 bar blues form and the B sections a "Rhythm Changes" bridge. The solo itself is four 44 bar choruses long.

Solo Section: 4 Choruses

Tempo: 280 beats per minute

Key: C major

Phrasing and Articulation: Hayes plays long eighth note lines with very little rest. Hayes uses standard bebop articulation. He frequently accents the highest note of each phrase.

\section{Content: Vocabulary, Formula, Repeated Material:}

Hayes plays long eighth note lines with very little rest. Given the fast tempo of this tunes it is fair to assume that Hayes is generally playing pre-learnt material during this solo.

Many common elements of the jazz language are present here including digital patterns, change running, enclosures and scalar patterns. Although the A sections of the tune are a blues form the tune lends itself more to straight bebop playing and the $\mathrm{C}$ blues scale is found in just seven short passages (bars 55-56, 80-83, 102-105, briefly in bar 128, bars $135-139,179-180$ and bars 261-163 during the four bar trades).

Repeated Material:

1. A Chromatic diminished passing chord substitution is implied three times during this solo (bars 47-48, 92, and 123-124), and hinted at in part in bar 152 also. This lick is seen in several of Hayes' other solos including 'Soon' and "'You for Me" on this album

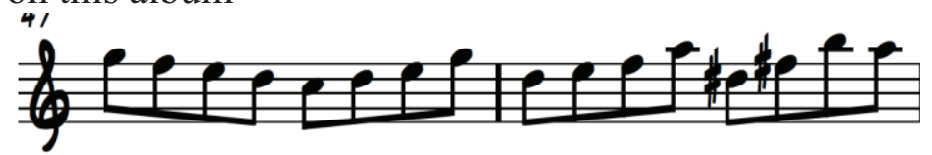

2. This lick appears six times during the solo in two different keys, it is simply a descending chromatic run from the flattened seventh of a given chord to the fifth with a turn on the first note. This is often used as the beginning of a phrase.

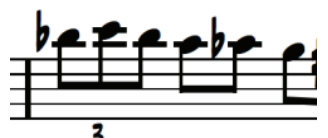

3. This enclosure lick appears three times throughout the solo in several keys (bars 107,129 , and with slight variation in bar 116) 


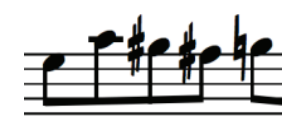

4. This motif occurs by itself three times throughout the solo

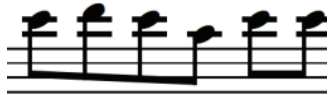

and in bars 167-169 it is used as the basis for a sequence.

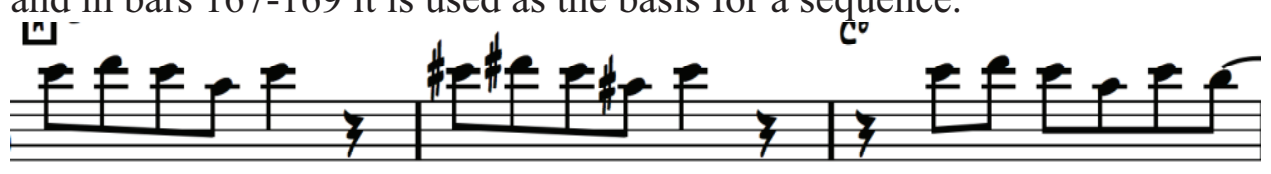

5. This lick in $\mathrm{C}$ major (first seen in bar 58)

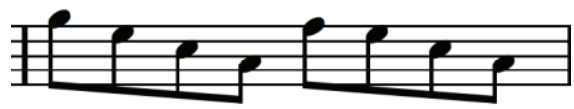

reappears in bar 212, displaced by two beats and with the addition of a turn:

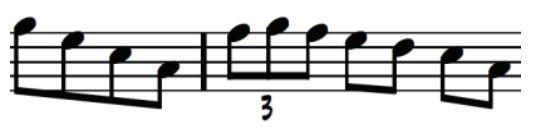

A variation on this lick is also seen in bar 157.

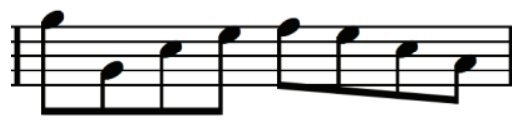

6. The "Cry Me a River" lick (with the addition of a turn on the first note) is used three times throughout the solo (bars 78, 88 and142), each time beginning from the sharpened ninth of a dominant chord. In this example shown from bar 78 it links straight into a 'bebop lick' starting on $\mathrm{Bb}$

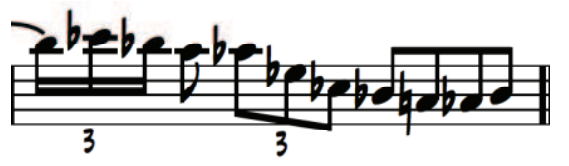

7. Identical phrases are noted in the bridge section: bars 73-74

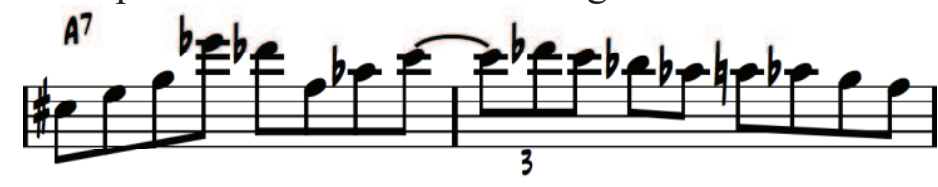

and bars 117-118.

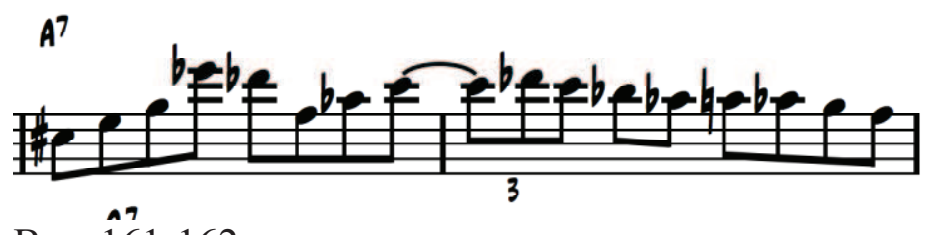

8. Bars $\hat{\imath} \mathfrak{6} 1-162$

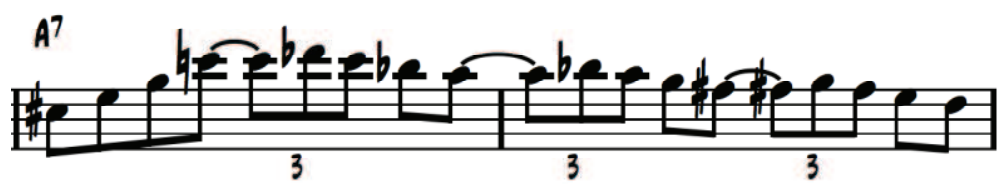


and 205-206

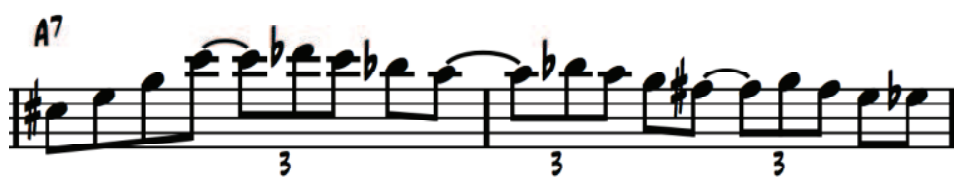

are also nearly identical. This is a partial A7 arpeggio followed by a series of consecutive turns starting on the flattened ninth, root, and thirteenth. These do not appear to be related to any particular scale.

Other Points of Interest:

1. A typical C major scale lick in bar 147 (987835)

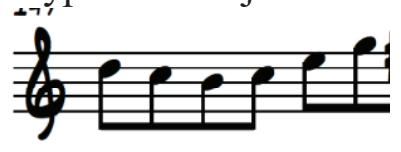

is the beginning of a sequence through bars 147-150

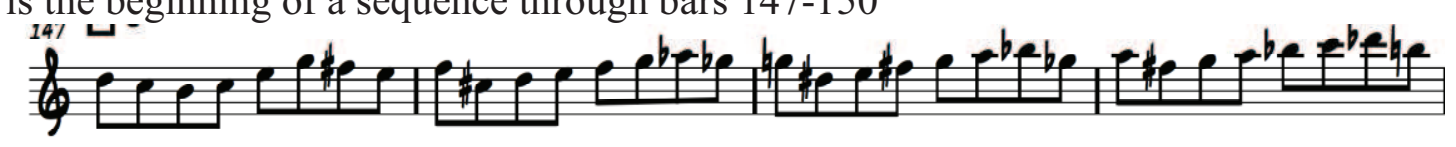

that is based on $\mathrm{C}$ major scale and linked with a series of chromatic enclosures.

2. In bar 221 a series of digital patterns is used to imply the turn around: $1, \mathrm{~b} 3, \mathrm{~b} 6$, b9.

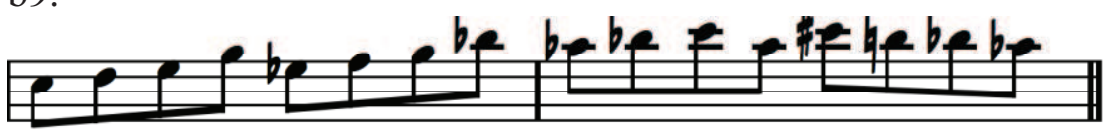

This also shows up in Hayes' solos on 'Soon' and "'You for Me"” in the key of F major.

3. This whole tone scale idea is used in bars 172-174

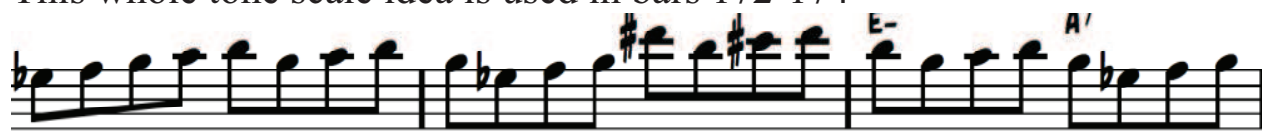

4. In bar 185 a whole idea (with the addition of one non-scale note) is played starting on E then repeated a semitone lower in bar 186

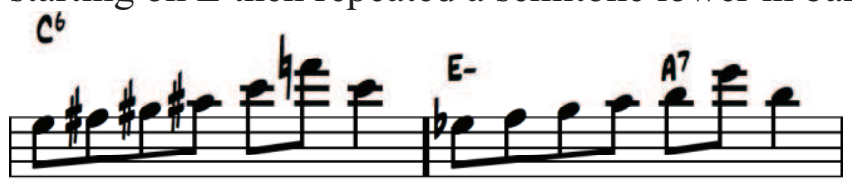

5. Hayes often uses a major seventh over a minor 7 chord. Here is an example in bar 175

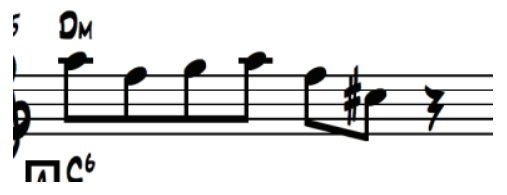




\section{Analysis of Tubby Hayes' Solo on 'Soon'}

Composer: George and Ira Gershwin

Style: Medium- up tempo bebop

Form: AABA 32 bar form

Solo Section: 5 choruses

Tempo: 200 beats per minute

Key: F major

Phrasing and Articulation: Hayes uses standard bebop articulation. During the doubletime passages he frequently accents the highest note of each phrase. He uses glissandos, pitch bends, grace notes, and subtle vibrato. He shapes phrases using crescendos and decrescendos.

\section{Melodic Development:}

While this solo is primarily through-composed some very melodic playing is noted. The most melodic passages are nearly always found at the very beginning of each section of the form (with the one exception of bar 136 where Hayes continues a double time passage right through the first bar of the new chorus).

Examples are found at bars: 49-51:
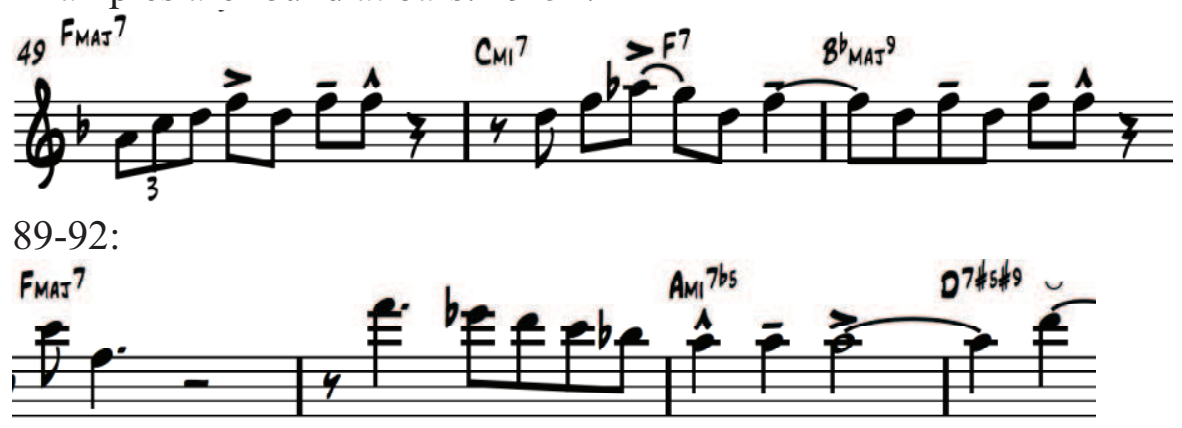

105-107:

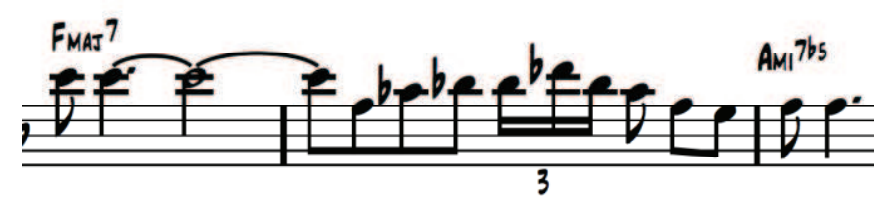

120-123:

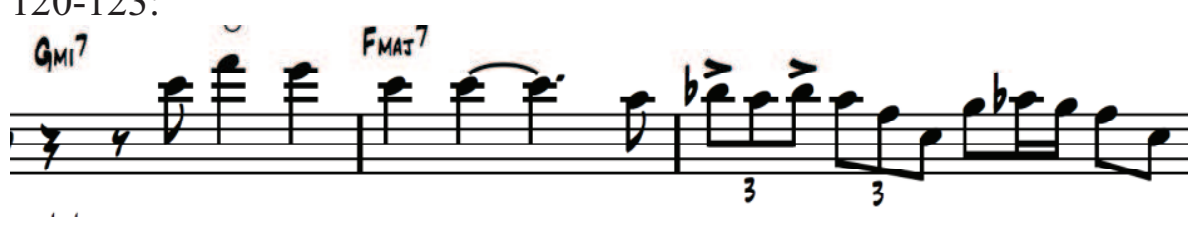




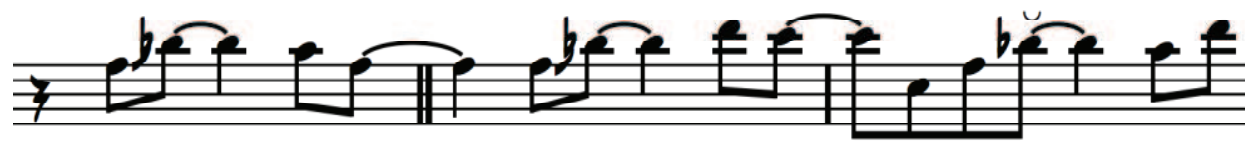

192-197:

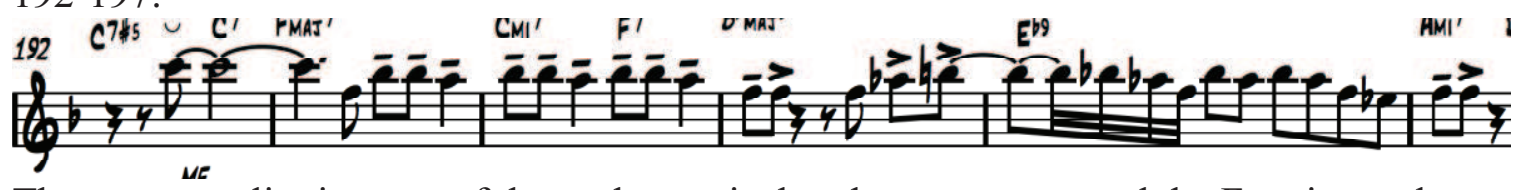

The commonality in most of these phrases is that they centre around the F major scale tones 1,3,4 (and at times 6).

When Hayes is playing melodically he often uses ideas based on the blues scale. The F Blues scale is used exclusively in bars 105-106:

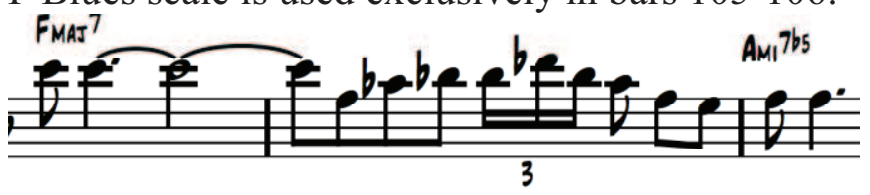

In bars 49-51 the relative minor key blues scale is used, giving a 'major blues' sound:

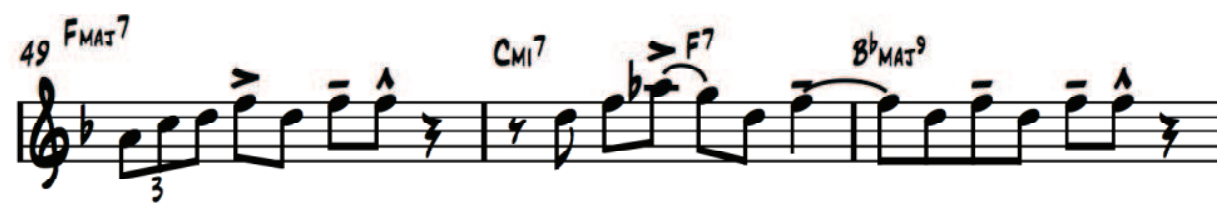

Early on in the solo there is an example of sequence through bars 67-69:

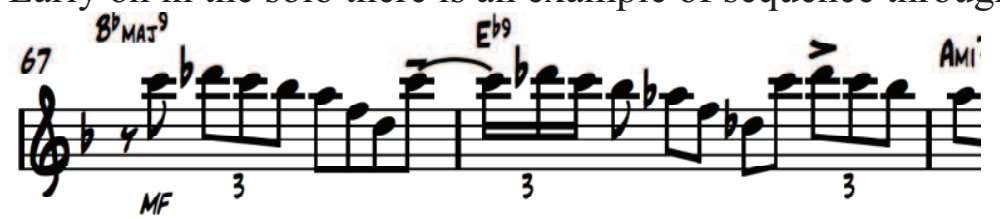

However, interestingly most of Hayes' melodic playing during this solo occurs during the B section of his last chorus where a simple melodic phrase is stated at bar 187:

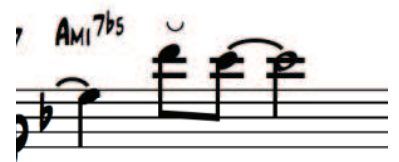

Then reiterated at bar 189 and used as the basis for a sequence through to bar 191: 


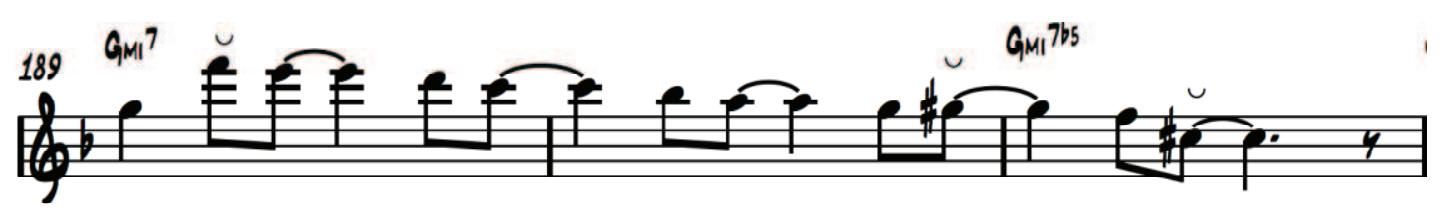

Bars 192-193 comprise of a very simple repeated idea (once again using the scale tones 1,3 and 4 of $\mathrm{F}$ major) followed by a sequential phrase using the $\mathrm{F}$ blues scale predominantly:

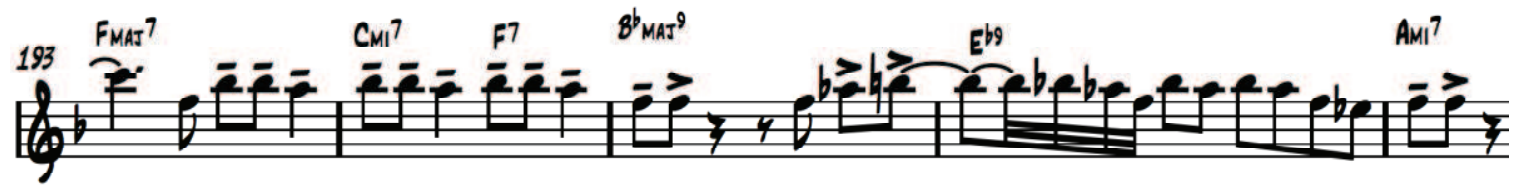

What is unusual about this is the way Hayes has structured this solo, using doubletime passages and chord oriented bebop lines from the outset finishing with a very melodic last half chorus. This is quite the opposite of what many players would choose (being much more conventional to start a solo melodically and build up into a climax of double playing at the end).

\section{Content: Vocabulary, Formula, Repeated Material:}

Careful inspection of Hayes' double time passages on this tune revealed that Hayes' double time passages are predominantly made up of a number of different formulas which are varied and joined together with chromatic enclosures.

Analysis of the extended double time passages in 'Soon' revealed ten different formulas as follows:

1. A diminished scale passage descending from $\mathrm{F} \#$ to the $\mathrm{G}$ below (this is usually played over a $\mathrm{C} 7$ chord resolving to the root note of the $\mathrm{F}$ chord on beat one of the next bar) Shown here in bar 56:

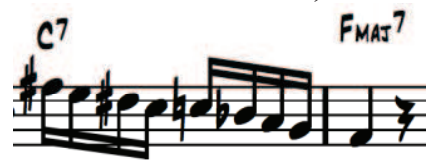

2. A short chromatic scale passage moving from the flattened third to the fifth of the chord. (Shown here from bars 39-40 in the key of F):

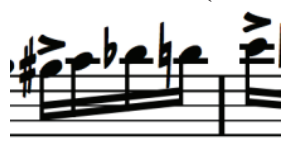

3. Digital Patterns. 5321, 4321 (otherwise seen as 9765,8765 over a dominant chord). Here is an example in bar 54.

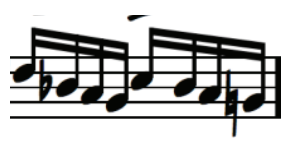


4. This passage is a minor scale from the root to the fifth with the chromatic note the sharpened fourth added, this passage is commonly followed by the flattened third and then the root note. (Shown here in bars 159-160)

5. This is a harmonic minor scale phrase, used here in $\mathrm{G}$ minor which alternates the minor scale with parts of the diminished chord starting on F\#. This is varied in how it is used in this solo but is often used as a blanket scale over any part of a 2-5-1 progression in the key of $\mathrm{G}$ minor. It is also used over a $\mathrm{G}$ minor 7 chord, giving more chromatic interest to Hayes' lines. This passage is shown in bars 141-142.

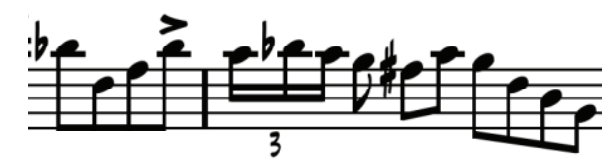

6. This is a partial scalar pattern that is used in several keys during the solo, most commonly in the key of F major, where it is often started on the $5^{\text {th }}$ of the chord (played 5345) and preceded by the scale tones 4,1,2,4. Shown here is a fragment from bar 179:

7. This is a phrase that uses the B flat major scale with one chromatic approach note. It is really just a simple combination of a Digital pattern and the previous mentioned scalar idea, shown here as 7,\#5,6,7 (using the sharpened $5^{\text {th }}$ as a chromatic approach note. It has been mentioned because it recurs frequently in this solo and is used both over $\mathrm{Bb}$ major and $\mathrm{G}$ minor chords. Bar 181:

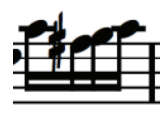

8. This is a phrase that combines the $\mathrm{C}$ dominant scale descending from the flattened $7^{\text {th }}$ to the $3^{\text {rd }}$ with a chromatic enclosure resolving to the $\mathrm{F}$ natural (the root note of the F major chord). Shown here in bar 77. Also seen in bars 109, 160-161 and 216.

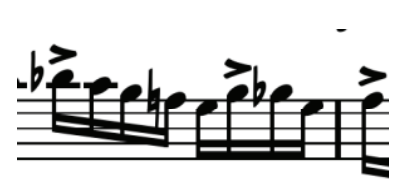


This is used many times, both in the context just mentioned and over a G minor 7 chord, usually followed by a descending $\mathrm{G}$ minor arpeggio (from the flattened $7^{\text {th }}$ to the root then another chromatic enclosure landing again on G). Shown in bars 77-78.

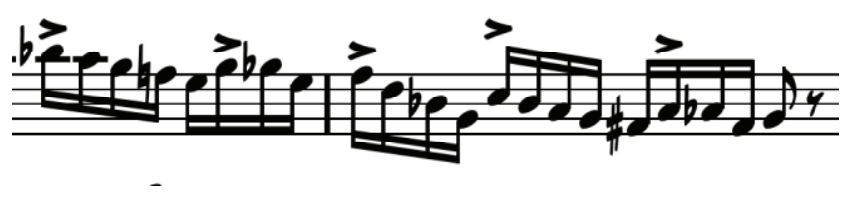

9. This is a four note idea played over a $\mathrm{C} 7$ chord (or in one case over a $\mathrm{G} \min 7$ chord to imply the $\mathrm{C} 7$ chord to follow). G\# E C\# B. It is not easy to ascertain whether Hayes was "thinking" (if thinking is at all possible when playing at this speed) in terms of using the sharpened fifth and flattened $9^{\text {th }}$ to create tension and the B natural (major $7^{\text {th }}$ ) as a potential chromatic note to enclose the root of the chord (although he does not do this at this point) or else slipping outside the harmony by outlining a $\mathrm{C \#}$ minor 7 chord over a $\mathrm{C}$ altered dominant. This formula is used three times during the solo and each time it is preceded by a $\mathrm{C}$ dominant scale passage descending from the root to the fifth, and then followed by the diminished scale as mentioned in example 1 . What is interesting about this is the way Hayes uses two quite distinctly different methods (an altered dominant sound and the diminished scale) to create tension in the same phrase, before resolving to the root of the next chord. This figure shown is the second beat of bar 176:

10. This is a four note pattern that recurs twice during this solo (bars 54 and 218). G\# $\mathrm{B} \mathrm{E} \mathrm{Eb}$ (resolving to D). It follows a $\mathrm{G}$ minor digital pattern $5 \mathrm{~b} 321$ on both occasions. To the ear it sounds very similar to the harmonic substitute idea (conventionally used over the 'Rhythm Changes' chord progression) although used in this context it doesn't follow any harmonic rules of this substitution. Although this only occurs twice in this solo it has been mentioned here due to Hayes' fondness of using this substitution frequently over many chord progressions. His well known solo on Cherokee is an example of this. Other examples will be shown during analysis of Hayes' solos on 'Opus Ocean' and 'You for Me'.

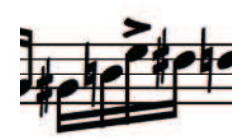

11.

Other devices found in the double-time passages: 
1. (Bar 55); digital patterns implying the turn around: 1, b3, b6, b9. Shown here in bar 55:

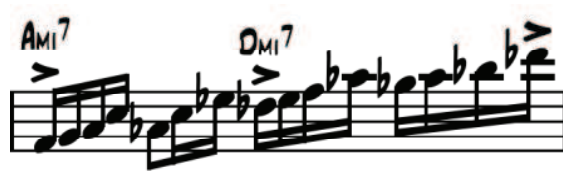

Hayes also uses a close variation of this phrase in eighth notes in bars 151-152:

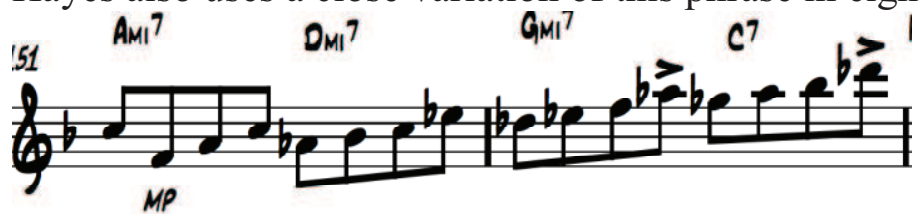

Again this is an idea that Hayes uses on other tunes and an example will be shown in the Analysis of 'Opus Ocean'.

2. A very common dominant 7 to 1 chord resolution lick. Shown here in the last two beats of bar 136:

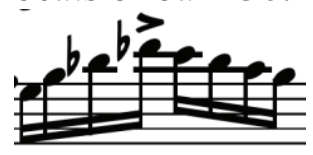

3. Shown here is an extended $\mathrm{F}$ major scalar pattern comprising of a series of diatonic triads. Bar 137:

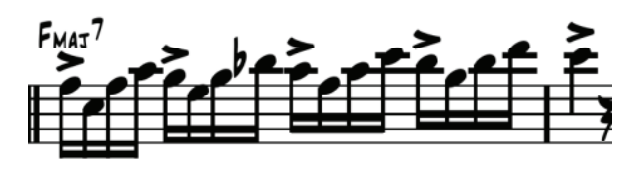

4. $\mathrm{Bb}$ dorian scale is played in entirety over one octave over the last two beats of bar 163:

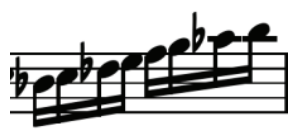

6. This Bb major idea has been mentioned as Hayes has used this phrase in entirety on other solos. Hayes' famous solo on 'Cherokee' is one example (although not featured on this album).

Shown here in bar 179:

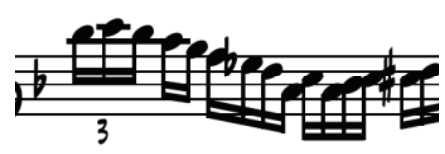


7. Numerous enclosures that both serve to join the phrases mentioned above and to create chromatic interest. 


\section{Analysis of Tubby Hayes' Solo on 'Doxy'}

\section{Composer: Sonny Rollins}

Form: AABA 16 bar form

Solo Section: 4 Choruses

Tempo: 116 beats per minute

Key: F major

Phrasing and Articulation: The solo is generally played in a blues based triplet feel with double time passages throughout. Dynamics are used to shape each phrase. Hayes gives careful attention to the articulation in this solo. Accents, pitch bends, and ghosted notes help to give this piece a bluesy feel.

Melodic Development: Some examples of Melodic Sequential playing are noted: in bars 23 and 24 an idea is followed by a similar idea a semitone lower. In bars 33-34 a sequential phrase also descends through the chord changes. In the following example in bars 55 and 56 a simple motif is played and then repeated in the next bar a semitone lower also displaced by a quarter of a beat.

\section{Content: Vocabulary, Formula, Repeated Material:}

The F blues scale is used extensively, D blues scale is also used throughout.

Repeated Material:

1. A descending portion of the $\mathrm{D}$ fifth mode of the harmonic minor bebop scale, starting on the flatted ninth of the D altered chord and ending on the third of the chord.

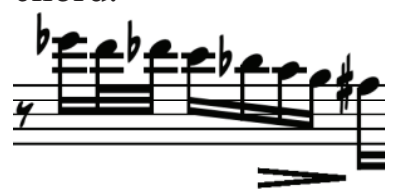

This is played 4 times through the solo with little variation (bars 46, 52, 54 and 61 ) and twice partially (bars 52 and 78)

2. A commonly used bebop lick. 978931 in F major (bar 29).

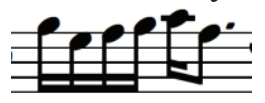

3. The digital pattern 12354321 seen here in $\mathrm{F}$, 


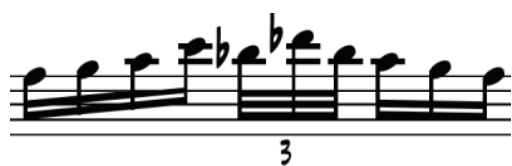

also used by Hayes in other solos in various keys. Here it is played twice (in bars 53- with a turn on the $4^{\text {th }}$ and 69) and varied, beginning with a different triad pattern: 31354321 in bar 37.

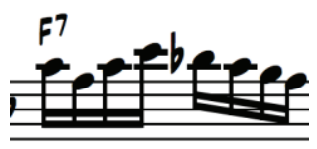

4. From beat 3 of bar 37 to the end of bar 38 the same phrase is repeated, descending in semitones.

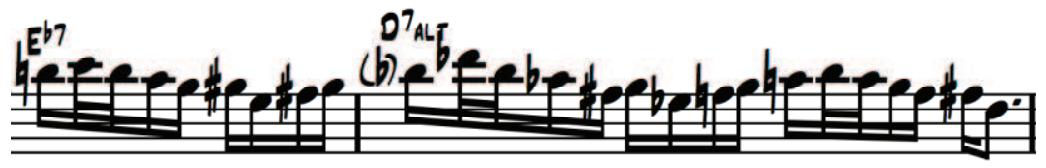

5. A very similar idea is played over the same chord sequence in bars 69 and 70

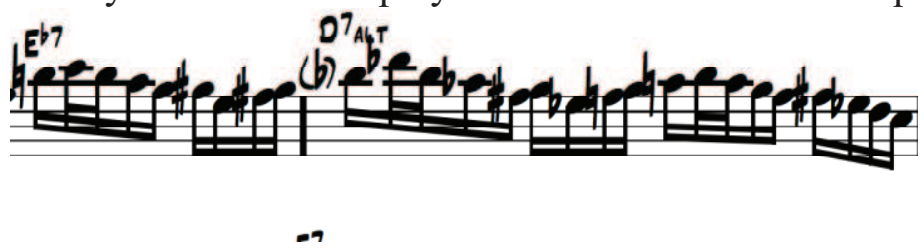

Other material used:

A descending F\#min9 Arpeggio played over an F7 chord in bar 74

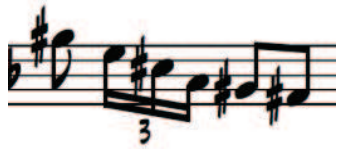

The idea played in bar 25 is also used (in the same key on Hayes' solo on 'Soon'):

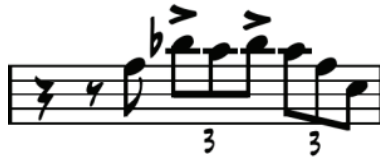




\section{Analysis of Tubby Hayes' Solo on 'Soho Soul'}

\section{Composer: Tubby Hayes}

Form: 12 Bar Blues

Solo Section: 6 choruses

Tempo: 116 Beats per minute

Key: G major

Phrasing and Articulation: The overall style of the solo is very blues based and more spacious than a lot of Hayes' improvised playing. Dynamics are used to shape each phrase. Hayes gives careful attention to the articulation in this solo. Accents, pitch bends, and ghosted notes add to the blues feel of the solo.

\section{Melodic Development:}

Hayes' solo starts with a sparse melodic approach that continues throughout the first chorus. The first five bars are played modally with $\mathrm{G}$ mixolydian scale used exclusively throughout the first three bars. A similar phrase is then played leading into the fourth bar of the form using $\mathrm{C}$ mixolydian scale. In the fifth and sixth bar a chromatic idea appears that is to be repeated later in the solo. Leading into the last four bars of the form is an answering phrase that exclusively uses the $\mathrm{G}$ minor pentatonic scale.
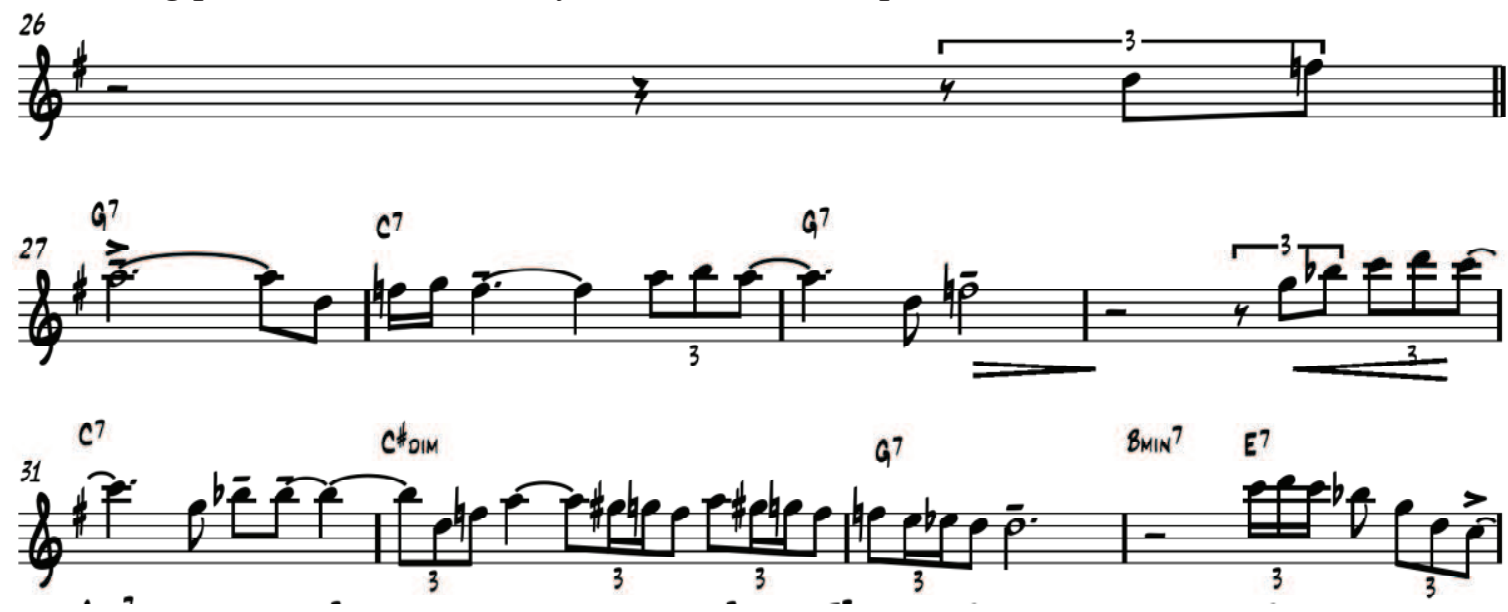

\section{Content: Vocabulary, Formula, Repeated Material:}

Two blues scales are used throughout; G blues scale and E blues scale. Together these make up over half the solo.

Repeated Material: 
1 This is a standard 7-3 resolution lick (with the addition of a turn) that appears 4 times throughout the solo and once further partially. It is played in the same key each time and appears in the eighth bar of the form in each case. This resolution lick is shown here as in bar 70:

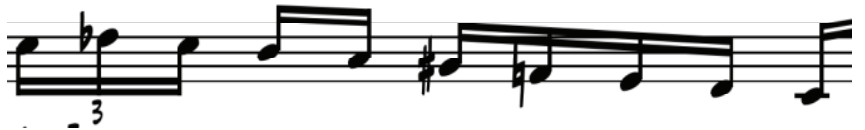

In bar 46 this idea is played twice consecutively, the second time an octave lower:

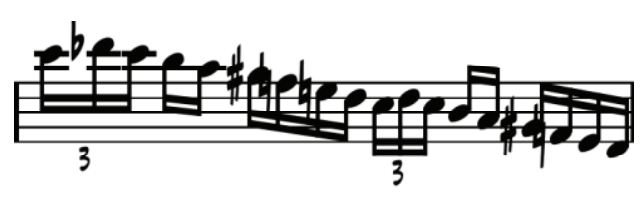

2 A Chromatic idea that is used over E7 chord, combines a descending chromatic scale run from the fifth to the third of the chord followed by a chromatic enclosure to the 7th of the chord. It is usually followed by the idea noted in example 3. Shown in bar 47:

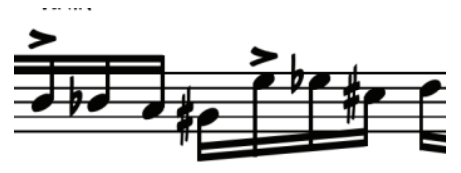

3 This example comprises of an ascending $\mathrm{C}$ major 9 arpeggio (or A min 11 arpeggio starting on the third) landing on a $\mathrm{C}$ usually preceded by a diatonic enclosure. Used over A min 7 chord. Shown here in bar 71:

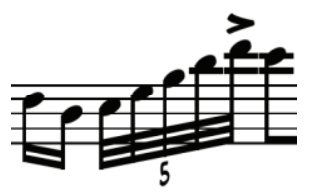

4. An ascending G min 9 arpeggio used twice (bars 39 and 55) In bar 39 is combined with the digital pattern 2171 (using the major 7th) This combination is one that Hayes uses in other solo also. Shown here in bar 55:

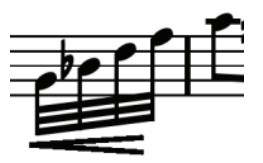

Other Material of Interest:

Bar 56: A repetition of the chromatic idea used in bar 32

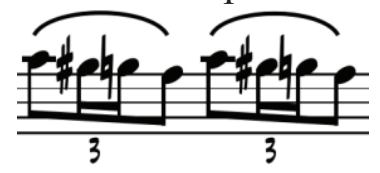

Bar 58: A Variation on the bebop lick. Started G natural, which is the sharpened ninth of the E7 chord. 


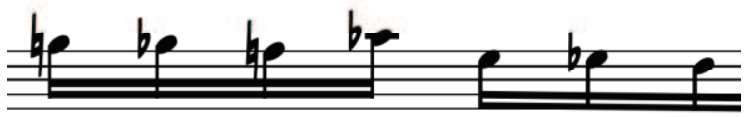

Bar 59: 12345\#5631 in A minor. This idea has been seen repeated in different keys in Hayes' other solos on this album (ie in the key of G minor in 'Soon')

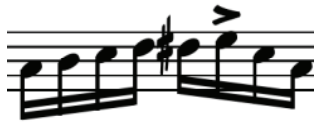

Bar 69: (Beats 2-4) This idea is an exact repetition of a phrase played on "The Simple Waltz"' (also in the key of G) It is a descending G triad followed by a C triad (preceded by a chromatic approach note) descending from the third followed by an $\mathrm{E}$ minor 7 th chord descending from the seventh.

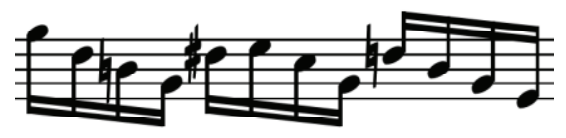

Bar 82: This phrase has been mentioned due to its similarity to a phrase that Hayes plays on his " Doxy" solo In 'Doxy' the digital pattern is 12354321 (often with a turn added on the 4th) which is played in F major (as well as several other keys). Interestingly this same phrase (still starting on $\mathrm{F}$ has been altered slightly to fit a Bmin7 E7 2-5 progression. (i.e. the $\mathrm{Bb}$ has changed to a $\mathrm{B}$ natural and the last two notes have changed to $\mathrm{G} \#$ and $\mathrm{B}$ natural, becoming chord tones of the E7 chord.

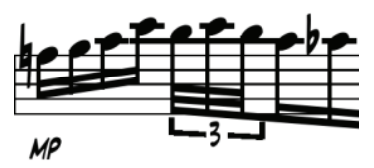

Bar 86: An extension of the chromatic idea mentioned in example 2. A descending chromatic scale run from the fifth to the third of the E7 chord is followed by a descending run from the flattened ninth to the seventh. The entire phrase is immediately repeated an octave higher.

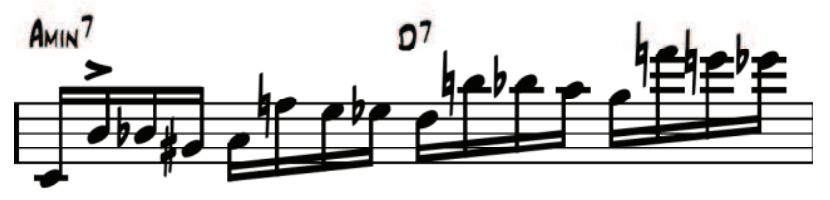

Bar 90: A Bebop lick starting from Bb (also started on the sharpened ninth of the $\mathrm{G}$ dominant chord) displaced by half a beat, joined by part of the "Cry Me a River" lick to another bebop lick. 


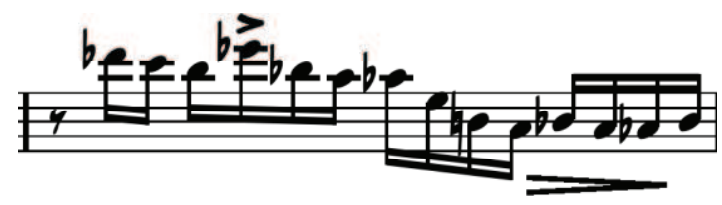

53 


\title{
Analysis of Tubby Hayes' Solo on 'The Simple Waltz'
}

\author{
Composer: Clarke Terry
}

Form: 24 bar blues form

Solo Section: 6 Choruses

Tempo: 176 Beats Per minute

Key: G Major

Phrasing and Articulation: The Articulation is much more legato than many of Hayes' other solos. Crescendos and decrescendos are used to shape phrases, and Hayes uses accents, pitch bends, and ghosted notes.

Melodic Development: The solo begins with a simple G blues scale phrase. G blues scale and $\mathrm{E}$ blues scale are used throughout the first 4 bars.

\section{Content: Vocabulary, Formula, Repeated Material:}

$\mathrm{G}$ blues scale and $\mathrm{E}$ blues scale are used throughout this solo.

\section{Repeated material}

1. This example through bars 69 and 70 is a typical Hayes' lick, which is seen in several other solos in various keys

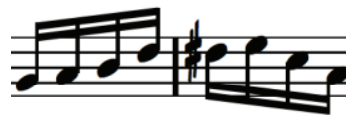

2. The second beat of bar 70 implies part of a chromatic diminished passing chord substitution as seen in many of Hayes' solos including 'Opus Ocean' (in C) and Soon and 'You for Me' (in F).

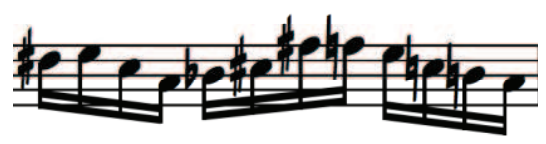

This blues lick is used over the $\mathrm{C} 7$ chord in bars 65-66

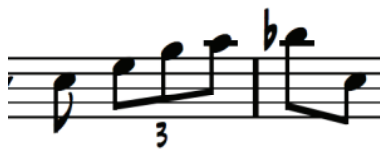

It is altered slightly and used as the beginning of a double-time phrase in bar 67: 


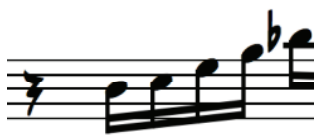

It is seen again, with the addition of a chromatic enclosure in bar 137:

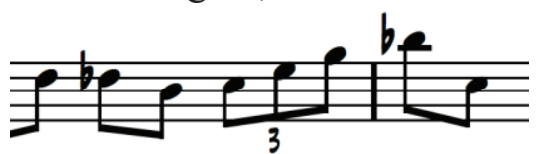

3. The following blues phrase is seen at bars 60 and 84 :

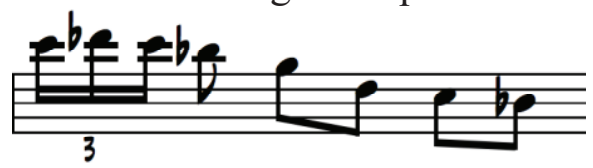

and again with a triplet rhythm replacing the turn on beat 1 at bar 100:

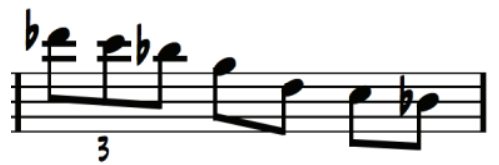

1. This phrase (shown here in bar 79) is seen also in "Soho Soul"” (also a G blues) and "Airegin""

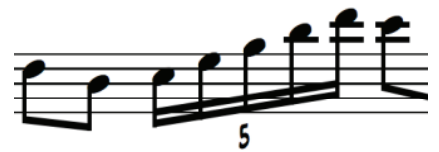

2. This exact phrase (shown here starting from the second beat of bar 117 to the first beat of bar 118 is also used on 'Soho Soul', also in the key of G)

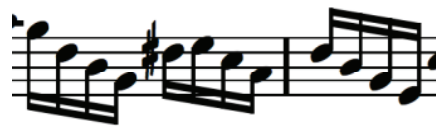

3. This is an ascending chromatic scale passage from the flattened third to the fifth of a chord, shown here as part of a double time passage in bar 89 used over a C7 chord:

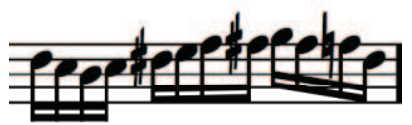

and repeated in bars 109-110 over a G chord:

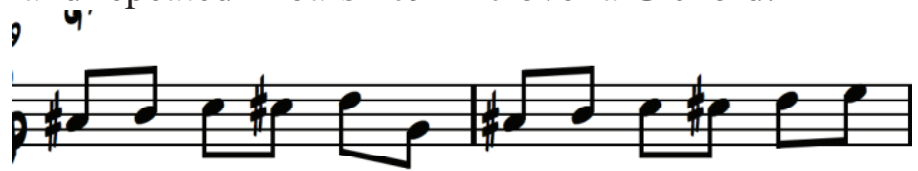

4. A Classic Example of CESH (contrapuntal elaboration of static harmony used here over a A minor chord:

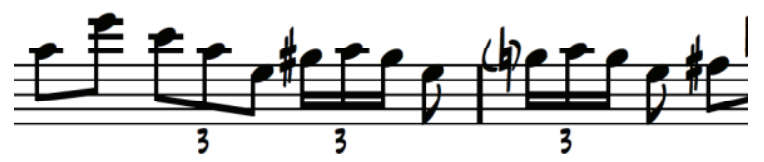


5. In bar 119 an entire $G$ major scale ascending over one octave from $G$ preceeds one of Hayes' most commonly used phrases (2171):

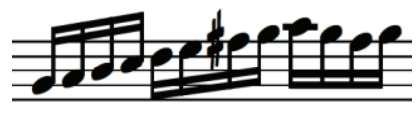

This same phrase (2171) is also seen in bar 93

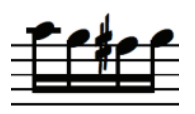

and in the key of $\mathrm{C}$ in bar 89:

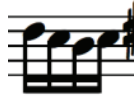

6. This is a 'Cry me a river' lick (with a turn) starting on the sharpened ninth of a G dominant chord linked to a "Bebop lick" starting on the same note an octave lower. Hayes also plays this combination in the same key on 'Soho Soul' and again over a G7 chord in 'Opus Ocean'. Shown here through bars 135-136:

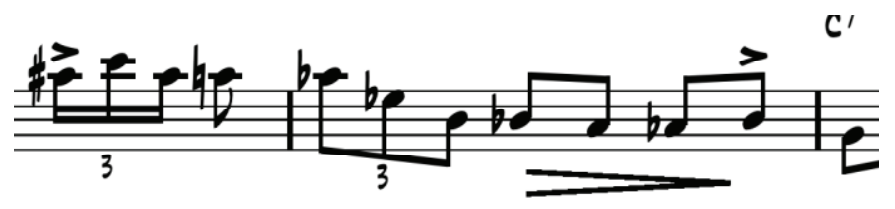

\section{Other Material of interest:}

1. This Phrase in bar 115 is a chromatic enclosure pattern repeated down a semitone.

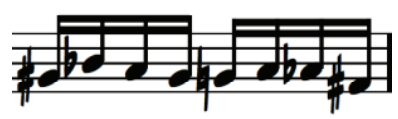

2. The Phrase mentioned in example 3 (Page 55) is extended into a sequence through bars 109-111 using the whole tone scale:

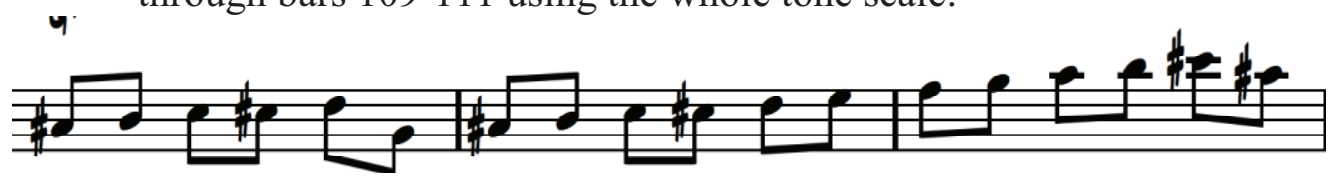

Much of Hayes' playing particularly in the double time passages is a series of (usually descending) digital patterns combined with enclosures. Bar 68 is a very typical example where a $\mathrm{C}$ minor 5321 pattern is followed by a B minor triad (135) linked by 1 chromatic note to a descending 5321 A minor pattern.

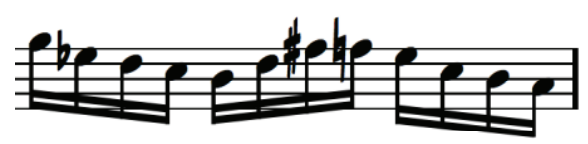


Other example of Hayes using descending digital patterns to create lines can be found in his solo on 'Doxy'

3. Here is as example of an ascending melodic sequence through bars 141-143

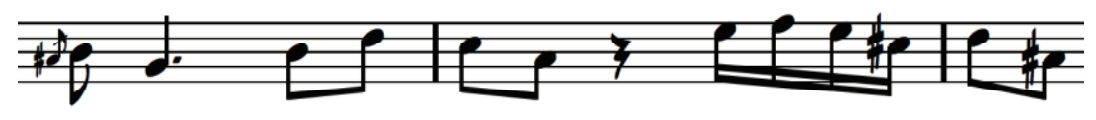

57 


\section{Analysis of Tubby Hayes' Solo on 'Half a Sawbuck'}

\section{Composer: Tubby Hayes}

Style: Medium-up tempo bebop with an underlying latin feel in parts of the head.

Form: 16 bar introduction, 36 bar form.

Solo Section: 4 choruses

Tempo: 192 beats per minute

Key: F major

Phrasing and Articulation: Hayes uses crescendos and decrescendos to shape phrases. During the double-time passages he frequently uses accents to mark the highest notes of each phrase.

\section{Melodic Development:}

Rhythmically, this solo is a lot more varied than some of Hayes' other solos. Eighth note lines are interspersed with triplets; short bursts of semiquavers (Charlie Parker style) and rests as well as Hayes' signature double time passages. The content in this solo tends towards very standard bebop language, although there is some more repetitive melodic playing, centered mainly around the chord movement between the A minor 7 chord and the $\mathrm{Bb} 13$ chord between the ninth and twelfth bar of each chorus. Here is an example taken from bars 61 through to 65 :

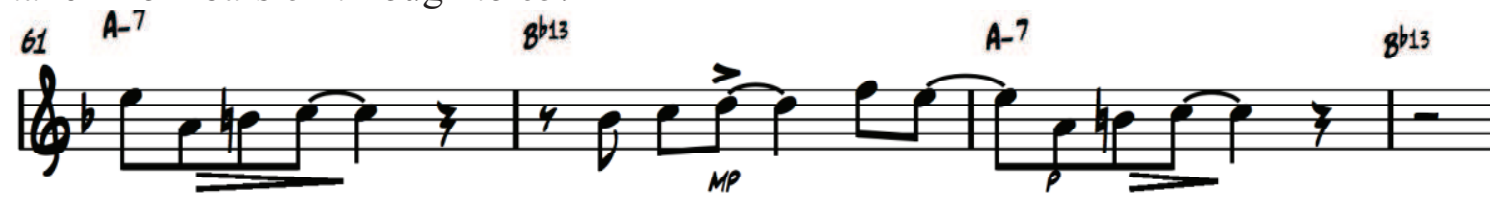

There are some examples of very melodic sequential playing for example bars 61-65.

\section{Content: Vocabulary, Formula, Repeated Material:}

\section{Repeated material:}

Bars 117 and 118:

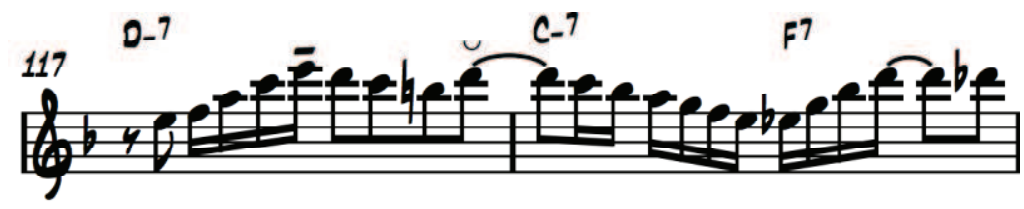

are constructed almost identically to bars 153 and 154 : 


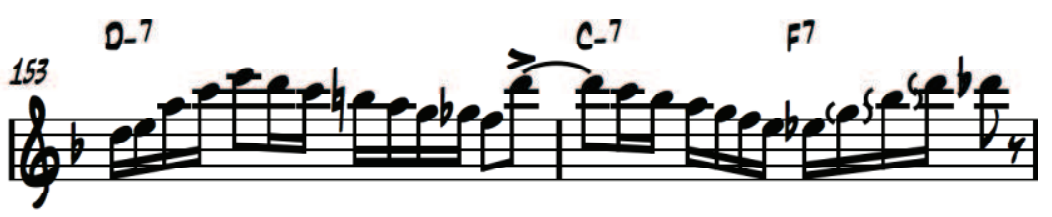

The phrases at bars 108:
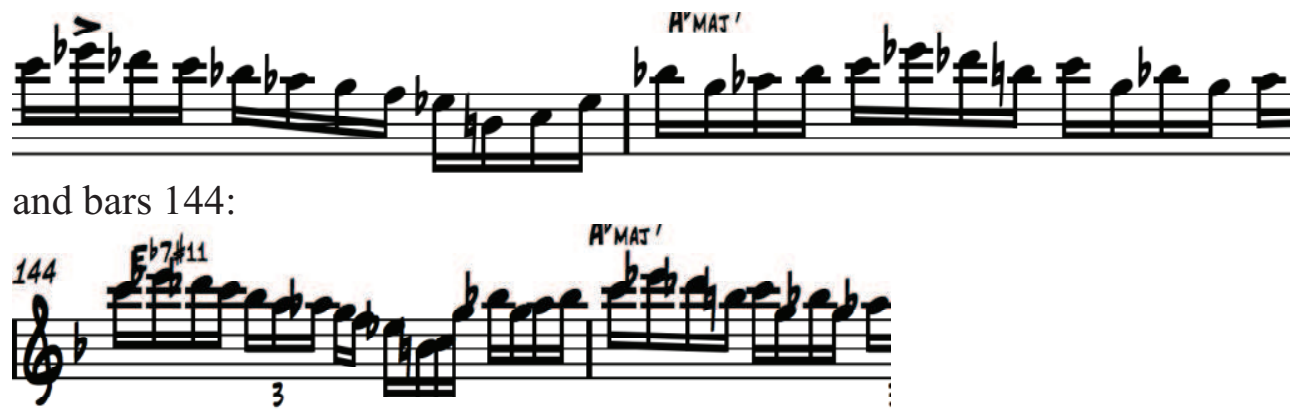

are virtually identical, with the exception of an added chromatic note and displacement by 1 beat.

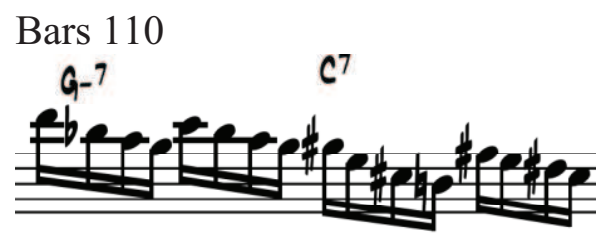

and 146:

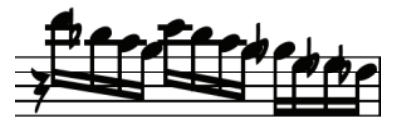

contain many similarities, with the same phrase having been displaced by one beat in bar 146.

A common digital pattern that Hayes uses is: $12 \mathrm{~b} 34$ \#45. It is seen in bar 82 in $\mathrm{C}$ minor: C-7

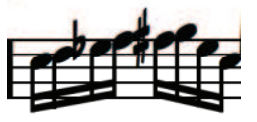

and bar 149 in A minor:

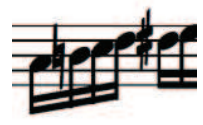

The first two beats of bars 136: 


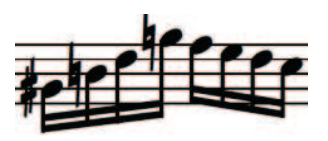

and 150:

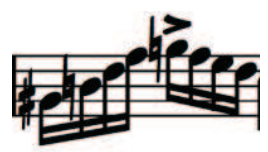

are identical. This is an ascending diminished arpeggio followed by a descending scale fragment (which may be part of the Lydian dominant) played over a $\mathrm{Bb} 13$ chord

Bars 66:

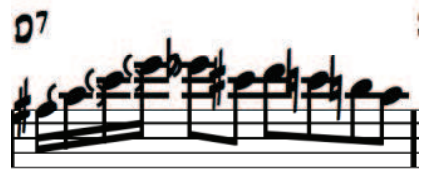

and 138:

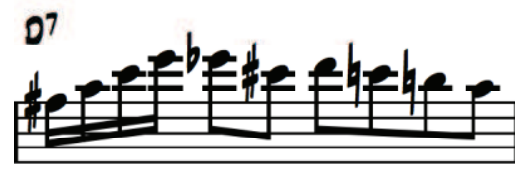

are nearly identical. This is a combination of a dominant $9^{\text {th }}$ arpeggio starting from the $3^{\text {rd }}$ linked by an enclosure to a descending scale fragment.

Hayes favours this phrase over the $\mathrm{Ab}$ major 7 chord:

\section{A $^{\text {MaJ }}{ }^{7}$}

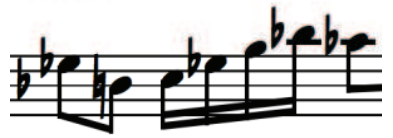

seen in bars 93, 120, 129 and 156 displaced by a beat:

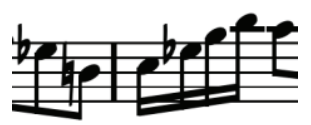

It is also played, in part, in bar 158 over a Gb major 7 chord:

\section{Q $^{\text {MaT }}{ }^{7}$}

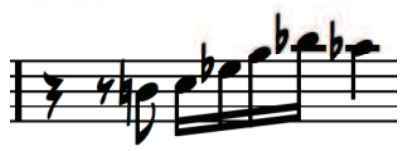

Here are some common jazz phrases seen in many of Hayes' solos:

bar 84: 


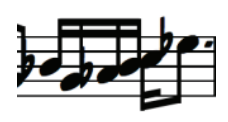

bar 81:

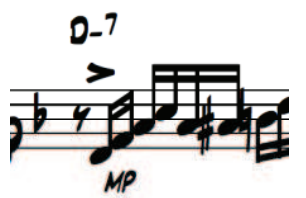

When bar 126 of Hayes' solo in "Half a Sawbuck":

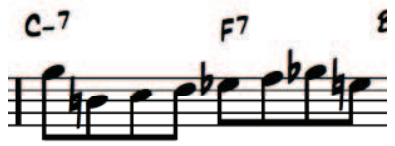

is compared to bar 148 of his solo in "'Opus Ocean"” :

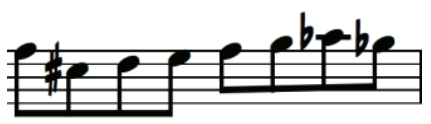

there is just one note different. This is an example of Hayes using a pre-learnt finger pattern spontaneously in completely different contexts,

Other Features:

This ascending triplet diminished chord lick is played over a short two five progression in $\mathrm{Bb}$ major as a precursor to a long extended double time passage at bar 142:

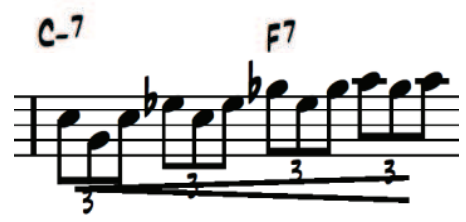




\title{
Analysis of Tubby Hayes' Solo on 'You Are My Everything'
}

\author{
Composer: Harry Warren
}

Style: Ballad.

Form: AABA 36 Bar Form

Solo Section: In typical ballad style the head is not distinct from the solo section, Hayes instead improvises around the head for one chorus, then following 16 bars of solo piano, Hayes returns with the out head at the bridge

Tempo: 60 beats per minute

Key: C major

\section{Phrasing and Articulation:}

Hayes uses a wide sub-tone vibrato, particularly on the lower notes a style reminiscent of Stan Getz. The entire solo is played in the lower to middle register of the horn. Turns are used to a much lesser extent here than in any of Hayes' other solos on this album. Sudden crescendos and decrescendos give this solo a particularly emotional quality.

\section{Melodic Development:}

The style of this solo is very melodic, with much of the improvisation based around the original melody of this tune.

\section{Content: Vocabulary, Formula, Repeated Material:}

Some commonly used elements of the jazz language do occur throughout the solo, such as enclosures and arpeggiation of the chords.

The following $\mathrm{C}$ blues scale phrase is played leading into bar 22:

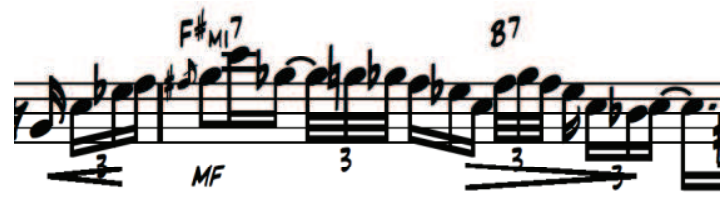

The following phrase is played in bar 67 during the solo cadenza. It is a diminished/ chromatic scale phrase. A series of descending "bebop" licks each starting from a diminished chord tone are linked together.

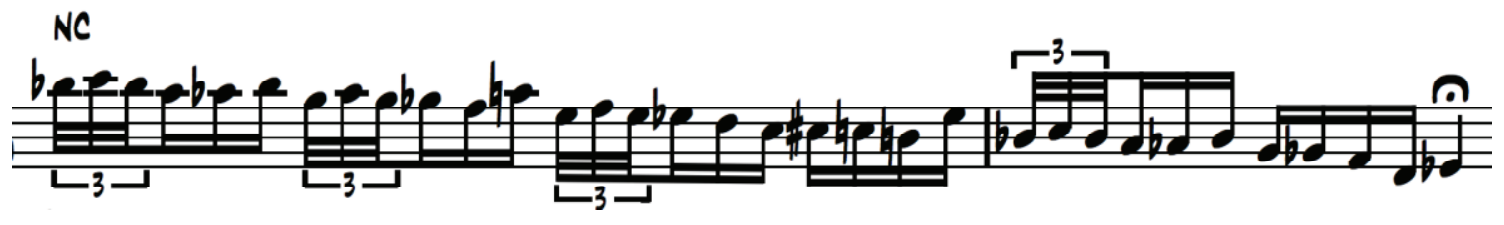




\section{Repeated material:}

Compared with Hayes' other solos this solo contains very little repeated material, however there is distinct similarity in bars 29:

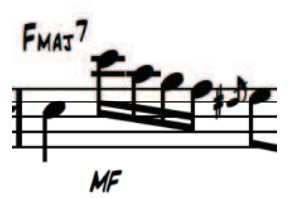

and 47:

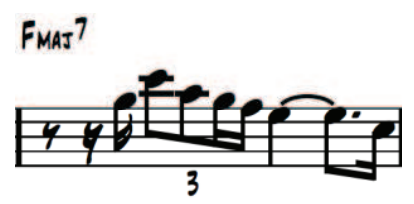

This is a descending digital pattern played over the F major chord, in both cases followed by the seventh and fifth note of the chord.

\section{Typical Language Used:}

Some of Hayes' typical phrases do appear in this solo for example:

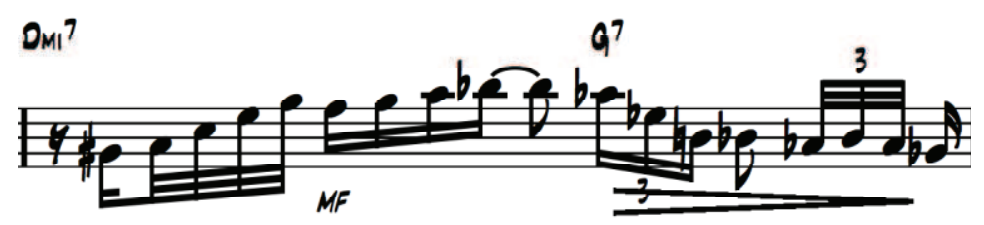

(Shown at bar 32), this is a typical Hayes' phrase, a double-time ascending A minor 7 arpeggio, it is followed, in the last two beats of the bar by a descending 'Cry Me a River' lick beginning on the sharpened ninth of the G dominant 7 chord.

A simple $\mathrm{C}$ major idea in the first beat of bar 33:

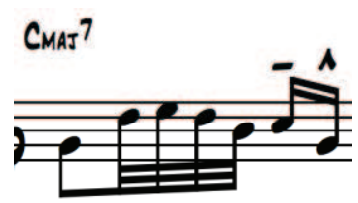

is developed into a melodic sequence through bar 33 and the first beat of bar 34:

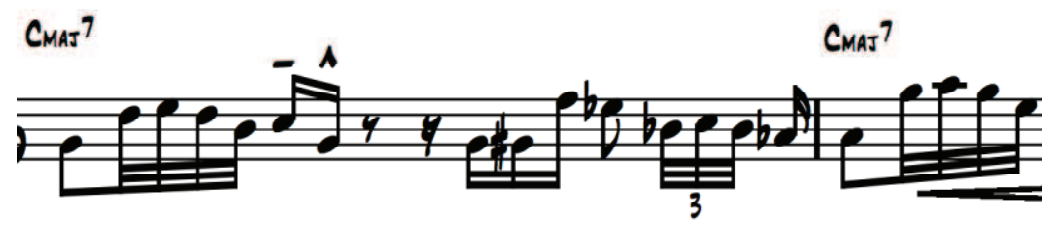


This phrase shown here in D minor at bar 16 is also seen several times in 'Soon' and 'Airegin' in G minor (for example at bar 109 in Airegin').

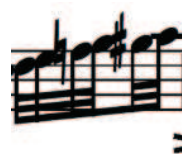

Bar 41 is a variation on a standard "C.E.S.H" lick.

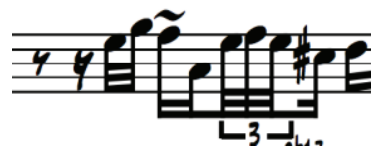

Various Devices are used to give this solo a more emotional dramatic quality;

In places wider intervals create tension as shown here in bar 19:

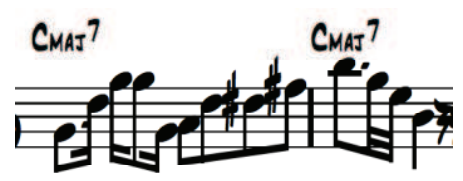

In bar 37 two consecutive ascending chromatic scale runs.

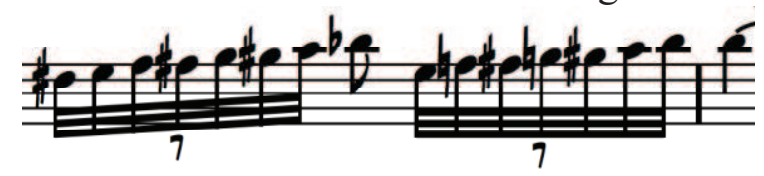




\section{Section 4: Hayes' Improvisational Style: Summary and Overview}

\section{Content}

Throughout his improvisations, Hayes drew on many standard, commonly used elements of the jazz language including scales, arpeggios, enclosures, and other commonly used elements.

\section{Scales}

Hayes would most often use a combination of two blues scales as noted under the heading 'Blues Playing'. He also used major and harmonic minor scales, bebop scales, whole-tone scales and diminished scales (the latter two were most commonly played in a 'pattern' of sorts). For example here is a whole-tone scale pattern shown in bars 172-174 of 'Opus Ocean':

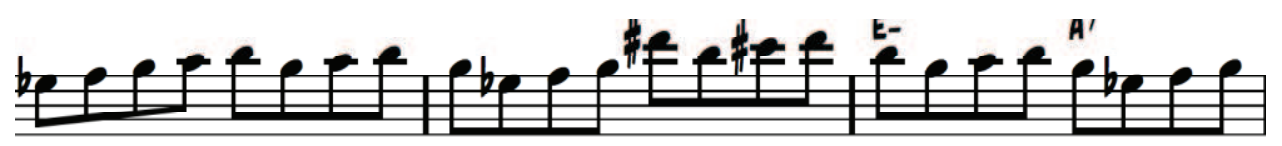

\section{Arpeggios}

Major, minor, dominant $7^{\text {th, }}$ and diminished arpeggios are commonly used throughout Hayes' solos. They are often used in brief bursts of ascending double-time in the style of Charlie Parker. Please refer to page 73 for examples.

\section{Other common elements of the jazz language}

Enclosures are used throughout Hayes' solos as a means to link phrases together. Some well known jazz language is present, such as the 'bebop' lick (an example can be seen throughout the solo cadenza in "You are my Everything'), the 'Cry Me a River' lick (this is seen frequently throughout Hayes' solos usually beginning on the sharpened ninth of a dominant chord and with the addition of several triplet based turns) and a chromatic diminished passing chord substitution (see below).

\section{Hayes' Vocabulary, Repeated Material or 'Formula'}

Thomas Owens states that "Every mature jazz musician develops a repertory of motives and phrases which he uses in the course of his improvisations" ${ }^{\prime 0}$ and this is certainly true for Hayes. These ideas or formulas or clichés help give a player a very distinctive sound.

Hayes had certain patterns that would appear throughout different solos in various keys. There were different types of ideas depending upon the context: in a minor key; during a melodic passage; in a blues solo. In this next section a number of "Tubby Clichés" have been identified. These are examples of ideas that Hayes used particularly often.

\footnotetext{
${ }^{60}$ Thomas Owens 1974 pp17
} 
1. This Chromatic diminished passing chord substitution shown here in Hayes' solo on "'Opus Ocean"” is implied three times during this solo (bars 47-48, 92, and 123-124). This lick is seen in several of Hayes' other solos including 'Soon' and 'You for Me' on this album

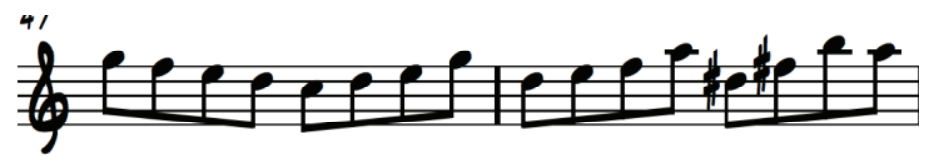

2. This simple melodic figure is seen on Hayes' solos on 'Doxy':

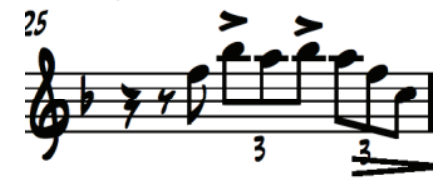

and 'Soon':

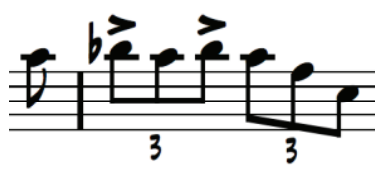

It is a triplet figure, based on the natural $11^{\text {th }}$ resolving to the $3^{\text {rd }}$ of the chord. It is played in both instances in the key of F major, where it falls with a very comfortable fingering on the saxophone. This may not have been something that Hayes had learnt in all keys. It may have been fragment of a melody he knew.

3. This example compares bar 126 of Hayes' solo in 'Half a Sawbuck'

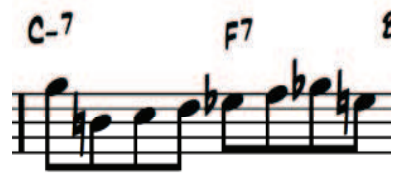

to bar 148 of his solo in 'Opus Ocean':

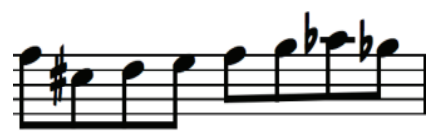

There is just one note different between these examples. It is an example of Hayes' using an automatic pre-learnt formula or finger pattern.

4. 4. A chromatic movement from the minor 3rd of a given chord to the fifth. This is found frequently in many of Hayes' solos Shown here C major in bar 59 of 'You for Me': 


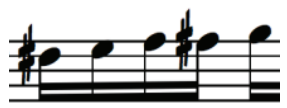

And in F major in bars 39-40 of 'Soon':

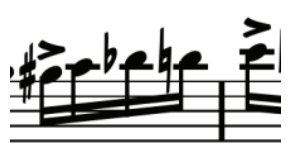

5. This phrase in G major is seen in 'Soho Soul' Bar 69:

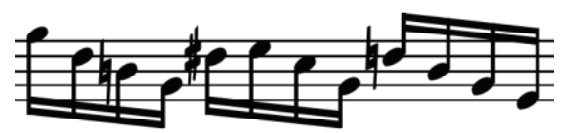

And ‘The Simple Waltz' Bars 117-118:

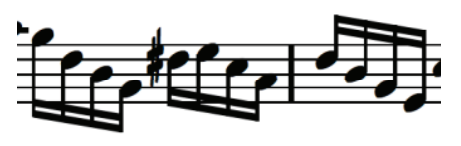

\section{Other Features in Hayes' Improvisation}

The shape of this phrase (usually in the form of a short burst of ascending double-time, landing on a note one tone lower than the highest note of a phrase) is seen many times throughout Hayes' solos. Some brief examples are shown here:

Bar 163 of 'Opus Ocean':

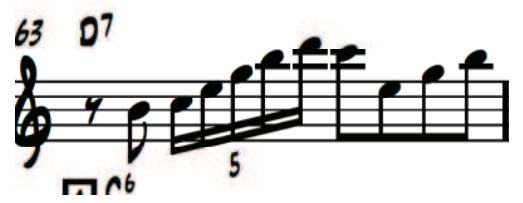

In bar 83 of 'Soho Soul':

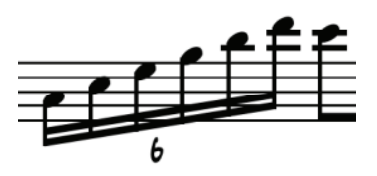

Bar 53 of 'Half a Sawbuck':

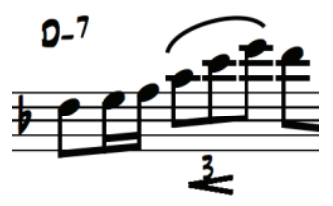


This is more of a rhythmic figure than a melodic one. It is a series of turns used often throughout Hayes' solos in various keys and over various chords. Interestingly it is very similar to something played by Charlie Parker through bars 16 and 17 of his solo in his solo on 'Parkers Mood' (please refer to page 72 to view this example).

\section{Double Time Passages}

A prominent feature of Hayes' improvisational style is his tendency towards extended double time passages, or as Simon Spillett colourfully describes "his signature saxophone athletics" $" 61$ This is a trait for which he has been both admired and criticized. In his own defense, Hayes said:

There are times when I will not use those fast runs and things - and there are times when I will. Sometimes I do it out of sheer exuberance - and get carried away with myself and get things going. It's not to flash off at the customers, believe me, because half the time I don't even know they're there when I really get involved in what I'm doing. The only time I'm conscious of the customers being there is when I'm not really feeling myself. If I feel suddenly: 'Oh — it's all happening' I might get carried away — but, on the other hand, it might happen one night that I feel the rhythm section is bugging me. Maybe it seems to be dragging down or not swinging as it might - than I might lose my temper and start doing it that way, as if to say: 'Come on!' ${ }^{2}$

Such double time passages are seen on this recording in nearly all the solos: 'Soon', 'You for Me', 'Half a Sawbuck', 'The Simple Waltz,' 'Pint of Bitter', 'Soho Soul', 'Doxy', and to a lesser extent the ballad 'You are my Everything'. Hayes was able to play double time passages, as shown in his solos on 'Soon' and 'You for Me' at tempo markings of around two hundred crotchet beats per minute, which does show that Hayes had remarkable technical facility. When analysed these double time passages show classic Charlie Parker style formulaic improvisation. Thomas Owens (1974) suggests that Parker "drew primarily on a repertory of about 100 motives of varying lengths, modifying them and combining them in a great variety of ways." ${ }^{63}$ Hayes' improvisational style shows a very similar approach, which is unsurprising given that Parker was Hayes' main inspiration.

A key feature of Parker's playing as Owens highlights is the use of scale passages in linking Parkers improvisations. "There is a basic organising device linking the great majority of Parker's improvised solos: descending scale passages". ${ }^{64}$ However, a key difference between Parker's improvisational style and Hayes' own is that as Thomas Owens discovered Parker used different material in different keys. ${ }^{65}$ Hayes on the other hand, while using some formulas more in certain keys than others (likely to be due to

\footnotetext{
${ }^{61}$ Simon Spillett 'The long shadow of the little Giant' November 2004 available from www.jazzscript.co.uk/extra/art.hayes.htm

${ }^{62}$ Les Tomkins interviews Tubby Hayes. 1966

${ }^{63}$ Thomas Owens 1974 pp35

${ }^{64}$ Thomas Owens 1974 pp270

65 Thomas Owens 1974 pp269
} 
how difficult these formulas are to execute at speed in various keys), did play the same thing in different keys. Here is an example of the same fragment being played in different keys in three different tunes:

'Pint of Bitter' bar 41 (in Bb Major):

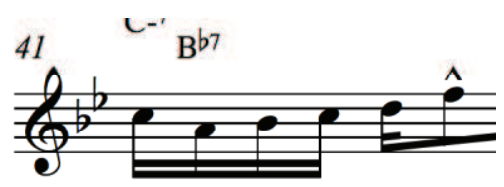

'Opus Ocean' bar 52 (in C major):

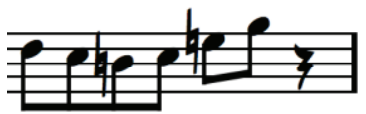

'Half a Sawbuck' bar 84 (in Ab major):

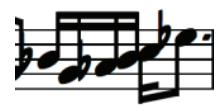

Here is another example of the same phrase being played in different keys during

'Airegin':

Bar 51 in $\mathrm{C}$ major:

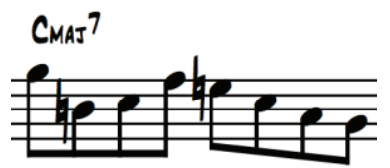

Bar 47 in D major:

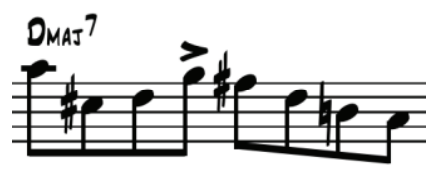

This is a technique which can only be learnt from practising as such. Hayes claimed to practice in all keys:

I never practised out of books, but I used to work out runs, scales and arpeggios. The trouble with that is: you get 'em all off in all the different keys, and then you do tend to use that technique a lot. ${ }^{66}$

\section{Preparation}

There are phrases on these solos that appear as though they may have been pre-learnt for these sessions. Examples are shown here in 'Doxy' and 'Half a Sawbuck' where Hayes plays nearly identical phrases in the same place during each chorus.

\footnotetext{
${ }^{66}$ Les Tomkins 2000 Tubby Hayes meets Sal Nistico available from: http://www.jazzprofessional.com/Exchange/HayesNistico.htm
} 
'Doxy' (bars 37-38)

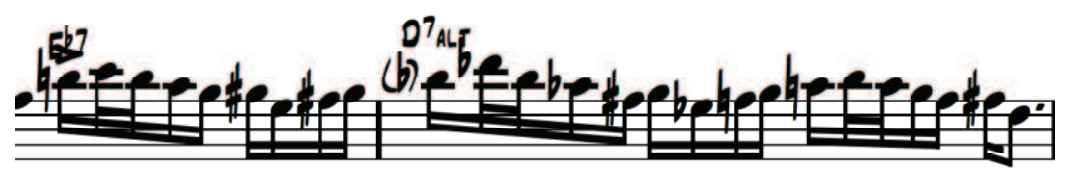

(bars 69-70)

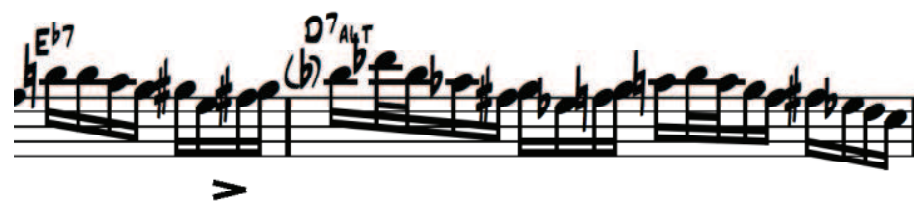

'Half a Sawbuck' (bars 117-118)

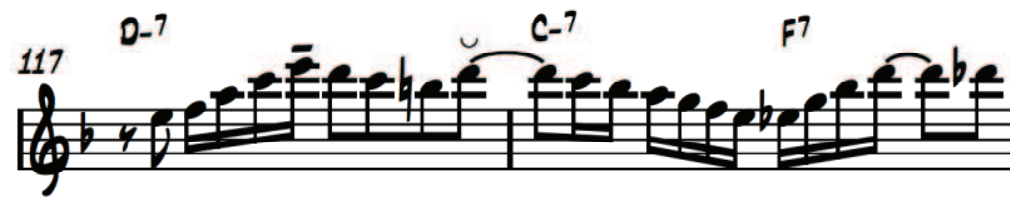

(bars 153-154)

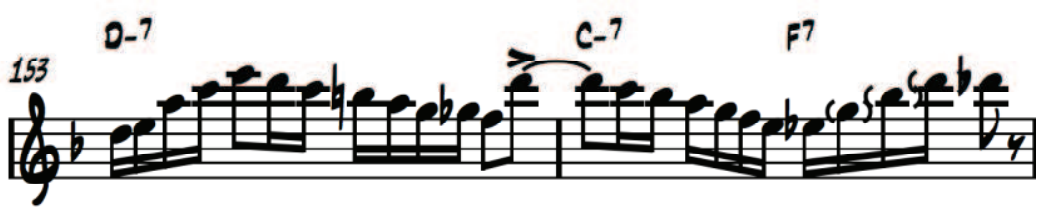

Similarly in 'You for Me' and 'Soon' difficult changes are often approached with near identical phrases in different choruses. Such as the Db 7 chord in 'You for Me' as shown here in bar 47:

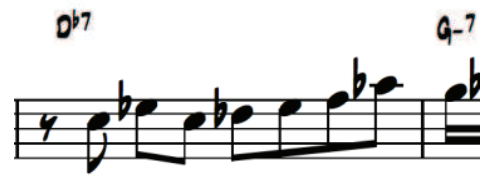

and bar 183:

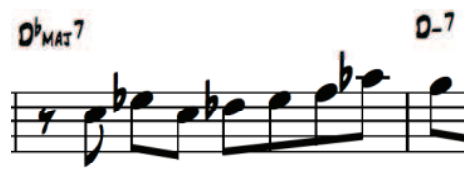


This is distinct from Hayes using his usual vocabulary in that here the various phrases he uses to get through difficult changes are only applied to a specific set of chord changes over one tune. This does indicate direct preparation of the tunes Hayes was to play during the session.

Stanley Dance, in his liner notes to the original release of these sessions states that indeed Hayes had done some preparation with familiarizing himself with the tunes he was to record.

Tubby's usual assurance had in any case been reinforced by a little unusual preparation. On each of the several days before the sessions, Tubby had gone to Columbia for three or four hours and shut himself up in a room, alone with a piano. There he had done his homework, familiarizing himself with the changes and thoroughly working over the numbers he was to record. ${ }^{67}$

\section{Tubby's Style}

Tubby Hayes has always had (above all his other considerable gifts) the gift of communicating sheer relish in the physical act of playing his instrument. He's an overwhelmingly exuberant player, firmly rooted in the bop tradition, which leaves no change unexplored and no tempo undoubled $^{68}$

\section{Bebop Playing}

Described by admirers as having a certain "exuberance" to his playing,

Tubby Hayes plays tenor saxophone and he loves to blow. He makes this clear immediately, wherever he plays. He blows with vitality, virtuosity and even, as a French admirer claims, with velocite, meaning speed. His energy and skill are not, however, deployed in the cause of exhibitionism. His most vigorous and fanciful flights spring rather from an inner urge toward complete expression of his joy and involvement in music. ${ }^{69}$

On a first listen to many of Hayes' recordings, particularly his uptempo bebop tunes it is easy to understand why. In addition to his eighth-note lines and seemingly spontaneous double-time passages, his solos are peppered with turns, glissandos, grace-notes, and lip bends. When playing melodies, on close inspection, Hayes appears to give each individual note special treatment. This is seen particularly in his playing of the melody on 'Soon', where trills, glissandos and subtle bends give each phrase colour.

\footnotetext{
${ }^{67}$ Stanley Dance, 1961, Liner Notes The New York Sessions, Tubby Hayes with Clark Terry.

${ }^{68}$ Stanley Dance, 1961, Liner Notes The New York Sessions, Tubby Hayes with Clark Terry.

${ }^{69}$ Stanley Dance, 1961, Liner Notes The New York Sessions, Tubby Hayes with Clark Terry.
} 


\section{The Strong Influence of Charlie Parker}

Hayes himself cites Charlie "Bird" Parker as his primary influence:

I always wanted to sound like Parker... he's my favourite saxophone player of the lot. There weren't any tenor players playing like that then. ${ }^{70}$

.... when I started playing, Parker was my idol, and I didn't want to play in any earlier idiom, like swing or Dixieland. But I had listened to all that before, as a kid. And, at the same time, I had to settle down to learning how to play the instrument. ${ }^{71}$

Parker's influence is seen in Hayes' playing through language, articulation, excessive use of turns, triplet rhythms and choice of tempos. Heavy use of turns is seen in many of Hayes' solos and a commonly used rhythmic phrase is based on linking a series of turns as shown here: (bars 40-41) in Hayes' solo on 'You for Me'.

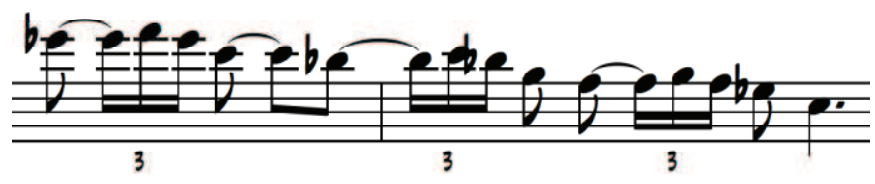

When compared to these excerpts from solos in 'The Charlie Parker Omnibook' it is possible to conclude that this trait of Hayes may have been something that he learnt directly from listening to his favorite player. Shown here is an excerpt from bars 20-21 of Charlie Parker's solo on "Parker's Mood"72

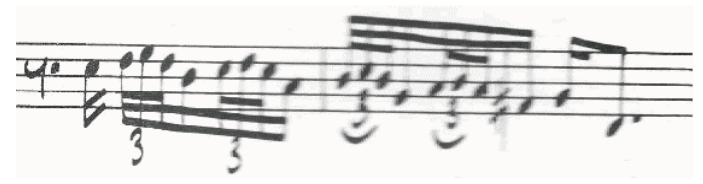

It is worth noting that although Charlie Parker's phrase (as shown here) is in sixteenth notes while Hayes is playing in eighth-notes, the tempo Hayes is playing at is more than double the tempo of 'Parkers Mood' ( 76 beats per minute) so when heard these phrases sound strikingly similar.

Here is a similar excerpt from 'My Little Suede Shoes' bars $52-52^{73}$

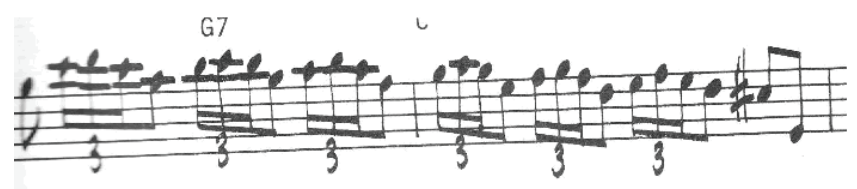

\footnotetext{
${ }^{70}$ Les Tomkins interviews Tubby Hayes. 1966

${ }^{71}$ Les Tomkins 2000 Tubby Hayes meets Sal Nistico available from: http://www.jazzprofessional.com/Exchange/HayesNistico.htm

${ }^{72}$ Charlie Parker Omnibook pp134

${ }^{73}$ Charlie Parker Omnibook pp121
} 
The shape of this phrase (usually in the form of a short burst of ascending double-time) is seen many times throughout Hayes' solos. Some brief examples are shown here:

Bar 163 of 'Opus Ocean':

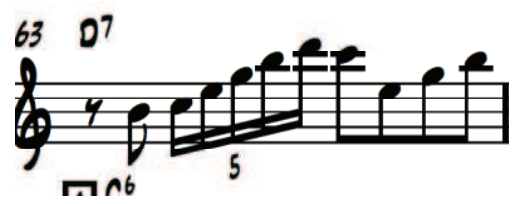

In bar 83 of 'Soho Soul':

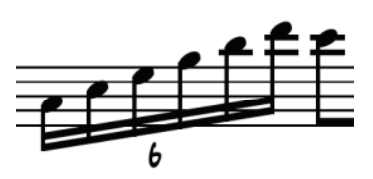

Bar 53 of 'Half a Sawbuck':

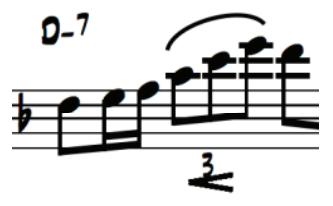

These are classic 'Parkerisms'

'My Little Suede Shoes' bar $42^{74}$ :

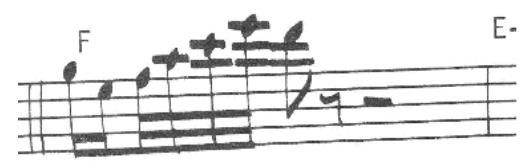

and in bar 45 in the same solo: ${ }^{75}$

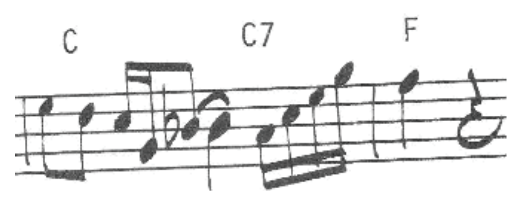

Hayes frequently uses scale passages throughout his solo, another trait that could possibly be traced back to Charlie Parker. As Thomas Owens (1974) points out Parker "was the first major figure in jazz to use disguised scalar descents as a basic organising force in jazz improvisation",76

Much of Hayes' language is strikingly similar, if not identical to Parker's, here are some brief examples:

\footnotetext{
${ }_{75}^{74}$ Charlie Parker Omnibook pp121

${ }^{75}$ Charlie Parker Omnibook pp121

${ }^{76}$ Thomas Owens 1974 pp271
} 
Bar 117 of Hayes' solo on 'The Simple Waltz' contains

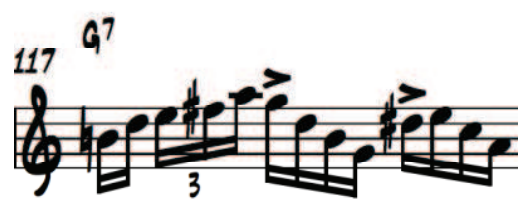

material identical to an excerpt from Parker's solo on 'Merry-Go-Round' ${ }^{77}$ (bar 2)

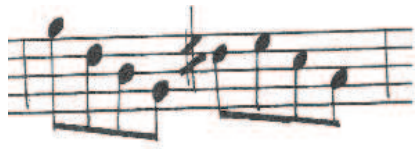

Shown here is an another excerpt from Parker's solo on "Merry-Go-Round ${ }^{78}$ (bar 4)

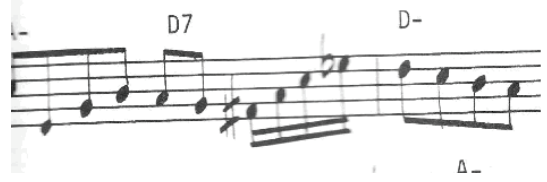

Bar 66 of Hayes' solo on 'Half a Sawbuck' uses this same phrase, shown here an octave higher, nearly identical except for the addition of a chromatic enclosure on the second beat of the bar.

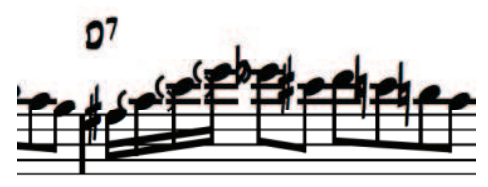

Other players that are often said to have influenced Hayes include tenor players Zoot Sims, Johhny Griffin. Stan Getz is said to have played an important part in shaping Hayes' ballad style throughout his career. This influence is demonstrated on much of Hayes' ballad work, particularly 'There's No You' recorded on July 29th 1955. Stan Getz's influence is also apparent in Hayes' version of 'You're my Everything', the one ballad from The New York Sessions, in his use of subtone, wide vibrato and lyrical phrasing.

\section{Blues Playing}

Another feature of Hayes' improvisation is the blues based playing that appears on this recording in the tunes 'Pint of Bitter', 'The Simple Waltz', 'Soho Soul', and 'Doxy'. In these solos Hayes plays with a laid back triplet driven style and generally uses two blues scales over one key; the tonic blues scale, and the blues scale starting a minor third below (for example E blues scale in the key of $\mathrm{G}$ referred to by some as the " $\mathrm{G}$ major blues scale"). These two scales give two distinct, bluesy sounds and are often combined together forming the basis for much blues playing.

\footnotetext{
${ }^{77}$ Charlie Parker Omnibook pp117

${ }^{78}$ Charlie Parker Omnibook pp117
} 
In Hayes' more blues based solos, his vocabulary, formulas and favorite patterns do appear, but more often in short bursts of double time playing. What stands out in these solos is his subtlety with dynamics and articulation. In Hayes' solo on 'Doxy' he plays with a wide dynamic range, often using rapid decrescendos on descending blues phrases, punchy articulation which is contrasted with tenuto phrases, ghosted notes and bends. Phrases played with the dynamic marking pianissimo do not lose their intensity due to the attention Hayes gives to their articulation.

\section{Tubby Playing Ballads}

One feature of Hayes' playing for which he is less well known is his ballad playing, seen on this album in 'You are my Everything'. This solo is played in a completely different style from the other tracks; a very beautiful tender rendition of a ballad, played very melodically with sub tone and wide vibrato, particularly in the lower register. This style is thought by many to be reminiscent of the great tenor player Stan Getz. Hayes said:

But I read these things where people say 'too many notes' and so on, and, quite honestly, I couldn't give a damn. I play as I want to play. And I can play a ballad. I love playing ballads. ${ }^{79}$

There is definitely some formulaic playing apparent in this ballad and Hayes does use his typical vocabulary. However the way it is put together differs completely from his uptempo playing. In this context, Hayes' vocabulary is used to create very melodic lyrical lines. For example, in the cadenza on this tune a series of classic bebop licks are joined together to create a very lyrical end to the solo.

Though the language Hayes uses throughout this solo is quite standard, it is the dynamic contrasts, and the sudden crescendos that give this piece a very emotional quality. Hayes said to fellow saxophonist Sal Nestico:

We've got the same sort of problem. We both like to play ballads, or any kind of thing, but we're sort of stereotyped. Everybody expects the tear-up tempos all the time. ${ }^{80}$

Stanley Dance described this ballad as "perhaps the biggest surprise of the album...An envoi that reveals another facet of his musical character." 81 That Hayes was not well known for his ballad playing is reflected in this comment he made to Sal Nestico:

There was the time I went on a concert with the Quartet at the Festival Hall. There were about two or three bands on before us - all good groups - and they were all playing mainly fast loud things. We were closing the first half, and everybody had overrun, so we didn't have much time. They didn't want us to overrun, because Maynard [Ferguson] was going on after the interval. So I said: 'Let's play a ballad.' So we went on, played a ballad, and it went down

\footnotetext{
${ }^{79}$ Les Tomkins interviews Tubby Hayes. 1966.

${ }^{80}$ Les Tomkins 2000 Tubby Hayes meets Sal Nistico available from: http://www.jazzprofessional.com/Exchange/HayesNistico.htm

${ }^{81}$ Stanley Dance, 1989, Liner Notes The New York Sessions, Tubby Hayes with Clark Terry.
} 
very well. And they wrote it up and said I must have been sick! ${ }^{82}$

\section{Articulation}

Articulation is varied in relation to the overall mood of each piece, showing that Hayes can be adaptable in his style of playing. Some points remain consistent; throughout the double-time passages accents either fall on the beat (in 4 note groupings of semi-quavers) or on the highest point of each phrase, as is very typical in the bebop idiom). The way Hayes articulates through a tune seems (to some extent) to follow the feel of the piece. 'The Simple Waltz' is a very legato 3/4 melody and the articulation is more legato throughout Hayes' solo. In 'You are my Everything' Hayes' articulation is also much more legato, contributing to the very lyrical feel of the piece. Hayes also uses dramatic dynamic contrasts, which brings a very emotional quality to the piece. In the slower more blues influenced pieces ('Soho Soul', 'Doxy' and 'Pint of Bitter') the articulation becomes very defined and the phrases are shaped with dynamics, subtle pitch bends and ghosted notes.

\footnotetext{
${ }^{82}$ Les Tomkins 2000 Tubby Hayes meets Sal Nistico available from: http://www.jazzprofessional.com/Exchange/HayesNistico.htm
} 


\section{Conclusions}

It is worth considering that in most cases, even the most acclaimed, highly regarded jazz musician will not be creating new material. Rather, they will put together the material they have learnt throughout their career and training in a way that will be most appropriate to the tune and genre being played, will relate to the chord changes, and engage the listener. "No one can be creative all the time...the only hope the improviser has is to be as creative as possible most of the time, and otherwise try to be as tasteful and interesting as possible" ${ }^{83}$ Even the most accomplished improvisers are not necessarily constantly creating new material. The mark of a great improviser is not necessarily to create new material that one has not yet "learnt" but rather the ability to apply what one knows from his/her subconscious in a spontaneous, and engaging manner. "Every mature jazz musician develops a repertory of motives and phrases which he uses in the course of his improvisations." 84

In cases of Hayes' double time playing there is very little question as to whether he was doing so subconsciously and spontaneously, given the speed at which he is playing these formulas and linking them. Given that recurrent melodic patterns are indeed an "inevitable and necessary feature of the improvisational process in jazz" 85 it is certainly worth noting Hayes' technical achievement in creating coherent, harmonically relevant jazz lines at a speed that most would find difficult to hear, let alone play on a tenor saxophone. This is not however, by any means the essence or sole appeal of Hayes' improvisational style.

The beauty in these solos lies in what Hayes can overtly communicate to his audience. In Hayes' solos nothing is done by halves. Hayes is best known for his ability to play fast tempos and when Hayes played a fast tempo, he did so tirelessly and energetically from beginning to end, an "overwhelming torrent of musical energy." 86 When Hayes played ballads, he did so beautifully, creating touching lyrical versions. If he played a slow rhythmic, blues-influenced piece then every phrase was carefully shaped and each note articulated.

Stanley Crouch deems that "the vast majority of musicians at any time in history and in any idiom are not innovators themselves-even if they are among the first to embrace new vocabularies." 87 Hayes is by no means one of the great innovators of his time. However this lack of innovation by no means makes his playing any less meaningful or personal. Les Tomkins notes "Tubby, in a quartet setting, could take major standard songs and fashion immensely personal jazz out of them"88 (Les Tomkins)

\footnotetext{
${ }^{83}$ Paul Rinzler. 2008 pp133

${ }^{84}$ Thomas Owens 1974 pp 17

${ }^{85}$ Gregory Smith 1983 pp144

${ }^{86}$ Simon Spillett 2004

${ }^{87}$ Stanley Crouch Considering Genius pp 209

${ }^{88}$ Les Tomkins Tubby Hayes Live in London Cover Notes 2003 available at: http://www.jazzprofessional.com/cd_reviews/TubbyHayes.htm
} 
Hayes played well within the tradition of jazz, particularly the bebop idiom. It is fair to say that Hayes was more of an imitator than an innovator in the jazz idiom, yet at the same time he managed to have a style that was inimitably his own. He had the talent and the energy to take the best attributes from his heroes. Simon Spillett remarks that "his talents had matured into those of a consolidator, and represented what may well be the most perfect freeze frame of the finest virtues of jazz saxophone as it stood at the beginning of the 1960s.... he could be as dare-devilishly intense as [Johnny] Griffin, as melodically graceful as [Stan] Getz or as boomingly omniscient as Sonny Rollins". ${ }^{9}$

His career of a little over twenty years contained evidence enough of his being a truly mature talent and a forthright and honest musical voice. He had packed more than a lifetime's energetic enthusiasm into his art, and had become a well loved larger than life figure on the British jazz scene... He was indisputably the most accomplished and characterful British jazzman of his generation. His music ranks amongst the finest jazz of his day and still has the power to move those who, nearly fifty years later, encounter it for the first time. ${ }^{90}$

${ }^{89}$ Simon Spillett 2004

${ }^{90}$ Simon Spillett 2004 


\section{Bibliography}

Aebersold, Jamey., Goldsen, Michael The Charlie Parker Omnibook, New York :Atlantic Music Corp. 1978

Boulton, David. Jazz in Britain. London: W.H. Allen. 1958.

Byrnside, Ronald. "The Performer as Creator: Jazz Improvisation" In Contemporary Music and Music Cultures Englewood Cliffs, NJ: Prentice-Hall, 1975.

Carr, Ian., Fairweather, Digby., Priestly, Brian. The Rough Guide to Jazz. New York: Penguin. 2000.

Chilton, John. Who's Who of British Jazz (2nd Ed). London: Continuum International Publishing Group. 2004.

Columbia University Centre for Jazz Studies, 'The jazz glossary' available from http://ccnmtl.columbia.edu/projects/jazzglossary/f/formulaic_improvisation.html.

Cook, Richard. Morton, Brian. The Penguin Guide to Jazz Recordings ( $8^{\text {th }}$ ed.). New York: Penguin Group. 2006.

Crouch, Stanley. Considering Genius. (2006) New York: Basic Civitas Books

Dance,Stanley. Liner Notes: The New York Sessions, Tubby Hayes with Clark Terry. (1961) New York: Columbia Records

Dance, Stanley. Liner Notes: The New York Sessions, Tubby Hayes with Clark Terry. (1989) New York: Columbia Records

Erlewine, Stephen., Bogdanov, Vladimir.,Woodstra, Chris., \& Yanow, Scott. All Music Guide to Jazz (3 ${ }^{\text {rd }}$ ed.). San Francisco: Miller Freeman Books. 1998

Feather, Leonard \& Gitler, Ira . The Encyclopaedia of Jazz in the Seventies. New York: Horizon Press. 1976.

Gonda, Janos "Problems of Tonality and Function in Modern Jazz Improvisation," Jazzforschung/Jazz Research, $3 / 4$ (1971/1972)

Gridley, Mark. Jazz Styles. Englewood Cliffs, NJ: Prentice Hall 2006

Harrison, Max., Thacker Eric., Fox, Charles. The Essential Jazz Records (Vol 2):

Modernism to Postmodernism. California: Mansell Publishing. 2000.

Kernfield, Barry. Two Coltranes Annual Review of Jazz Studies, Vol 2, 1983, pp7-66 
Kernfield, Barry. Adderly, Coltrane, and Davis at the Twilight of Bebop: The Search for Melodic Coherence (Volumes one and two). Michigan: UMI Dissertation Services. 1981

Kernfield, Barry., Gardner, M. (2007). Grove Music Online. England: Oxford University Press. Www.grovemusic.com/index.html accessed 10th August 2009 accessed 20th October 2008

Kirchner, Bill. The Oxford Companion to Jazz. New York: Oxford University Press. 2000

Martin, Henry. Charlie Parker and Thematic Improvisation. Boston: Scarecrow Press Inc. 1996.

Moore, Hillary. Inside British Jazz: Crossing Borders of Race, Nation and Class. Cornwall: NPG Books Ltd. 2007.

Nissenson, Eric. Blue: The Murder of Jazz. New York: St Martin’s Press, 1997.

Owens, Thomas. Charlie Parker: Techniques of Improvisation Parts one and two. Michigan: UMI Dissertation Services. 1974

Rinzler, Paul. The Contradictions of Jazz. Maryland: Scarecrow Press Inc. 2008

Smith, Gregory. Homer, Gregory, and Bill Evans? The Theory of Formulaic Composition in the Context of Jazz Piano Improvisation. Michigan: UMI Dissertation Services. 1983

Spillet, Simon. (2004). Tubby Hayes : The Long Shadow of the Little Giant http://www.jazzscript.co.uk/extra/art.hayes.htm accessed 12 January 2009

Spillet, Simon. British Jazz Saxophonists 1950-1970: An Overview http://www.jazzscript.co.uk/extra/brit.sax.htm

Spillet, Simon. (2004). 'Blue Hayes:' The Tempo Anthology. Jasmine Records (Liner Notes).

Tirro, Frank. Jazz: A History. $2^{\text {nd }}$ ed. New York: W. W. Norton \& Company, 1993.

Tomkins, Les. Les Tomkins interviews Tubby Hayes. (1966). available from: http://www.jazzprofessional.com/interviews/tubby_hayes.htm accessed 20th October 2008

Tomkins, Les. Tubby Hayes meets Sal Nistico (2000)available from:

http://www.jazzprofessional.com/Exchange/HayesNistico accessed January 13th 2009

Wickes, John. Innovations In British Jazz (Volume: 1960-1980)

England: Soundworld. 1999. 


\section{The Improvisation of Tubby Hayes in 'The New York Sessions'}

Ten Transcriptions submitted in partial fulfilment of a

Masters in Musicology

Amity Rose Alton-Lee

20 February 2010

New Zealand School of Music 


\section{Table of Contents}

You for Me............................................................ 2

Pint of Bitter ............................................................. 7

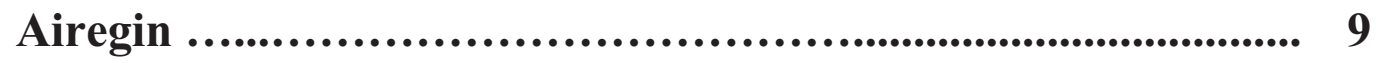

Opus Ocean................................................................... 16

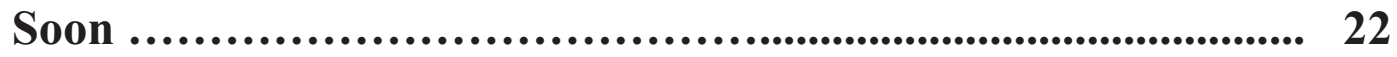

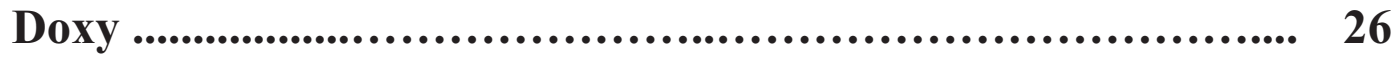

Soho Soul............................................................... 29

The Simple Waltz.................................................. 32

Half a Sawbuck.......................................................... 37

You are my Everything.................................................... 41 
TEMPO $=200$

YOU FOR ME

TEMPO =

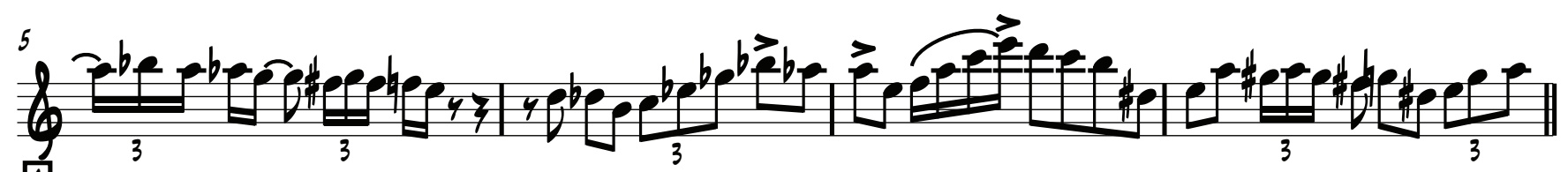
$\begin{array}{lllll}\text { A } & \text { CMAJ } & & & \\ 9 & 0-7 & 9^{7} & \text { CMAJ }^{7}\end{array}$

(6)

19) ${ }_{\text {MAT }}^{7}$ (a)

21 CMAT7

$29 \mathrm{CMAT}^{7}$ (6) (b) (6) $45 \mathrm{CMAJ}^{7}$

8-7 EAM? 8-7 $\quad E^{7}$

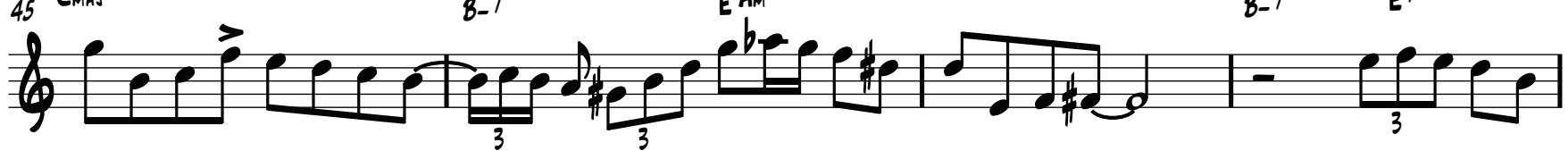
(49)

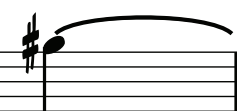


$b=0.000$

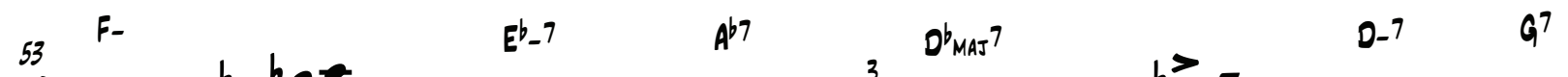
6) b)

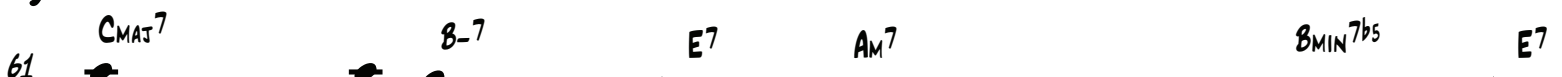
b

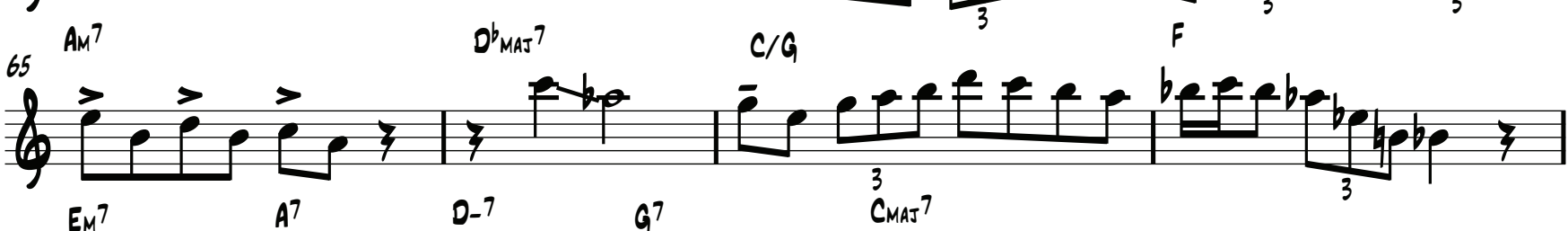

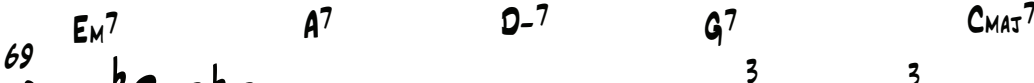

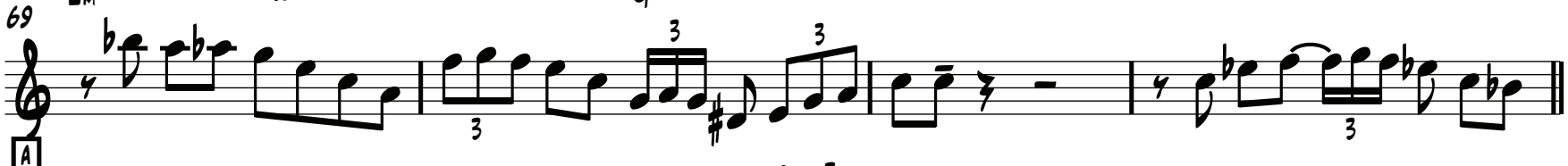

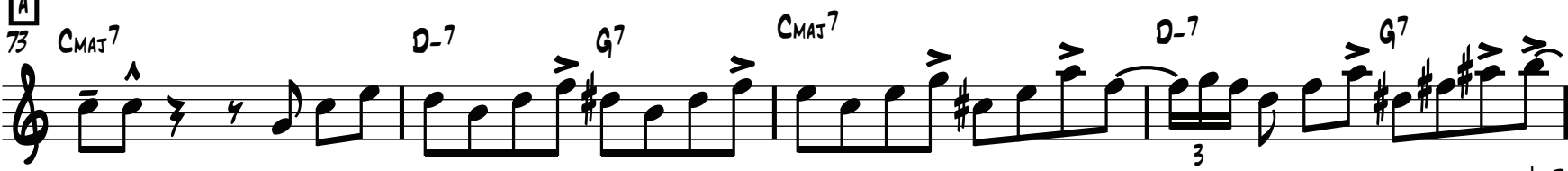
b)

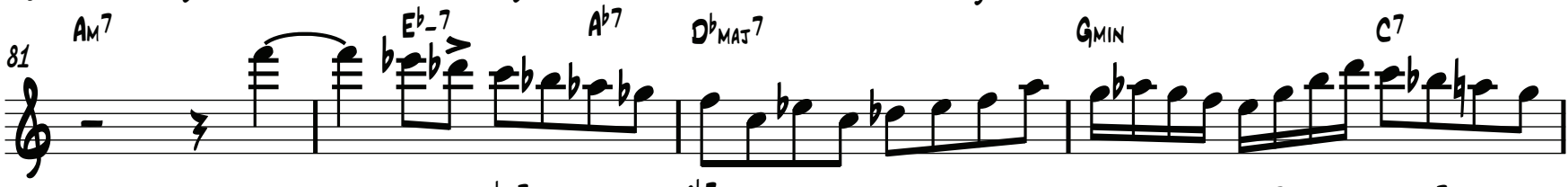

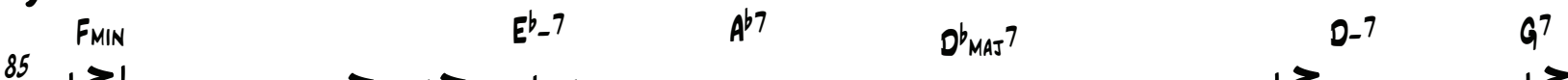
b) 6) b) b. 
101 EMIN $\quad A^{7} \quad D_{\text {MIN }}{ }^{7} \quad G^{7} \quad$ CMAT $^{7}$

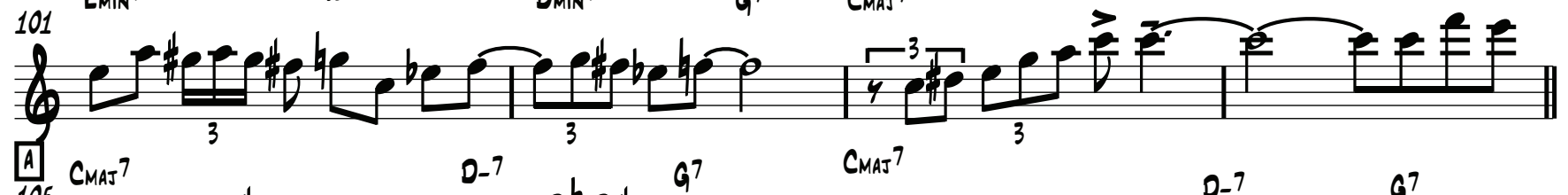
${ }_{105}^{\mathrm{CMAT}^{7}}$

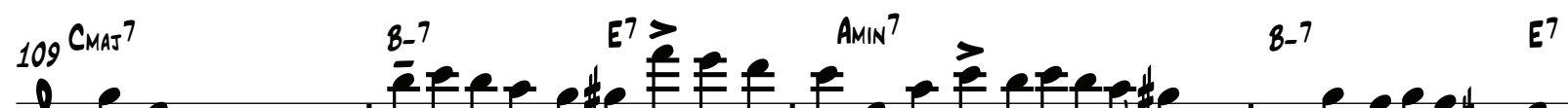
(6) (113 (117 ${ }_{121}^{B^{\mathrm{CMAT}^{7}}}$ ${ }_{125}^{\text {CMAT7 }^{2}}{ }^{\text {AMIN7 }}$ $\underbrace{129}_{A^{7}}{ }^{A M N N^{7}}$

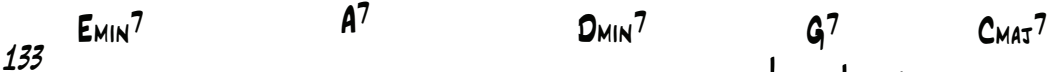

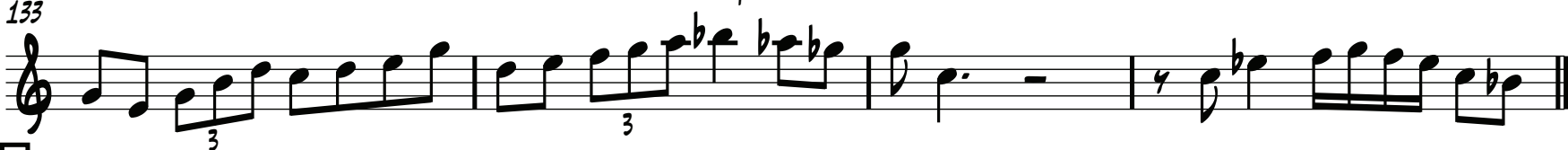
(6)

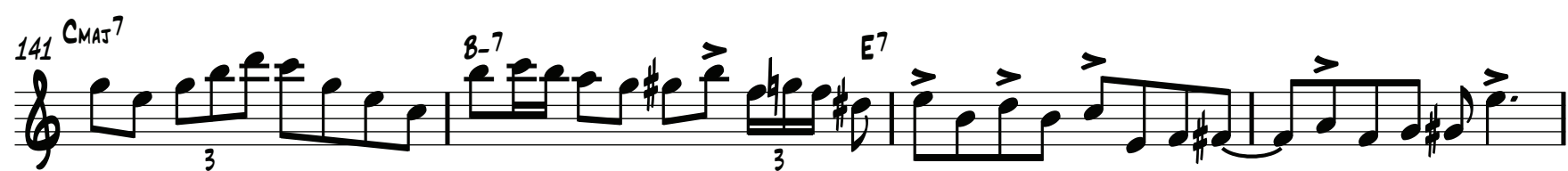

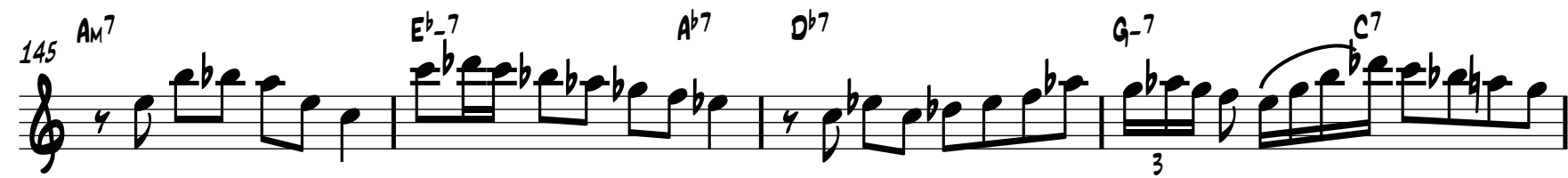
149 b- ${ }^{\mathrm{F}}$ 


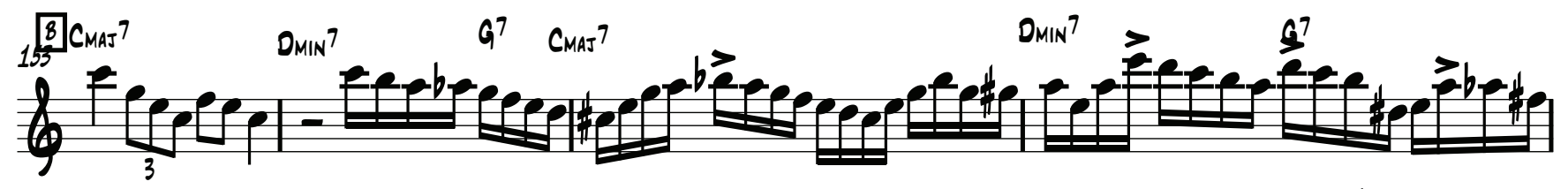
(4) ty

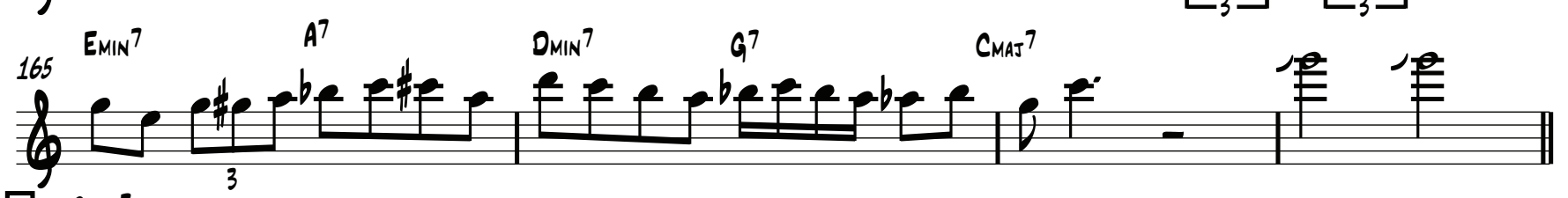

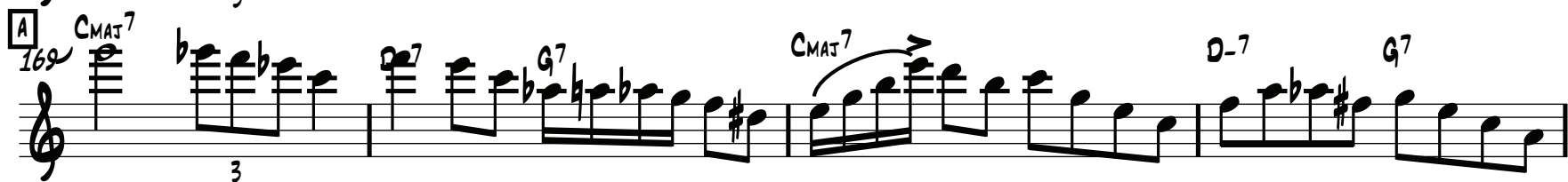

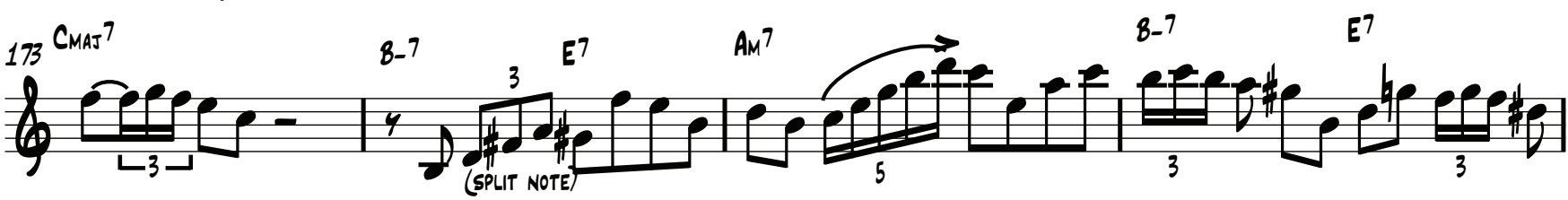

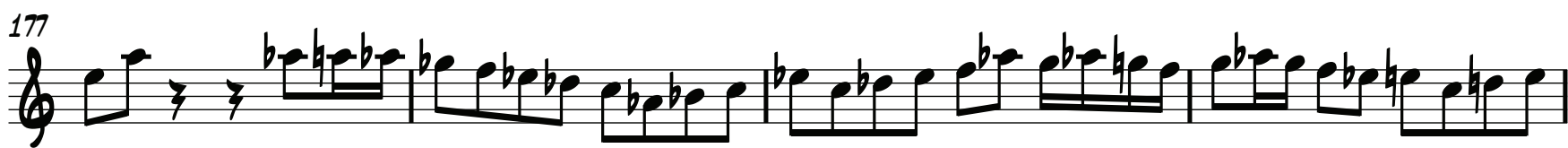

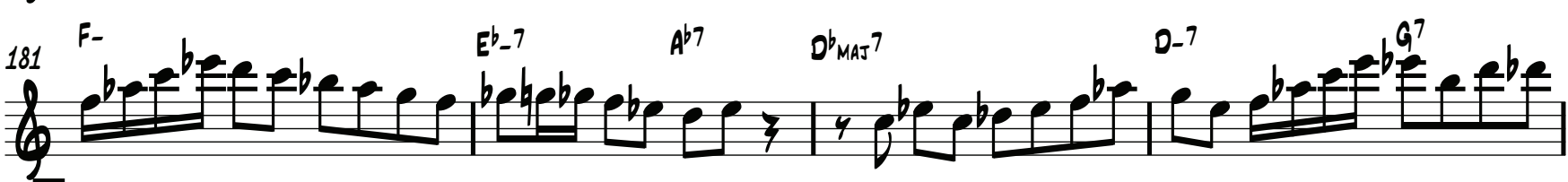

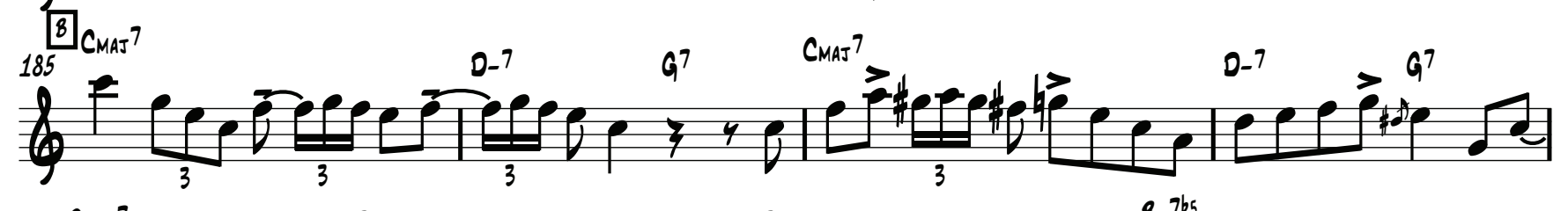

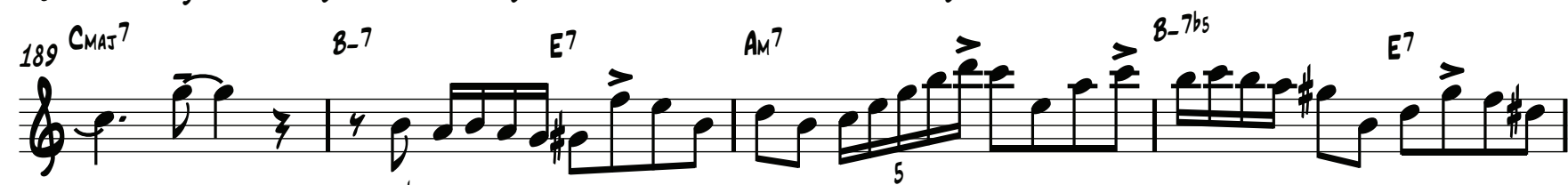

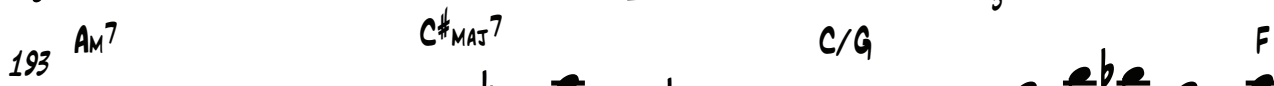

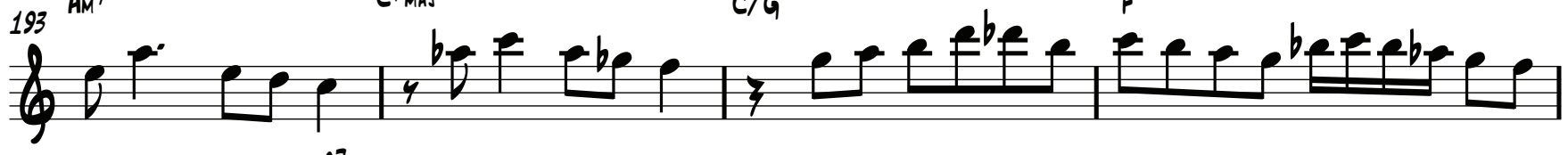
ben" 然 


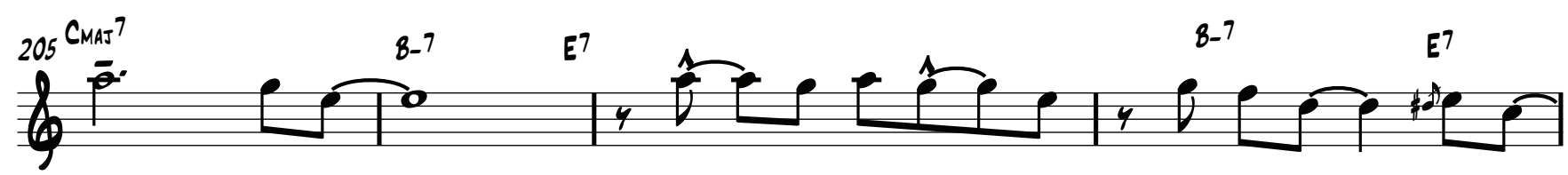
b"

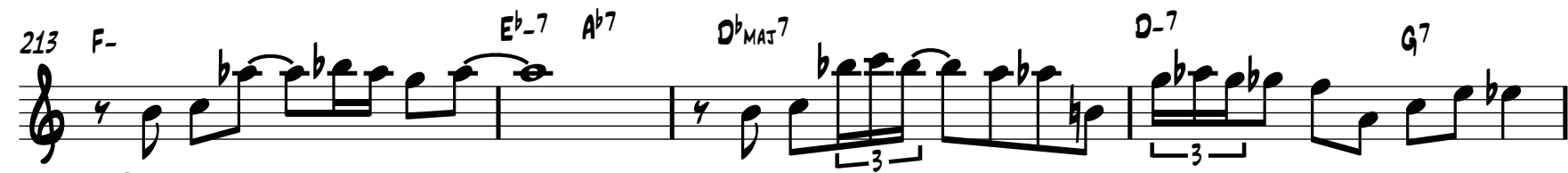

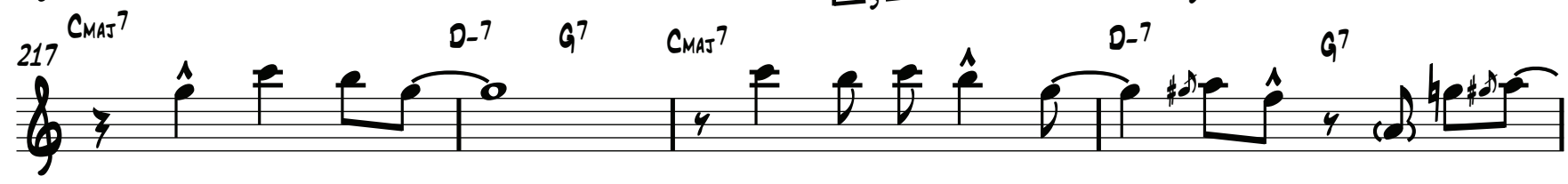

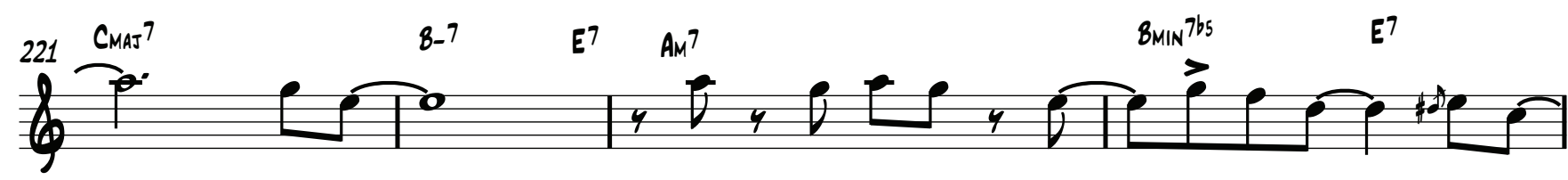

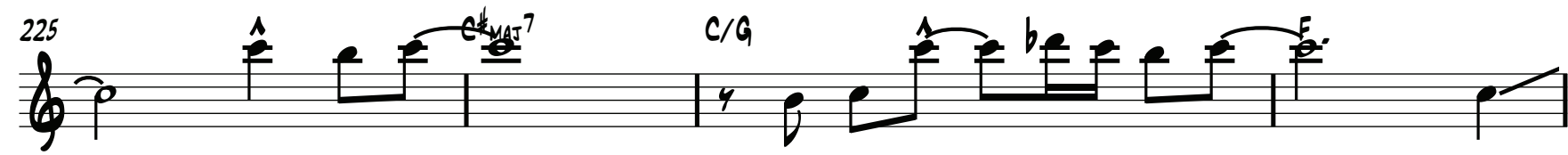
然" (a) 
TEMPO= $\frac{112}{112}$

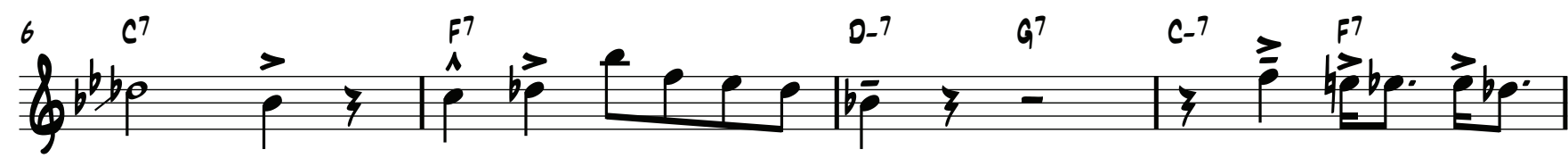

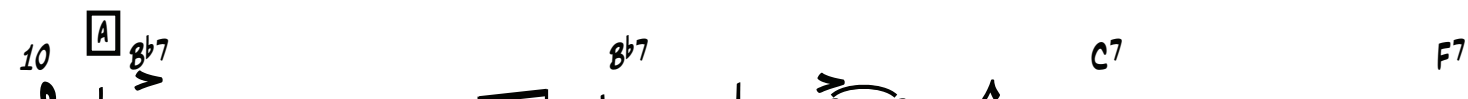

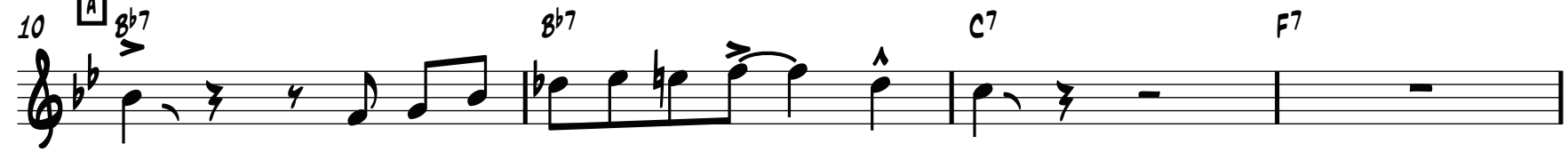
(a) (6)

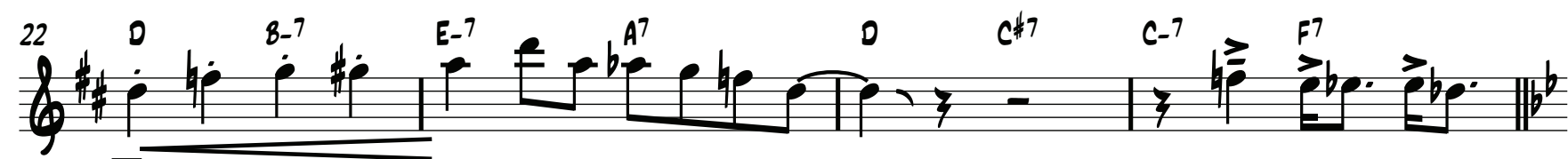

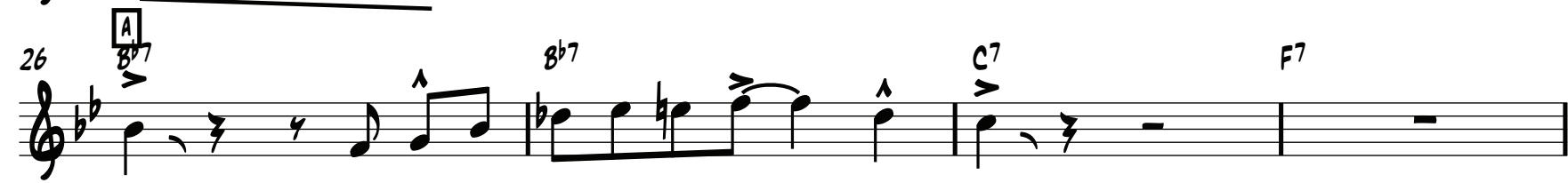

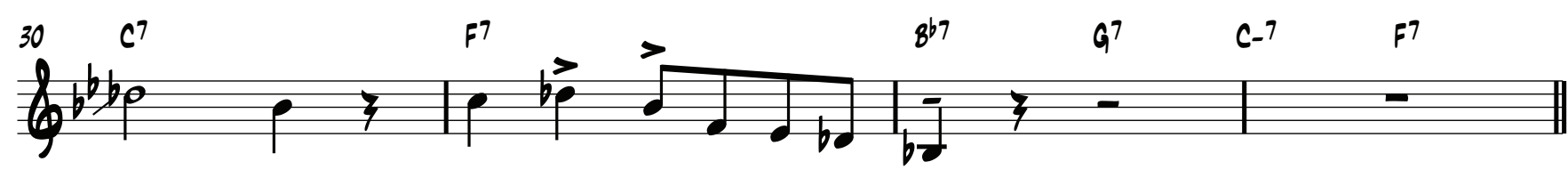
$34 b^{b}$

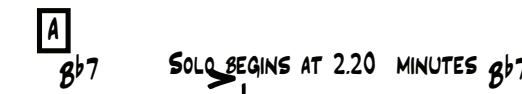
(4)

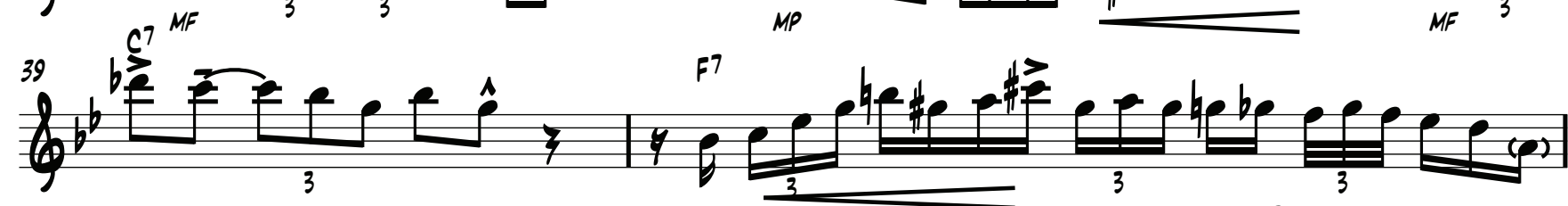
(15

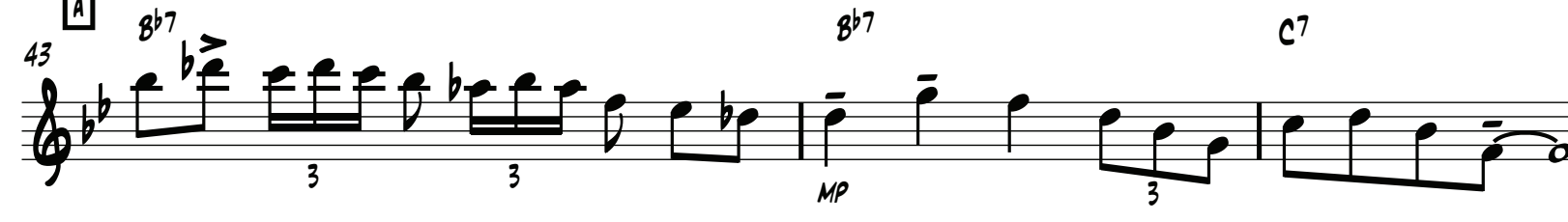




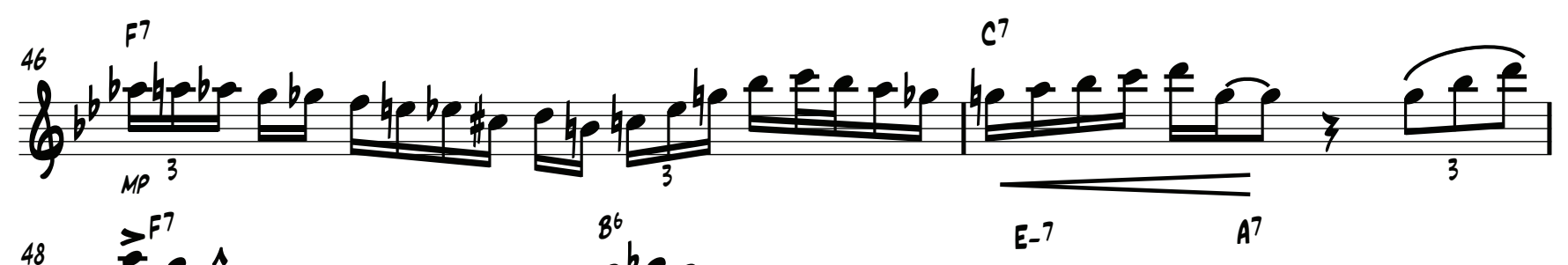
6 4. bit. 6)

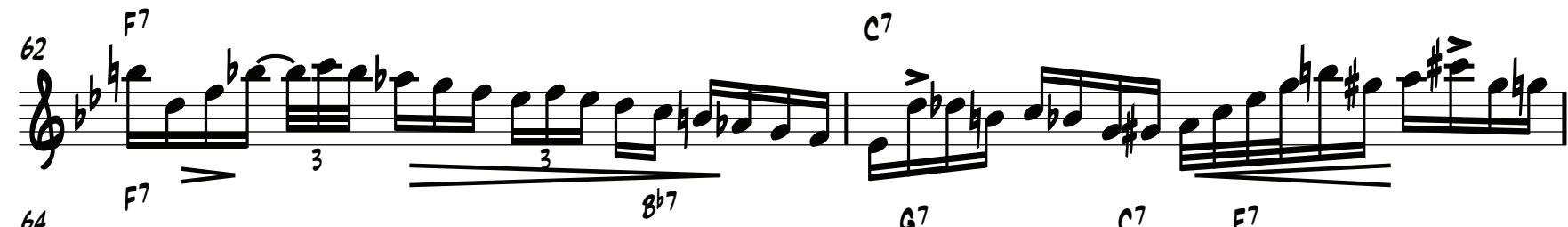

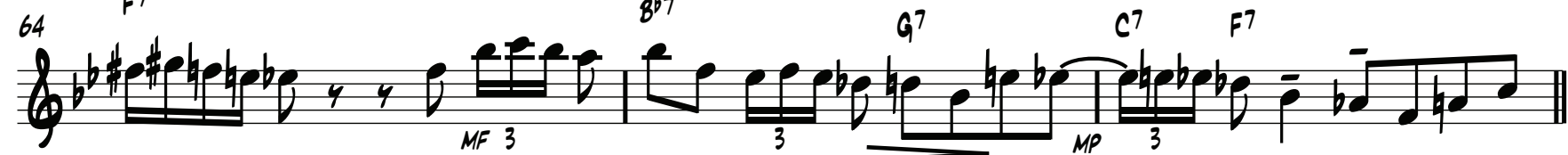
$67 \quad 867$ ENO SOLO 6. 

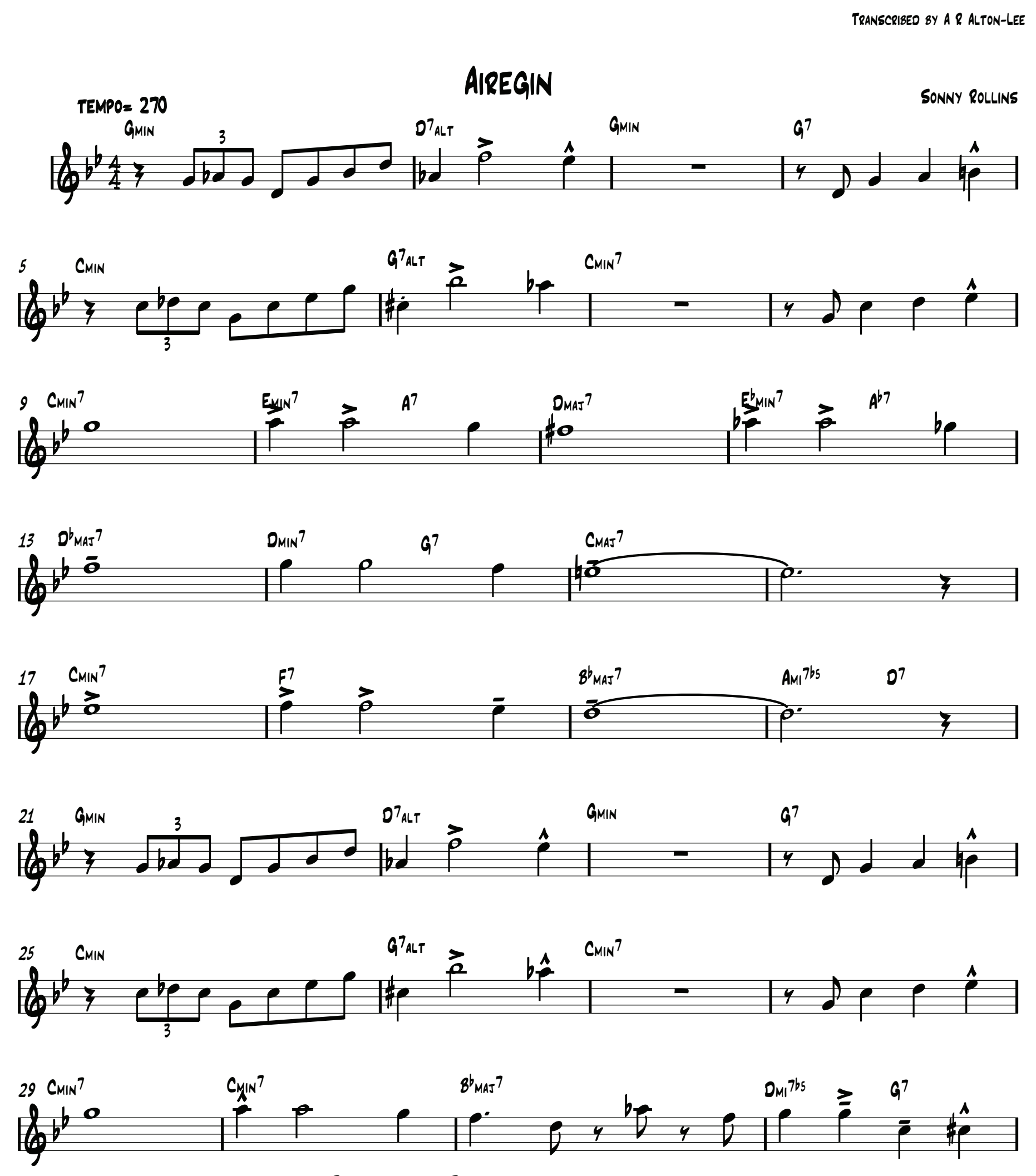
की

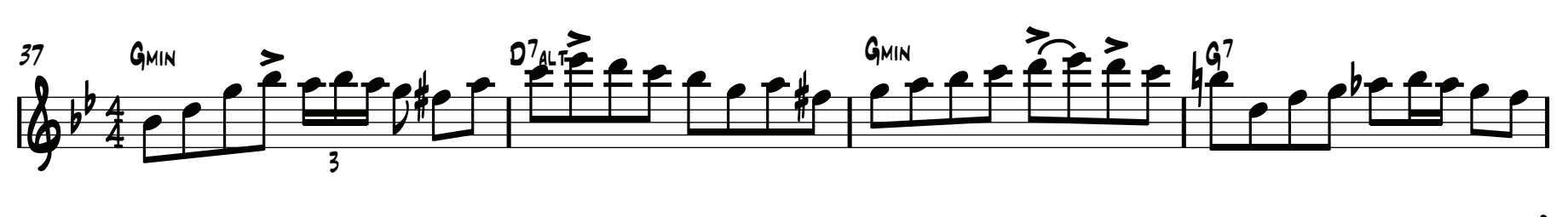




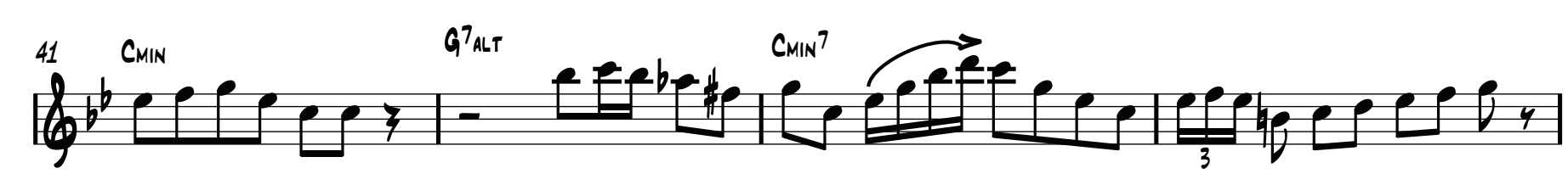

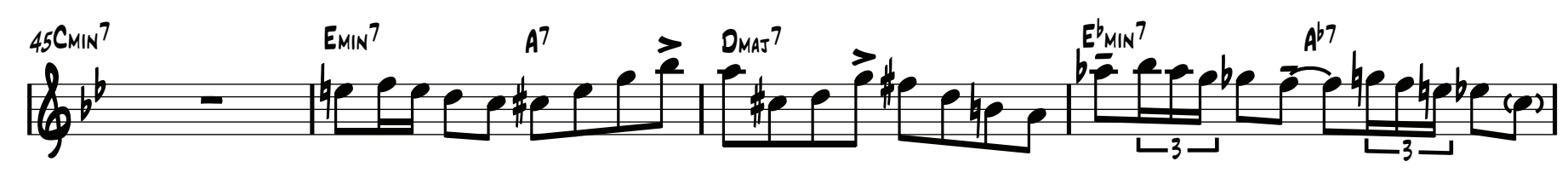

然

का

".

垈

管

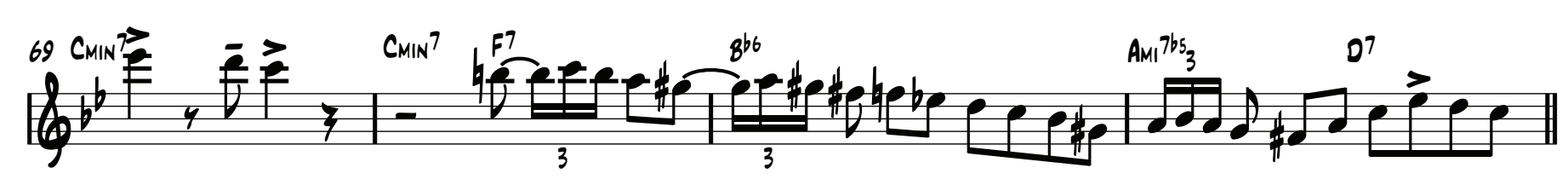

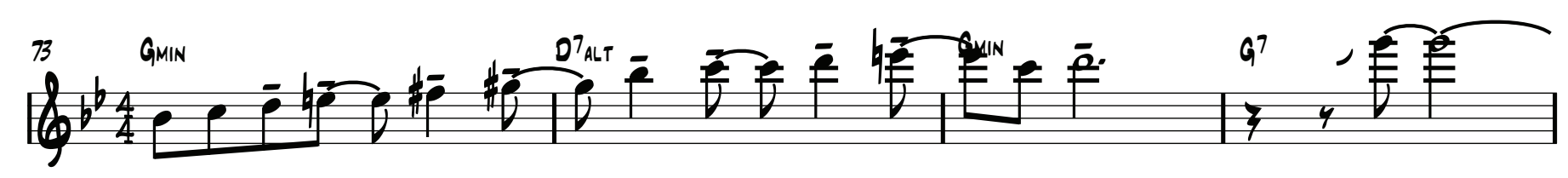

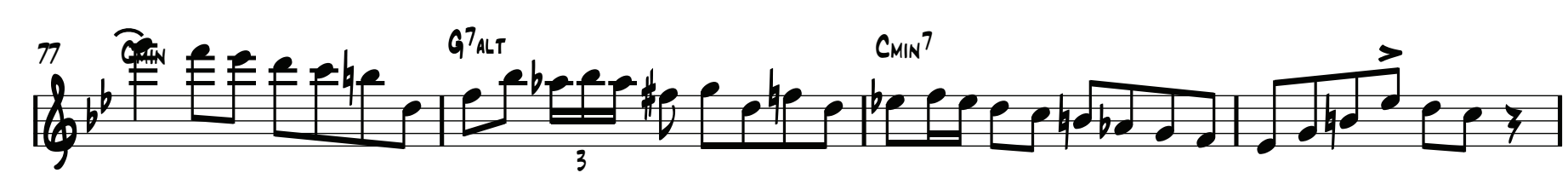


(n)

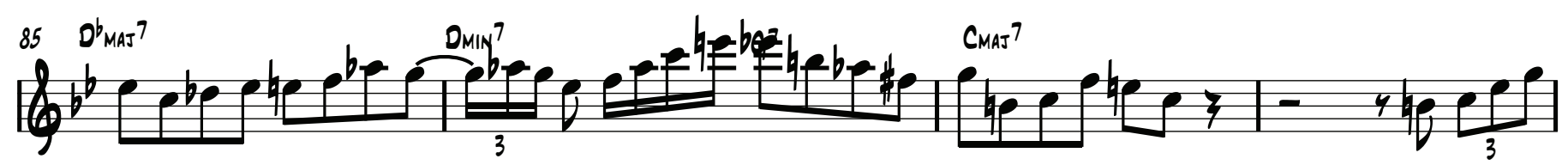
年

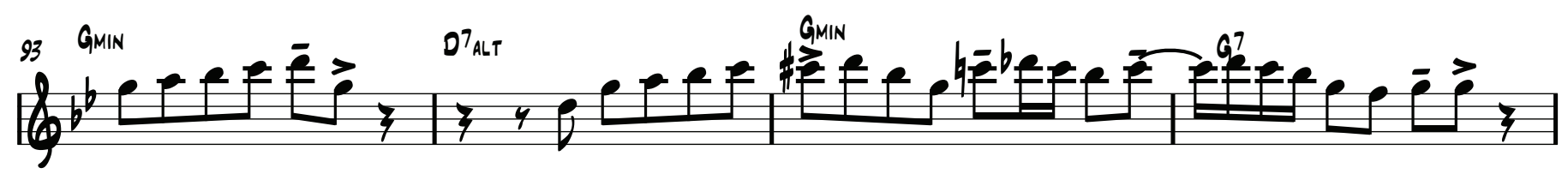

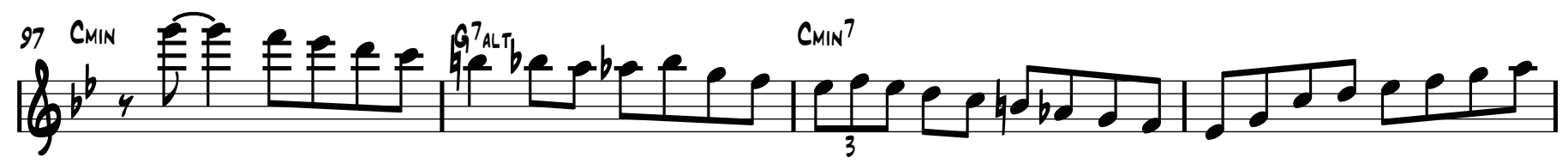

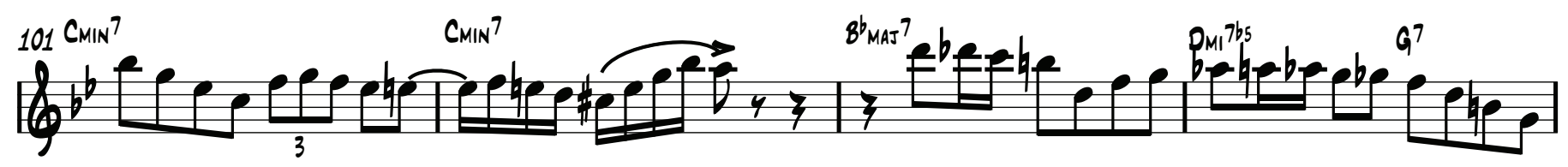

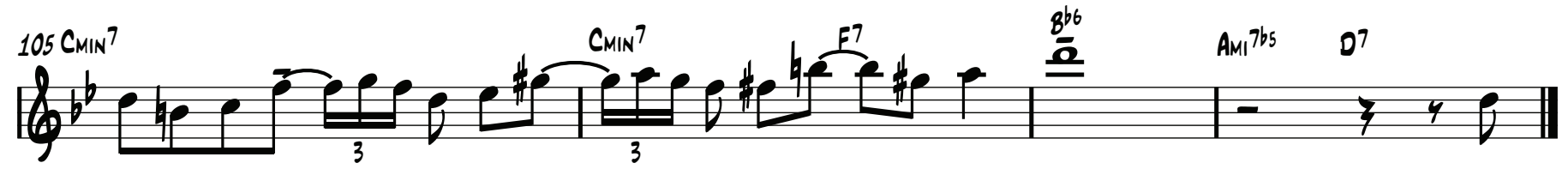

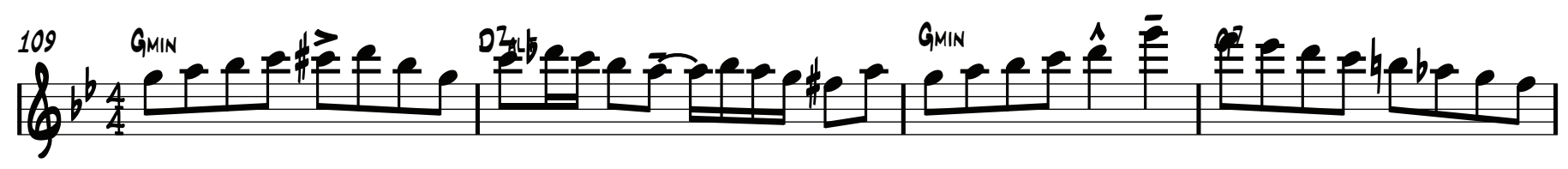
(18)

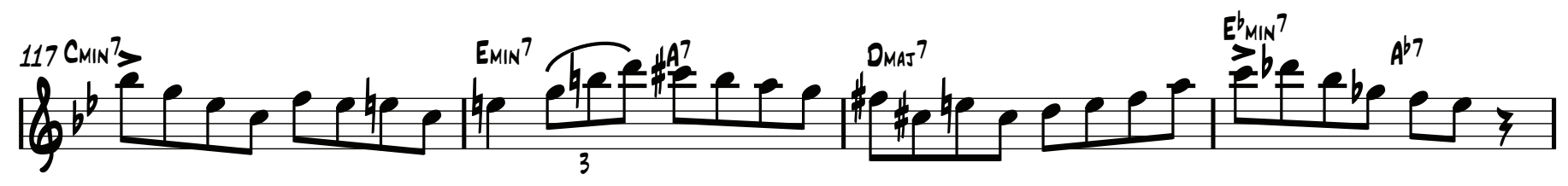




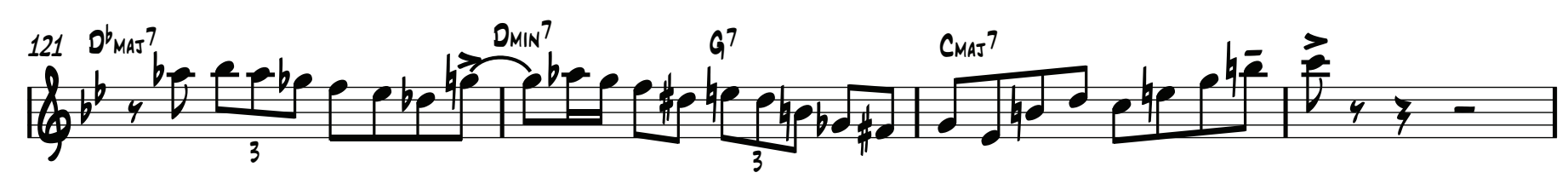
等

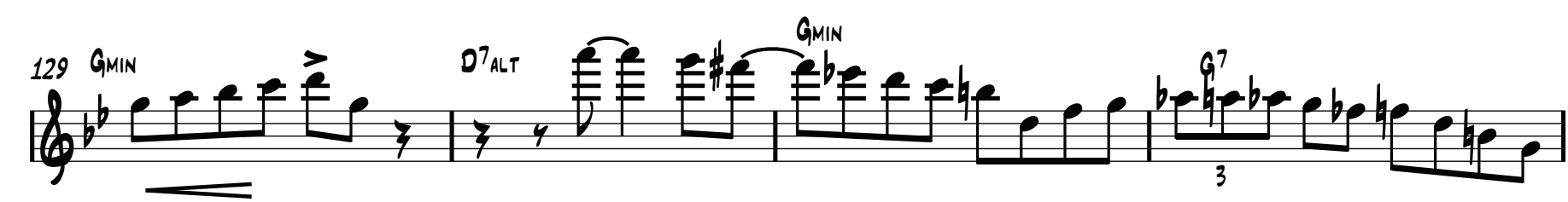

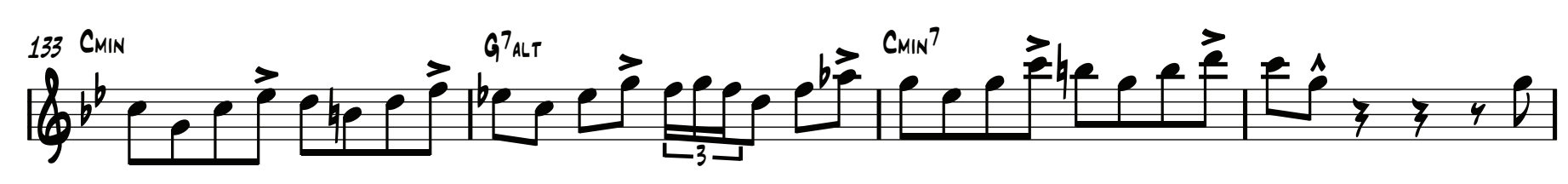

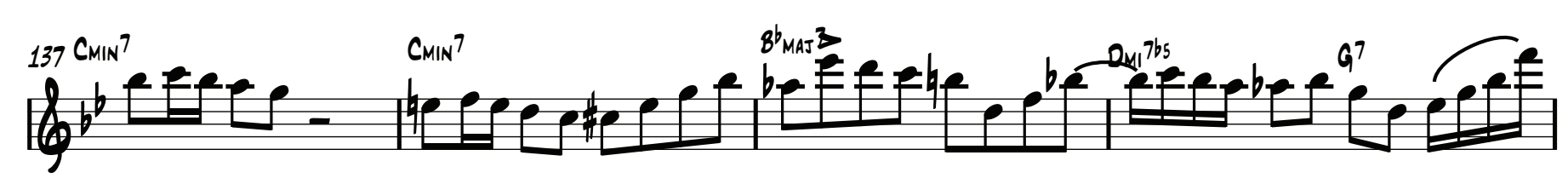

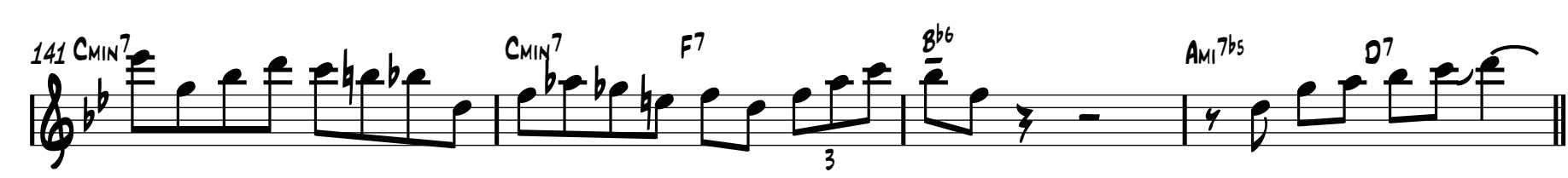

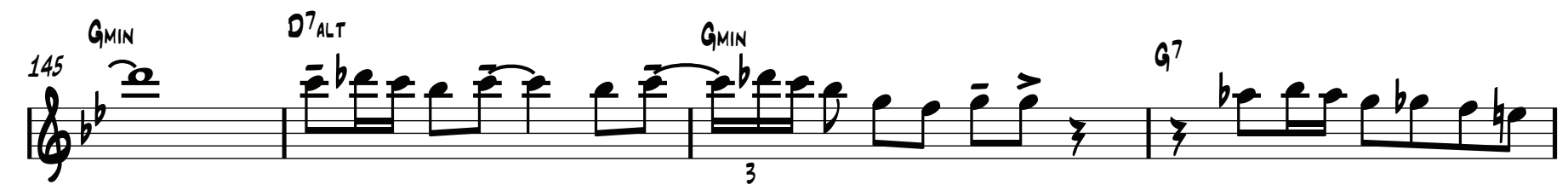

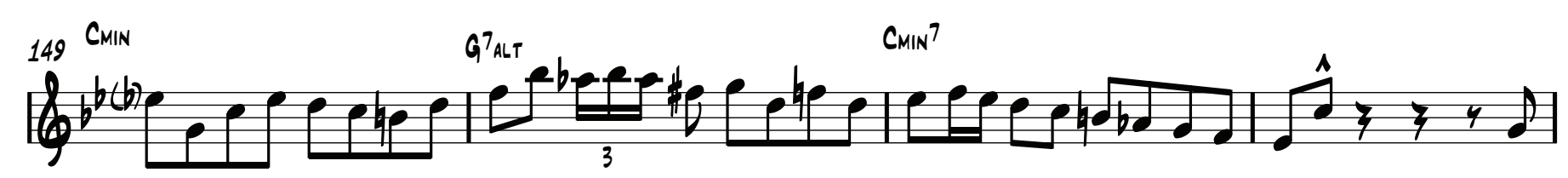
(a)

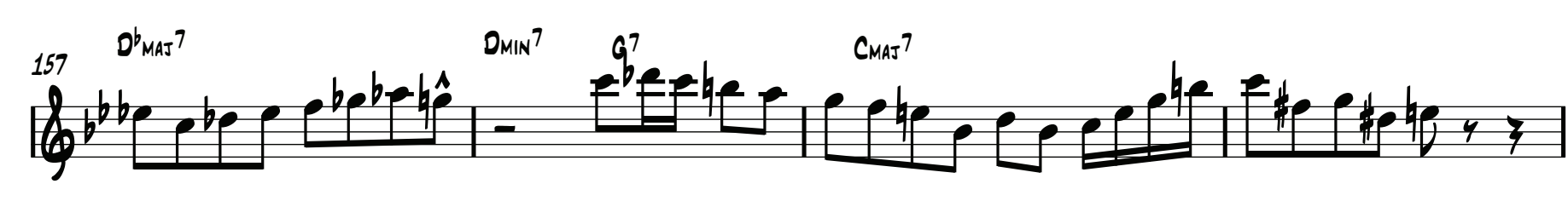


(16) cumr (t5 年9 (1)

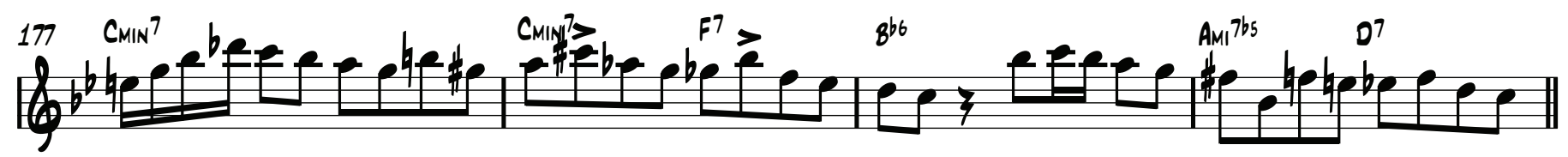
END SOLO TRADES BETWEEN SAX \& VIBES BEGIN AT 7.19 MINUTES t. (t) (a)

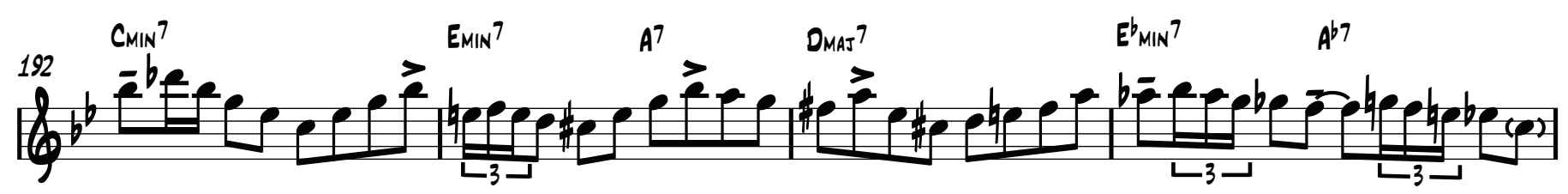
(a) 


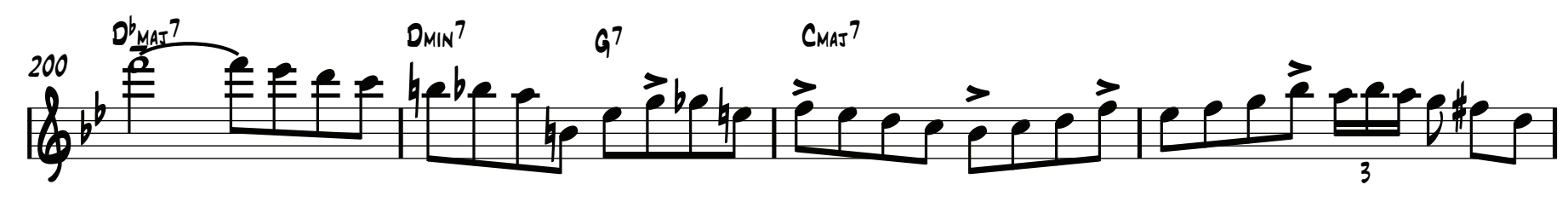

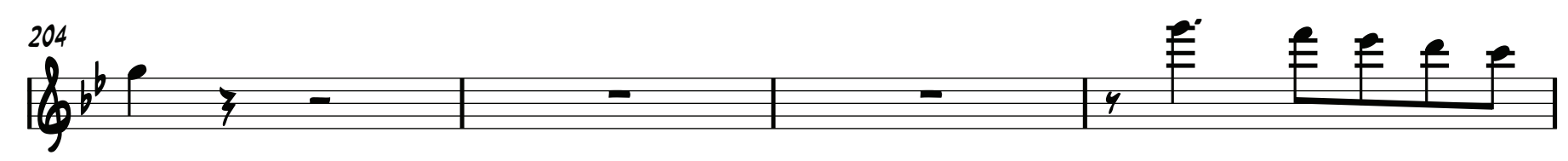

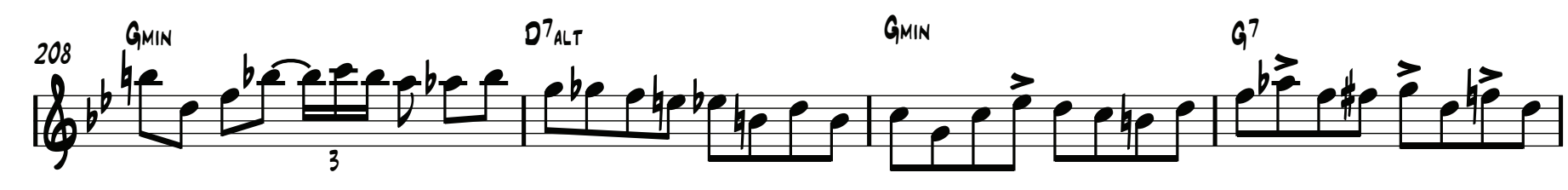

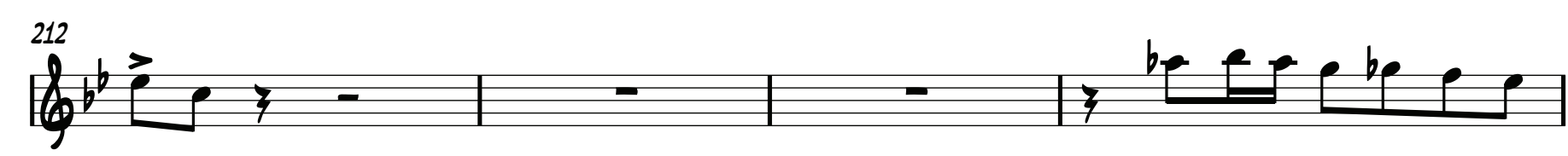

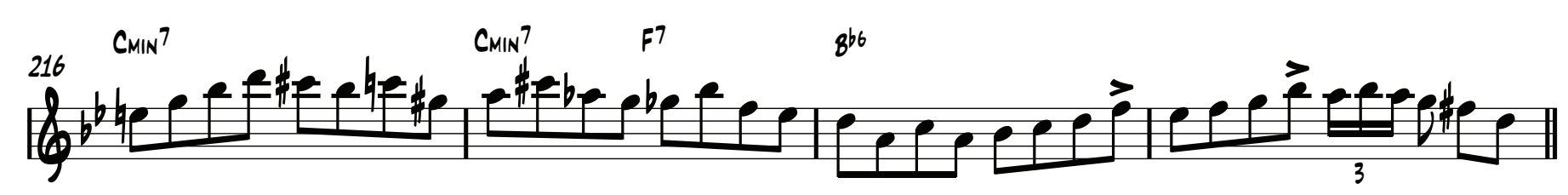
$b^{20}$

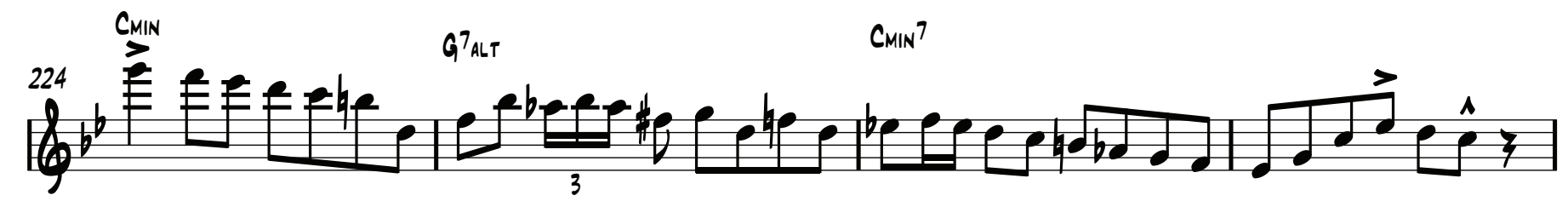
- $1=1-1-1=0$ 留

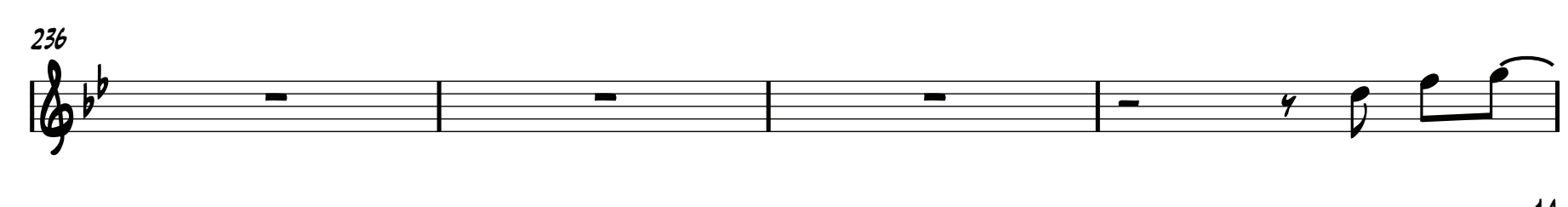


20.

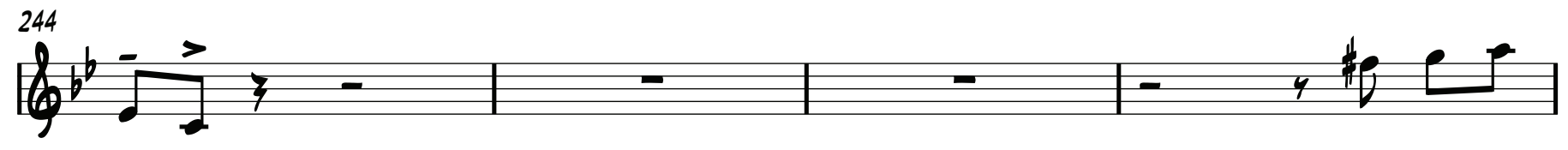

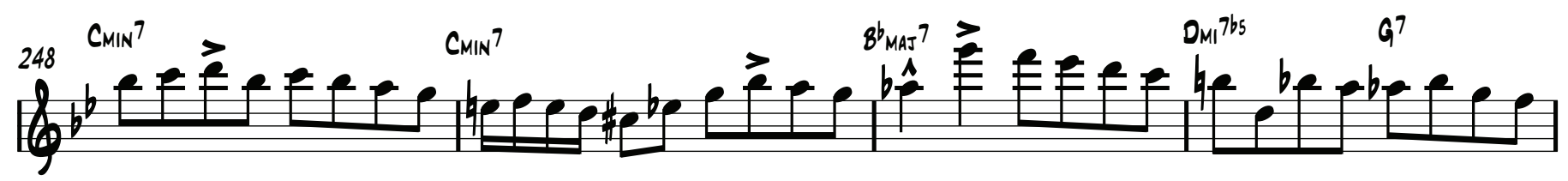

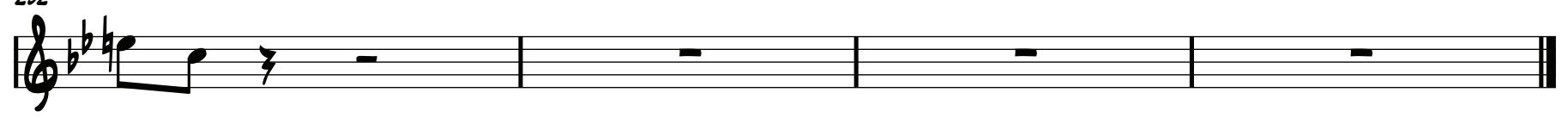




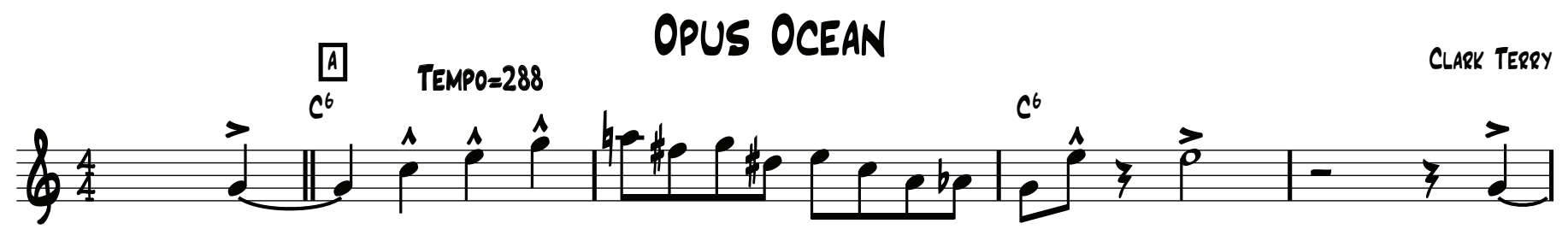

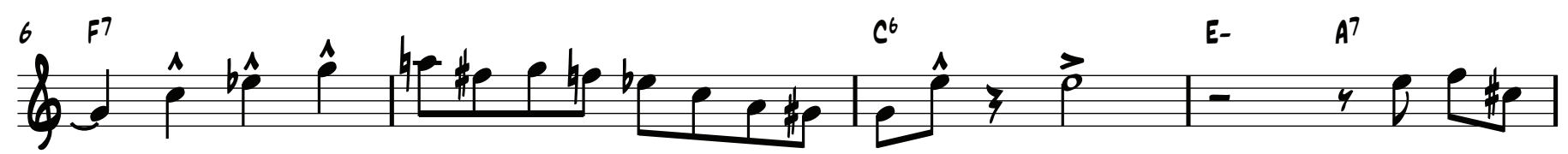

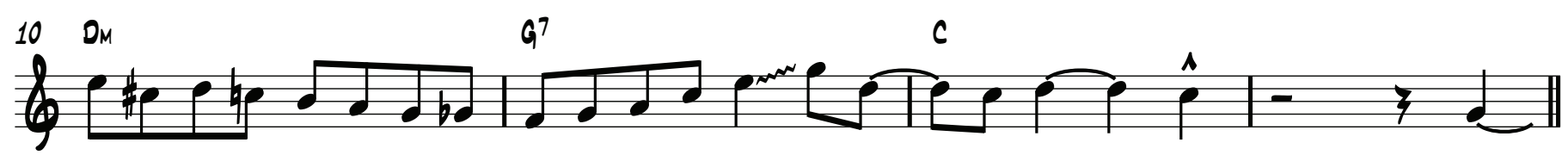

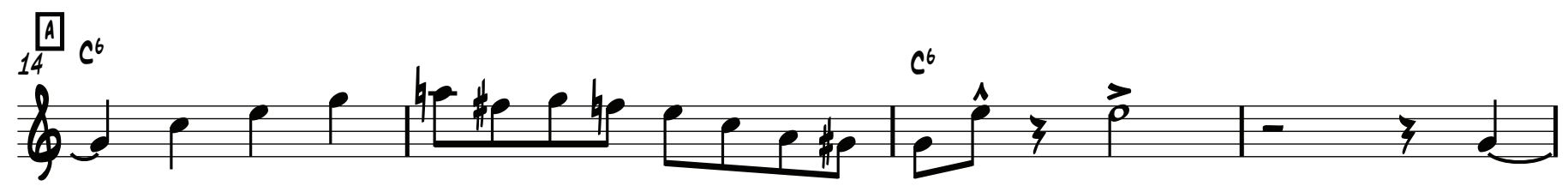
b.

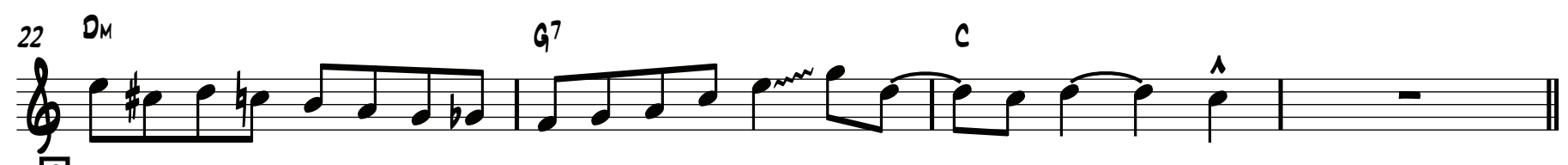
${ }_{2} \mathrm{~B}^{\mathrm{E}}$

bं i

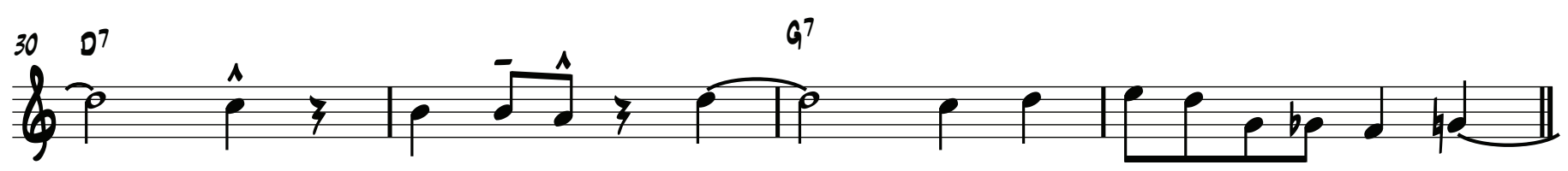
A b)

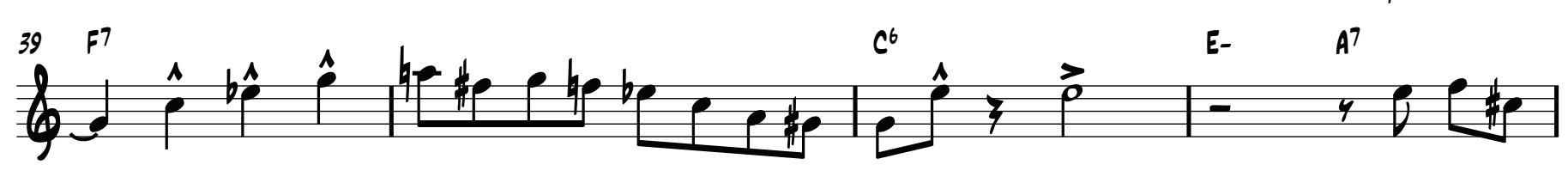

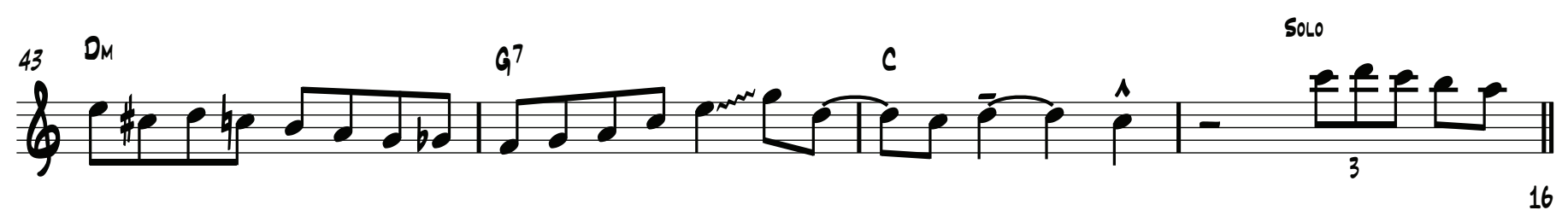




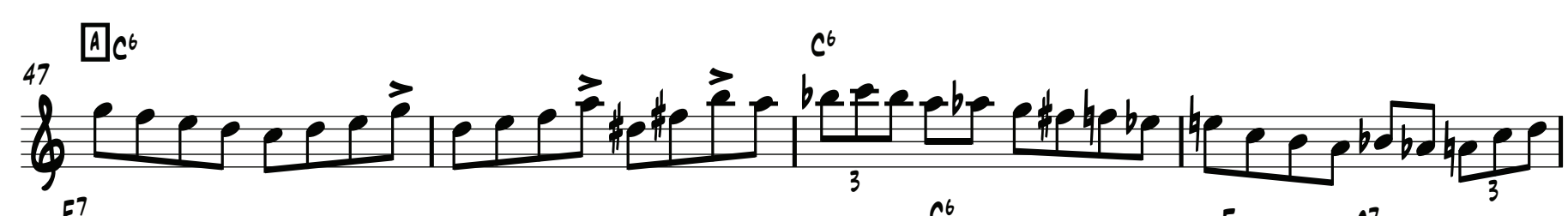

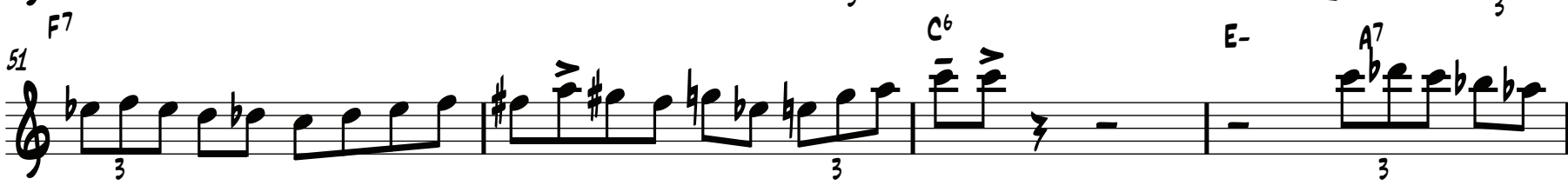
$\frac{6}{6}$.

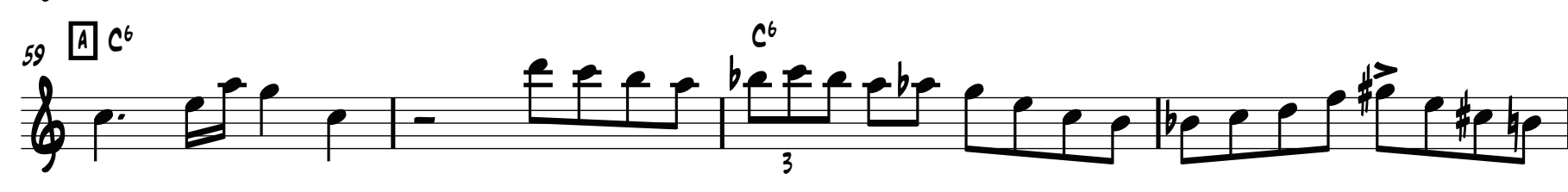
6" b) 6 国

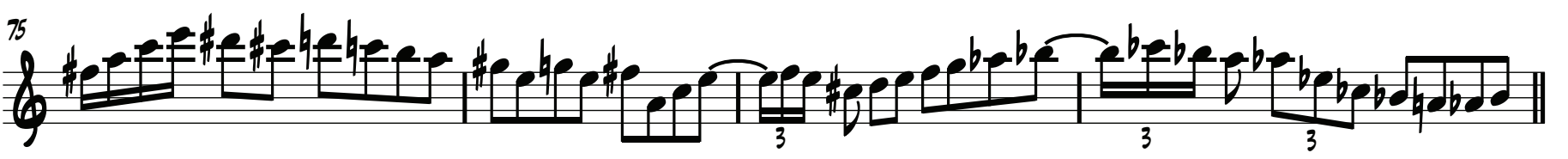

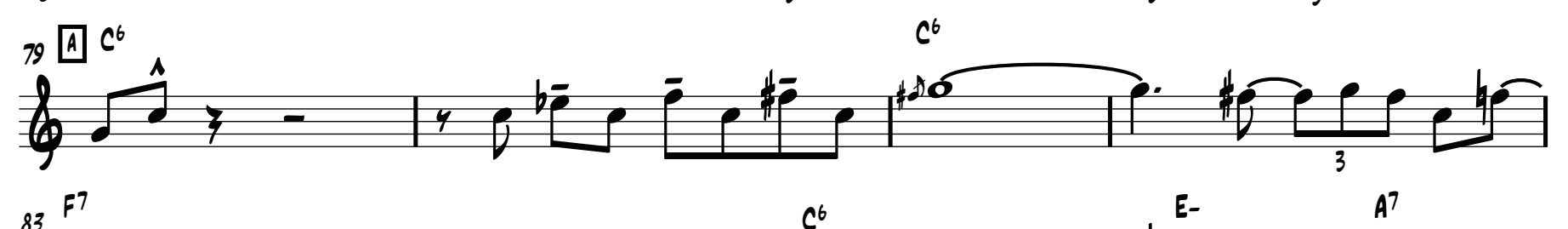

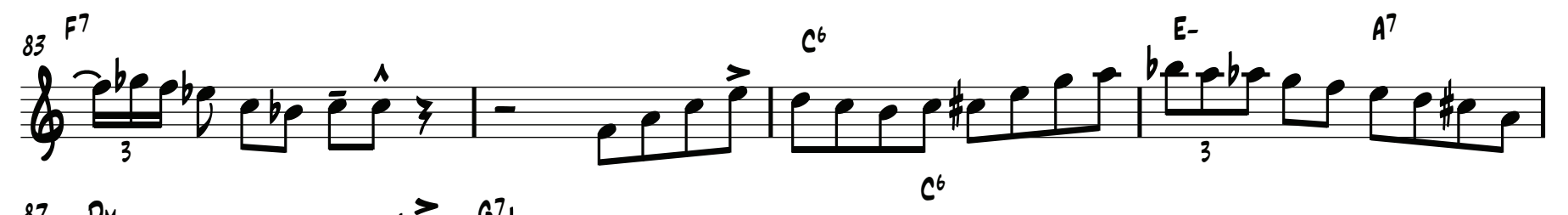
$b^{2}$ 6 
$6+10+0^{2}$

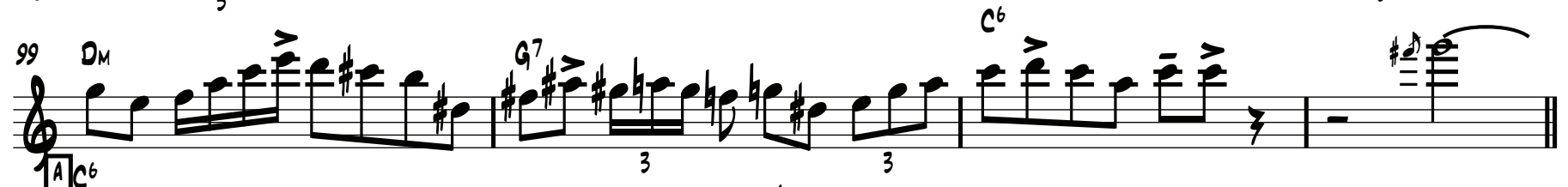

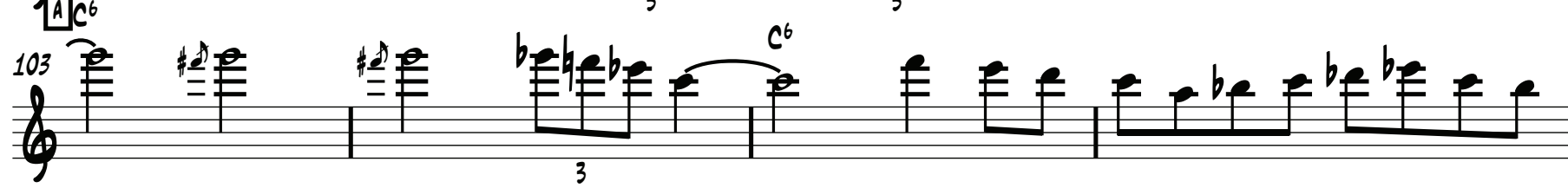
by

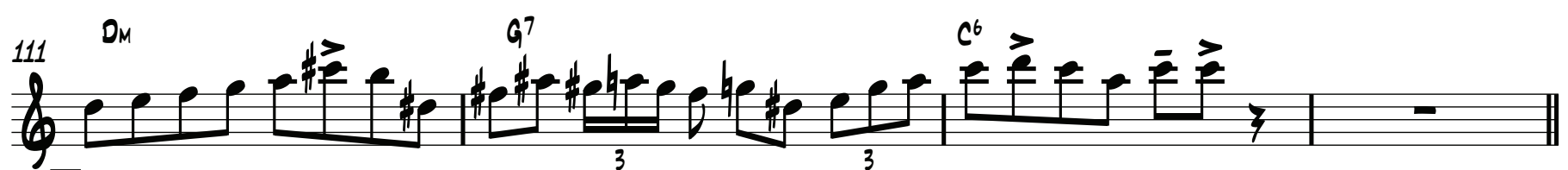

$\frac{6}{3} \frac{1}{3}$ b)

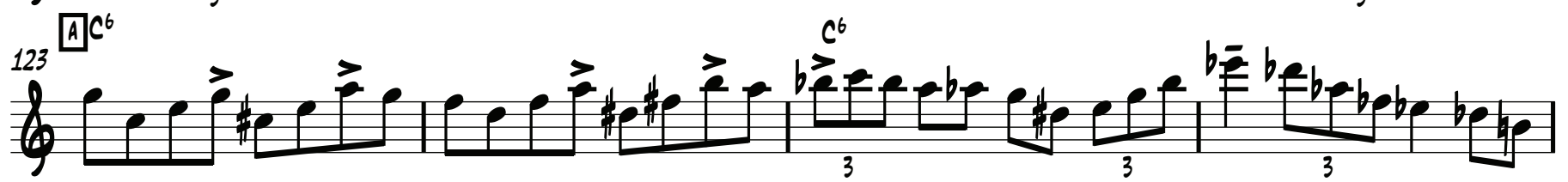

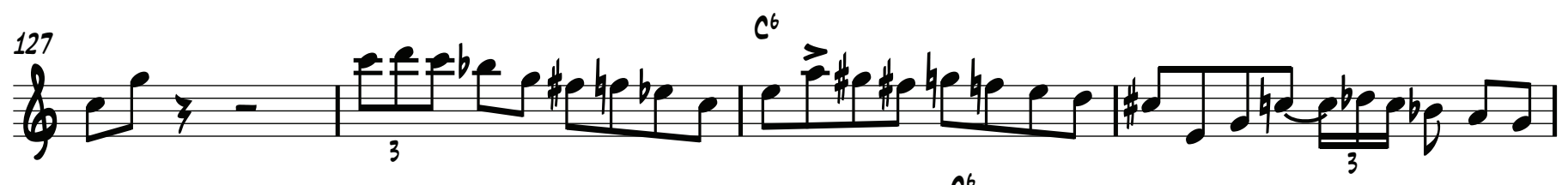
6. on ace

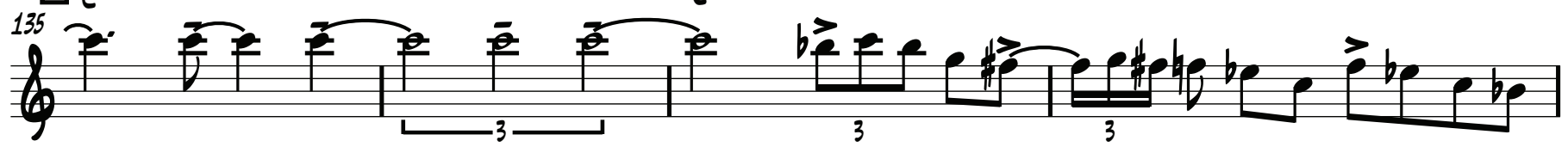

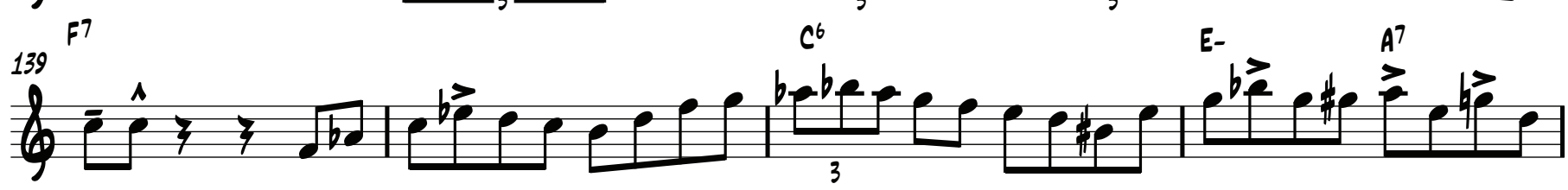




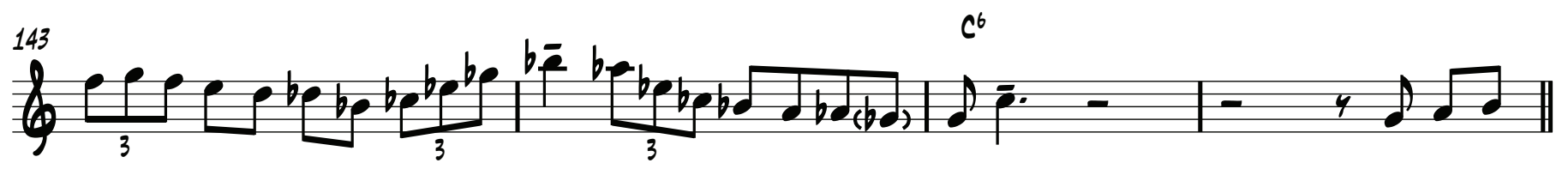

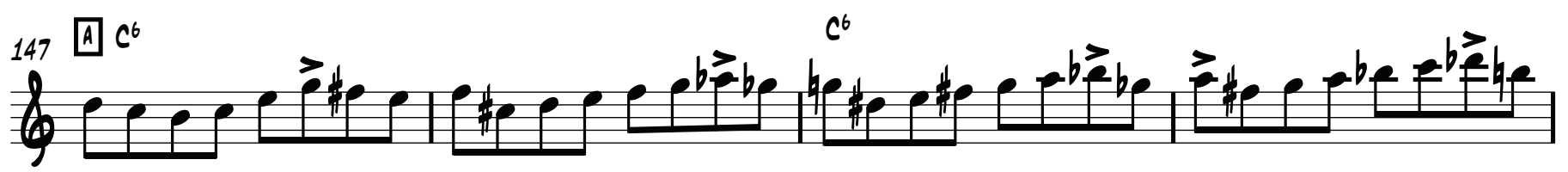
b)

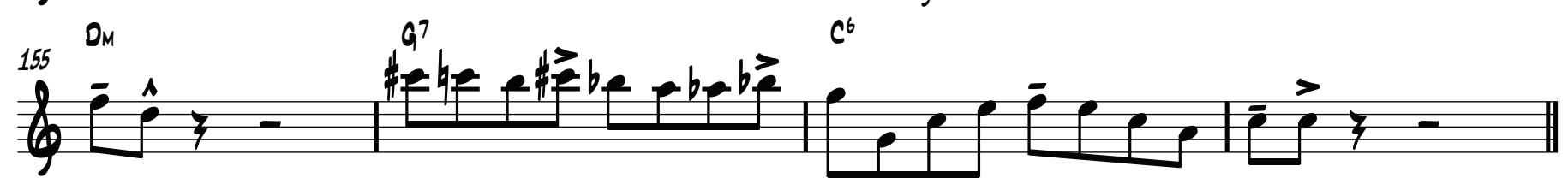
6) 6 o

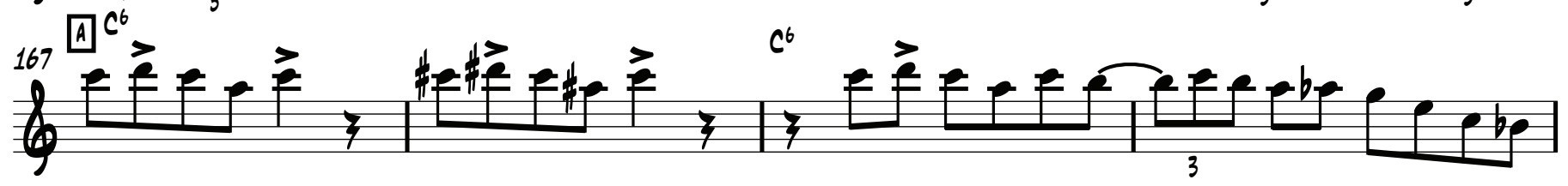

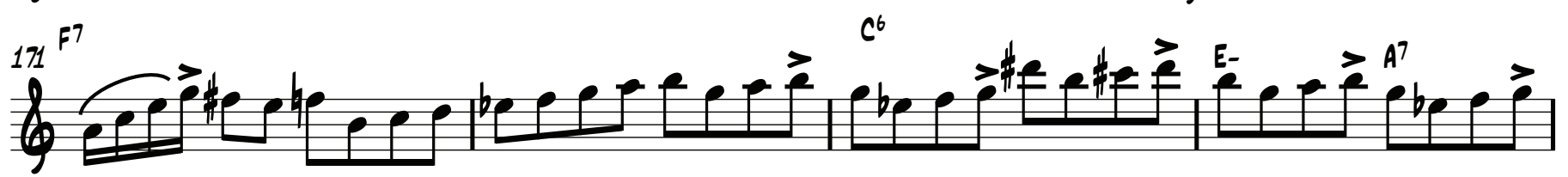

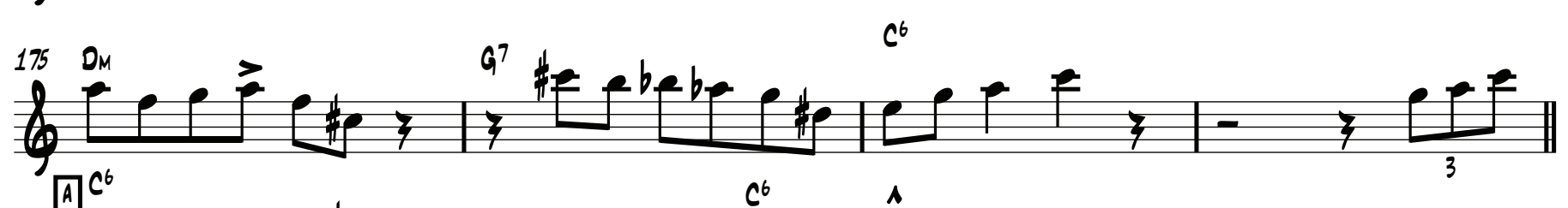

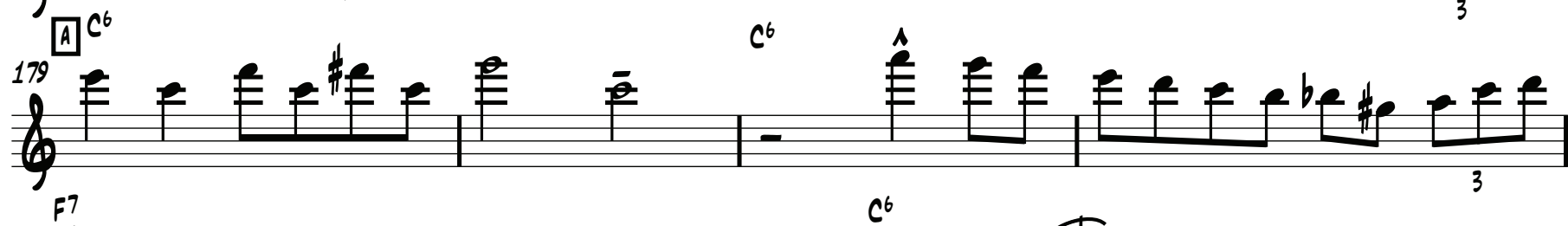

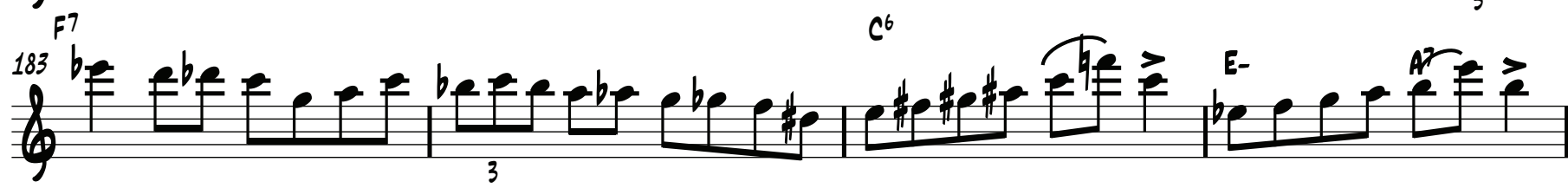

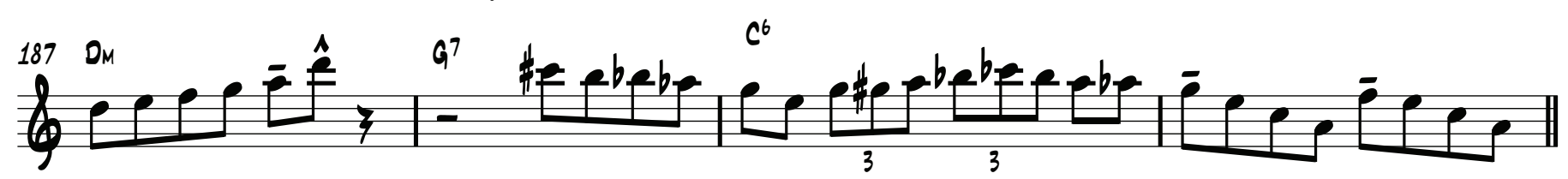


b欧
$A^{7}$

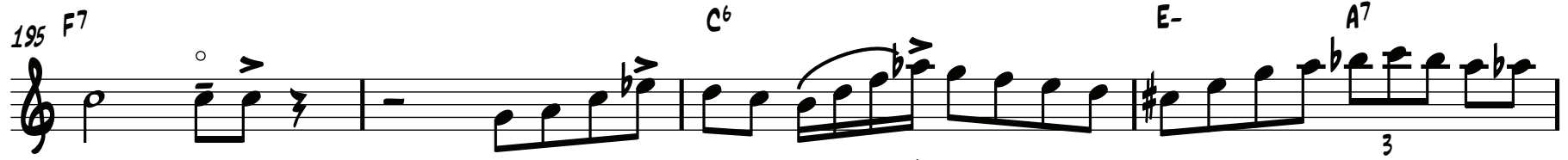

$b^{2 g^{57}}$

(195

$199{ }^{D_{M}}$

(4) $2070^{07}$

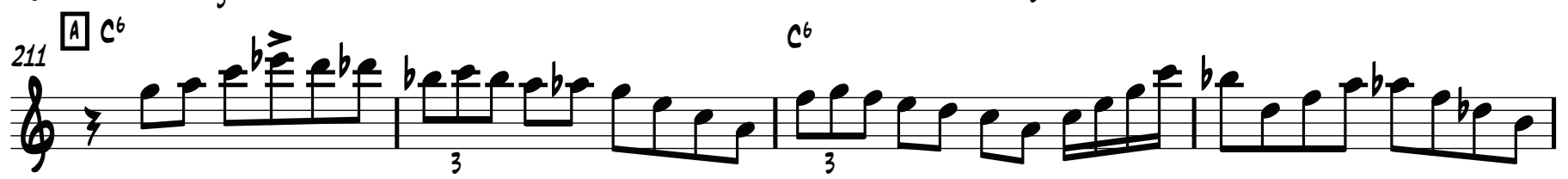
$f_{6}^{215^{77}}$ $f_{(0)}^{219} \stackrel{D_{M}^{2}}{a^{7}}$ 223

(⿻) SOLOS: TPT, PAANO

225 TRADES WITH TPT BEgIN AT 6.07 MINUTES

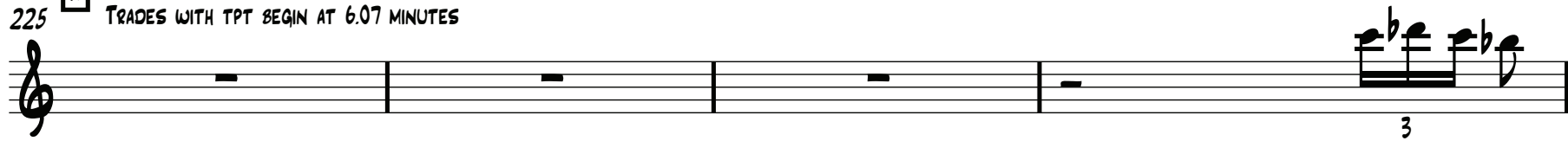

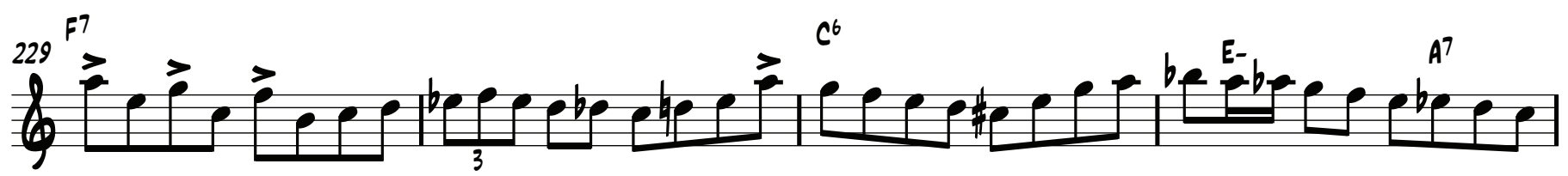

(a) 


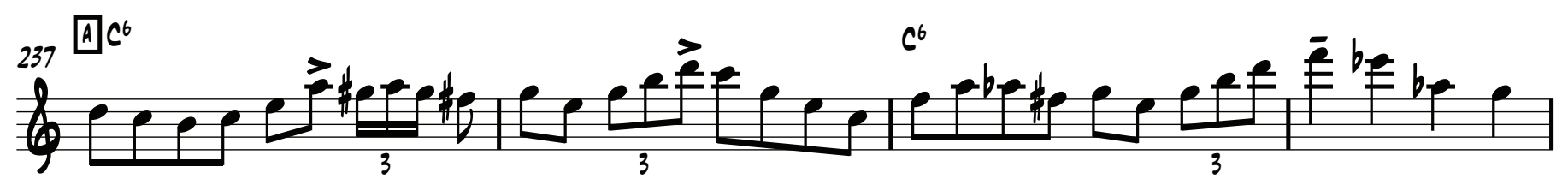

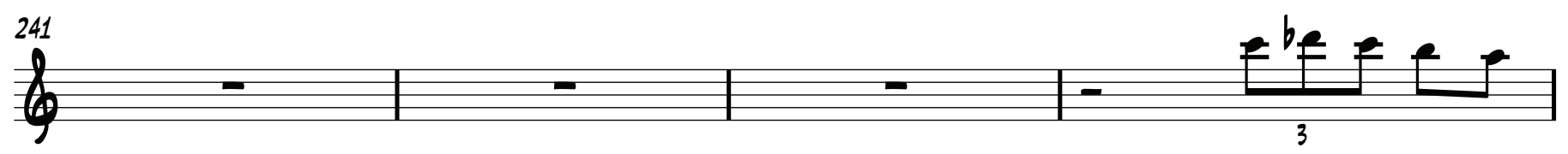

$\frac{6}{6} L^{20}$

然

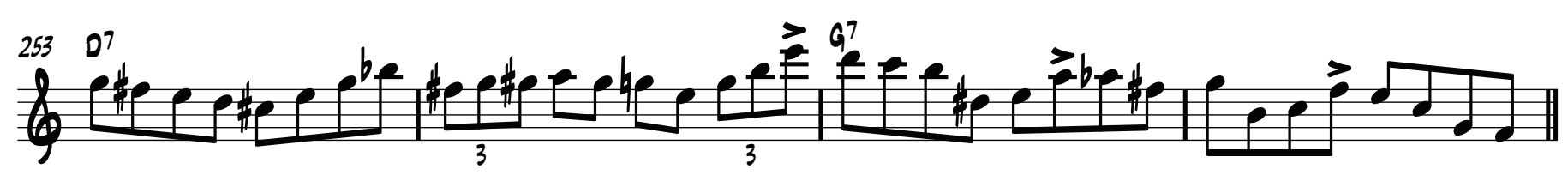

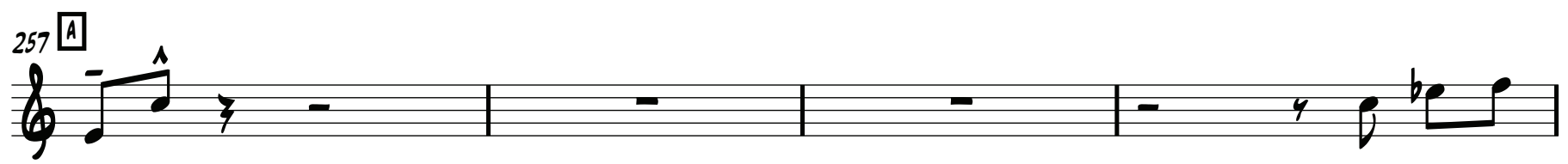

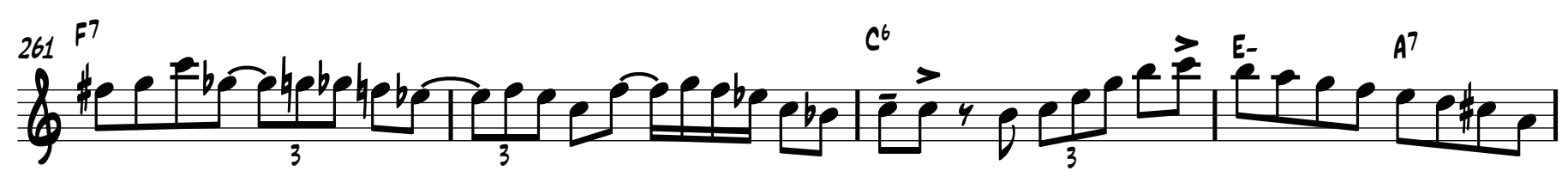

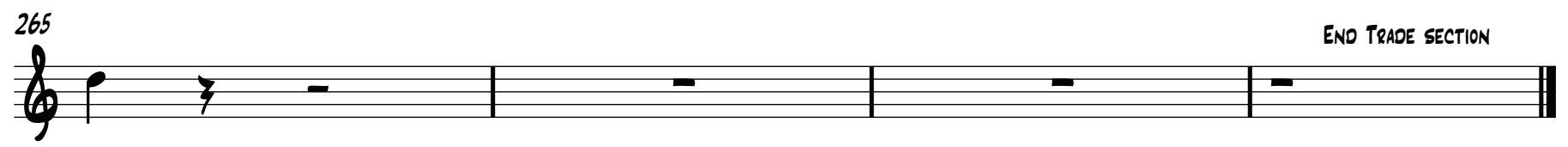

$c^{6}$ 
TRANSCRIBED BY A R ALTON-LEE

TEMPO $=200$

G-7

SOON

D-7

FMAJ $^{7}$

C.\$\$ $\$$ \$9

GEORGE AND IRA GERSHWIN

5 FMAJ $^{7}$

0769

G-7

$C^{7} \quad F \$ 7$

7

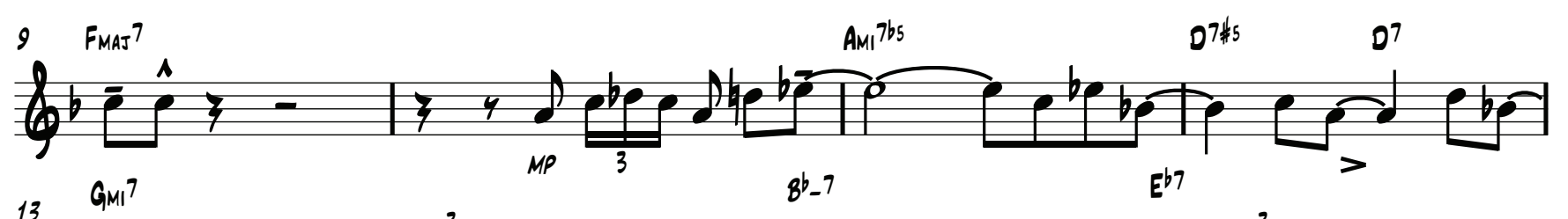

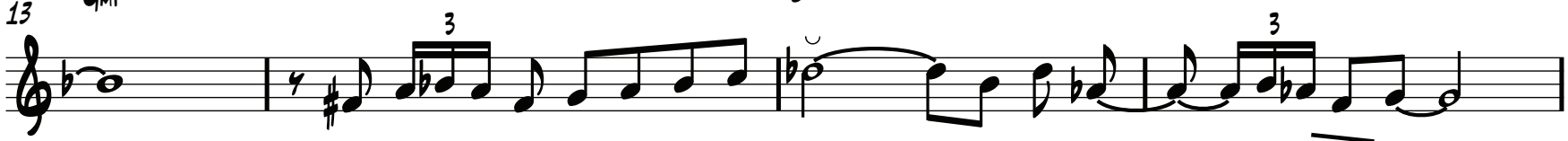

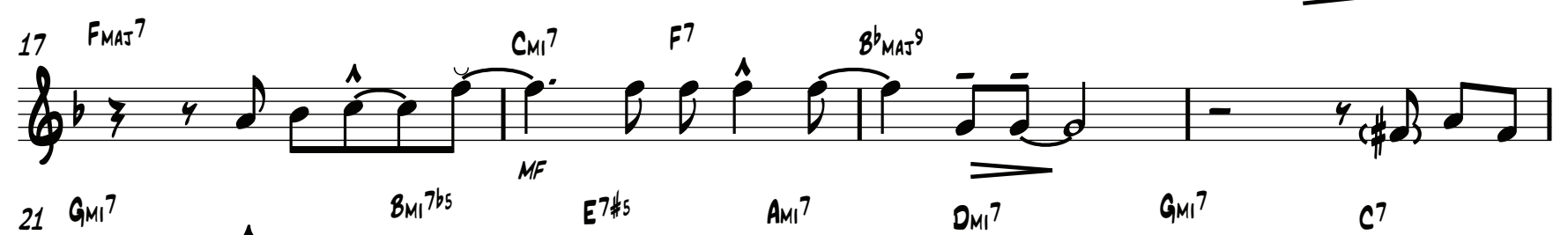

$21 \mathrm{GMI}^{7}$

${ }_{25 \mathrm{GMI}^{7}}^{25}{ }^{\mathrm{MMA}^{7}}$

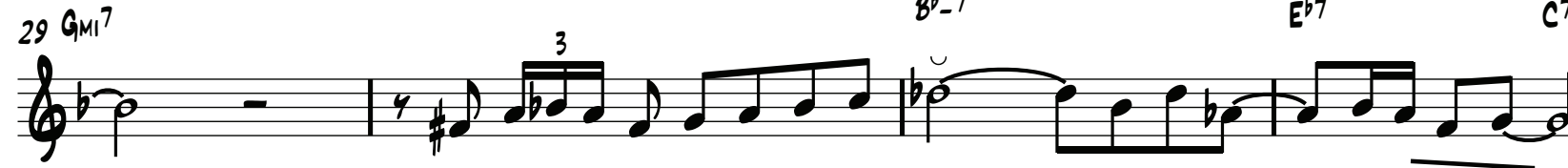

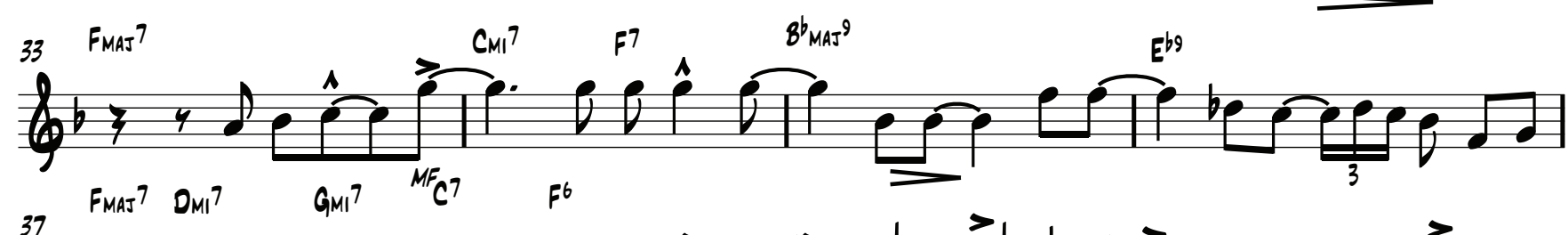

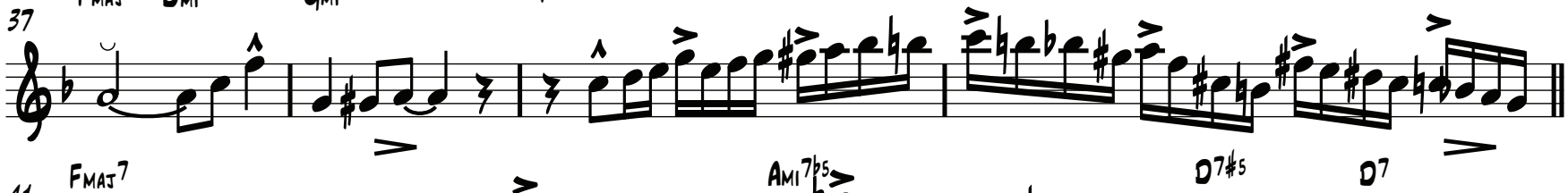

by

$b^{45} \cdot \cos ^{-1} \hat{f}$

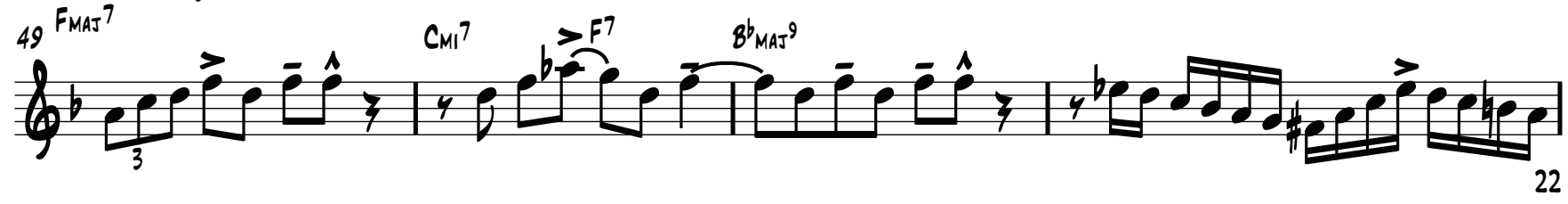




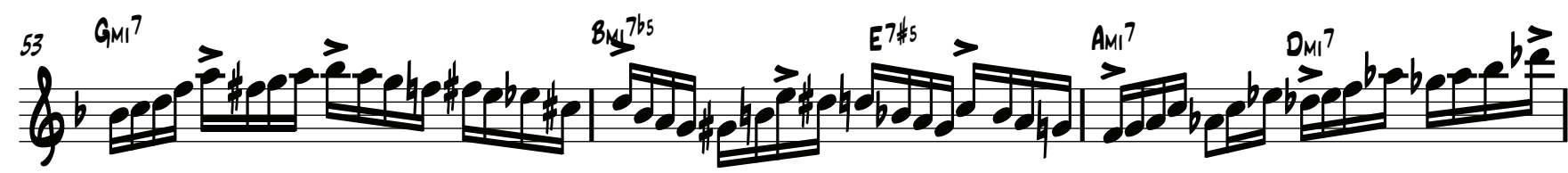
b.

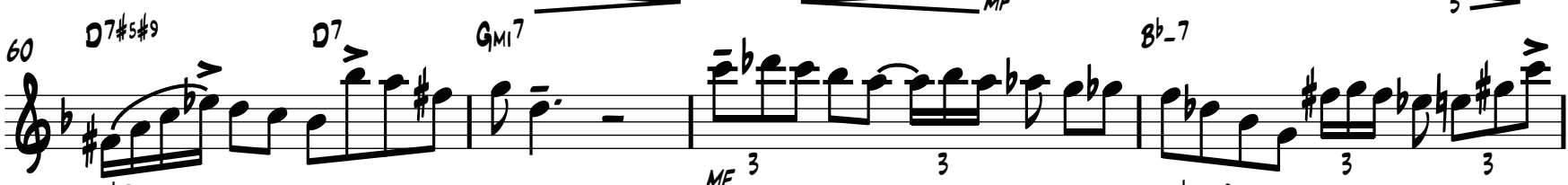
6) "Es E

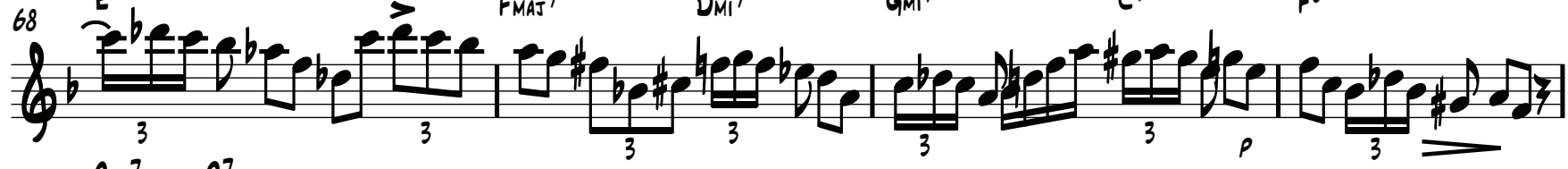

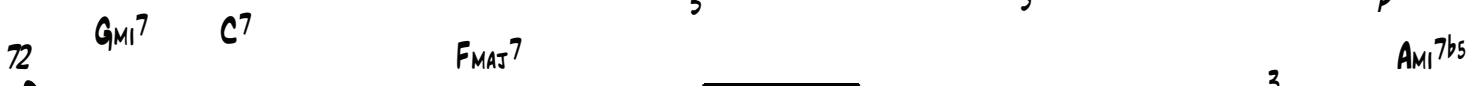
b- "०C 6) w $0^{\text {ch }}$

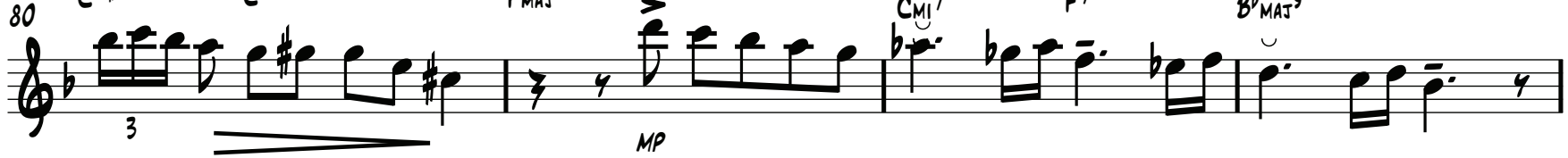
6.

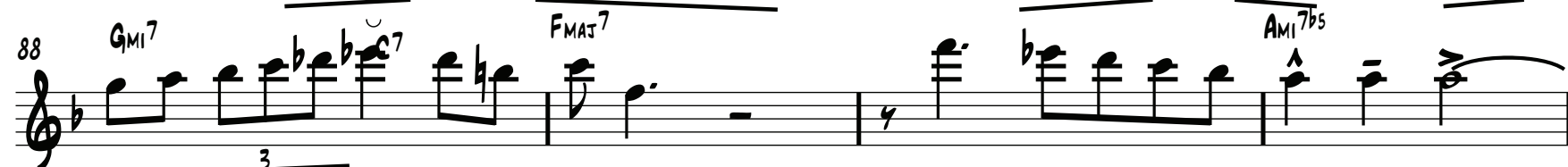

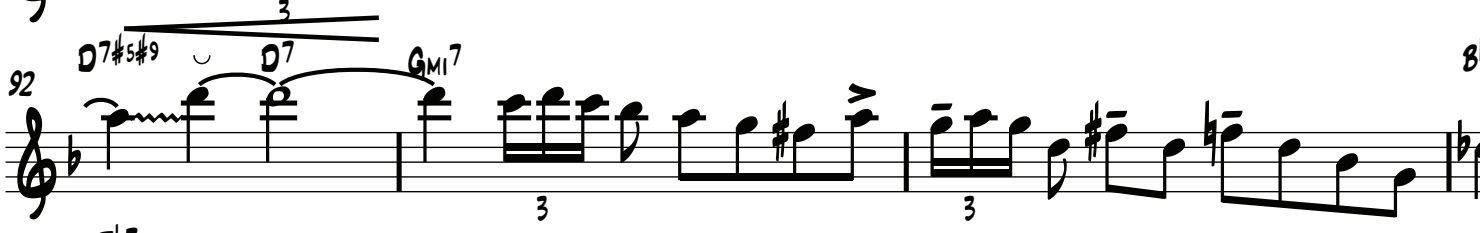
"6)

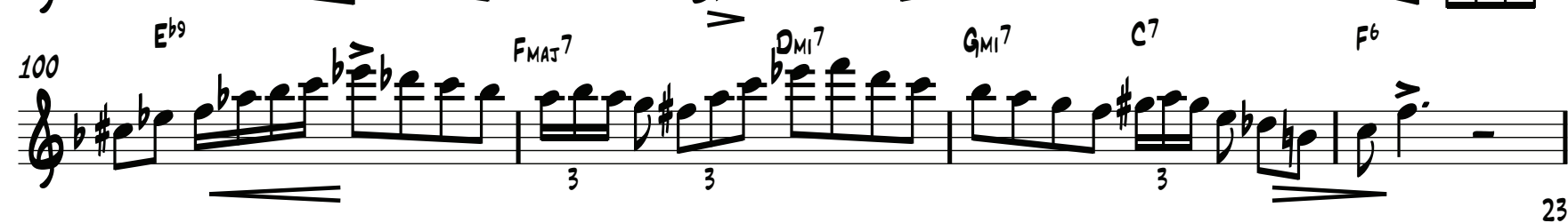


ber bon b"

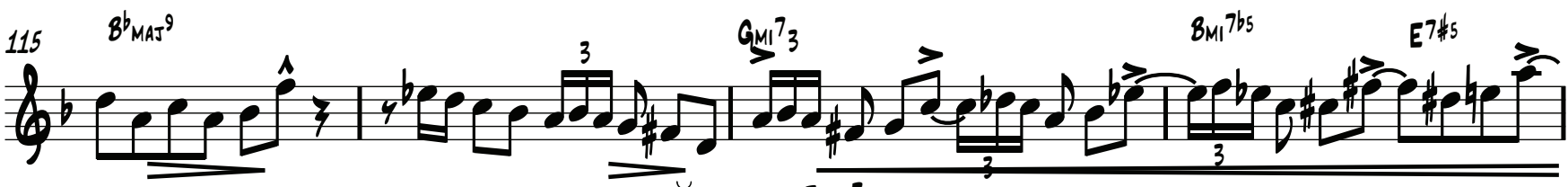
6)

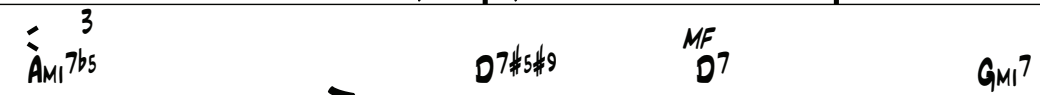

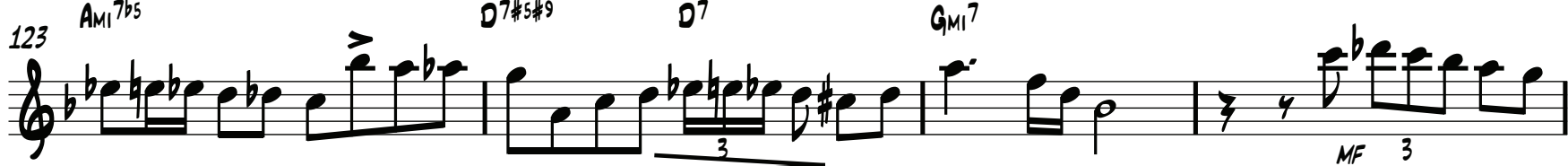
by bis

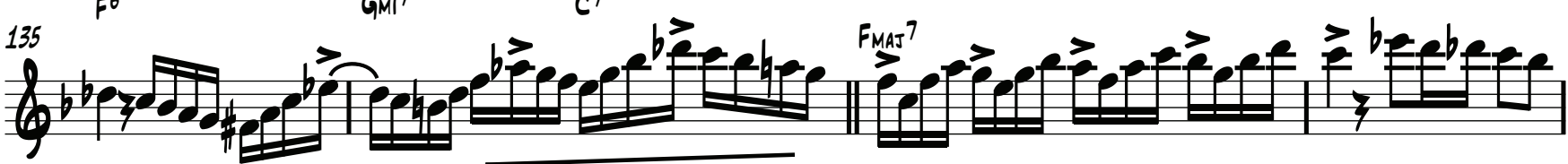
6)

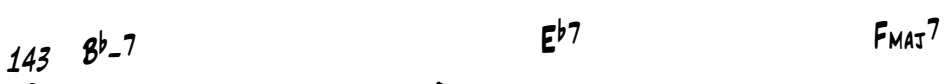

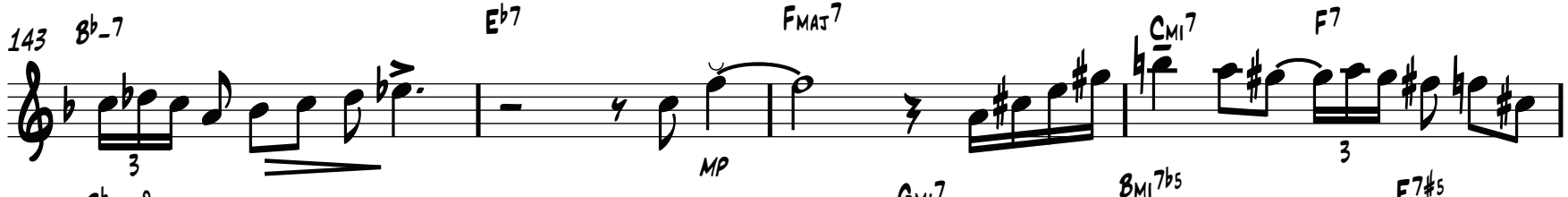
the suri

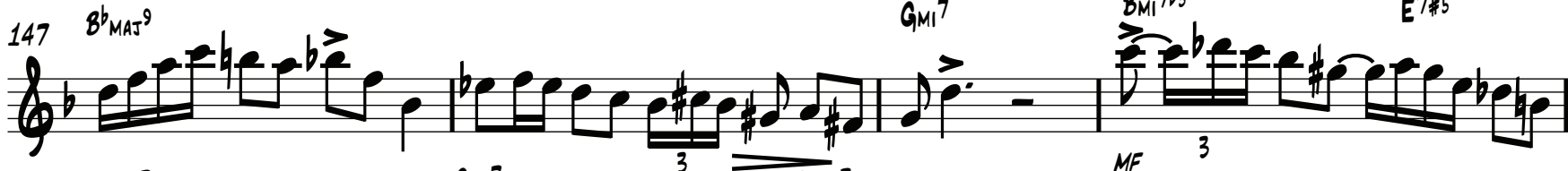
bis 
bin

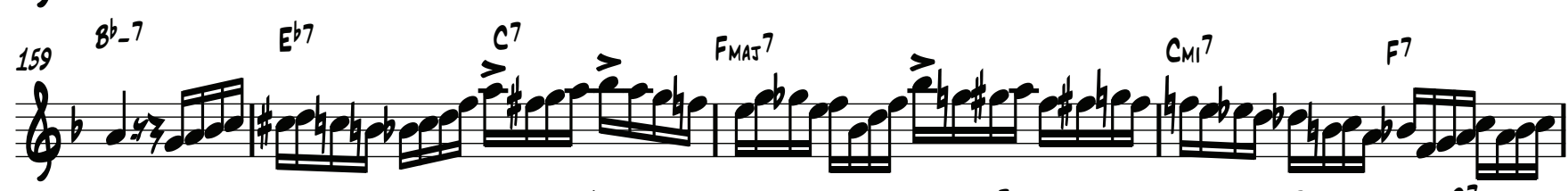
6he

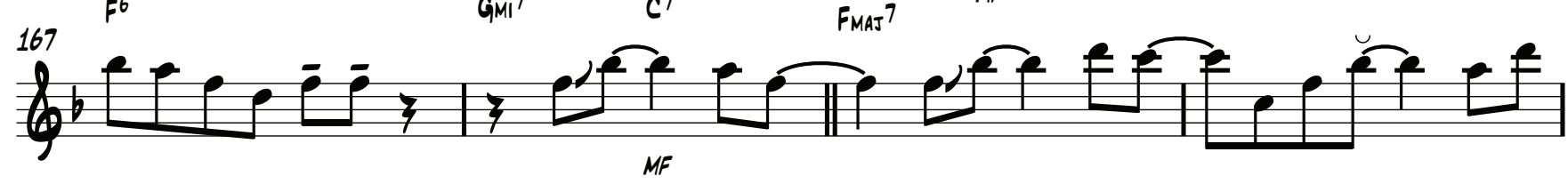

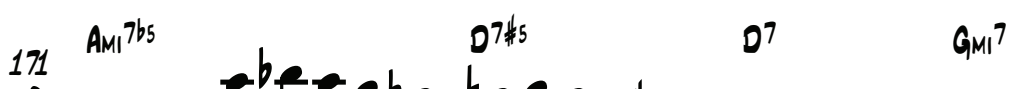

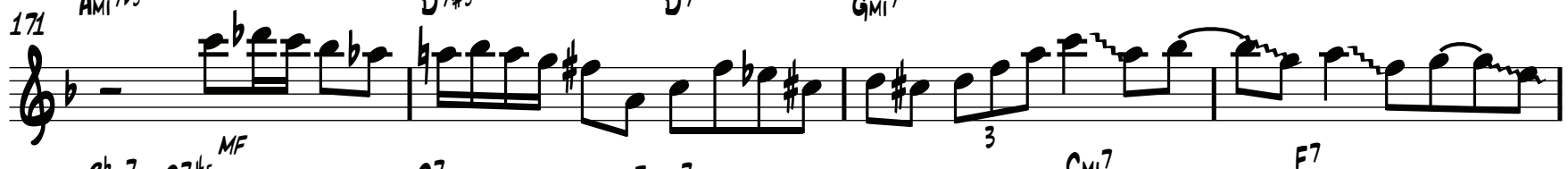

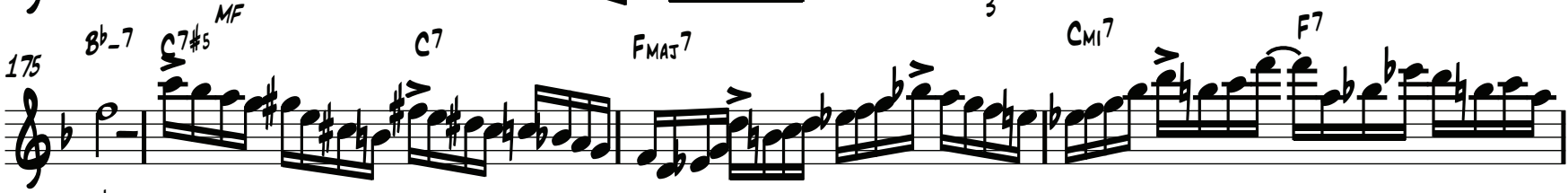

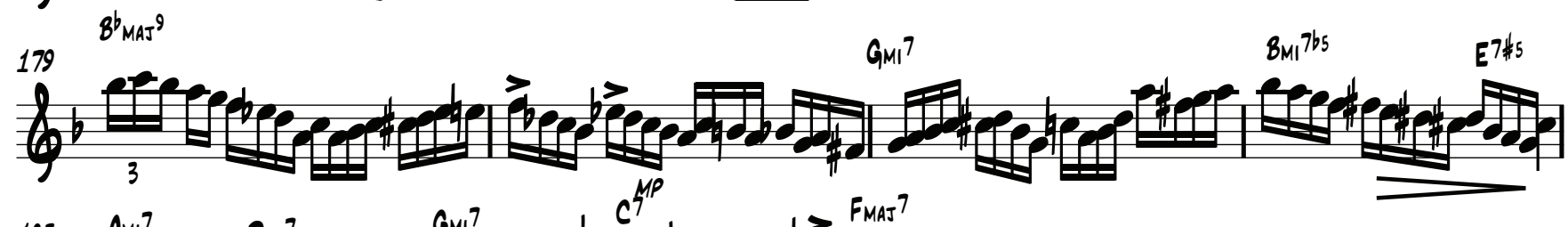

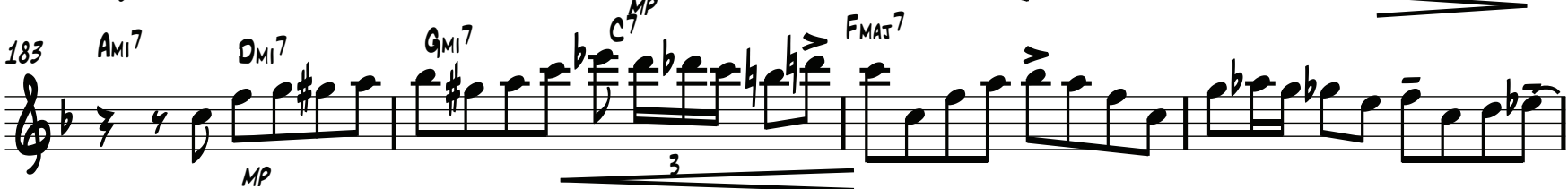
6010

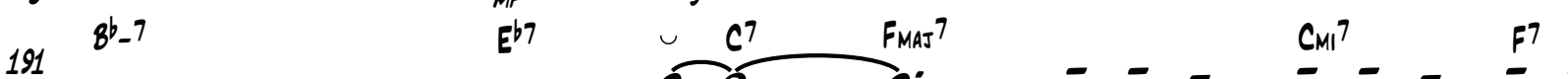

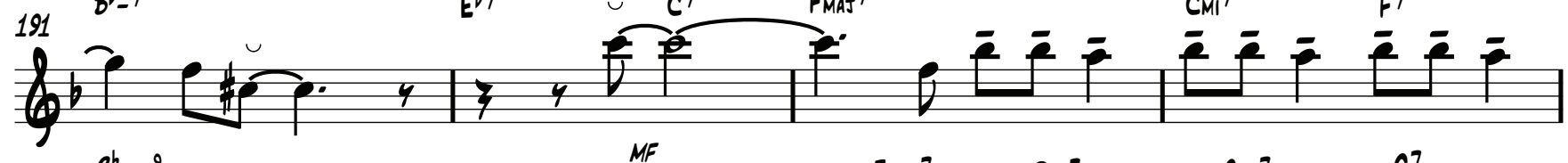
(15) (19) 6 sons 
620

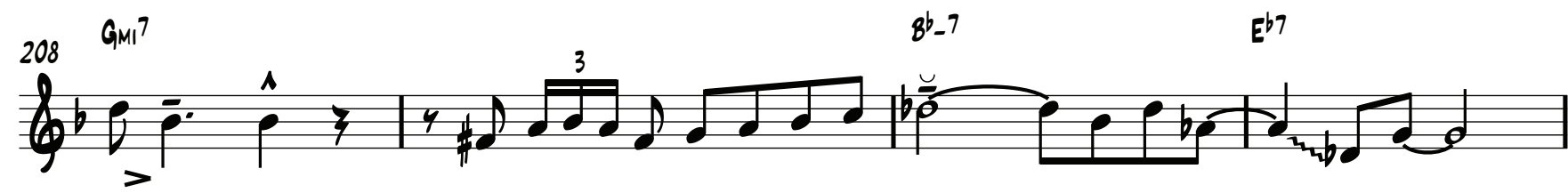

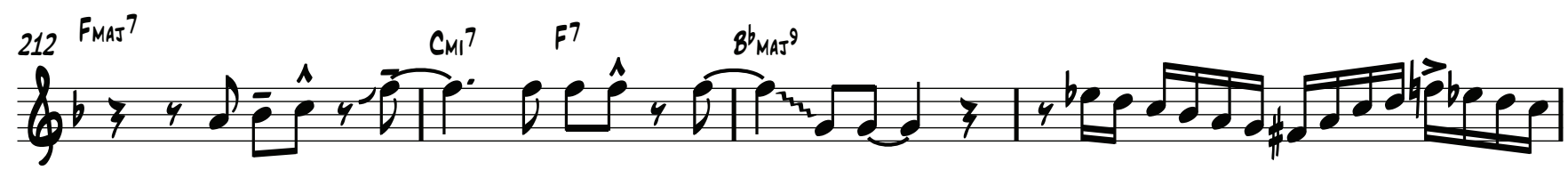

G.

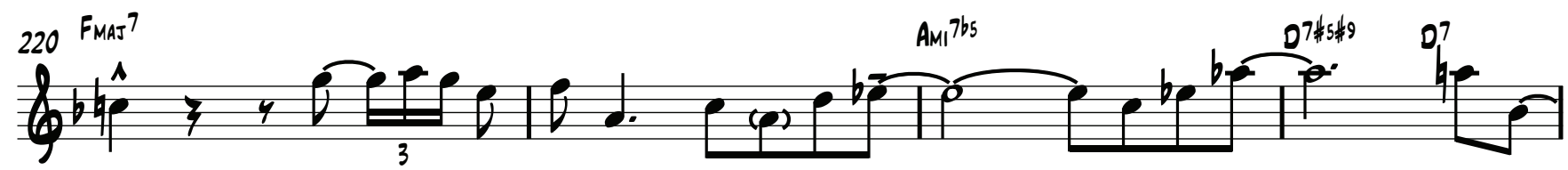

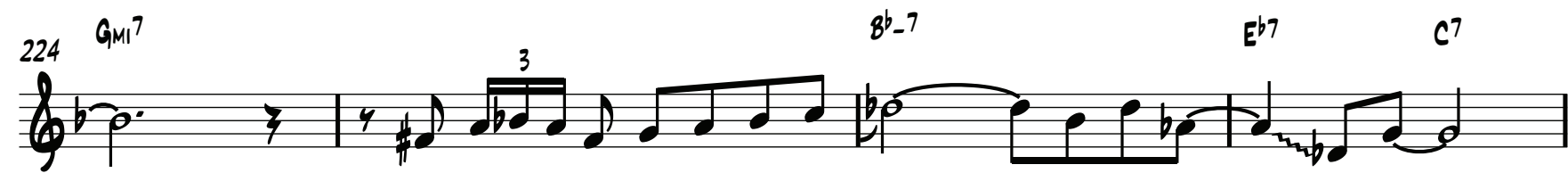

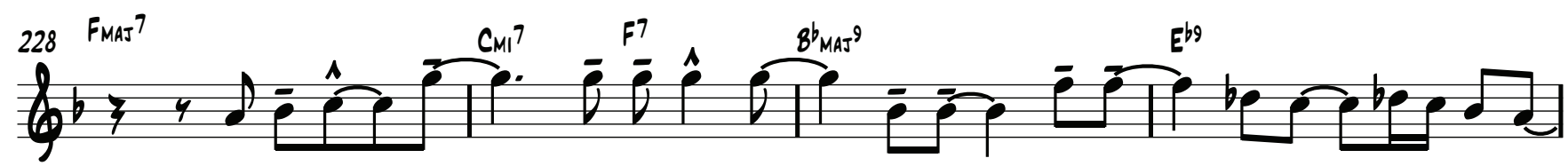

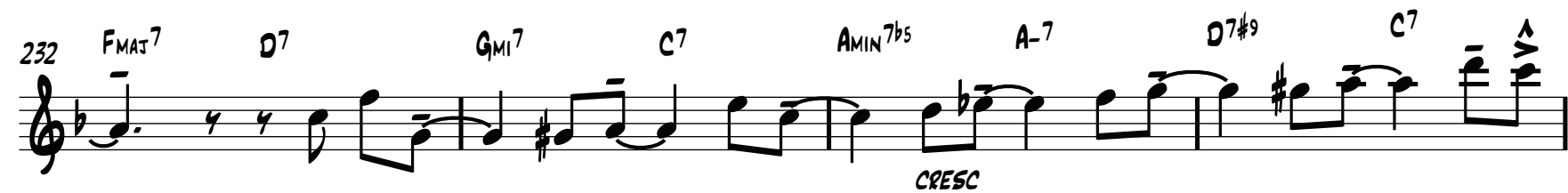

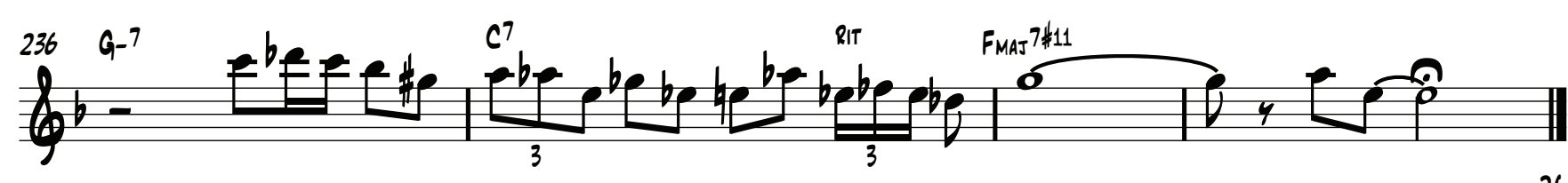


TRANSCRIBED BY A R ALTON-LEE

Doxy

TEMPO =116 F7 $\quad D^{7}$ ALT $\quad G^{7} \quad C^{7} \quad P^{7} \quad$ SONNY ROLLINS

bat.

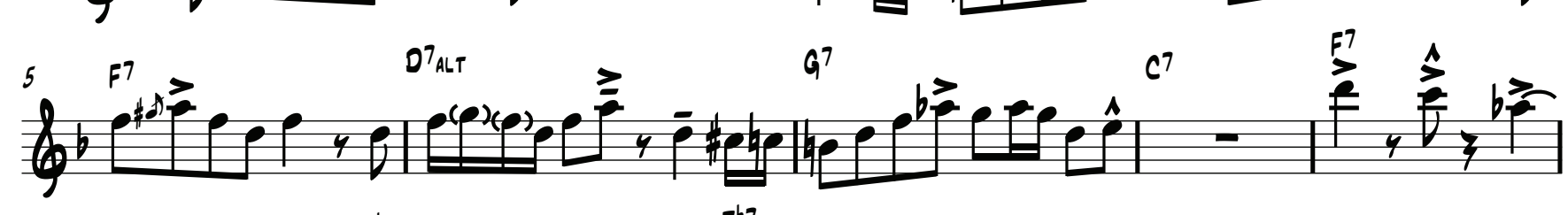

6)

by -

bis

br enter

6)

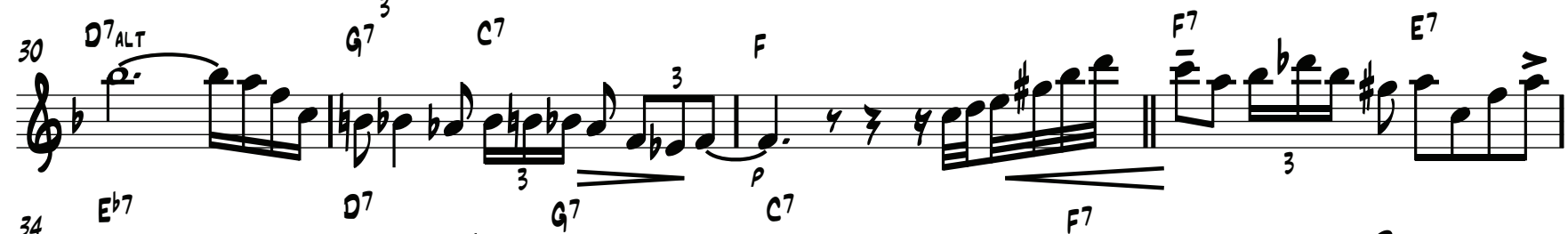

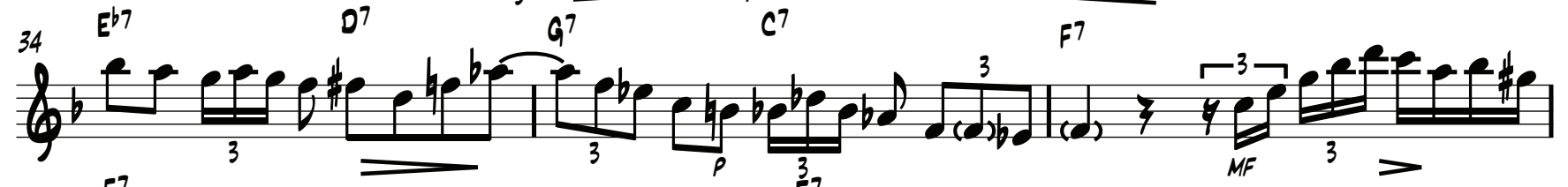

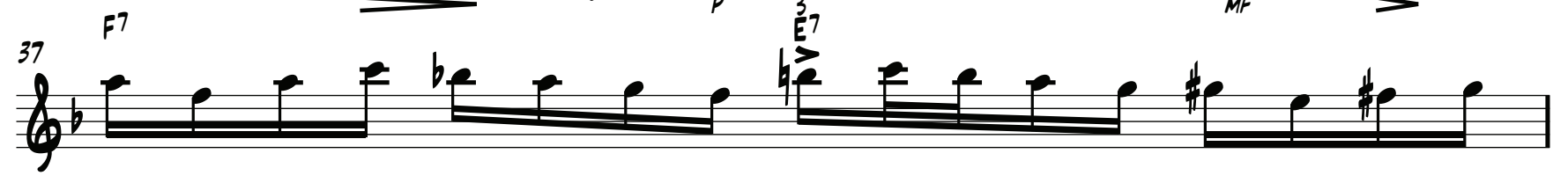

6)

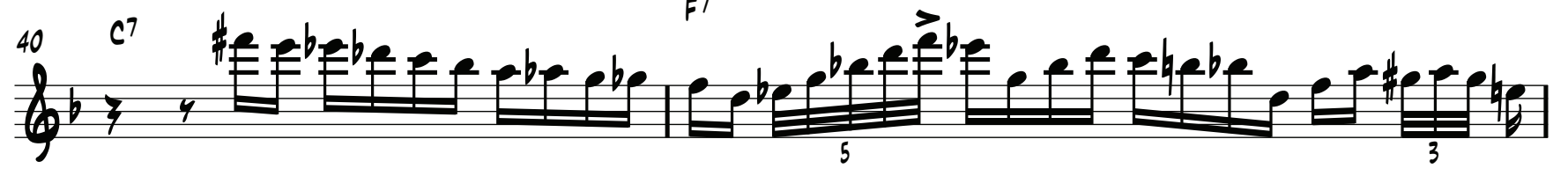

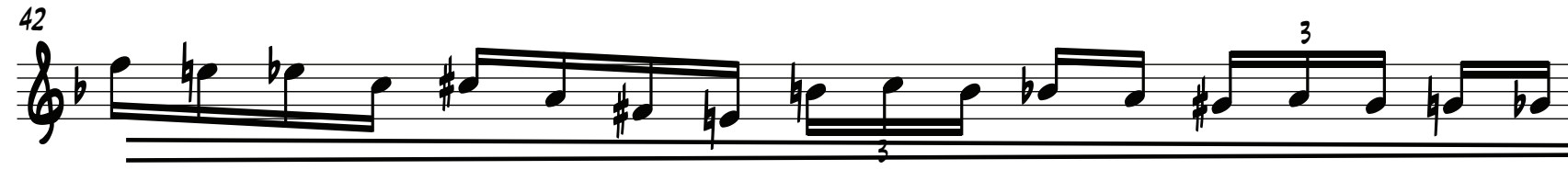


6) 管

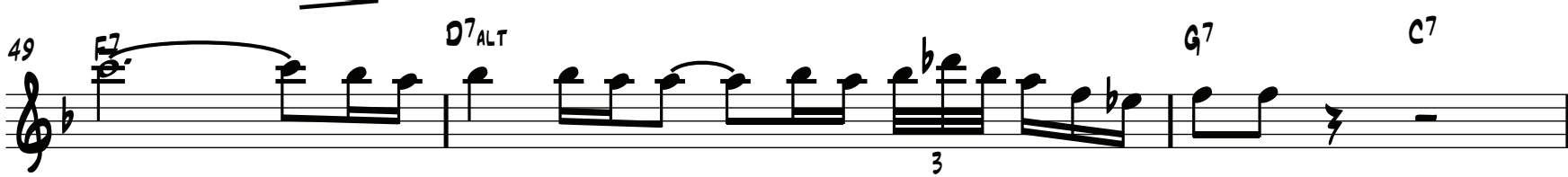
b"

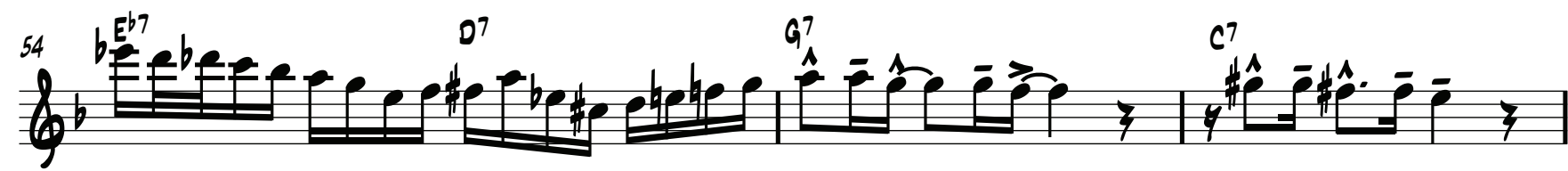
bre

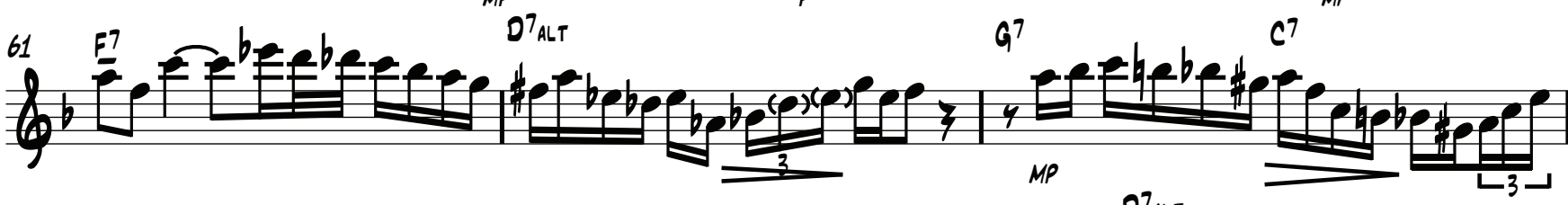
b) 6)

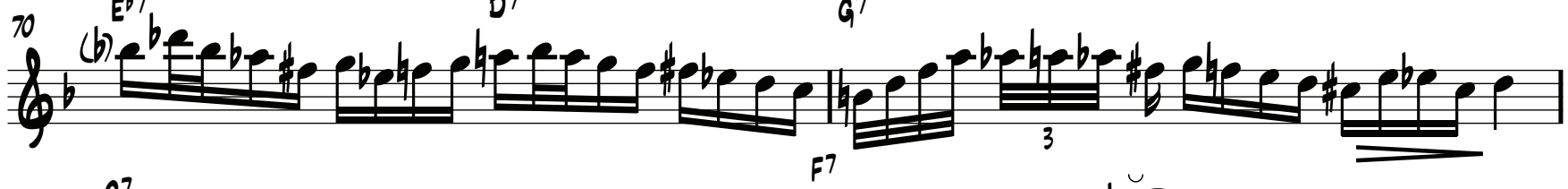
on

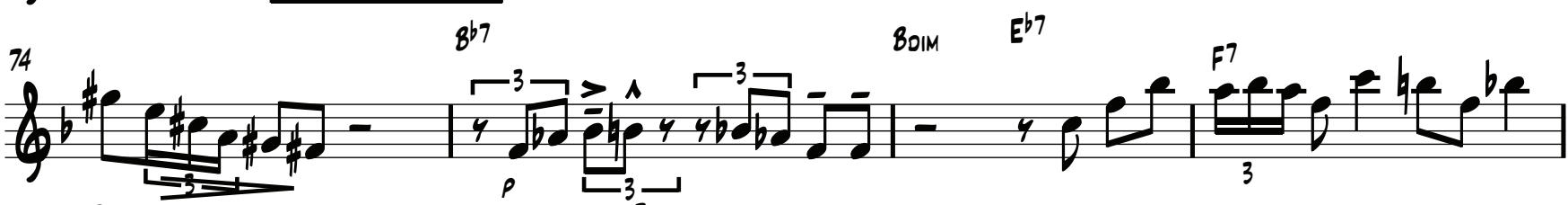

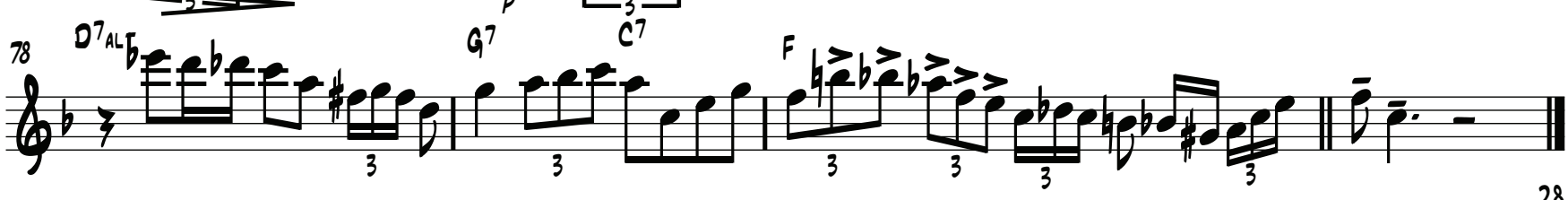


SOHO SOUL

TEMPO $=116$ $G^{7}{ }^{79} C^{7}$

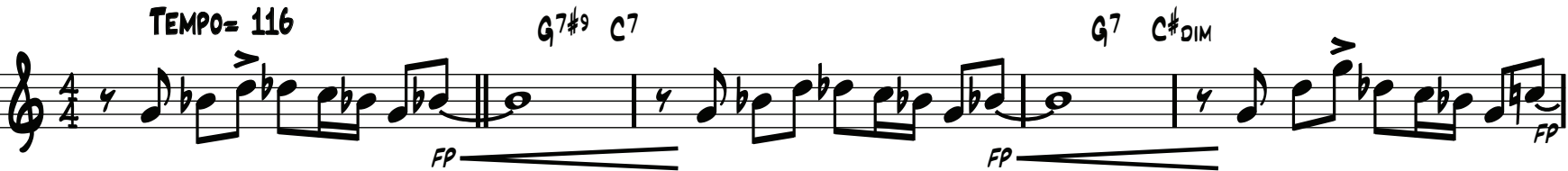

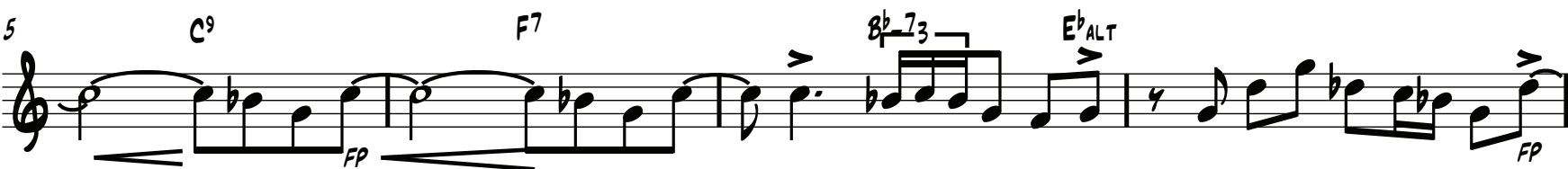

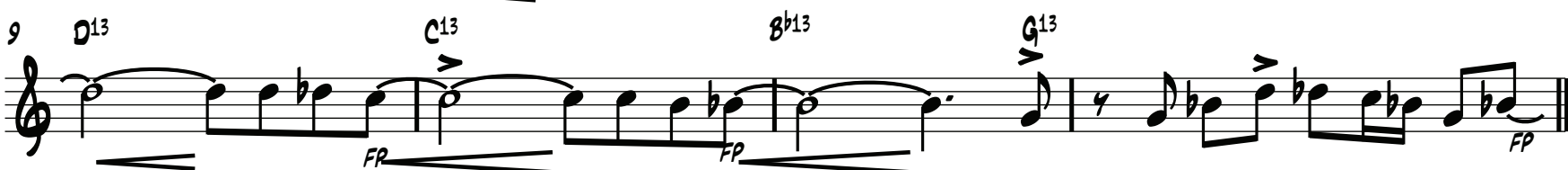

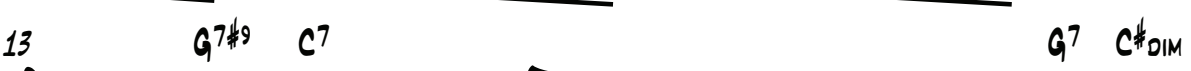

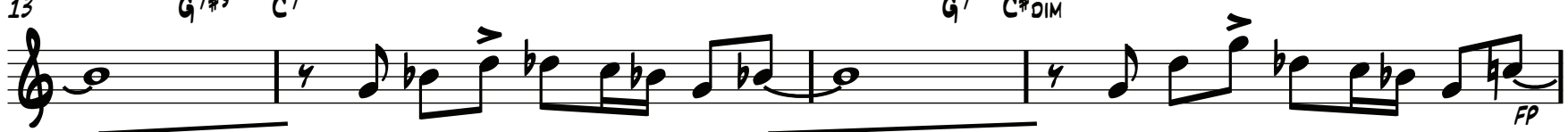

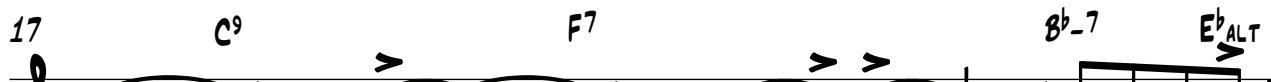

(b) $\overbrace{(1)}^{213}$

SOLOS: PIANO, BASS (6) $\begin{array}{rrrrr}C^{7} & C_{01 M} & G^{7} & \text { BMIN }^{7} & E^{7}\end{array}$ ${ }_{35}{ }_{\text {AMIN }}^{31}{ }_{07}^{31}$ ${ }^{35}{ }^{A M N^{7}}$ $G^{7} \quad c^{7} \quad=a^{7}$ 


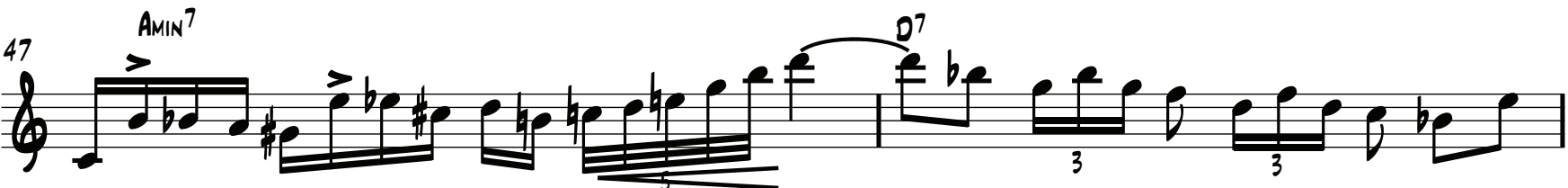

$\underbrace{49}_{G^{7}} \int_{C_{M I N}^{7}}^{B^{7}}$

לे

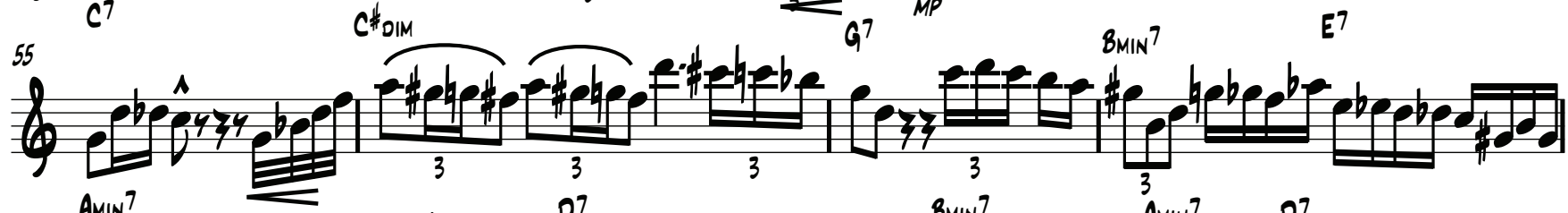

b.

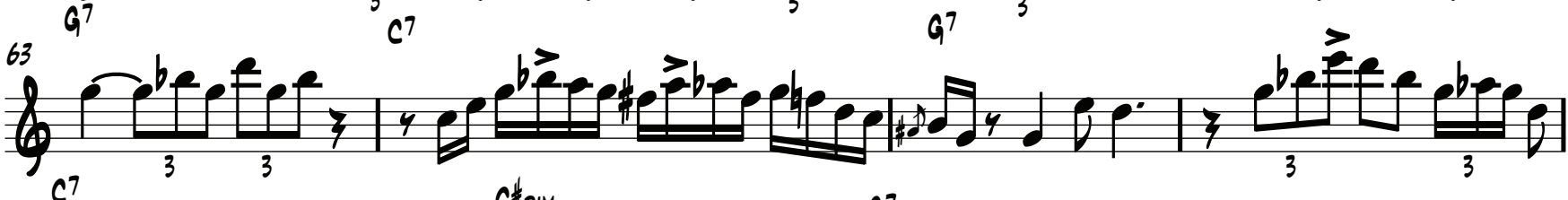

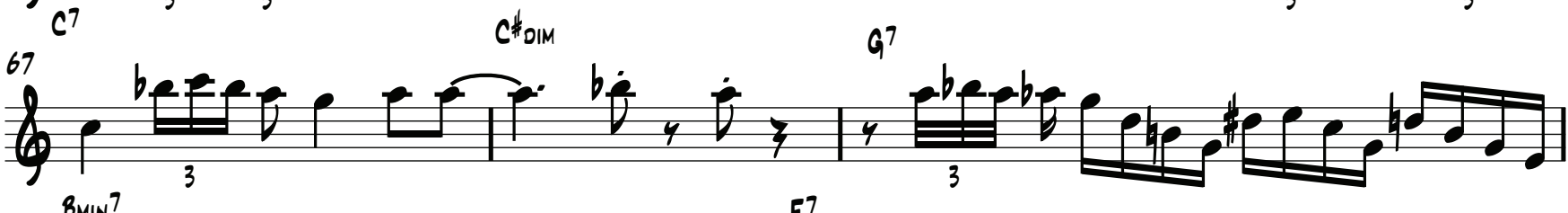

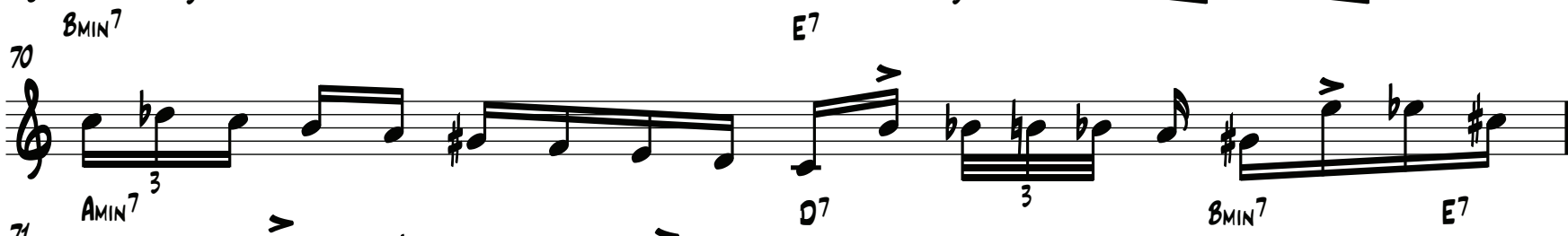

$6 \sum_{0}^{2}$

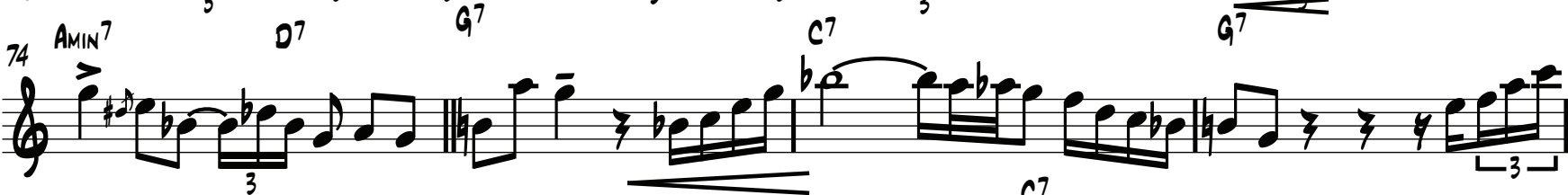
6

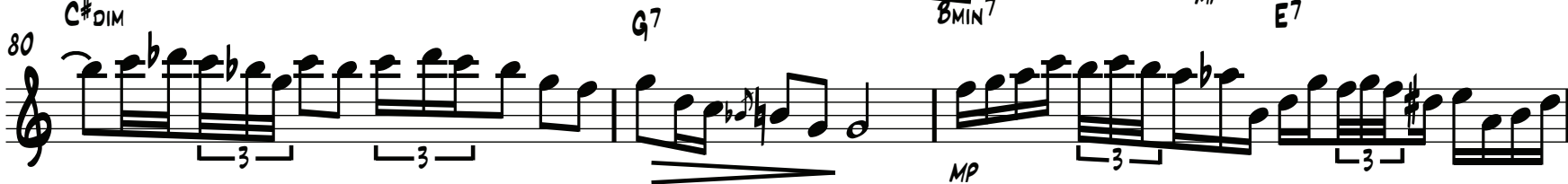

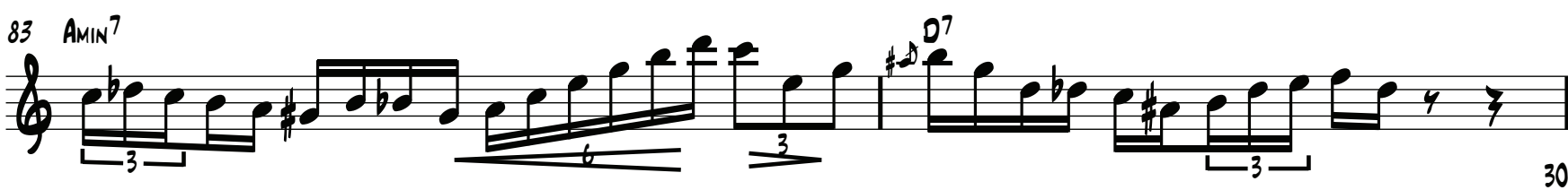



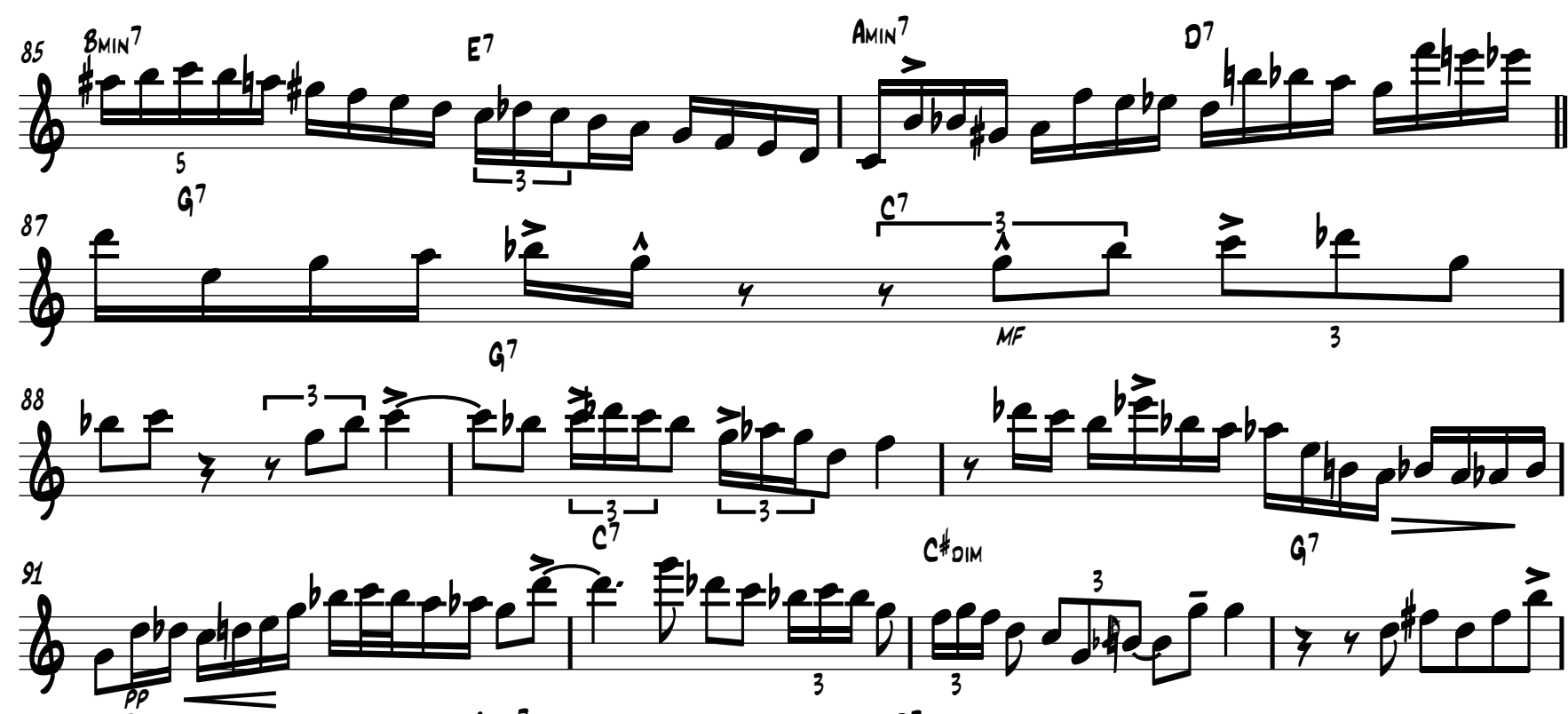

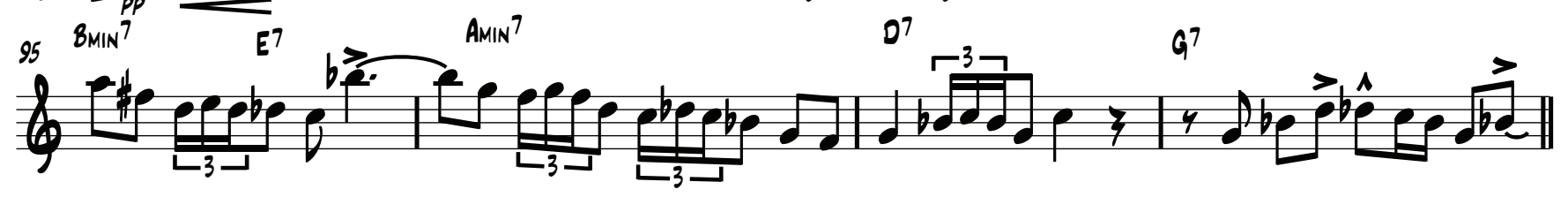
b 

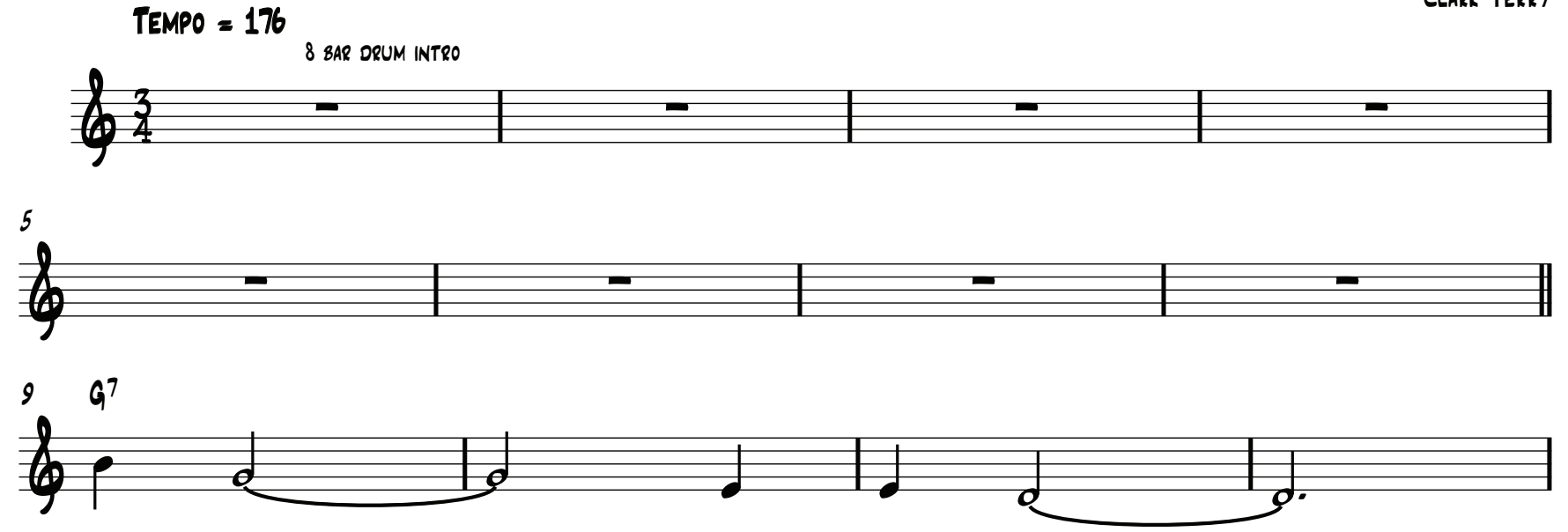

$13 G^{7}$

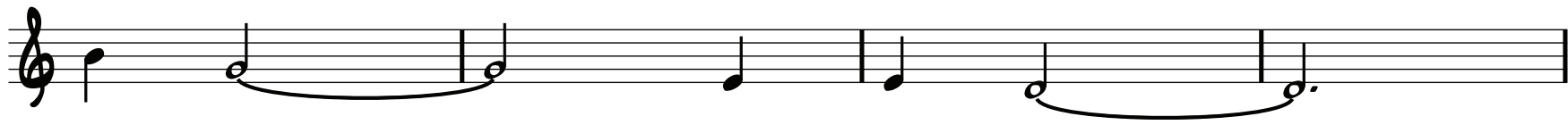

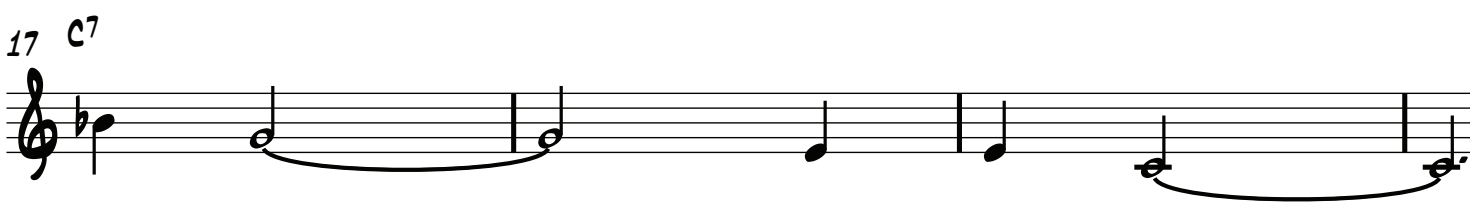

$\underbrace{a^{7}}_{-1}$

$f_{0}^{25}$

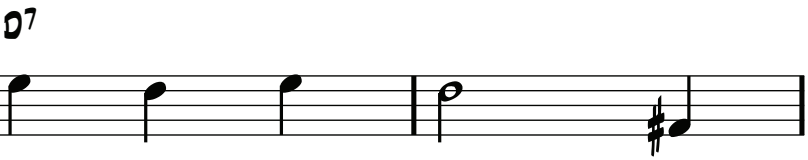

$29^{9}$

${ }^{33^{9}}$

$10+2$

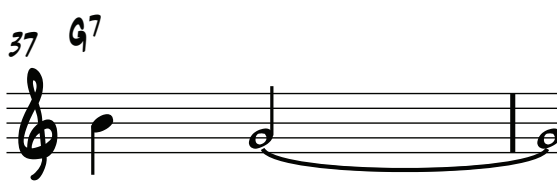

$13 \sqrt{2}$

$11^{c^{7}}$
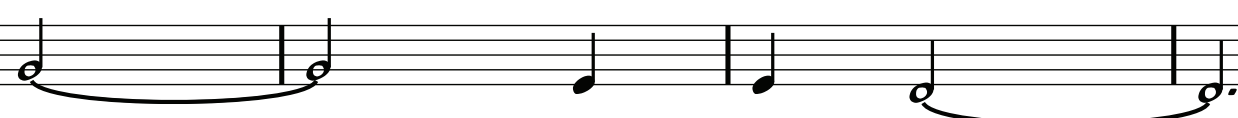

O.

$459^{7}$

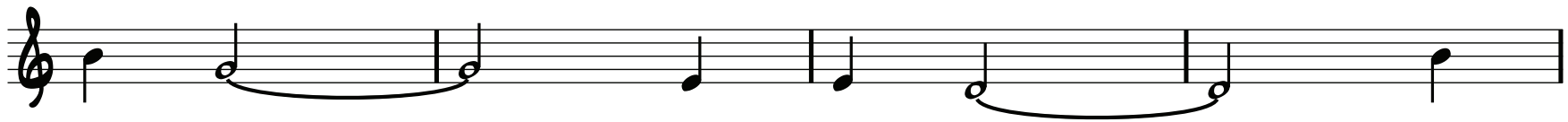

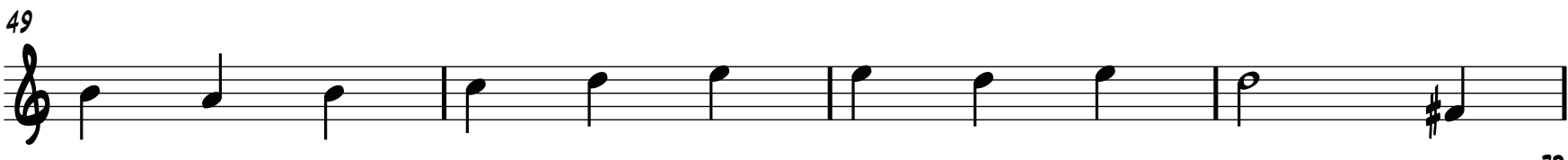


$539^{7}$

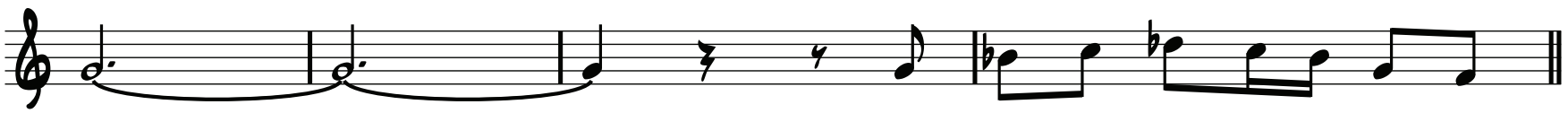

$f^{57}>3$ $61^{9^{7}}$

b(t)

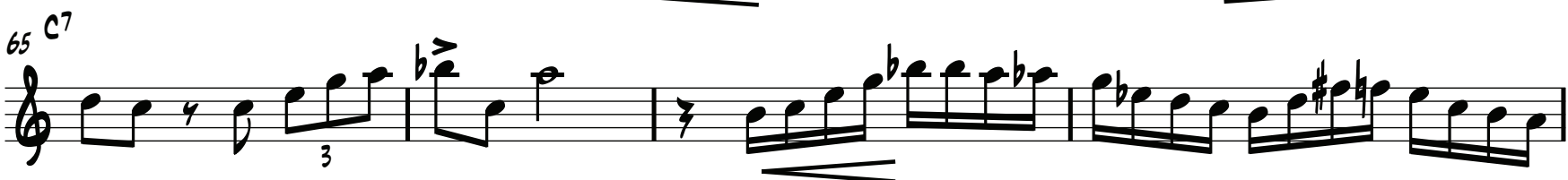

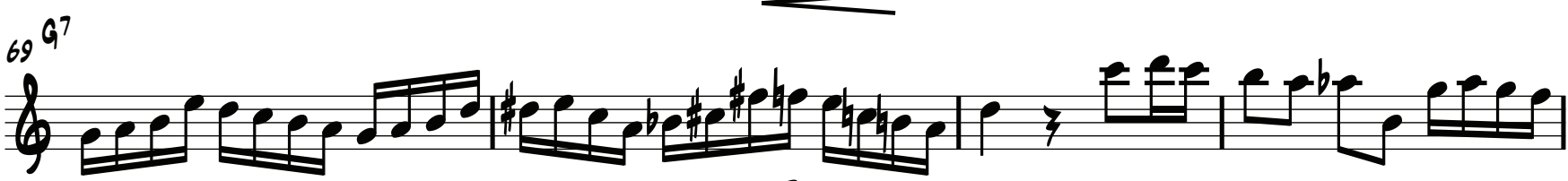
(6) $13 ; z ; z$

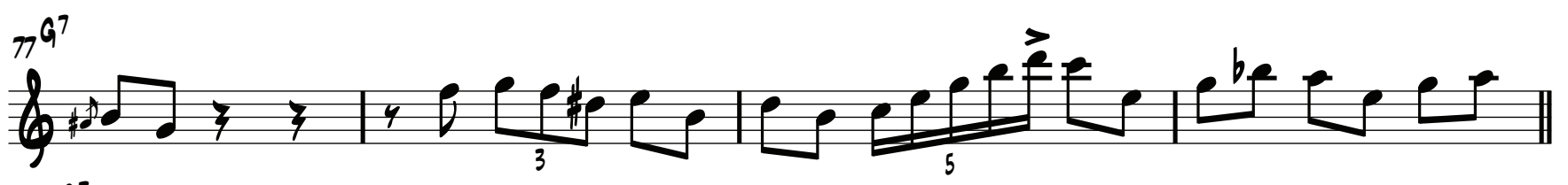

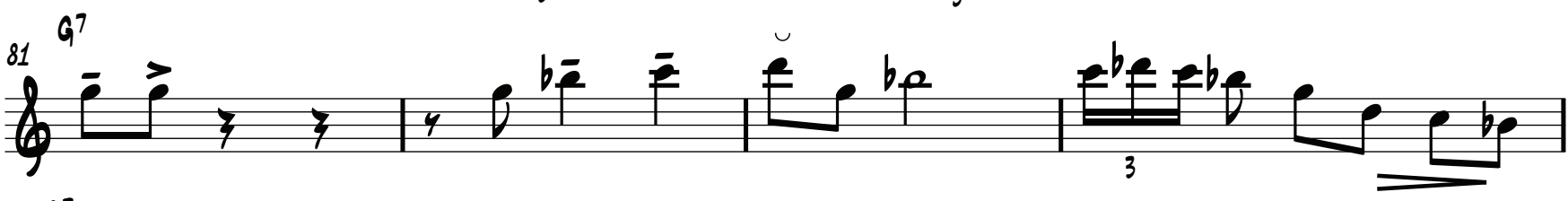
${ }_{85}^{9^{7}}$

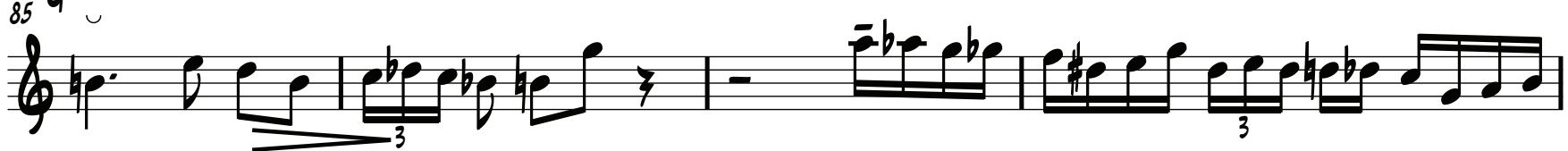

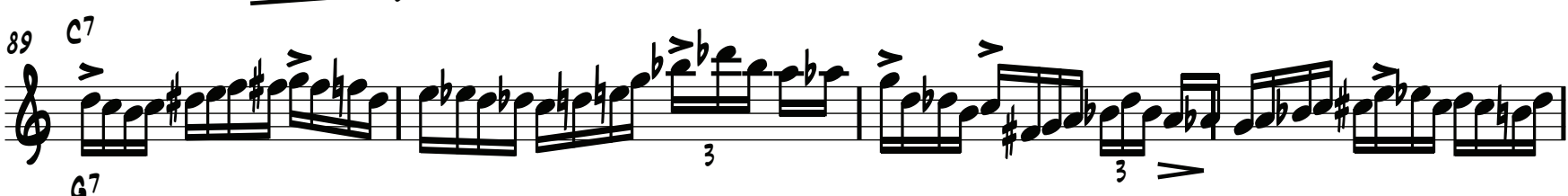
(6) ${ }^{97}{ }^{7}$

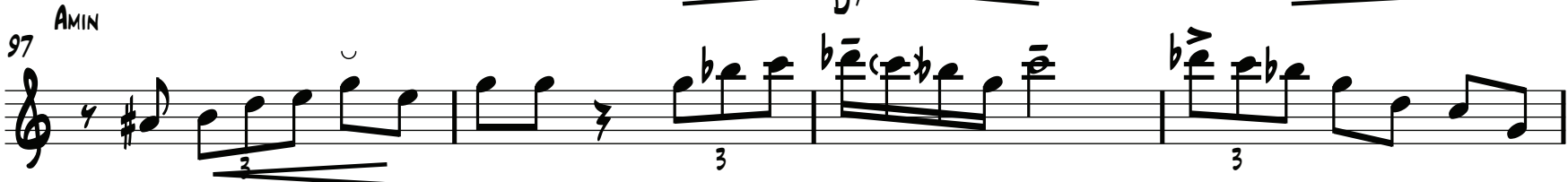

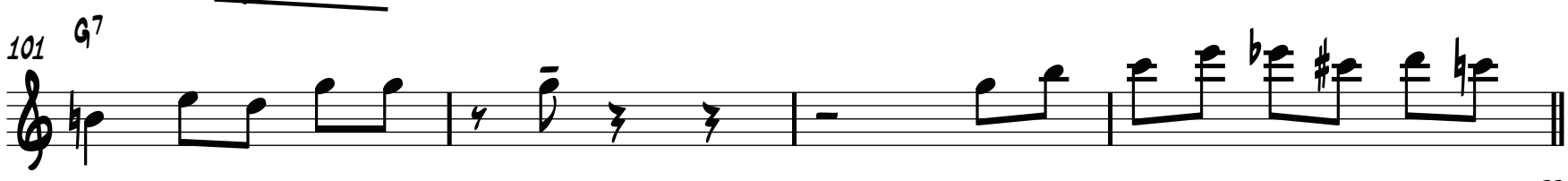


$b^{106} a^{\circ}$

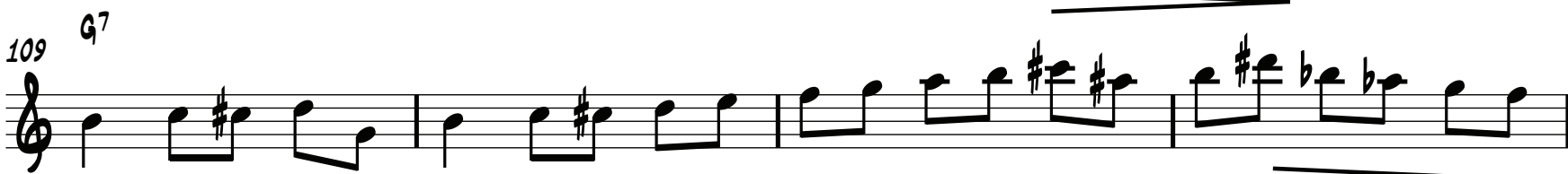

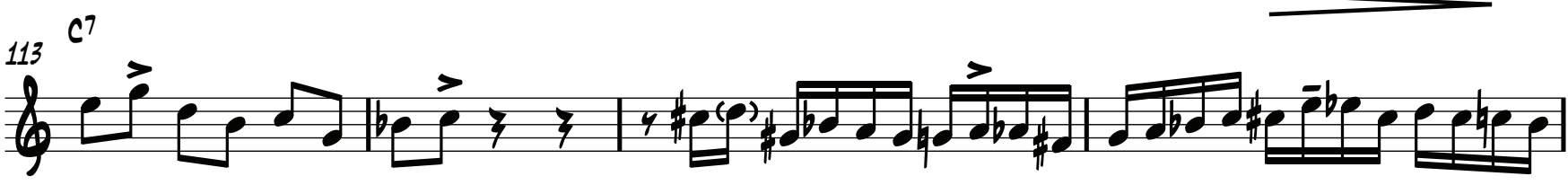
b" 6" $b^{129^{97}}$. $b^{129}$ be

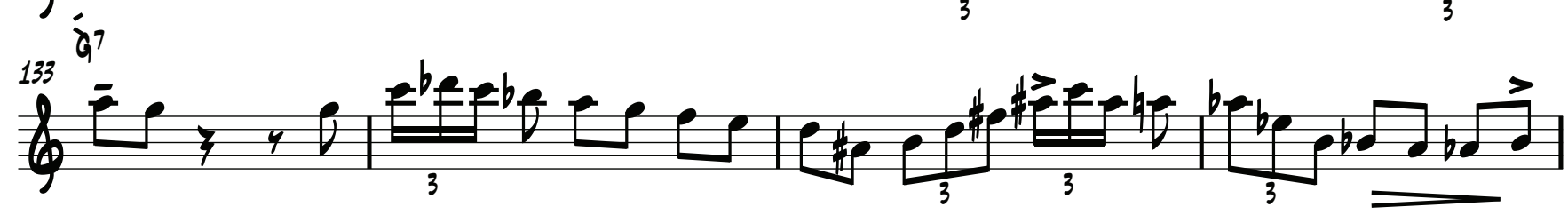

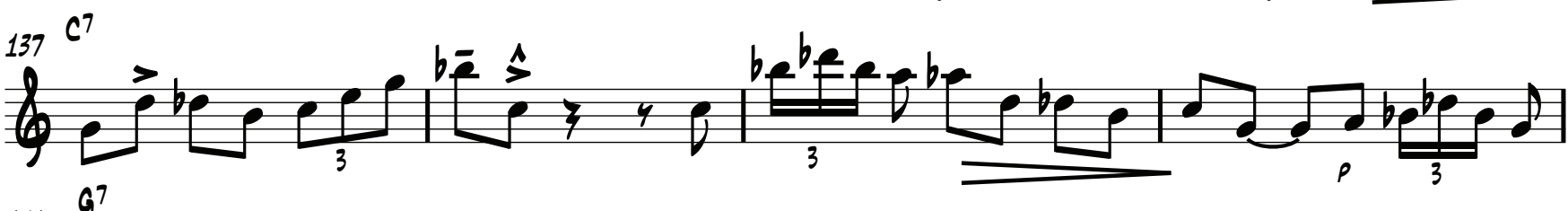
$14 a^{\prime}$

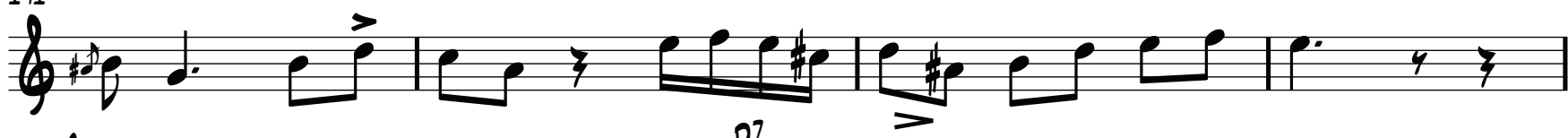
(45) $b^{49^{9}}+1$ be CO 
155 Begin TRADES Between SAX AND tPT at 6.22 MinUtes

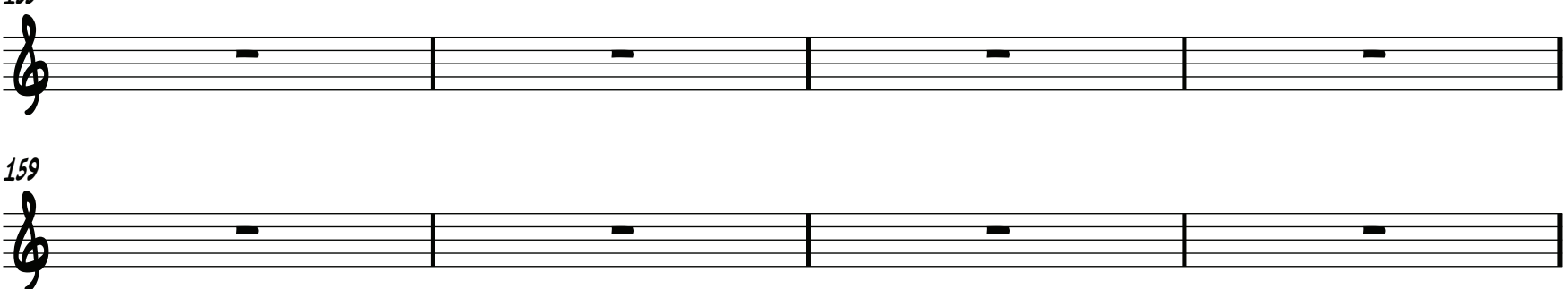

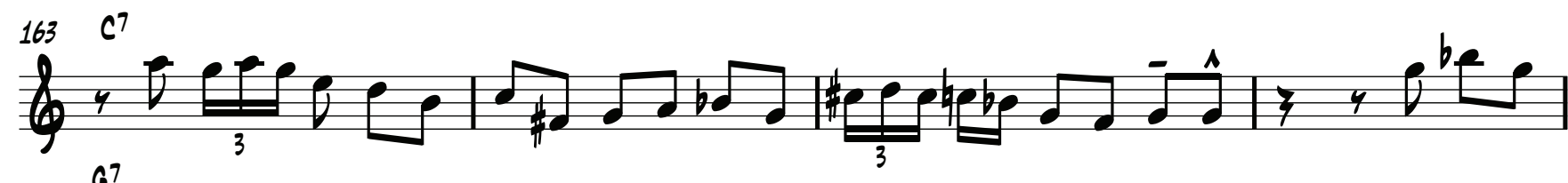
6) bै।

$6-1-1-1+4$

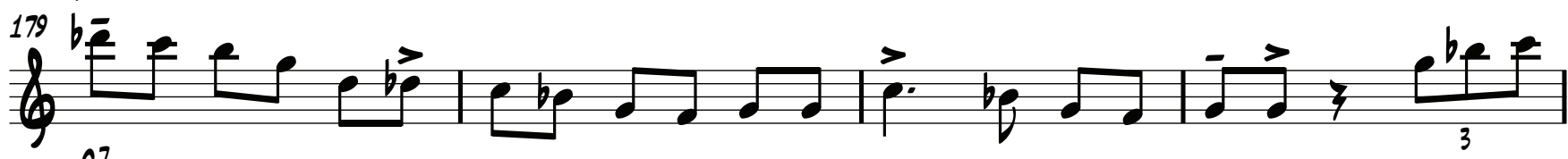

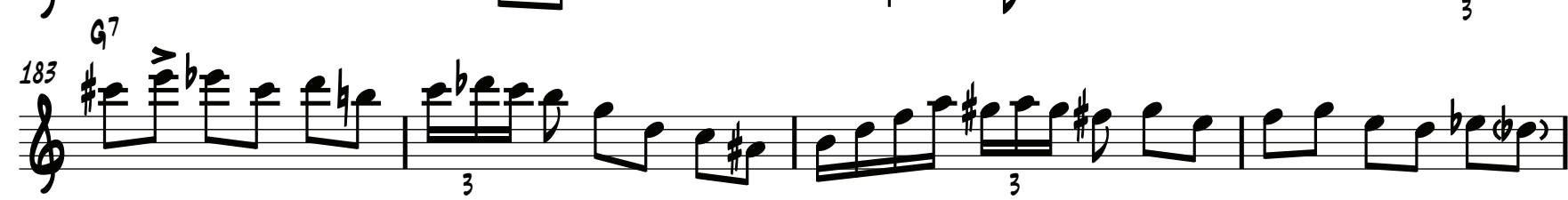
be

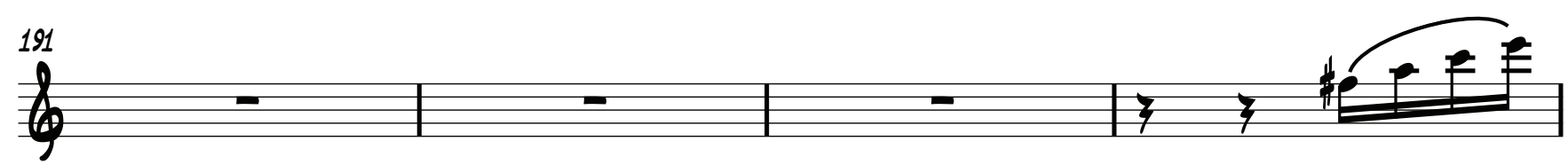

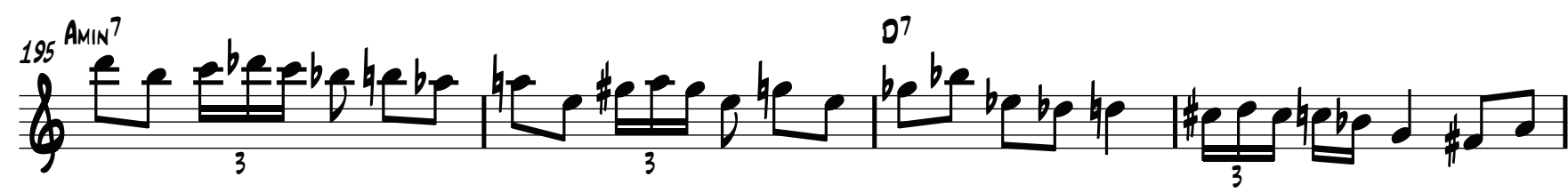

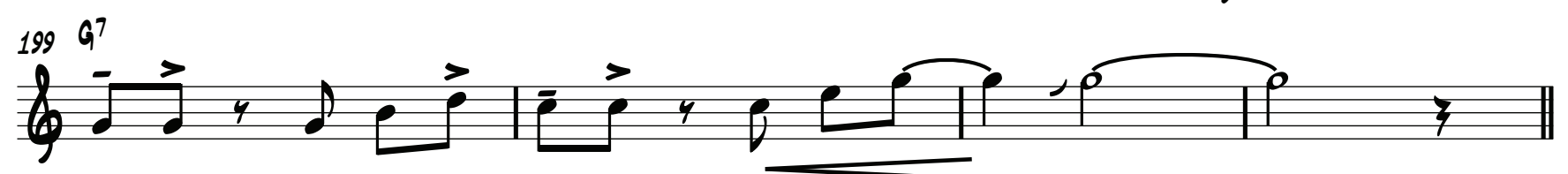
$\frac{23}{6}$ - 
6

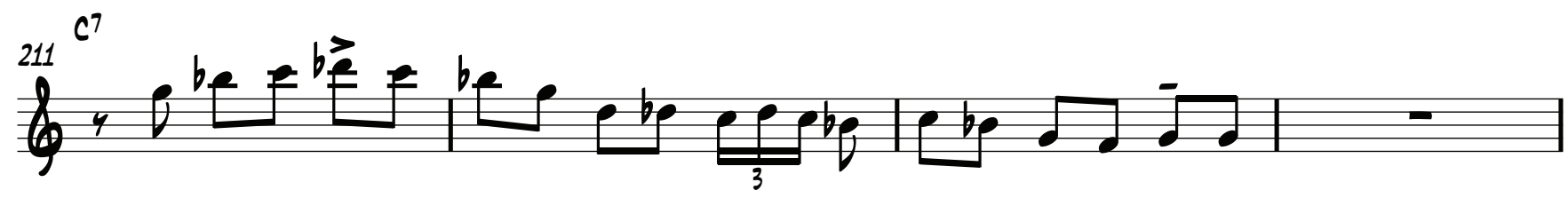
6)

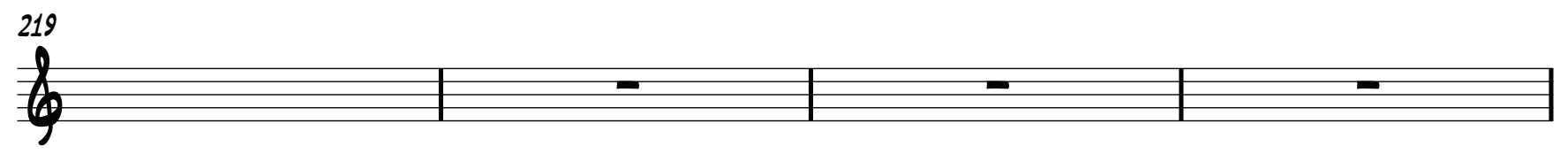
(b) -

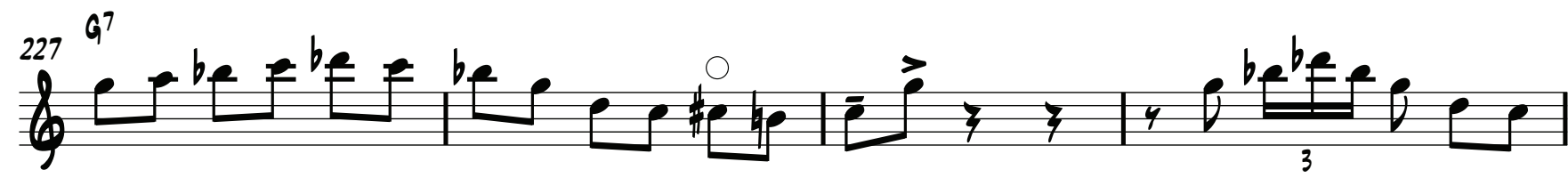

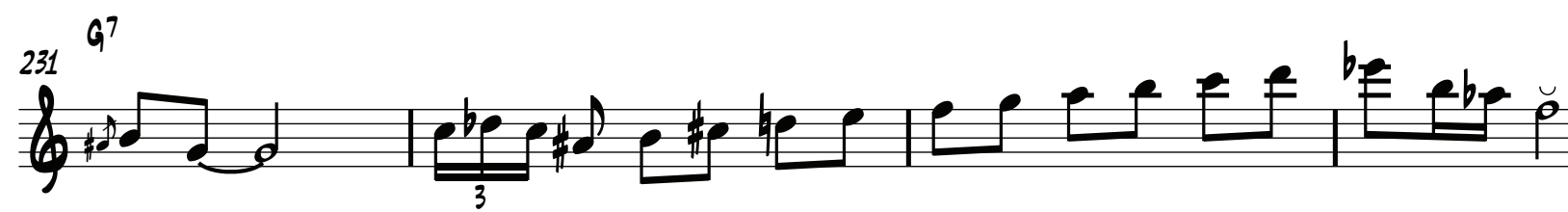

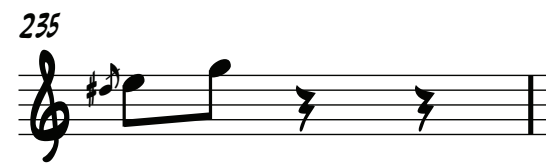

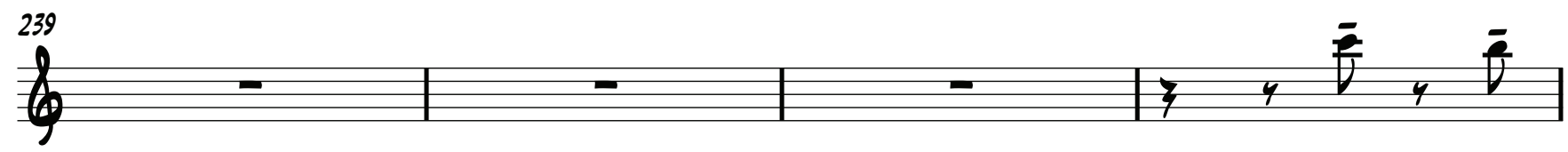

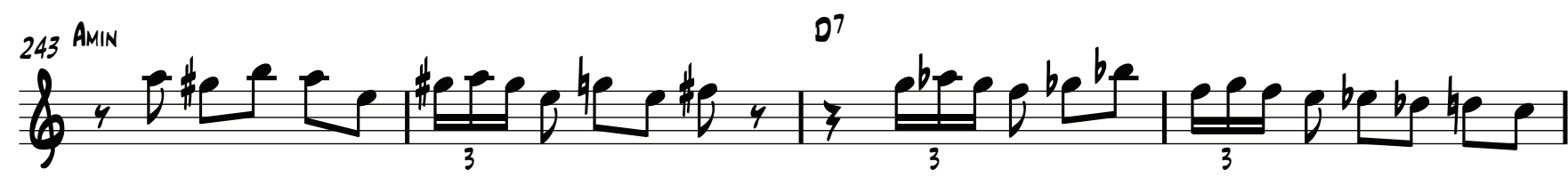
b) 


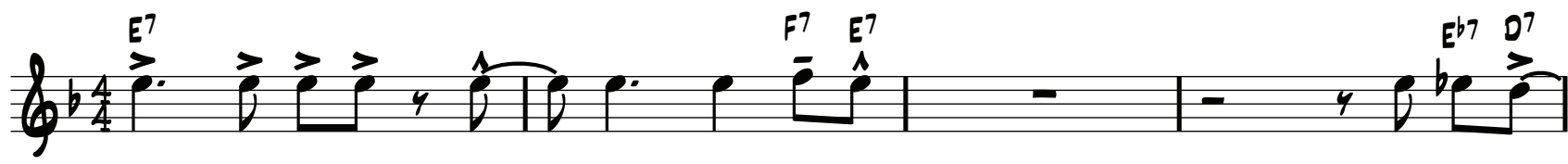

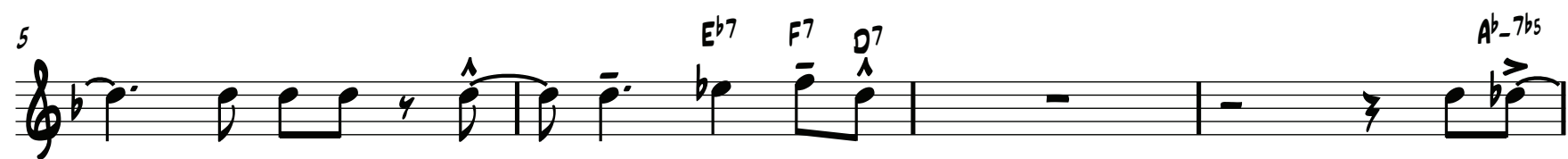

(b)

(6)

(b)

$21 \mathrm{~A}_{\text {MAJ }}{ }^{7}$

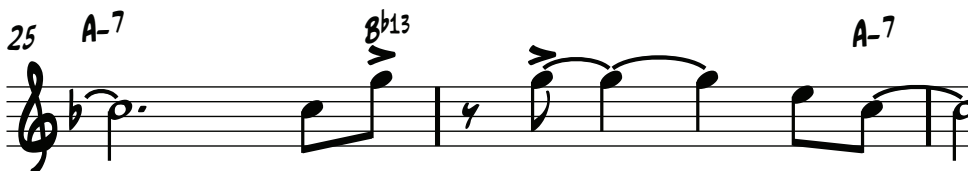

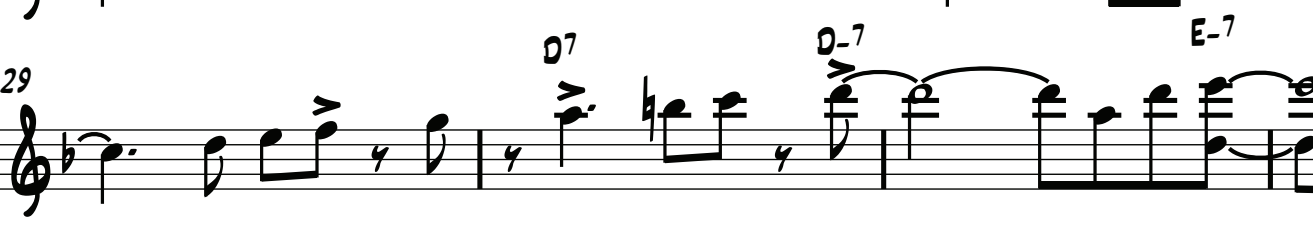

(6)

$37^{A^{6} \text { MAJ }^{7}}$

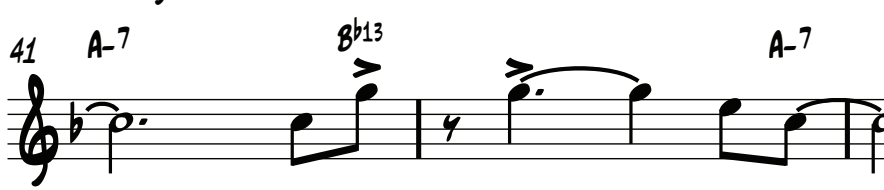

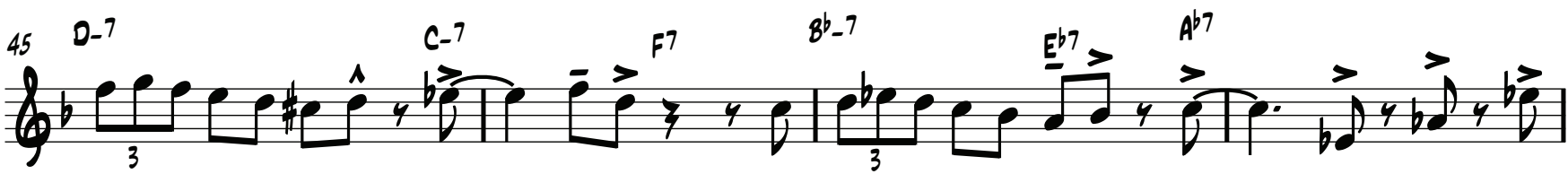

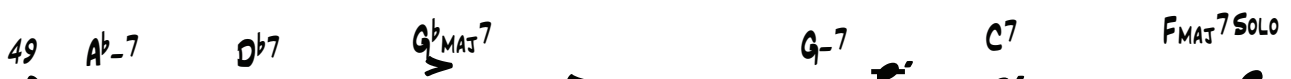
(b) 
b. b) " " " " "

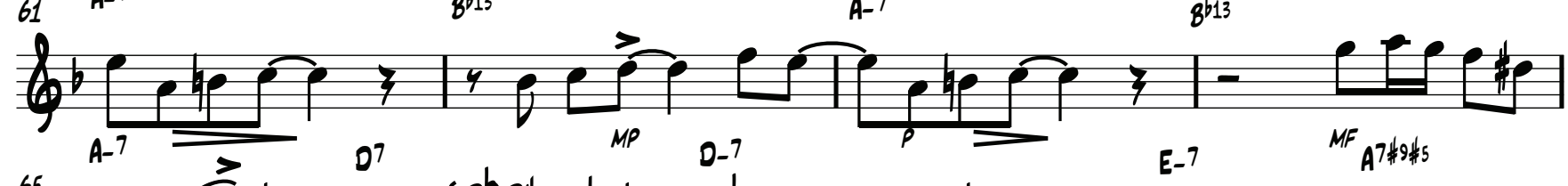
brom " o. c. c) sher 40 ond

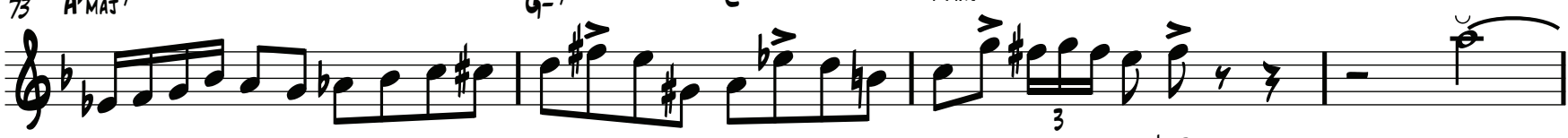
6. "

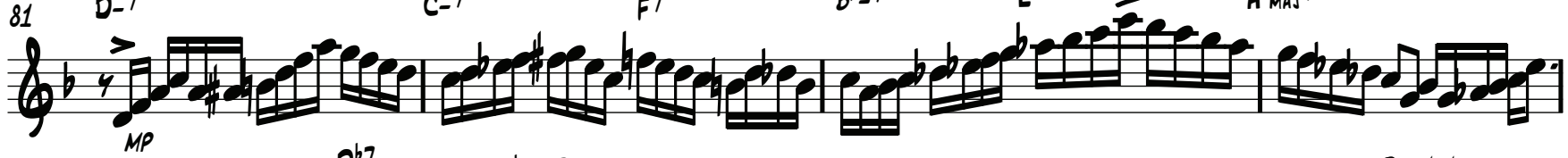
b. brection

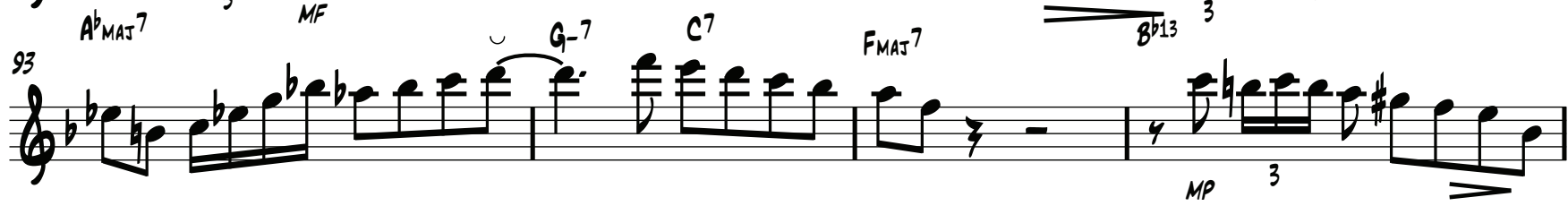

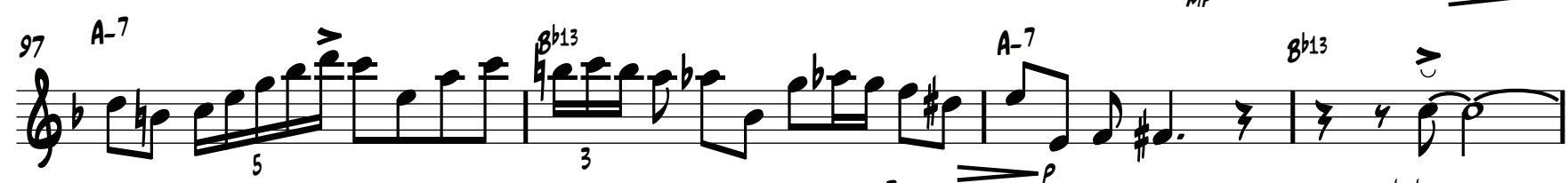

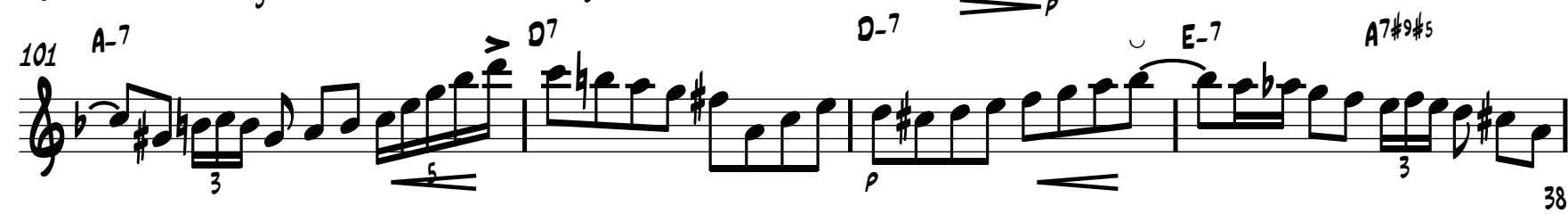


bes God Awr 6) 6)

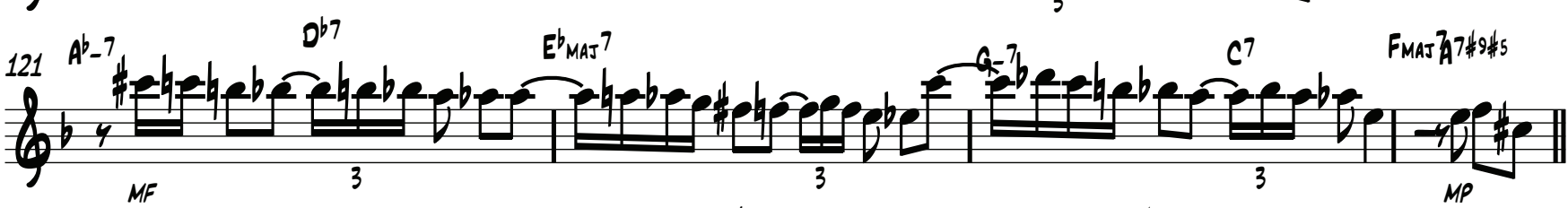

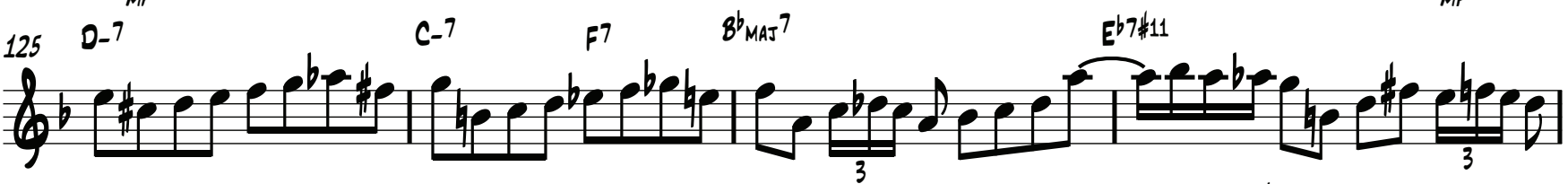

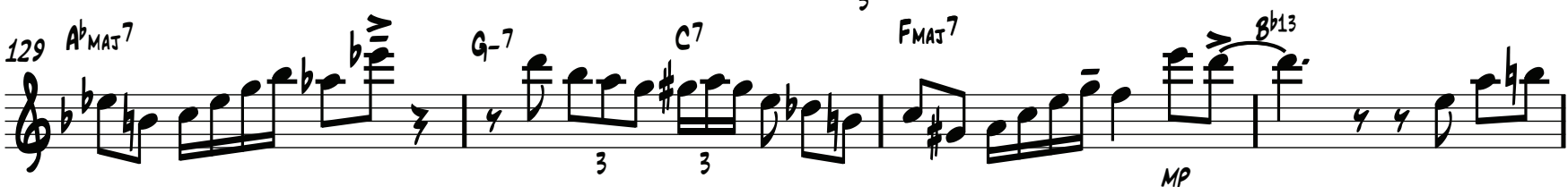

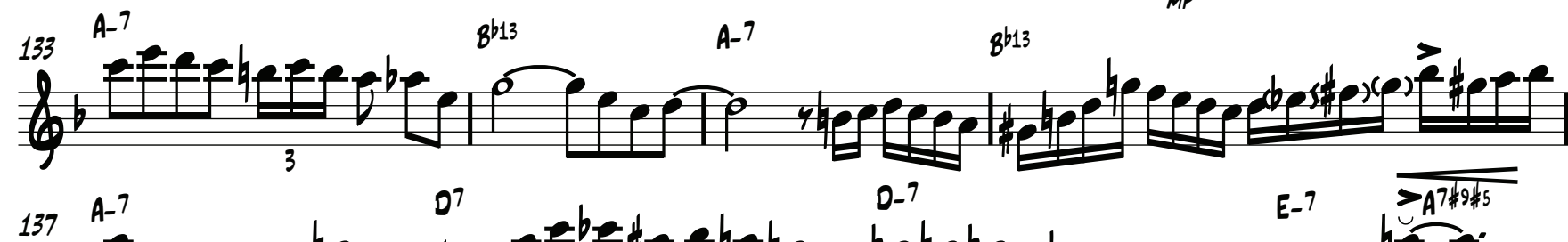

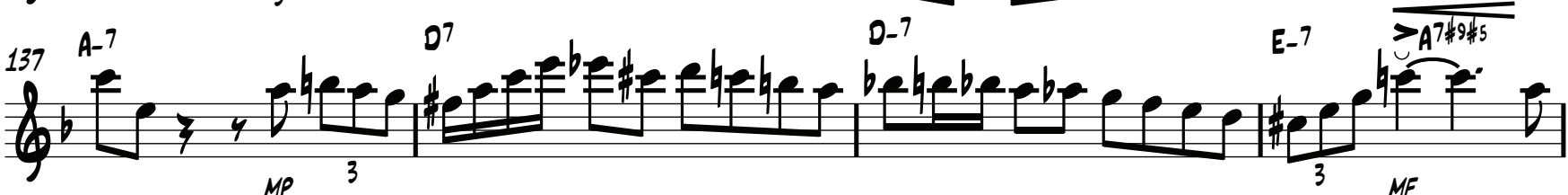
6) 146

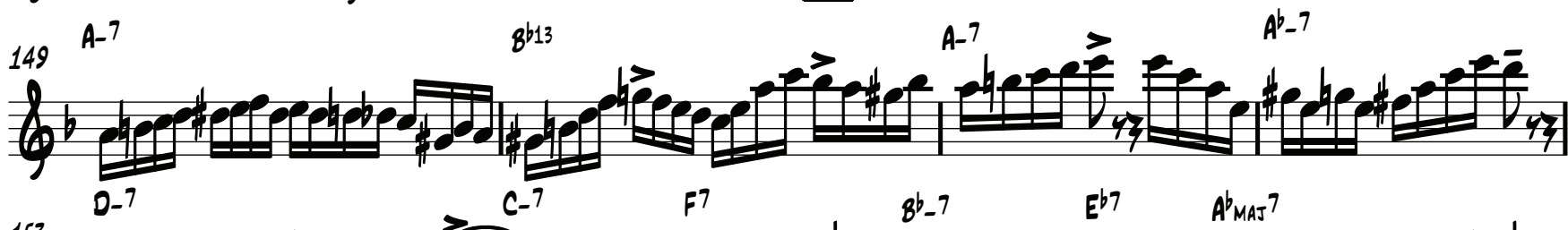
65 


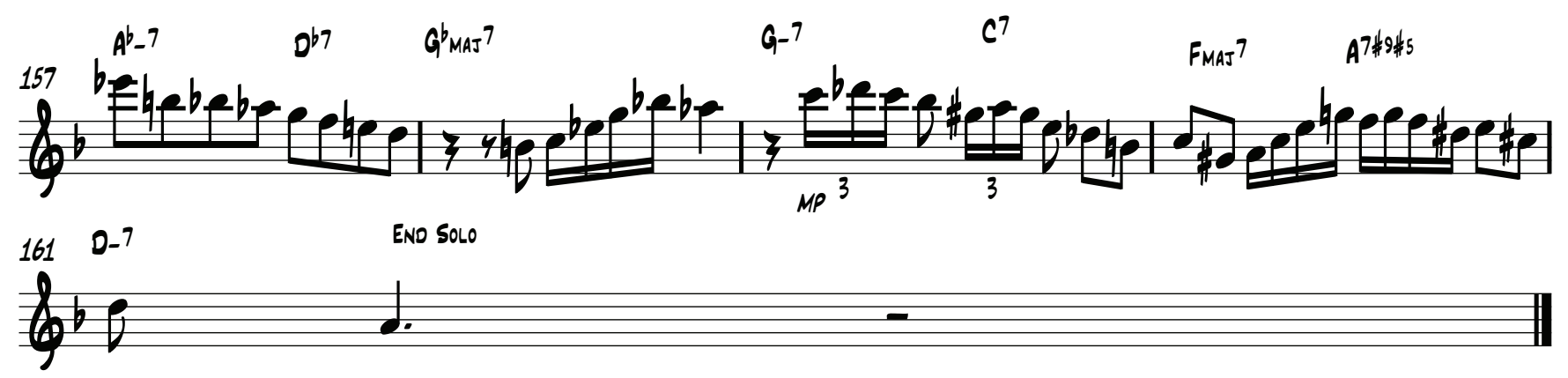




\section{YOU ARE MY EVERYTHING}

(t)

3 SUBTONE ${ }^{7}{ }^{\mathrm{OMI}^{7}}{ }_{2}^{\mathrm{OMI}^{7}}$ $11{ }^{E_{M 1}^{7}}$ (6) $B$

19 CMAT⿱ $^{7}$

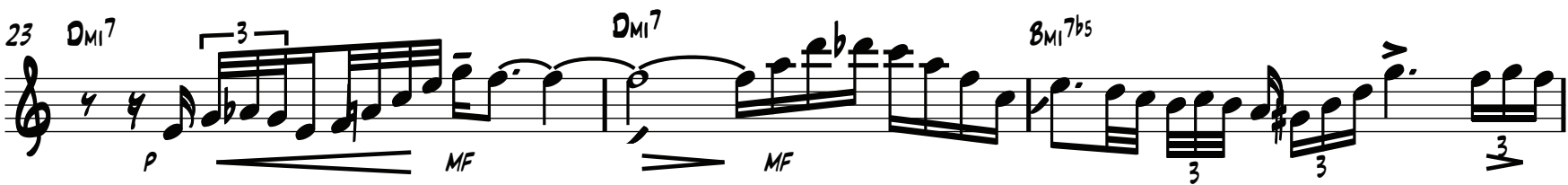
$26{ }^{E^{7}}$ ${ }^{31}{ }_{E M I^{7}}^{E_{2}}$ ${ }^{\text {CMAT }^{7}}$ 
A

${ }_{35}$ CMAJ $^{7}$

(t)

(6)

16 8AR PAANO SOLO

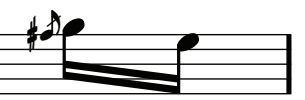

$39 \quad F \#_{M 17} \quad B 7 \quad E_{M 17}$

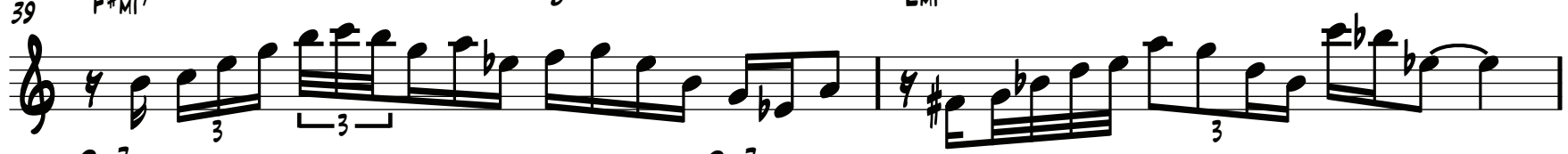

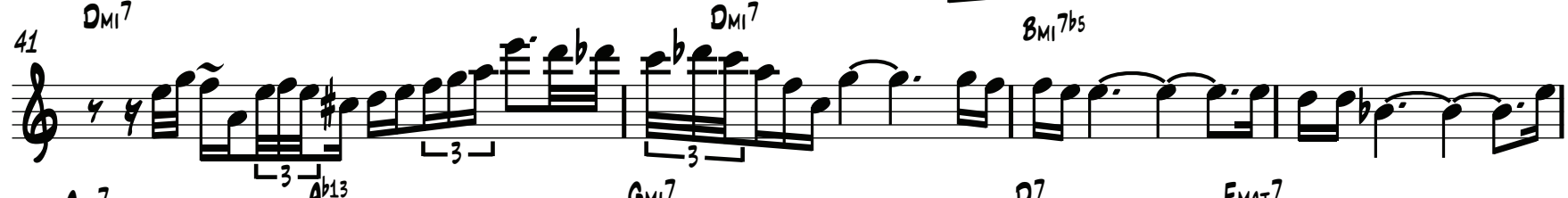

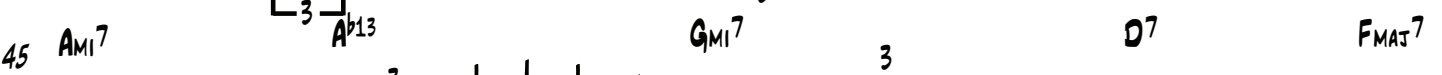

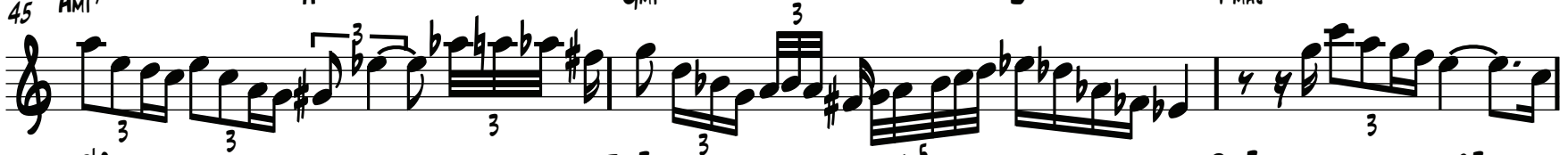
${ }_{N C}^{48}{ }^{B^{b 9}}$ (6) (4) 